Extração automática de termos simples baseada em aprendizado de máquina 

SERVIÇO DE PÓS-GRADUAÇÃO DO ICMC-USP

Data de Depósito:

Assinatura:

\title{
Extração automática de termos simples baseada em aprendizado de máquina
}

\author{
Merley da Silva Conrado Laguna
}

Orientadora: Profa. Dra. Solange Oliveira Rezende Coorientador: Prof. Dr. Thiago Alexandre Salgueiro Pardo

Tese apresentada ao Instituto de Ciências Matemáticas e de Computação - ICMC-USP, como parte dos requisitos para obtenção do título de Doutor em Ciências de Computação e Matemática Computacional. VERSÃO REVISADA

\section{USP - São Carlos}

Julho de 2014 
Ficha catalográfica elaborada pela Biblioteca Prof. Achille Bassi e Seção Técnica de Informática, ICMC/USP, com os dados fornecidos pelo(a) autor(a)

da Silva Conrado Laguna, Merley
Extração automática de termos simples baseada em
disle dendizado de máquina / Merley da Silva Conrado
Laguna; orientadora Solange Oliveira Rezende; co-
orientador Thiago Alexandre Salgueiro Pardo. -- São
Carlos, 2014.
159 p.
Tese (Doutorado - Programa de Pós-Graduação em
Ciências de Computação e Matemática Computacional) --
Instituto de Ciências Matemáticas e de Computação,
Universidade de São Paulo, 2014.
1. Extração automática de termos. 2. Aprendizado
de máquina. 3. Classificação indutiva. 4.
Classificação transdutiva. 5. Mineração de textos. I.
Oliveira Rezende, Solange, orient. II. Salgueiro
Pardo, Thiago Alexandre, co-orient. III. Título.


Dedico esta tese aos meus pais, esposo, irmã e sobrinhos. 



\section{Agradecimentos}

A Deus, por tudo e sempre.

Aos meus pais, Lindinalva e Gecé, pelo exemplo, amor, apoio, encorajamento e pelos ensinamentos que formaram os alicerces de minha história. Novamente, essa conquista é nossa!

Ao meu esposo Víctor, pelo amor, incentivo e compreensão ao longo da trajetória que me levou à concretização deste sonho. Aos meus sogros e cunhado, pelo apoio.

A minha irmã Midiam e cunhado Caio, pelo amor e carinho de sempre, e a meus sobrinhos, por seus sorrisos que me fazem ainda mais feliz. Em especial, a Tássyla.

A minha orientadora, Solange Rezende, pelos ensinamentos, conversas profissionais e pessoais e por caminhar comigo desde o mestrado. Você fez a diferença.

Ao meu coorientador, Thiago Pardo, pela contínua simpatia, exemplo, incentivo e ensinamentos. Sua colaboração foi essencial para esta pesquisa.

Aos professores Gustavo Batista e Cláudia por sempre me receberem tão bem. À professora Ariani Di Felippo, pela disposição e por gentilmente disponibilizar um dos corpora utilizado nesta pesquisa. À professora Gladis Almeida, pela simpatia e por também gentilmente ceder outro corpus.

Aos professores Josuka Díaz-Labrador e Joseba Abaitua, da UDeusto-Espanha, e Marilyn Walker, da UC-USA, por me proporcionarem um ambiente amigável e profissional durante minhas estadias no exterior. Aos amigos encontrados nessa jornada no exterior, Claudia Tavares e Walter Koza, pelas horas agradabilíssimas passadas juntas. Los echo de menos.

Às grandes amizades feitas durante essa trajetória e que levarei comigo para onde for, Marcos Cintra, Ana Winck, Juliana Andresa, Luis Araújo, Bruno Nogueira, Vanessa Araújo, Fernanda Moura (por me tratar como uma filha), Paulo Gabriel, Rafael Rossi, Lucía Castro, Everton Cherman e Giovana Tangerino.

Aos amigos e colegas de laboratório (LABIC, NILC e demais laboratórios) e de São Carlos. Essa jornada me proporcionou conhecer muitas pessoas especiais, entre elas Ígor, Bárbara, Jorge, Diego, Ricardo, Fabiano, Celso, Débora, Newton, Renan, Marcos, Rafael, Vinícius, Camila, Anand, Izilda, Gustavo, Vânia e Nayza.

Aos amigos de sempre, Andréia Camargo, por me mostrar que uma grande amizade se mantém mesmo a distância, Laura Maria, por sua alegre companhia desde a infância, Danilo Dias e Nádia Castilho, pelo carinho.

Aos professores e funcionários do ICMC.

Ao CNPq (Conselho Nacional de Desenvolvimento Científico e Tecnológico), FAPESP (Fundação de Amparo à Pesquisa do Estado de São Paulo) e ERASMUS MUNDUS, pelo apoio financeiro imprescindível para o desenvolvimento desta pesquisa. 



\section{Resumo}

$\mathcal{A}$

Mineração de Textos (MT) visa descobrir conhecimento inovador nos textos não estruturados. A extração dos termos que representam os textos de um domínio é um dos passos mais importantes da MT, uma vez que os resultados de todo o processo da MT dependerão, em grande parte, da qualidade dos termos obtidos. Nesta tese, considera-se como termos as unidades lexicais utilizadas para designar conceitos em um cenário tematicamente restrito. Para a extração dos termos, pode-se fazer uso de abordagens como: estatística, linguística ou híbrida. Normalmente, para a Mineração de Textos, são utilizados métodos estatísticos. A aplicação desses métodos é computacionalmente menos custosa que a dos métodos linguísticos, entretanto seus resultados são geralmente menos interpretáveis. Ambos métodos, muitas vezes, não são capazes de identificar diferenças entre termos e não-termos, por exemplo, os estatísticos podem não identificar termos raros ou que têm a mesma frequência de não-termos e os linguísticos podem não distinguir entre termos que seguem os mesmos padrões linguísticos dos não-termos. Uma solução para esse problema é utilizar métodos híbridos, de forma a combinar as estratégias dos métodos linguísticos e estatísticos, visando atenuar os problemas inerentes a cada um deles. Considerando as características dos métodos de extração de termos, nesta tese, foram investigados métodos estatísticos, formas de obtenção de conhecimento linguístico e métodos híbridos para a extração de termos simples aqueles constituídos de somente um radical, com ou sem afixos - na língua portuguesa do Brasil. Quatro medidas estatísticas (tvq, tv, tc e comGram), originalmente utilizadas em outras tarefas, foram avaliadas na extração de termos simples, sendo que duas delas ( $t v q$ e $t v$ ) foram consideradas relevantes para essa tarefa. Quatro novas medidas híbridas (n_subst., $n_{-} a d j ., n_{-}$po e $n_{-} v e r b o$ ) foram propostas, sendo que três delas ( $n_{-}$subst., $n_{-} a d j$. e $n_{-} p o$ ) auxiliaram na extração de termos. Normalmente os métodos de extração de termos selecionam candidatos a termos com base em algum conhecimento linguístico. Depois disso, eles aplicam a esses candidatos medidas ou combinação de medidas (e/ou heurísticas) para gerar um ranking com tais candidatos. Quanto mais ao topo desse ranking os candidatos estão, maior a chance de que eles sejam termos. A escolha do limiar a ser considerado nesse ranking é feita, em geral, de forma manual ou semiautomática por especialistas do domínio e/ou terminólogos. Automatizar a forma de escolha dos candidatos a termos é a primeira motivação da extração de termos realizada nesta pesquisa. A segunda motivação desta pesquisa é minimizar o elevado número de candidatos a termos presente na extração de termos. Esse alto número, causado pela grande quantidade de palavras contidas em um corpus, pode aumentar a complexidade de tempo e os recursos computacionais utilizados para se extrair os termos. A terceira motivação considerada nesta pesquisa é melhorar o estado da arte da extração automática de termos simples da língua portuguesa do Brasil, uma vez que os resultados dessa extração (medida $\mathrm{F}=$ $16 \%$ ) ainda são inferiores se comparados com a extração de termos em línguas como a inglesa (medida $\mathrm{F}=92 \%$ ) e a espanhola (medida $\mathrm{F}=68 \%$ ). Considerando essas motivações, nesta tese, foi proposto o método MATE-ML (ㅅutomatic $\underline{\text { Term }}$ Extraction based 


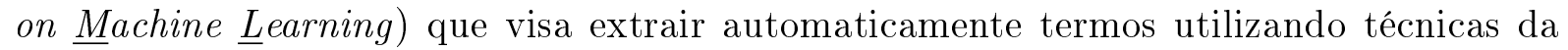
área de aprendizado de máquina. No método MATE-ML, é sugerido o uso de filtros para reduzir o elevado número de candidatos a termos durante a extração de termos sem prejudicar a representação do domínio em questão. Com isso, acredita-se que os extratores de termos podem gerar listas menores de candidatos extraídos, demandando, assim, menos tempo dos especialistas para avaliar esses candidatos. Ainda, o método MATE-ML foi instanciado em duas abordagens: (i) ILATE (Inductive Learning for $\underline{\text { Automatic }}$ Term Extraction), que utiliza a classificação supervisionada indutiva para rotular os candidatos a termos em temos e não termos, e (ii) TLATE (ㅁansductive Learning for $\underline{\text { A utomatic }}$ Term Extraction), que faz uso da classificação semissupervisionada transdutiva para propagar os rótulos dos candidatos rotulados para os não rotulados. A aplicação do aprendizado transdutivo na extração de termos e a aplicação ao mesmo tempo de um conjunto rico de características de candidatos pertencentes a diferentes níveis de conhecimento linguístico, estatístico e híbrido também são consideradas contribuições desta tese. Nesta tese, são discutidas as vantagens e limitações dessas duas abordagens propostas, ILATE e TLATE. Ressalta-se que o uso dessas abordagens alcança geralmente resultados mais altos de precisão (os melhores casos alcançam mais de $81 \%$ ), altos resultados de cobertura (os melhores casos atingem mais de $87 \%$ ) e bons valores de medida F (máximo de 41\%) em relação aos métodos e medidas comparados nas avaliações experimentais realizadas considerando três corpora de diferentes domínios na língua portuguesa do Brasil. 


\section{Abstract}

7 ext Mining (TM) aims at discovering innovating knowledge in unstructured texts. The extraction of terms that represent the texts of a specific domain is one of the most important steps of TM, since the results of the overall TM process will mostly depend on the quality of these terms. In this thesis, we consider terms as lexical units used to assign concepts in thematically restricted scenarios. The term extraction task may use approaches such as: statistical, linguistic, or hybrid. Typically, statistical methods are the most common for Text Mining. These methods are computationally less expensive than the linguistic ones, however their results tend to be less human-interpretable. Both methods are not often capable of identifying differences between terms and non-terms. For example, statistical methods may not identify terms that have the same frequency of non-terms and linguistic methods may not distinguish between terms that follow the same patterns of non-terms. One solution to this problem is to use hybrid methods, combining the strategies of linguistic and statistical methods, in order to attenuate their inherent problems. Considering the features of the term extraction methods, in this thesis, we investigated statistical methods, ways of obtaining linguistic knowledge, and hybrid methods for extracting simple terms (only one radical, with or without the affixes) for the Brazilian Portuguese language. We evaluated, in term extraction, four new hybrid measures ( $t v q, t v, t c$, and comGram) originally proposed for other tasks; and two of them ( $t v q$ and $t v$ ) were considered relevant for this task. We proposed four new hybrid measures (n_subst., $n_{-} a d j ., n_{-} p o$, and $n_{-} v e r b o$ ); and three of them (n_subst., $n_{-} a d j$. , and $n_{-} p o$ ) were helpful in the term extraction task. Typically, the extraction methods select term candidates based on some linguistic knowledge. After this process, they apply measures or combination of measures (and/or heuristics) to these candidates in order to generate a ranking. The higher the candidates are in the ranking, the better the chances of being terms. To decide up to which position must be considered in this ranking, normally, a domain expert and/or terminologist manually or semiautomatically analyze the ranking. The first motivation of this thesis is to automate how to choose the candidates during the term extraction process. The second motivation of this research is to minimize the high number of candidates present in the term extraction. The high number of candidate, caused by the large amount of words in a corpus, could increase the time complexity and computational resources for extracting terms. The third motivation considered in this research is to improve the state of the art of the automatic simple term extraction for Brazilian Portuguese since the results of this extraction $(\mathrm{F}-$ measure $=16 \%)$ are still low when compared to other languages like English $(\mathrm{F}$-measure $=92 \%)$ and Spanish $(\mathrm{F}$-measure = $68 \%$ ). Given these motivations, we proposed the MATE-ML method (Automatic Term Extraction Based on Machine Learning), which aims to automatically extract simple terms using the machine learning techniques. MATE-ML method suggests the use of filters to reduce the high number of term candidates during the term extraction task without harming the domain representation. Thus, we believe the extractors may generate smaller candidate lists, requiring less time to evaluate these candidates. The MATE-ML method 
was instantiated in two approaches: (i) ILATE (Inductive Learning for $\underline{\text { Automatic }}$ Term Extraction), which uses the supervised inductive classification to label term candidates, and (ii) TLATE (Transductive Learning for Automatic Term Extraction), which uses transductive semi-supervised classification to propagate the classes from labeled candidates to unlabeled candidates. Using transductive learning in term extraction and using, at the same time, a rich set of candidate features belonging to different levels of knowledge (linguistic, statistical, and hybrid) are also considered as contributions. In this thesis, we discuss the advantages and limitations of these two proposed approaches. We emphasize that the use of these approaches usually achieves results with higher precision (the best case is above of $81 \%$ ), high coverage results (the best case is above of $87 \%$ ), and good F-measure values (maximum of $41 \%$ ) considering three corpora of different domains in the Brazilian Portuguese language. 


\section{Sumário}

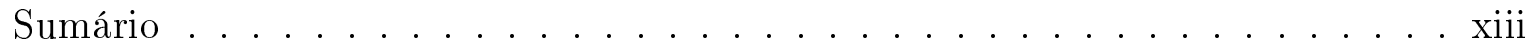

Lista de Figuras . . . . . . . . . . . . . . . . . . xvii

Lista de Tabelas ...................... . . .

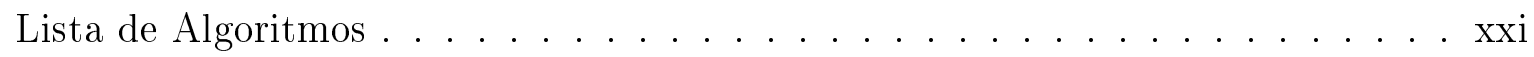

Lista de Abreviaturas.............................. . . . . .

1 Introdução 1

1.1 Motivações e Lacunas . . . . . . . . . . . . . . . . . . . . 4

1.2 Objetivos e Novidades da Pesquisa . . . . . . . . . . . . . . . 5

1.3 Hipóteses . . . . . . . . . . . . . . . . . 6

1.4 Organização desta Tese . . . . . . . . . . . . . . . . 6

2 Mineração de Textos $\quad 7$

2.1 Etapas do Processo de Mineração de Textos . . . . . . . . . . . . . . . . 7

2.1 .1 Identificação do Problema . . . . . . . . . . . . . 7

2.1.2 Pré-Processamento ...................... 8

2.1.3 Extração de Padrões . . . . . . . . . . . . . . . . . . . 11

2.1.4 Pós-Processamento e Utilização do Conhecimento . . . . . . . . . . . . . 12

2.2 Algumas Aplicações da Mineração de Textos . . . . . . . . . . . . . . . . 13

2.3 Considerações Finais . . . . . . . . . . . . . . . . 15

3 Extração (Semi)Automática de Termos para o Português do Brasil 17

3.1 Termos e as Dificuldades da sua Extração . . . . . . . . . . . . . 17

3.2 Abordagens de Extração de Candidatos a Termos . . . . . . . . . . . . 21

3.2 .1 Abordagem Estatística . . . . . . . . . . . . . . . . . . . 22

3.2 .2 Abordagem Linguística . . . . . . . . . . . . . . . . 27

3.2 .3 Abordagem Híbrida . . . . . . . . . . . . . . . . . . . . 29

3.3 Medidas de Avaliação para Extração de Candidatos a Termos . . . . . . . . 32

3.4 Corpora da Língua Portuguesa . . . . . . . . . . . . . . . . 34

3.5 Estado da Arte da Extração de Candidatos a Termos no Português do Brasil 37

3.5.1 Pesquisas Desenvolvidas para a Extração de Candidatos a Termos no Português do Brasil . . . . . . . . . . . . . . . 38

3.5.2 Pesquisas relacionadas à Extração de Termos na Língua Portuguesa do Brasil . . . . . . . . . . . . . . . . . . . 42

3.5.3 Projetos Relacionados à Extração de Termos na Língua Portuguesa do Brasil . . . . . . . . . . . . . . . . . . . 43

3.6 Ideia Geral da Extração de Termos para o Inglês e o Espanhol . . . . . . . 48 
3.7 Discussão sobre o Estado da Arte da Extração de Candidatos a Termos na Língua Portuguesa do Brasil . . . . . . . . . . . . . . . . 50

3.8 Considerações Finais . . . . . . . . . . . . . . . . . . . . 51

4 MATE-ML: um Método para Extração Automática de Termos Baseado em Aprendizado de Máquina

4.1 Motivações para a Proposta do Método MATE-ML para Extração Automática de Termos . . . . . . . . . . . . . . . . . 55

4.2 Descrição do Método MATE-ML . . . . . . . . . . . . . . 68

4.2.1 Pré-processamento dos Textos . . . . . . . . . . . . . 68

4.2 .2 Extração de Características . . . . . . . . . . . . . . . 69

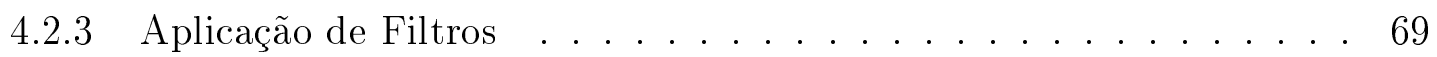

4.2.4 Classificação de Candidatos a Termos . . . . . . . . . . . . . . 70

4.3 Método Utilizado para Avaliação dos Termos Extraídos . . . . . . . . . . 70

4.4 Considerações Finais . . . . . . . . . . . . . . . . 71

5 ILATE: uma Abordagem para Extração Automática de Termos Utili$\begin{array}{ll}\text { zando Aprendizado Indutivo } & \mathbf{7 3}\end{array}$

5.1 Descrição da Abordagem ILATE . . . . . . . . . . . . . . . . . . . . . . . . 73

5.1 .1 Pré-processamento dos Textos . . . . . . . . . . . . . . . . . . 74

5.1 .2 Extração de Características . . . . . . . . . . . . . . . . . . . . . . . . . . . . . 74

5.1 .3 Aplicação de Filtros . . . . . . . . . . . . . . . . . . . 74

5.1.4 Classificação Indutiva de Candidatos a Termos . . . . . . . . . . . . 75

5.2 Primeira Avaliação Experimental da ILATE . . . . . . . . . . . . . . . . 76

5.2 .1 Pré-processamento dos Textos . . . . . . . . . . 76

5.2 .2 Extração de Características . . . . . . . . . . . . . . . . . . . 77

5.2 .3 Aplicação de Filtros . . . . . . . . . . . . . . . . . . . . 79

5.2.4 Classificação Indutiva de Candidatos a Termos . . . . . . . . . . . . 83

5.3 Apresentação, Análise e Discussão dos Resultados da Primeira Avaliação

Experimental da ILATE . . . . . . . . . . . . . . 85

5.3 .1 Discussão sobre os Resultados da ILATE . . . . . . . . . . . 85

5.3.2 Comparações entre ILATE e outros Trabalhos de Extração de Termos 89

5.3.3 Discussão acerca da Junção de Características de Diferentes Níveis de Conhecimento para a Extração de Termos Utilizando ILATE . . 92

5.4 Segunda Avaliação Experimental da ILATE . . . . . . . . . . . . . . 93

5.4 Pré-processamento dos Textos . . . . . . . . . . . . . . . . . . . . 93

5.4 .2 Extração de Características . . . . . . . . . . . . . . . . . . . . . 95

5.4 .3 Aplicação de Filtros . . . . . . . . . . . . . . . . 96

5.4.4 Classificação Indutiva de Candidatos a Termos . . . . . . . . . . . . 99

5.5 Apresentação, Análise e Discussão dos Resultados da Segunda Avaliação

Experimental da ILATE . . . . . . . . . . . . . . . . . . 99

5.5.1 Discussão sobre os Resultados das duas Avaliações Experimentais da ILATE . . . . . . . . . . . . . . . . . . . . . . 99

5.5.2 Discussões sobre os Resultados da ILATE em Relação a outros Trabalhos de Extração de Termos . . . . . . . . . . . . . 106

5.5.3 Discussão acerca das Características dos Candidatos Consideradas para a Extração de Termos Utilizando a Segunda Avaliação Experimental da ILATE . . . . . . . . . . . . . . . . . . . . . . . . . . . . . . . . . . . . .

5.6 Considerações Finais . . . . . . . . . . . . . . . . . . 112 
6 TLATE: uma Abordagem para Extração Automática de Termos Utilizando Aprendizado Transdutivo $\mathbf{1 1 3}$

6.1 Descrição da Abordagem TLATE . . . . . . . . . . . . . . . . . . . 113

6.2 Avaliação Experimental da TLATE . . . . . . . . . . . . . . . 115

6.2.1 Geração de Redes Homogêneas baseadas em Similaridade . . . . . . 115

6.2.2 Algoritmos de Aprendizado Transdutivo . . . . . . . . . . . . . . 117

6.3 Apresentação, Análise e Discussão dos Resultados da TLATE . . . . . . . 118

6.3.1 Exemplo de Propagação de Rótulos para Classificar os Candidatos

a Termos . . . . . . . . . . . . . . . . . 119

6.3.2 Discussão sobre os Resultados da TLATE . . . . . . . . . . . 120

6.3.3 Discussões sobre os Resultados da TLATE em Relação à ILATE e outros Trabalhos de Extração de Termos . . . . . . . . . . . . 125

6.4 Considerações Finais . . . . . . . . . . . . . . . . . 127

7 Conclusões e Trabalhos Futuros $\quad 131$

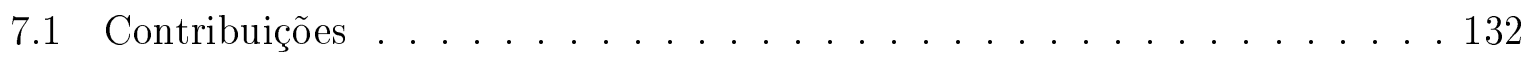

7.2 Lista de Publicações . . . . . . . . . . . . . . . . . 135

7.3 Limitações e Trabalhos Futuros . . . . . . . . . . . . . . 138

Referências $\quad 159$ 



\section{Lista de Figuras}

1.1 Classificação de exemplos de tarefas que utilizam termos. . . . . . . . . . 2

2.1 Etapas do processo de Mineração de Textos (Rezende et al., 2003) . . . . . 8

2.2 Hierarquia das atividades preditivas e descritivas juntamente com o aprendizado de máquina - Baseada nos trabalhos de Monard e Baranauskas (2003) e Rezende et al. (2003) . . . . . . . . . . . . . . . . . . 11

3.1 Níveis linguísticos de conhecimento - Adaptada de Jurafsky e Martin (2000) 27

3.2 Medidas de avaliação de termos. Adaptada de Vivaldi e Rodríguez (2007) . 33

3.3 Organização dos trabalhos relacionados com a extração de termos para a língua portuguesa do Brasil. . . . . . . . . . . . . . . . 38

3.4 Mapeamento dos trabalhos, projetos e corpora relacionados à extração de termos na língua portuguesa do Brasil. . . . . . . . . . . . . . . 52

4.1 Relação entre os resultados mais altos de precisão, cobertura e medida $\mathrm{F}$ com seus respectivos números de candidatos extraídos - Corpus ECO. . . . 66

4.2 Relação entre os resultados mais altos de precisão, cobertura e medida $F$ com seus respectivos números de candidatos extraídos - Corpus EaD. . . . 66

4.3 Relação entre os resultados mais altos de precisão, cobertura e medida F com seus respectivos números de candidatos extraídos - Corpus Nano. . . . 66

4.4 Etapas do MATE-ML - método para extração automática de termos baseada em aprendizado de máquina. . . . . . . . . . . . 68

4.5 Método para avaliação dos termos extraídos. . . . . . . . . . . . 71

5.1 ILATE - abordagem para extração automática de termos utilizando aprendizado indutivo. . . . . . . . . . . . . . . . . 74

5.2 Matrizes dos candidatos a termos. . . . . . . . . . . . 80

5.3 Número de candidatos considerados por cada filtro aplicado vs. número de termos da lista de referência mantidos por cada filtro. . . . . . . . . . . . 81

5.4 Seleção de características considerando diferentes filtragens de candidatos. $\quad 82$

5.5 Porcentagem da escolha de cada característica considerando todos os métodos de seleção de características e os três corpora utilizados. . . . . . . 83

5.6 Resultados de precisão - Corpus ECO. . . . . . . . . . . . . . . . . 86

5.7 Resultados de cobertura - Corpus ECO. . . . . . . . . . . . . . 86

5.8 Resultados de medida F - Corpus ECO. . . . . . . . . . . . . . . 86

5.9 Resultados de precisão - Corpus EaD. . . . . . . . . . . . . 87

5.10 Resultados de cobertura - Corpus EaD. . . . . . . . . . . . . . 87

5.11 Resultados de medida F - Corpus EaD . . . . . . . . . . . . . 87 
5.12 Resultados de precisão - Corpus Nano. . . . . . . . . . . . . . . 88

5.13 Resultados de cobertura - Corpus Nano. . . . . . . . . . . . . 88

5.14 Resultados de medida F - Corpus Nano. . . . . . . . . . . . . . . 88

5.15 Comparação do número de candidatos considerados por cada filtro aplicado vs. número de termos da lista de referência mantidos por cada filtro. . . . . 97

5.16 Seleção de características considerando diferentes filtragens de candidatos realizadas na segunda avaliação experimental da ILATE. . . . . . . . . . . 98

5.17 Comparação das distribuições das características selecionadas nas duas avaliações experimentais da ILATE considerando os 3 corpora utilizados. . . . 99

5.18 Resultados de precisão obtidos na segunda avaliação experimental - Corpus ECO. . . . . . . . . . . . . . . . 100

5.19 Resultados de cobertura obtidos na segunda avaliação experimental - Corpus ECO. . . . . . . . . . . . . . . . . . 100

5.20 Resultados de medida F obtidos na segunda avaliação experimental - Corpus ECO. . . . . . . . . . . . . . . . . . 101

5.21 Resultados de precisão obtidos na segunda avaliação experimental - Corpus EaD. . . . . . . . . . . . . . . . . 101

5.22 Resultados de cobertura obtidos na segunda avaliação experimental - Corpus EaD.

5.23 Resultados de medida F obtidos na segunda avaliação experimental - Corpus EaD. . . . . . . . . . . . . . . . . . . 102

5.24 Resultados de precisão obtidos na segunda avaliação experimental - Corpus Nano. . . . . . . . . . . . . . . . . . . . . . . 102

5.25 Resultados de cobertura obtidos na segunda avaliação experimental - Corpus Nano. . . . . . . . . . . . . . . . . . . 102

5.26 Resultados de medida F obtidos na segunda avaliação experimental - Corpus Nano. . . . . . . . . . . . . . . . . . 103

5.27 Resultados de precisão obtidos nas duas avaliações experimentais - Corpus ECO. . . . . . . . . . . . . . . . . . 103

5.28 Resultados de cobertura obtidos nas duas avaliações experimentais - Corpus ECO. . . . . . . . . . . . . . . . . 103

5.29 Resultados de medida F obtidos nas duas avaliações experimentais - Corpus ECO. . . . . . . . . . . . . . . . . . 104

5.30 Resultados de precisão obtidos nas duas avaliações experimentais - Corpus EaD . . . . . . . . . . . . . . . . . . . . . 104

5.31 Resultados de cobertura obtidos nas duas avaliações experimentais - Corpus EaD. . . . . . . . . . . . . . . . . . . . 104

5.32 Resultados de medida F obtidos nas duas avaliações experimentais - Corpus EaD. . . . . . . . . . . . . . . . . . 105

5.33 Resultados de precisão obtidos nas duas avaliações experimentais - Corpus Nano. . . . . . . . . . . . . . . . . . . 105

5.34 Resultados de cobertura obtidos nas duas avaliações experimentais - Corpus Nano. . . . . . . . . . . . . . . . . . . . 105

5.35 Resultados de medida F obtidos nas duas avaliações experimentais - Corpus Nano. . . . . . . . . . . . . . . . . . 106

6.1 Abordagem para extração automática de termos utilizando aprendizado transdutivo (TLATE). . . . . . . . . . . . . . . . . 114

6.2 Exemplo de representação dos candidatos a termos utilizando rede. . . . 120 


\section{Lista de Tabelas}

2.1 Padrão de matriz atributo-valor (Martins, 2003) . . . . . . . . . . . . . 10

3.1 Exemplos de termos simples e complexos de diferentes domínios. . . . . . . 19

3.2 Corpora na língua portuguesa do Brasil . . . . . . . . . . . . . . . 35

3.3 Síntese dos trabalhos sobre extração de termos . . . . . . . . . . . . . 42

3.4 Síntese dos projetos, portal e repositório relacionados com a extração de

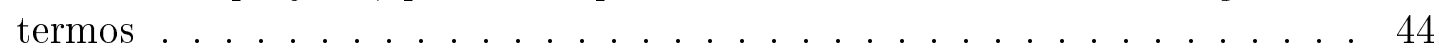

4.1 Medidas, métodos e formas de obtenção de conhecimento utilizados na extração tradicional de termos. . . . . . . . . . . . . . . . 58

4.2 Corpora utilizados nos experimentos . . . . . . . . . . . . . 59

4.3 Ordenação de candidatos utilizando a característica tf - Corpus ECO. . . . 61

4.4 Resultados mais altos obtidos pela ordenação de candidatos utilizando diferentes características - Corpus ECO. . . . . . . . . . . . 62

4.5 Resultados mais altos obtidos pela ordenação de candidatos utilizando diferentes características - Corpus EaD. . . . . . . . . . . 63

4.6 Resultados mais altos obtidos pela ordenação de candidatos utilizando diferentes características - Corpus Nano. . . . . . . . . . . . 64

4.7 Matriz de Contingência . . . . . . . . . . . . . . . 71

5.1 Medidas, métodos e formas de obtenção de conhecimento utilizados na ILATE. . . . . . . . . . . . . . . . . . . . . 77

5.2 Comparação dos resultados mais altos - Corpus ECO. . . . . . . . . . 90

5.3 Comparação dos resultados mais altos - Corpus EaD. . . . . . . . . . . . 91

5.4 Comparação dos resultados mais altos - Corpus Nano. . . . . . . . . . . 92

5.5 Medidas, métodos e formas de obtenção de conhecimento utilizados na segunda avaliação experimental. . . . . . . . . . . . . . 96

5.6 Comparação dos resultados mais altos das duas avaliações experimentais da ILATE - Corpus ECO. . . . . . . . . . . . . . . . . . . . 107

5.7 Comparação dos resultados mais altos das duas avaliações experimentais da ILATE - Corpus EaD. . . . . . . . . . . . . . . . . . . . . 108

5.8 Comparação dos resultados mais altos das duas avaliações experimentais da ILATE - Corpus Nano. . . . . . . . . . . . . . . . . . . . . 109

5.9 Comparação dos tempos gastos para extrair termos utilizando as duas avaliações experimentais da ILATE. . . . . . . . . . . . . . . . . . . . . . 109

5.10 Palavras que deram origens aos radicais utilizados como exemplos do corpus Nano. . . . . . . . . . . . . . . . . . . 110

5.11 Exemplos de resultados da ILATE utilizando o corpus Nano. . . . . . . . . 111 
6.1 Termos e não-termos considerados para exemplificar a classificação. . . . . 119

6.2 Exemplo de propagação de rótulos para classificar os candidatos a termos. 120

6.3 Resultados top-25 de precisão da EAT utilizando aprendizado transdutivo - Corpus ECO. . . . . . . . . . . . . . . . . . . 121

6.4 Resultados top-25 de cobertura da EAT utilizando aprendizado transdutivo - Corpus ECO. . . . . . . . . . . . . . . . . 121

6.5 Resultados top-25 de medida F da EAT utilizando aprendizado transdutivo - Corpus ECO. . . . . . . . . . . . . . . . . . 122

6.6 Resultados top-25 de precisão da EAT utilizando aprendizado transdutivo - Corpus EaD. . . . . . . . . . . . . . . . . . . 122

6.7 Resultados top-25 de cobertura da EAT utilizando aprendizado transdutivo - Corpus EaD. . . . . . . . . . . . . . . . . . . 122

6.8 Resultados top-25 de medida F da EAT utilizando aprendizado transdutivo - Corpus EaD. . . . . . . . . . . . . . . . . . . 123

6.9 Resultados top-25 de precisão da EAT utilizando aprendizado transdutivo - Corpus Nano. . . . . . . . . . . . . . . . . . 123

6.10 Resultados top-25 de cobertura da EAT utilizando aprendizado transdutivo - Corpus Nano. . . . . . . . . . . . . . . . . . 123

6.11 Resultados top-25 de medida F da EAT utilizando aprendizado transdutivo - Corpus Nano. . . . . . . . . . . . . . . . . . . . 124

6.12 Comparação dos resultados mais altos obtidos com a TLATE vs. diferentes formas de extração de termos - Corpus ECO. . . . . . . . . . . . 126

6.13 Comparação dos resultados mais altos obtidos com a TLATE vs. diferentes formas de extração de termos - Corpus EaD. . . . . . . . . . . . . . . 126

6.14 Comparação dos resultados mais altos obtidos com a TLATE vs. diferentes formas de extração de termos - Corpus Nano. . . . . . . . . . . . . . 127

6.15 Vantagens e desvantagens das abordagens ILATE e TLATE. . . . . . . . 128 


\title{
Lista de Abreviaturas
}

\author{
AM aprendizado de máquina \\ atf frequência média de termo (average term frequency) \\ comGram comprimento do n-grama \\ ctw context term weight \\ df frequência de documentos (document frequency) \\ dice coeficiente de Dice
}

EAT extração automática de termos

ei expressão indicativa

GFHF gaussian fields and harmonic functions

idf frequência inversa de documento (inverse document frequency)

ILATE extração automática de termos utilizando aprendizado indutivo (inductive learning for automatic term extraction)

KNN K-Nearest Neighbors

11 logaritmo da razão de máxima verossimilhança

LLGC learning with local and global consistency

MATE-ML método para extração automática de termos baseado em aprendizado de máquina (method for automatic term extraction based on machine learning)

mi informação mútua (mutual information)

MT mineração de textos

NB Nä̈ve Bayes

NSP Ngram Statistics Package

PB português do Brasil

pm classe gramatical

rf frequência relativa (relative frequency) 
ridf frequência inversa residual de documento (residual inverse document frequency)

SVM máquinas de vetores de suporte (support vector machine)

tc contribuição do termo (term contribution)

tds índice de especificidade de domínio (term domain specificity)

tf frequência de termo (document frequency)

tf-dcf frequência de termo - frequência de disjunção de corpora (term frequency - disjoint corpora frequency)

TF-IDF frequência de dermo - frequência inversa de domínio (term frequency, inverse domain frequency)

tf-idf frequência de termo - frequência inversa de documento (term frequency inverse document frequency)

thd índice termhood

TLATE extração automática de termos utilizando aprendizado transdutivo (transductive learning for automatic term extraction)

tv variância do termo (term variance)

tvq qualidade da variância do termo (term variance quality)

zstf zone-scored term frequency 


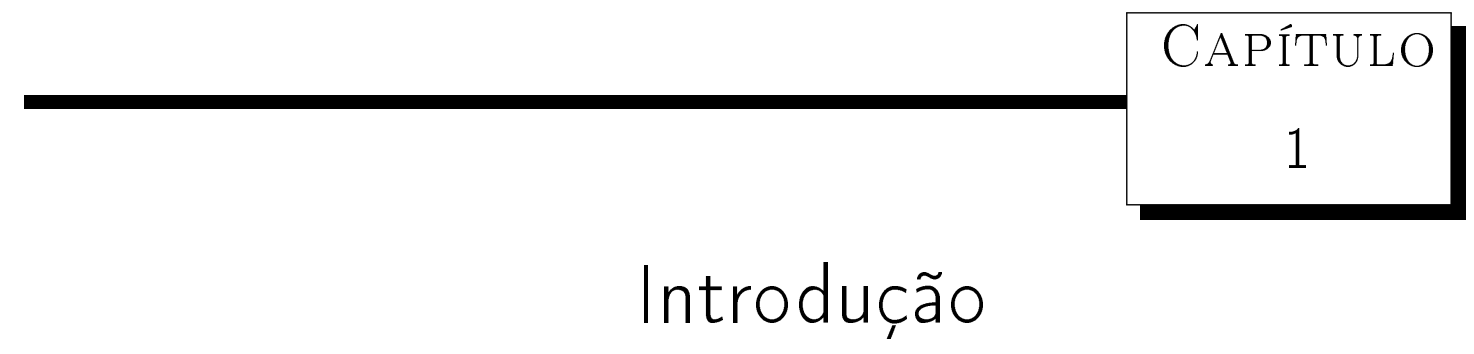

$\mathcal{A}$ quantidade de dados disponíveis em formato digital na internet e dentro das corporações tem aumentado aceleradamente. De acordo com Gantz e Reinsel (2012), o universo digital terá 40 trilhões de gigabytes em 2020 e estima-se também que 33\% dessa enorme quantidade de dados terá informações valiosas para análise.

Grande parte desses dados é representada por documentos textuais, considerando que essa é a forma mais natural de armazenar informações. Muitos desses documentos estão na forma de relatórios, artigos, especificações de produtos, resumos, notas, correspondências eletrônicas e todo tipo de publicações eletrônicas textuais - bibliotecas virtuais e acervos documentais variados (Han e Kamber, 2006). Nesses documentos, em geral, há uma enorme quantidade de conhecimento incorporado. Esse conhecimento pode ser utilizado para os mais diversos objetivos, como para servir de vantagem competitiva ou como suporte à tomada de decisão dentro das empresas, para apoiar decisões de marketing (Shaw et al., 2001), para entender melhor os defeitos de um produto com base nas reclamações de clientes (Lie et al., 2007) ou para ajudar consumidores entender a terminologia usada por profissionais da área da saúde (Pathak et al., 2013).

Nesse contexto, torna-se necessário realizar tarefas capazes de transformar essa grande quantidade de documentos, de forma automática ou semiautomática, em conhecimento útil e organizado. Na Figura 1.1, são mostrados exemplos de tarefas usadas na busca de conhecimento. Essas tarefas são classificadas tanto sob a perspectiva linguística como computacional. Ambas perspectivas utilizam recursos tanto da área de aprendizado de máquina (AM) como de processamento de língua natural (PLN). A base dessas tarefas são os termos, uma vez que estes representam o domínio dos documentos. Nesta tese, os termos são definidos como unidades lexicais utilizadas para designar conceitos em um cenário tematicamente restrito. No domínio de Ecologia, exemplos de termos simples aqueles constituídos de somente um radical, com ou sem afixos _ (1990) - seriam "clima" e "vegetais" e de termos compostos - com mais de um radical - seriam "mata atlântica" e "umidade do solo".

Para realizar a maioria dessas tarefas, pode-se fazer uso do processo de Mineração de Textos (MT), que é definido como um conjunto de técnicas e processos aplicados para descobrir conhecimento inovador nos textos não estruturados (Hearst, 1999; Ebecken et al., 2003; Kao e Poteet, 2007). Para extrair o conhecimento, a MT visa identificar padrões, tendências e regularidades em textos escritos em língua natural. Essa extração de conhecimento pode ser realizada utilizando termos que representam o corpus. Na 


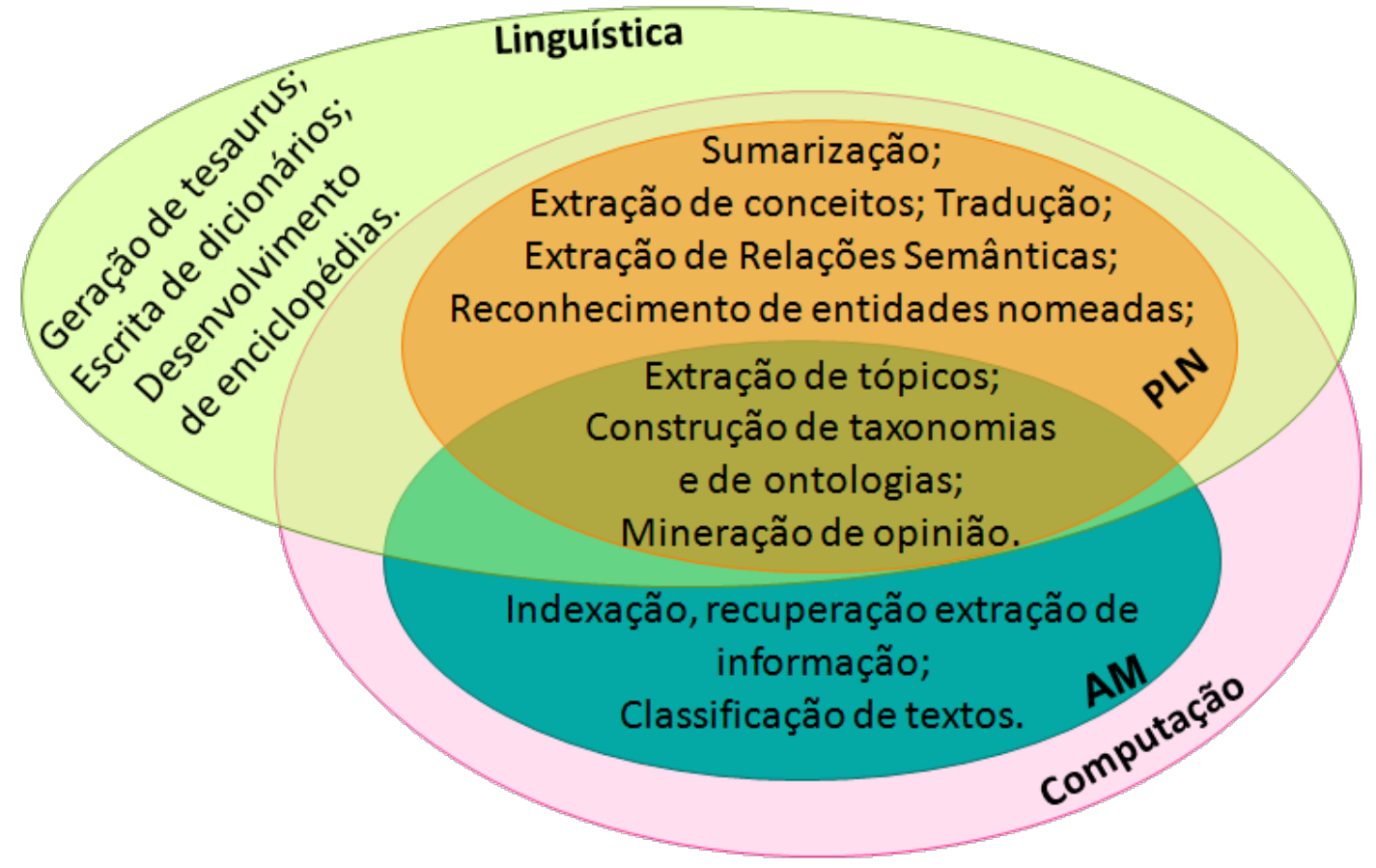

Figura 1.1: Classificação de exemplos de tarefas que utilizam termos.

pesquisa apresentada nesta tese, consideram-se como termos (ou unidades terminológicas) as unidades lexicais utilizadas para designar conceitos em um cenário tematicamente restrito. Já um corpus, de acordo com a tradução feita do trabalho de Sanchez (1995), é:

"Um conjunto de dados linguísticos (pertencentes ao uso oral ou escrito da língua, ou a ambos), sistematizados segundo determinados critérios, suficientemente extensos em amplitude e profundidade, de maneira que sejam representativos da totalidade do uso linguístico ou de algum de seus âmbitos, dispostos de tal modo que possam ser processados por computador, com a finalidade de propiciar resultados vários e úteis para a descrição e análise"

Souza e Felippo (2010), no âmbito do projeto TermiNet, detalhado na Seção 3.5.3 do Capítulo 3, página 43, resumem os critérios que definem "corpus" em: representatividade, amostragem, tamanho, autenticidade, diversidade e balanceamento.

A extração de termos é um das tarefas mais importantes da Mineração de Textos, uma vez que os resultados de todo o processo da MT dependerão, em grande parte, da qualidade dos termos obtidos. A qualidade, nesse contexto, é medida dependendo do objetivo pré-estabelecido da MT. Um exemplo de qualidade pode ser a representatividade dos termos em relação ao domínio.

De acordo com Cabré e Vivaldi (2001) e Pazienza et al. (2005), a extração dos termos pode fazer uso de diferentes níveis de conhecimento, sendo eles: linguístico, estatístico e híbrido. O uso desse conhecimento define em qual abordagem (estatística, linguística ou híbrida) a extração de termos é baseada. Para o entendimento das principais diferenças entre essas abordagens, considere, por exemplo, as sentenças:

Mineração de dados textuais é mineração de dados sobre dados textuais. Dados textuais são coleções textuais em vários formatos. Mineração de dados tem várias definições, mas dados são sempre dados que levam a significados e usos especiais.

Se for realizada uma extração de termos a partir dessas sentenças utilizando a abordagem linguística e considerando os padrões sintáticos substantivo+preposição+subs- 
tantivo e substantivo+adjetivo, seriam obtidos os seguintes candidatos a termos: $M i$ neração de dados, dados textuais, coleções textuais e usos especiais. Nessa abordagem é importante manter todas as etiquetas morfossintáticas das sentenças, como preposições e artigos.

Já na abordagem puramente estatística, costuma-se remover as stopwords, como preposições, artigos, etc. e, então, aplicar alguma medida estatística aos candidatos a termos. Se para as mesmas sentenças forem retiradas as stopwords, as sentenças ficariam assim:

\section{Mineração dados textuais é mineração dados dados textuais. Dados textuais são coleções textuais formatos. Mineração dados tem definições, dados são dados levam significados usos especiais.}

Então, para a abordagem estatística, se considerados apenas candidatos a termos que ocorram, por exemplo, pelo menos duas vezes nas novas sentenças, ter-se-iam: mineração, dados, textuais, são, mineração dados, dados textuais.

De acordo com os exemplos mostrados, embora os resultados do método estatístico aparentemente sejam menos interpretáveis em relação aos do método puramente linguístico, a aplicação do método estatístico é computacionalmente menos custosa que a do linguístico. Este último necessita de ferramentais adicionais para sua aplicação, como, no caso mostrado, um etiquetador morfossintático.

Normalmente, para a Mineração de Textos, utilizam-se métodos estatísticos para a extração dos termos. Esses métodos conseguem trabalhar melhor com grandes quantidades de documentos, por serem computacionalmente mais simples do que os linguísticos. Por outro lado, os métodos estatísticos, muitas vezes, deixam a desejar em relação à extração de termos que representam o domínio do corpus em questão. Por exemplo, assim como podem haver termos bastante frequentes no corpus, sendo esses possíveis de serem identificados pelos métodos estatísticos, podem também haver termos que são raros ou que têm a mesma frequência de não-termos. Os métodos somente estatísticos, em geral, não são capazes de identificar essas diferenças.

Então, visando melhorar a qualidade dos termos extraídos, poder-se-ia aplicar os métodos linguísticos. Entretanto, esses apresentam um alto custo computacional se comparado aos estatísticos, o que não seria aconselhável para tarefas que exigem um processamento rápido dos dados textuais. Além disso, se considerar somente os métodos linguísticos, os termos que seguem os mesmos padrões linguísticos dos não-termos não são identificados. Uma solução para esse problema é utilizar métodos híbridos, uma vez que eles combinam as estratégias dos métodos linguísticos e estatísticos, atenuando os problemas inerentes a cada uma delas

Entretanto, mesmo utilizando os métodos híbridos, a extração de termos continua sendo uma tarefa não trivial, uma vez que nem mesmo os especialistas de um mesmo domínio concordam inteiramente entre si quanto à identificação e seleção dos termos. Em média, segundo Estopa et al. (2005), a concordância entre eles fica em torno de 60\%, revelando que o reconhecimento das unidades terminológicas é uma tarefa subjetiva.

Há diversas pesquisas sobre a extração (semi)automática de termos (EAT) disponíveis na literatura (Zavaglia et al., 2005; Vivaldi e Rodríguez, 2007; Zavaglia et al., 2007; Honorato e Monard, 2008; Ribeiro Junior e Vieira, 2008; Muniz e Aluísio, 2010; Muniz et al., 2011; Nazar, 2011; Lopes, 2012; Lopes e Vieira, 2012). Entretanto, elas realizam a extração considerando cenários diferentes, como a variação dos corpora de teste e das condições e medidas de avaliação dos resultados. Essas variações fazem com que seja difícil escolher o melhor método de EAT. Portanto, a comparação dos métodos de EAT é, ainda, uma lacuna existente na área. 
Apesar da dificuldade em encontrar um padrão de comportamento dos extratores automáticos, devido a essas variações, verifica-se em algumas pesquisas, como as de Cabré e Vivaldi (2001) e Korkontzelos et al. (2008), que aproximadamente $80 \%$ das unidades linguísticas extraídas pelos métodos de EAT são efetivamente validadas como unidades terminológicas pelos especialistas de domínio.

Um dos trabalhos mais relevantes sobre EAT a partir de textos em língua inglesa é o de Nazar (2011), que alcança precisão de $75 \%$ na extração de termos utilizando métodos estatísticos. No que diz respeito à EAT a partir de textos em português do Brasil (PB), os resultados mais altos também se aproximam de $80 \%$ de precisão ao utilizar um extrator híbrido (Lopes, 2012). Para a língua espanhola, um dos trabalhos mais conhecidos é o extrator híbrido YATE (Vivaldi e Rodríguez, 2007), que atinge uma precisão de $98 \%$ para corpora do domínio da medicina.

A avaliação dos extratores também deve ser analisada de acordo com a abrangência dos mesmos, ou seja, se os métodos são capazes de extrair todas as (ou a maioria das) unidades terminológicas previstas pelos especialistas de domínio. Normalmente, quando se alcança precisões altas, a abrangência é baixa e vice-e-versa. Por exemplo, um corpus de um domínio específico tem 50 termos e são extraídos somente dois desses termos. Com esse resultado, o valor de precisão obtido por esse extrator é $100 \%$, mas a cobertura é $4 \%$.

Apesar das limitações da EAT, o desenvolvimento dos extratores automáticos permite que as tarefas de identificação e obtenção de termos, antes realizadas de forma manual a partir de textos impressos, sejam automatizadas. Isso vem agilizando e, em alguns casos, refinando consideravelmente a sistematização das "terminologias".

\subsection{Motivações e Lacunas}

Normalmente os métodos de extração de termos selecionam candidatos a termos com base em algum conhecimento linguístico (Pazienza et al., 2005). Depois disso, eles aplicam a esses candidatos medidas ou combinação de medidas (e/ou heurísticas) para gerar um ranking com tais candidatos (Frantzi et al., 1998; Kozakov et al., 2004b; Kit e Liu, 2008; Vivaldi et al., 2012). Quanto mais ao topo desse ranking os candidatos estão, maior a chance de que eles sejam termos. Então, especialistas do domínio e/ou terminólogos analisam manual ou semiautomaticamente o ranking para escolher um limiar no qual os candidatos que têm valores acima dele são considerados termos. Essa análise, em geral, é subjetiva porque depende da interpretação pessoal do humano e conhecimento do domínio, além de requerer tempo para ser realizada. Automatizar a forma de escolha dos candidatos a termos durante o processo de extração é uma motivação desta pesquisa.

A segunda motivação é reduzir o elevado número de candidatos a termos presente na extração de termos. Esse alto número, causado pelo grande quantidade de palavras contidas em um corpus (Kim et al., 2000; Yu e Liu, 2004; Nogueira et al., 2008), pode aumentar a complexidade de tempo e os recursos computacionais utilizados para se extrair os termos, inviabilizando o processo de MT.

Pode-se relacionar essas duas motivações citadas à extração de termos independente da língua adotada. Por delimitação do escopo desta tese, focou-se na extração de termos simples. Termos simples são constituídos de somente um radical, com ou sem afixos (_, 1990, p. 7). Exemplos e definições de termos são apresentados na Seção 3.1 do Capítulo 3, página 17. A terceira motivação considerada nesta pesquisa é melhorar o estado da arte da extração automática de termos simples da língua portuguesa do Brasil. Os resultados dessa extração específica (Zavaglia et al., 2007) ainda são inferiores se comparados com a extração de termos simples em outras línguas, como a inglesa (Gelbukh et al., 2010) e a 
espanhola (Vivaldi e Rodríguez, 2007).

A escolha da língua portuguesa é devido à existência de uma lacuna considerável de recursos linguístico-computacionais voltados exclusivamente a essa língua, quando comparados, por exemplo, ao inglês (Lima et al., 2007; Di Felippo, 2010). Além disso, o português está entre as línguas mais faladas, havendo aproximadamente 250 milhões de pessoas no mundo ${ }^{1}$ que falam alguma de suas variantes (Pardo et al., 2010). Ainda, a doutoranda é falante nativa da língua, o que possibilita entender melhor os textos utilizados para a extração de termos, bem como analisar melhor os resultados dessa extração.

\subsection{Objetivos e Novidades da Pesquisa}

Considerando as motivações desta pesquisa apresentadas anteriormente, o primeiro objetivo é investigar métodos estatísticos, formas de obtenção de conhecimento linguístico e métodos híbridos para a extração de termos na língua portuguesa do Brasil.

O segundo objetivo dessa pesquisa é automatizar a escolha dos candidatos do ranking que devem ser considerados termos. Para isso, propõe-se um método para extração automática de termos utilizando técnicas da área de aprendizado de máquina. Esse método não ordena os candidatos, ou seja, não faz uso de ranking e é instanciado em duas abordagens: uma que utiliza a classificação indutiva para rotular os candidatos a termos em temos e não termos e a outra que faz uso da classificação transdutiva para propagar os rótulos dos candidatos rotulados para os não rotulados. Ressalta-se que, pela primeira vez, o aprendizado transdutivo é aplicado à EAT.

O terceiro objetivo é reduzir o elevado número de candidatos a termos presente na extração de termos. Para isso, o método de EAT proposto faz uso de filtros para diminuir a quantidade de candidatos a ser trabalhada sem prejudicar a representação do domínio em questão. Com isso, acredita-se que os extratores de termos podem gerar listas menores de candidatos extraídos, demandando, assim, menos tempo dos especialistas para avaliar esses candidatos.

As principais novidades desta pesquisa são:

- Investigação de métodos linguísticos, estatísticos e híbridos de extração de termos simples para a língua portuguesa do Brasil considerando um mesmo cenário, ou seja, o uso dos mesmos corpora, a mesma maneira de pré-processar os textos desses corpora e a mesma forma de avaliar os resultados.

- Proposta de um método de extração automática de termos independente de língua voltado para os desafios enfrentados na extração de termos dentro do processo de Mineração de Textos.

- Duas instanciações do método para EAT proposto, sendo que uma avalia a aplicação do aprendizado indutivo na EAT e a outra propõe o uso do aprendizado transdutivo.

- Avaliação de medidas na extração de termos que são tradicionalmente utilizadas em outras áreas.

- Proposta de novas medidas para extração de termos.

- Avanço do estado da arte da extração de termos simples para a língua portuguesa do Brasil quando consideradas as medidas de avaliação de precisão e medida F.

\footnotetext{
${ }^{1} \mathrm{O}$ português é a língua oficial de 10 países, a saber: Brasil, Portugal, Angola, Cabo Verde, TimorLeste, Guiné-Bissau, Guiné-Equatorial, Macau (China), Moçambique e São Tomé e Príncipe.
} 
Adicionalmente, considera-se contribuir para o crescimento da pesquisa sobre extração automática de termos simples utilizando técnicas adotadas na Mineração de Textos.

\subsection{Hipóteses}

Em relação aos objetivos listados anteriormente, a hipótese principal - tese - abordada nesta pesquisa é que, com a junção de características pertencentes a diferentes níveis de conhecimento (linguístico, estatístico e híbrido), é possível melhorar os resultados de EAT.

As hipóteses secundárias são:

- Reduzir o elevado número de candidatos a termos presente na extração de termos mantendo a representatividade do domínio em questão melhorará os resultados da extração.

- A automatização da escolha de quais candidatos devem ser considerados como termos durante o processo de extração de termos não afetará negativamente os resultados da extração.

- A aplicação do aprendizado de máquina na extração automática de termos obterá resultados melhores do que a extração tradicional de termos.

\subsection{Organização desta Tese}

Para melhor entendimento da pesquisa descrita nesta tese, no próximo capítulo, são definidos os principais conceitos da Mineração de Textos, com foco em sua etapa de Préprocessamento na qual a extração de termos é realizada. Também são listadas algumas das aplicações da MT. No Capítulo 3, é realizada uma revisão da extração (semi)automática de termos, na qual se detalham as abordagens estatística, linguística e híbrida que podem ser adotadas para extrair termos, bem como os corpora disponíveis na língua portuguesa do Brasil e os principais trabalhos e projetos relacionados com a extração. Adicionalmente, é realizada uma discussão do estado da arte da extração de termos para o português em relação às línguas inglesa e espanhola. No Capítulo 4, são detalhadas as motivações do método proposto para extração automática de termos. Esse método é descrito juntamente com o método utilizado para avaliar os termos extraídos nesta pesquisa. Como mencionado anteriormente, o método para EAT proposto é instanciado em duas abordagens sendo que uma utiliza o aprendizado indutivo e a outra o transdutivo para extrair os termos. A primeira proposta de instanciação é apresentada no Capítulo 5, juntamente com seus experimentos e a discussão dos resultados. No Capítulo 6, é descrita a instanciação do método de EAT que utiliza aprendizado transdutivo para extrair os termos, bem como seus experimentos e a discussão de seus resultados. Por fim, as considerações finais, as limitações dessa pesquisa e os trabalhos futuros são elencados no Capítulo 7. 
CAPÍTULO

\section{Mineração de Textos}

$\mathcal{A}$

Mineração de Textos é definida como um conjunto de técnicas e processos aplicados para descobrir conhecimento inovador nos textos não estruturados ${ }^{1}$ (Hearst, 1999; Ebecken et al., 2003; Kao e Poteet, 2007). Neste sentido, a MT é utilizada para descobrir padrões, tendências e regularidades em documentos escritos em língua natural, sem formato predefinido para seus conteúdos.

Neste capítulo, são abordados os principais conceitos das etapas do processo de Mineração de Textos, bem como são apresentadas algumas das aplicações da MT.

\subsection{Etapas do Processo de Mineração de Textos}

Existem diversas maneiras de descrever o processo de extração de conhecimento a partir de coleções textuais. Baseado nos trabalhos de Fayyad et al. (1996), Weiss e Indurkhya (1998) e Shearer (2000), os autores de Rezende et al. (2003) descrevem a Mineração de Dados utilizando cinco etapas: (i) Identificação do Problema, Pré-Processamento, (ii) Extração de Padrões, (iii) Pós-Processamento e (iv) Utilização do Conhecimento, conforme ilustrado na Figura 2.1. Na pesquisa apresentada nesta tese, também considera-se tais etapas para a Mineração de Textos, já que esta é uma instanciação da Mineração de Dados. O processo que utiliza tais etapas pode ser modificado de acordo com o objetivo pré-estabelecido. Cada etapa é discutida a seguir, bem como as definições e conceitos necessários à sua compreensão.

\subsubsection{Identificação do Problema}

A Identificação do Problema é uma etapa importante, dado que não existe descoberta de conhecimento sem demanda pelo mesmo. Nesta etapa, é identificado e delimitado o problema, a coleção de textos a ser analisada ou sua fonte de busca, a existência de algum conhecimento prévio de domínio que possa ser utilizado na análise, o que se espera obter e como os resultados poderão ser utilizados.

Rezende et al. (2003) definem quatro questões essenciais a serem respondidas nessa etapa:

- Quais são as principais metas do processo?

\footnotetext{
${ }^{1}$ Os textos não estruturados são aqueles que não obedecem a um padrão de formatação.
} 


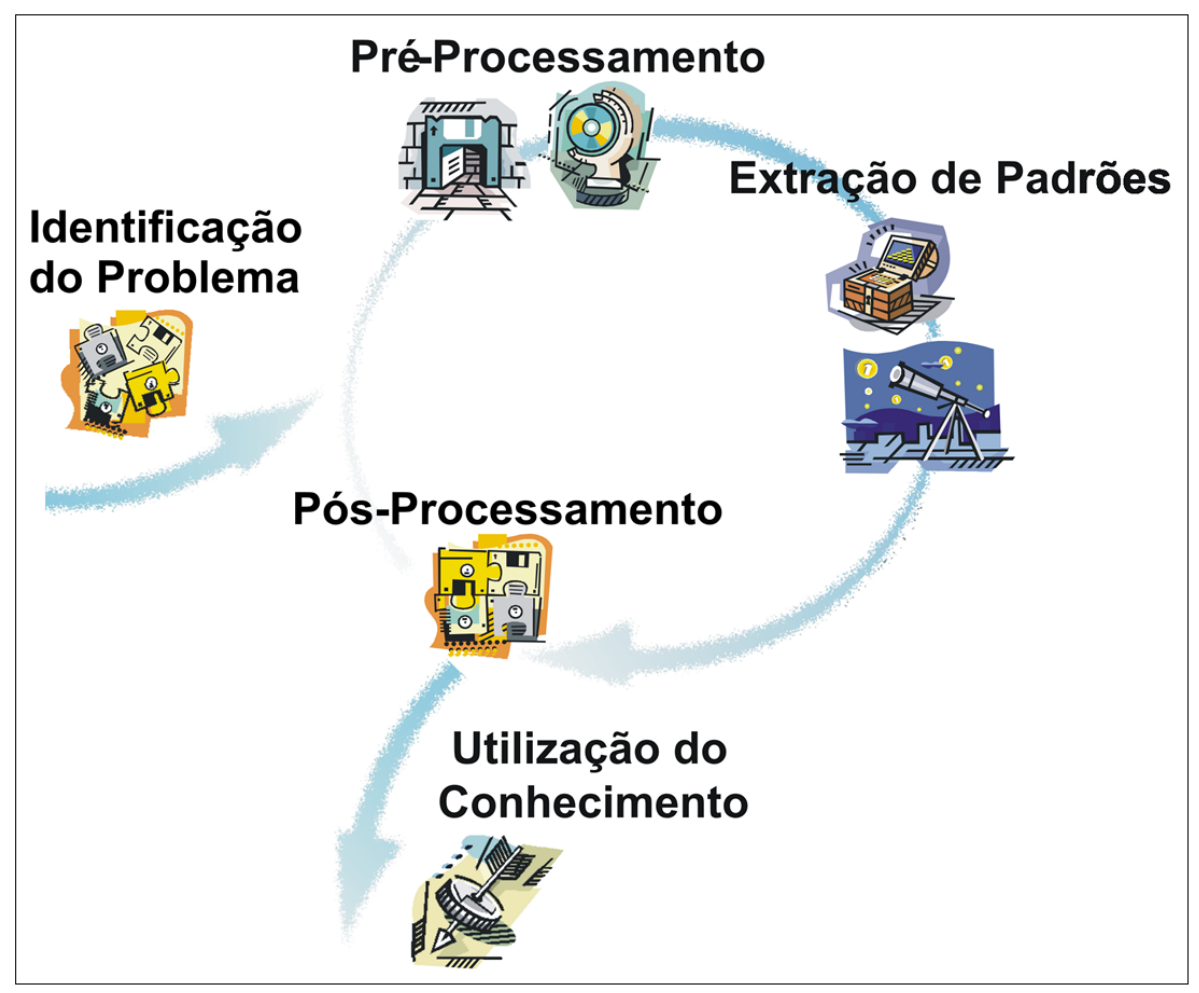

Figura 2.1: Etapas do processo de Mineração de Textos (Rezende et al., 2003)

- Quais critérios de desempenho são importantes?

- O conhecimento extraído deve ser compreensível a seres humanos ou um modelo do tipo caixa-preta é apropriado?

- Qual deve ser a relação entre simplicidade e precisão do modelo extraído?

A etapa de Identificação do Problema fornece subsídios a todo o processo, permitindo identificar requisitos e possíveis ferramentas para cada passo.

\subsubsection{Pré-Processamento}

O pré-processamento é responsável por tratar os documentos da coleção textual e gerar uma representação estruturada da coleção para, posteriormente, extrair conhecimento. As representações estruturadas, sejam elas baseadas em modelo espaço-vetorial (Salton e Buckley, 1987; Moura et al., 2008c; Rossi e Rezende, 2011) ou em redes (Rossi et al., 2014), são geradas utilizando termos que representam a coleção textual.

Dependendo da coleção textual a ser trabalhada, faz-se necessário remover documentos duplicados, reduzir o volume de textos ou balancear a coleção (Moura, 2009). Entretanto, deve-se sempre preservar as características da coleção textual necessárias para que os objetivos do processo de mineração sejam cumpridos.

Ao considerar o processo de MT, o pré-processamento é comumente realizado em cinco atividades que visam extrair os termos que representam a coleção textual. Essas atividades são: (i) padronização dos formatos dos textos, (ii) limpeza dos textos, (iii) normalização das palavras dos textos, (iv) identificação de termos e (v) representação da coleção textual. Essas atividades, destacadas em negrito no decorrer do texto, são descritas a seguir.

A coleção textual pode conter documentos de diferentes formatos, como hipertextos ou .pdf. Dependendo de como os documentos foram armazenados ou gerados, há a neces- 
sidade de padronizar os formatos em que se encontram, convertendo-os, geralmente, para a forma de texto plano.

Faz-se necessário realizar uma limpeza dos textos, que consiste da eliminação das stopwords nos documentos. As stopwords são basicamente palavras funcionais (p.ex.: preposições, artigos, conjunções, advérbios, etc) com nenhum valor terminológico para o domínio em questão. Sua definição depende dos objetivos estabelecidos e do domínio do conhecimento. O conjunto de stopwords é chamado de stoplist.

No trabalho de Braga (2009), é corroborado o benefício da remoção de stopwords para a extração de termos complexos. Moura (2009) enfatiza que a remoção de stopwords é uma forma de seleção inicial de candidatos a termos, pois ajuda a reduzir a dimensão final do vocabulário eliminando candidatos não significativos para a análise. Manning et al. (2008a) afirmam que eliminar as stopwords reduz significativamente a quantidade de palavras que são armazenadas, podendo-se deduzir que a quantidade de palavras que são processadas e o tempo gasto para isto também são reduzidos.

O número de palavras que compõem os documentos da coleção textual após a remoção das stopwords é, geralmente, ainda muito grande e, muitas vezes, algumas palavras se referem à variantes de escrita cujos conceitos são similares, como urbana e urbanismo. Assim, faz-se necessário normalizar as palavras dos textos, ou seja, buscar padrões que normalizem as diversas formas de apresentação dessas palavras mantendo-se o significado essencial. Entre as técnicas de normalização mais utilizadas para este fim, encontram-se a radicalização, lematização e substantivação, detalhadas na Subseção 3.2.2 do Capítulo 3, página 27. Após a aplicação de uma dessas técnicas, faz-se uso de medidas para obter candidatos a termos. As medidas que podem ser utilizadas nesta etapa são descritas na Subseção 3.2.1, página 22 .

Uma vez normalizadas as palavras dos textos ${ }^{2}$ é útil identificar os termos que representam o domínio da coleção de textos, já que ao se trabalhar somente com esses termos (ou com sua maioria), a descoberta de conhecimento sobre a coleção textual de entrada é facilitada. No processo de MT, candidatos a termos são normalmente identificados com uso de medidas estatísticas, por exemplo, (i) a frequência de termo ( $t f$ - term frequency) contabiliza quantas vezes um candidato aparece ao longo da coleção textual; (ii) a frequência de documentos ( $d f$ - document frequency) mede o número de documentos nos quais um candidato ocorre na coleção; (iii) a frequência de termo - frequência inversa de documento ( $t$-idf - term frequency inverse document frequency) (Salton e Buckley, 1987) atribui menor peso àqueles candidatos que aparecem em muitos documentos. Assim, candidatos muito comuns na coleção são considerados não representativos. Considerando o valor atribuído à cada candidato utilizando essas medidas, mantêm-se somente os candidatos cujos valores são maiores do que um threshold pré-definido.

Também, pode-se diminuir a quantidade desses candidatos utilizando métodos ou medidas encontrados na literatura (Nogueira, 2009), a saber: métodos de Luhn, de Salton, LuhnDF e medidas term contribution, term variance, term variance quality e zone-scored term frequency. Esses métodos são descritos a seguir enquanto que as medidas são detalhadas no Capítulo 3.

O método de Luhn (Luhn, 1958) é baseado na Lei de Zipf (Zipf, 1949), também chamada de Princípio do Menor Esforço. Esse método contabiliza a frequência dos candidatos e ordena o histograma resultante em ordem decrescente, formando a chamada "Curva de Zipf". Esse método propõe pontos de corte superior e inferior na Curva de Zipf, escolhidos subjetivamente, de maneira que candidatos a termos com alta e baixa $t f$ são descartados. Candidatos de alta $t f$ não são relevantes por geralmente aparecerem na maioria dos

\footnotetext{
${ }^{2}$ A normalização das palavras dos textos de entrada pode ser feita antes ou depois da identificação de termos, dependendo de como a identificação será realizada.
} 
textos. Já os candidatos de baixa $t f$ são considerados muito raros e não possuem caráter discriminatório.

O método de Salton (Salton et al., 1975) baseia-se no poder de discriminação de um candidato a termo, ou seja, quão bem um candidato é capaz de diferenciar um documento da coleção de outro documento. O valor de discriminação de um candidato reflete, portanto, o quanto a separação média entre documentos muda quando esse candidato é considerado, de maneira que os melhores candidatos são aqueles que atingem maior grau de separação. Para isso, esse método sugere considerar candidatos a termos que apresentem $d f$ entre $1 \%$ e $10 \%$ do total de documentos da coleção.

O método LuhnDF (Nogueira, 2009) é uma adaptação do método de Luhn que cria o histograma a partir dos candidatos a termos cujas frequências dos documentos $(d f)$ não sejam tão altas, nem tão baixas. Pode-se aplicar cortes de Luhn sobre esse histograma, escolhendo subjetivamente um ponto de corte superior e outro inferior.

Após a aplicação de um desses métodos ou medidas, tem-se uma quantidade de candidatos reduzida. Esses candidatos, por sua vez, deveriam corresponder aos termos da coleção.

Os (candidatos a) termos são utilizados para representar a coleção textual de maneira que os algoritmos de extração de padrões possam processá-los. Em tarefas de Mineração de Textos, o modelo mais comumente utilizado para representar um documento da coleção textual é o modelo espaço vetorial (Salton e Buckley, 1987; Weiss et al., 2005). Nesse modelo, cada documento $\left(d_{i}\right)$ é representado por um vetor e cada posição desse vetor corresponde a um (candidato a) termo (dimensão) do documento $\left(t_{i}\right)$. Assim, tem-se um vetor para cada documento da coleção e o conjunto desses vetores são representados em uma matriz atributo-valor, como mostrado na Tabela 2.1. A última coluna dessa matriz corresponde à classe dos documentos $\left(c_{i}\right)$, se estes forem rotulados. Caso os documentos não possuam rótulos, essa coluna é descartada da matriz atributo-valor. O modelo espaço vetorial é simples e permite o uso dos métodos tradicionais de extração de padrões que lidam com vetores de atributos numéricos. Para calcular os valores das células $\left(a_{i j}\right)$ da matriz atributo-valor, diversas medidas foram propostas na literatura. Essas medidas podem ser binárias ( 0 se o (candidato a) termo não ocorre no documento, e 1 se ocorre) ou baseadas em frequência, como $t f$ e $t f$ - $i d f$ (Salton e Buckley, 1987).

\begin{tabular}{c|cccc|c}
\hline & $t_{1}$ & $t_{2}$ & $\ldots$ & $t_{M}$ & classe \\
\hline$d_{1}$ & $a_{11}$ & $a_{12}$ & $\ldots$ & $a_{1 M}$ & $c_{1}$ \\
$d_{2}$ & $a_{21}$ & $a_{22}$ & $\ldots$ & $a_{2 M}$ & $c_{2}$ \\
$\vdots$ & $\vdots$ & $\vdots$ & $\ddots$ & $\vdots$ & $\vdots$ \\
$d_{N}$ & $a_{N 1}$ & $a_{N 2}$ & $\ldots$ & $a_{N M}$ & $c_{N}$ \\
\hline
\end{tabular}

Tabela 2.1: Padrão de matriz atributo-valor (Martins, 2003).

A abordagem bag-of-words é uma das formas de representação de documentos textuais que utiliza o conceito do modelo espaço vetorial. Nesta abordagem, os (candidatos a) termos extraídos de uma coleção textual são tratados como um conjunto desordenado de palavras independentes. Esta abordagem não considera a ordem nas quais os (candidatos a) termos do documento aparecem, onde eles ocorrem no documento, o quão perto eles estão uns dos outros, quais as relações entre eles, etc.

Quando se gera uma representação bag-of-words da coleção textual, tal representação tem como características a alta dimensionalidade e o fato de ser esparsa. A alta dimensionalidade é causada pelo grande número de (candidatos a) termos contidos em uma coleção de textos. Já a natureza esparsa da matriz é ocasionada pelo fato de que grande 
parte dos termos ocorre somente em uma pequena parte dos documentos, de maneira que a medida de relação com todos os outros documentos da coleção é igual a zero. Ante a esse contexto, vários algoritmos de extração automática de conhecimento têm o seu desempenho negativamente afetado. Yu e Liu (2004) destacam que o excesso de atributos utilizados pode causar lentidão no processo de treinamento, bem como decremento na qualidade do conhecimento extraído (overfitting, por exemplo).

Ressalta-se que esta etapa de Pré-Processamento pode ser redefinida e então repetida após as próximas etapas, uma vez que a descoberta de alguns padrões pode levar a estabelecer melhorias a serem empregadas sobre a medida a ser utilizada na matriz atributo-valor. Por exemplo, o uso de algum tipo de taxonomia após a descoberta da mesma.

\subsubsection{Extração de Padrões}

A etapa de Extração de Padrões consiste da escolha, configuração e aplicação de algoritmo(s) de mineração para extração dos padrões embutidos nos dados textuais.

As atividades que podem ser realizadas na etapa de Extração de Padrões utilizam aprendizado de máquina e são classificadas em preditivas ou descritivas. A hierarquia dessas atividades é mostrada na Figura 2.2.

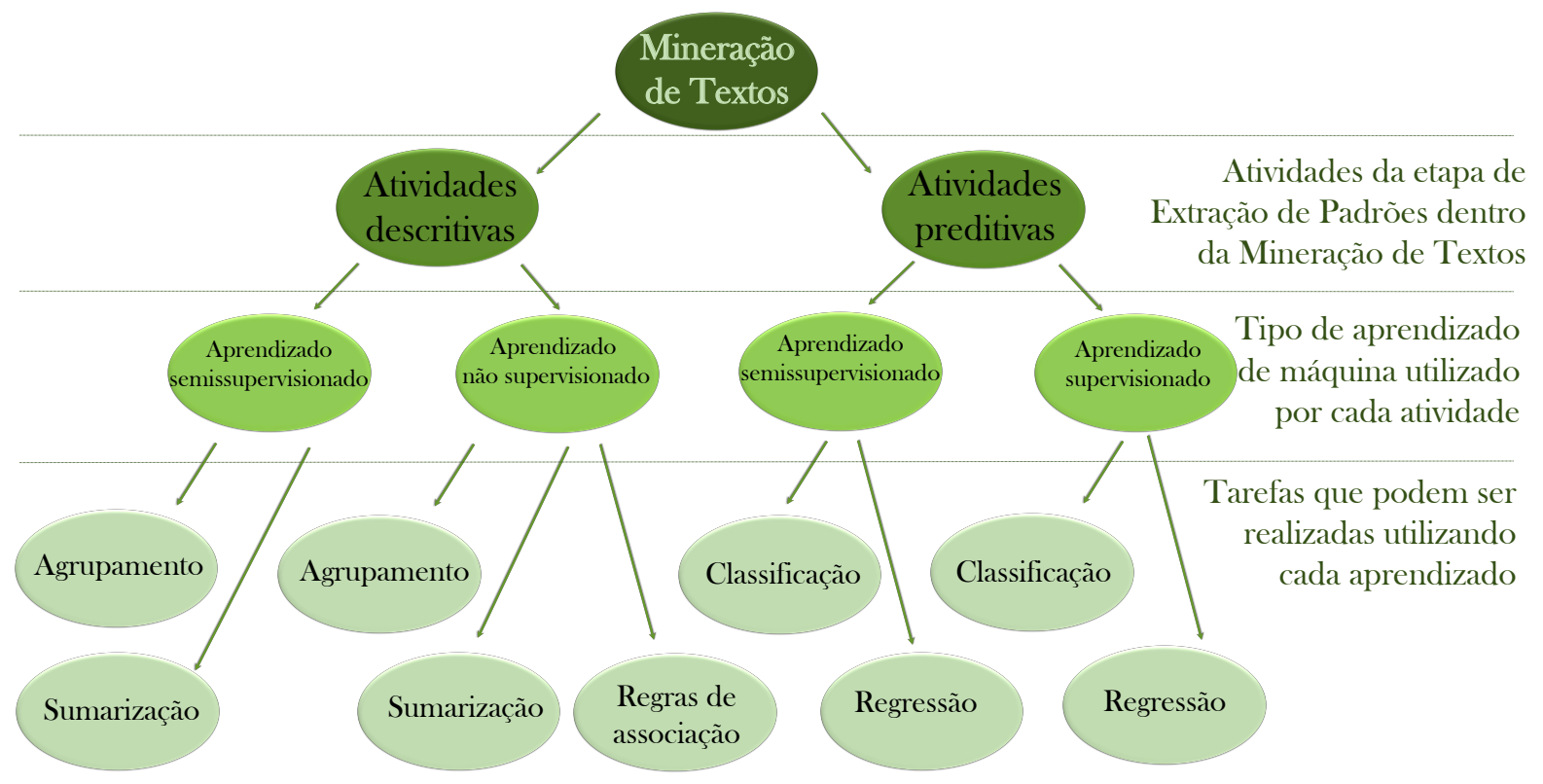

Figura 2.2: Hierarquia das atividades preditivas e descritivas juntamente com o aprendizado de máquina - Baseada nos trabalhos de Monard e Baranauskas (2003) e Rezende et al. (2003)

As atividades descritivas consistem na identificação de comportamentos intrínsecos da coleção de textos. Para tal identificação, são utilizadas técnicas de aprendizado de máquina não supervisionado ou semissupervisionado. As tarefas que utilizam o aprendizado não supervisionado não fazem uso de informação dos rótulos dos dados. Exemplos dessas tarefas são: regras de associação, que visam encontrar relações de coocorrência, chamadas de associações, entre os dados (Agrawal et al., 1993; Manning et al., 2008b; Liu, 2011); agrupamento (clustering), que visa agrupar documentos similares em clusters (Rezende et al., 2003; Aggarwal, 2012b); e sumarização, que objetiva gerar resumos a partir de um ou vários textos (Mani e Maybury, 2001; Nenkova, 2012). As principais tarefas que utilizam o aprendizado semissupervisionado compreendem: agrupamento e sumarização, sendo que a diferença neste caso é que, por exemplo, pode-se haver a supervisão do usuário (Chapelle et al., 2006; Zhu, 2008; Aggarwal e Zhai, 2012). 
As atividades preditivas, por sua vez, consistem na generalização de exemplos ou experiências passadas com respostas conhecidas. Essas atividades utilizam aprendizado de máquina supervisionado ou semissupervisionado, sendo que ambos podem compreender tarefas como classificação, que consiste em classificar novos textos (documentos) em uma ou mais classes definidas, sendo que o atributo classe tem valor categórico (Sebastiani, 2006), e regressão, que visa predizer valores de variáveis que possuem valores contínuos.

O aprendizado supervisionado assume que os rótulos de todos os exemplos são sempre conhecidos e disponíveis junto aos dados. Já o aprendizado semissupervisionado considera que apenas parte dos exemplos são rotulados, enquanto que no aprendizado não supervisionado todos os dados são não rotulados.

A extração de termos, que é o foco desta pesquisa, assemelha-se à tarefa de classificação se for considerado que o objetivo da extração pode ser visto como classificar um candidato a termo como termo ou não-termo. Neste sentido, na pesquisa apresentada nesta tese, a classificação, utilizando aprendizado supervisionado e semissupervisionado, é aplicada como meio para se extrair termos de domínios específicos.

Com relação à classificação, nesta pesquisa, levaram-se em conta dois cenários: (i) quando se tem disponível um número considerável de exemplos rotulados (aprendizado indutivo supervisionado (Carbonell, 1989; Mitchell, 1997; Sebastiani, 2002; Chapelle et al., 2006)) e (ii) quando se tem disponível poucos exemplos rotulados (aprendizado transdutivo semissupervisionado (Vapnik e Sterin, 1977; Chapelle et al., 2006; Zhu, 2008)). Como o foco da pesquisa apresentada nesta tese não é avaliar ou propor algoritmos de classificação, as descrições formais desses aprendizados são brevemente apresentadas a seguir e os algoritmos utilizados nesta pesquisa são descritos nos Capítulos 5 (página 73) e 6 (página 113).

O aprendizado indutivo supervisionado visa induzir um classificador, a partir de um conjunto de dados rotulados utilizados para treinamento, para rotular novos exemplos (Carbonell, 1989; Mitchell, 1997). Formalmente, considerando que $X^{L}$ seja os dados rotulados, um algoritmo indutivo aprende com uma função como $f: X^{L} \rightarrow Y^{L}$, de tal forma que $f$ obtenha um desempenho considerado bom em relação à predição de rótulos de novos exemplos não contidos em $X^{L}$.

Já o aprendizado transdutivo semissupervisionado, introduzido por Vapnik e Sterin (1977), tem como objetivo rotular os exemplos que são conhecidos mas não são rotulados sem criar um modelo de classificação. Isso é possível porque algoritmos transdutivos utilizam a informação dos dados rotulados e não rotulados para classificar os dados não rotulados. Formalmente, este aprendizado gera uma função como $f: X^{L+U} \rightarrow Y^{L+U}$ de tal forma que $f$ obtenha um desempenho considerado bom em relação à predição de classes de exemplos não rotulados conhecidos $\left(X^{U}\right)$.

Uma das vantagens do aprendizado indutivo é que ele não necessita conhecer todos os exemplos a serem rotulados previamente, ao contrário do transdutivo. Por outro lado, o aprendizado indutivo necessita de um número considerável de exemplos rotulados para que seja possível obter resultados satisfatórios. Já o aprendizado transdutivo geralmente necessita de poucos exemplos rotulados para propagar as classes desses exemplos rotulados para os não rotulados.

\subsubsection{Pós-Processamento e Utilização do Conhecimento}

Na etapa de Pós-Processamento, os padrões extraídos são validados quanto ao conhecimento obtido. Essa validação deve levar em consideração o contexto do problema e pode ser realizada utilizando métricas objetivas (Rezende et al., 2003; Tan, 2013) ou, ainda, 
por julgamento subjetivo de especialistas do domínio em questão.

Por exemplo, em aplicações que envolvam atividades preditivas, pode-se validar os padrões extraídos por meio de medidas relativas à precisão na predição de dados não vistos, como taxa de erro, precisão e cobertura. Já em aplicações que envolvam atividades descritivas, a validação das descobertas efetuadas é um pouco mais complicada, uma vez que o critério de validação varia de acordo com o objetivo do processo. Dessa forma, algumas vezes podem não existir medidas objetivas adequadas para avaliar o resultado do processo, ficando a validação a cargo de um especialista do domínio (avaliação subjetiva).

A análise minuciosa dos resultados obtidos permite que se valide a sua utilidade e até mesmo o próprio processo de MT, determinando a necessidade de retomar passos anteriores e reestruturando-os se necessário. Nesta etapa, o especialista do domínio e o de Mineração de Textos devem trabalhar juntos, procurando responder a questões como: representatividade do conhecimento obtido; o que há de novo nos resultados encontrados; de que maneira o conhecimento do especialista difere do obtido; validação dos resultados obtidos; identificação da adequação de procedimentos nas etapas anteriores para tentar melhorar os resultados; e de que maneira os resultados obtidos devem ser utilizados.

$\mathrm{Na}$ etapa de Utilização do Conhecimento, os resultados estão validados e aptos a serem utilizados. Dessa forma, o conhecimento extraído pode ser aplicado para apoiar algum processo de tomada de decisão, conforme objetivo pré-estabelecido na etapa de Identificação do Problema.

\subsection{Algumas Aplicações da Mineração de Textos}

Mineração de Textos tem como principal função identificar, em coleções textuais, informações singulares, e não necessariamente informações principais, como é o caso da recuperação e preservação da ideia central. Todavia, ela pode ser aplicada para diversos fins, como em algumas das aplicações listadas a seguir. Também são apresentados brevemente alguns trabalhos relacionados com estas aplicações.

- Classificação de textos consiste em classificar novos textos (documentos) em uma ou mais categorias ou classes definidas (Sebastiani, 2006). Cintra e Monard (2009) compararam alguns métodos clássicos de aprendizado de máquina para classificação (J4.8, Multilayer Perceptron, Naive Bayes, OneRule e ZeroRules) e dois métodos baseados na lógica fuzzy (DoCBased e Wang 86 Mendel). Colace et al. (2014) introduzem um novo método de classificação textual que utiliza poucas palavras rotuladas. Há diversos outros trabalhos que utilizam a classificação de textos para os mais diversos fins. Por exemplo, Lloret et al. (2010) utilizaram a acurácia obtida pelo classificador SVM para mostrar que os sumários gerados pelos autores obtiveram melhores resultados do que quando se trabalha com os textos completos. Saleh et al. (2010) classificaram artigos da Wikipedia a partir do reconhecimento de entidades nomeadas (pessoa, locais e organizações) dentro dos conteúdos dos artigos. Megerdoomian e Hadjarian (2010) realizaram uma mineração e classificação de neologismo pertencentes a blogs da internet em cinco categorias (internet, cinema e teatro, política, medicina e esporte). Ghazi et al. (2010) compararam o uso da classificação textual hierárquica com classificação flat para indicar em qual emoção (alegria, tristeza, medo, raiva, nojo e surpresa) determinadas sentenças estão relacionadas. Arora et al. (2010); Gupta et al. (2013) e Li e Xu (2014) classificaram, nesta ordem, sentenças, emails de atendimento ao cliente e eventos em textos em relação à emoção. 
- Agrupamento de documentos almeja descobrir agrupamentos naturais e, então, apresentar as possíveis classes em uma coleção de textos (Andrews e Fox, 2007). Em outras palavras, é considerado como um processo de agrupar documentos similares em clusters (Ribeiro et al., 2008). No trabalho de Jain (2010), os algoritmos de agrupamento e suas tendências são discutidos. Há também outros trabalhos cujo foco é agrupamento de textos, como os trabalhos de Steinbach et al. (2000); Moura et al. (2008b); Nogueira e Rezende (2009); Moura e Rezende (2010) e Mohammed et al. (2014).

- Sumarização de documentos não estruturados corresponde à geração de sumário, um resumo, com o objetivo de transmitir ou comunicar somente o que é importante de uma fonte textual de informação (Rino e Pardo, 2003). Existe a sumarização monodocumento que tem como objetivo gerar um sumário a partir de um único documento. Esse tipo de sumarização foi estendida visando produzir um único sumário a partir de um conjunto de documentos pertencentes ao mesmo domínio, dando origem à sumarização multidocumento. No trabalho de Jorge e Pardo (2010) foram gerados sumários multidocumento para a língua portuguesa do Brasil por meio do uso de uma ferramenta apresentada pelos autores, a CSTSumm (CST-based SUMMarizer). Há também pesquisas que exploram a sumarização de documentos cross-language, que consiste na geração de sumários em uma língua a partir de conjuntos de documentos pertencentes a outra diferente língua, como é o caso do trabalho de Wan et al. (2010). Também há pesquisas recentes que sumarizam textos de dispositivos móveis (Foong et al., 2014).

- Recuperação de informação tem como objetivo encontrar documentos que contenham uma determinada informação a partir de uma coleção de textos (Manning et al., 2008a; Bettio e Rodriguez, 2009). No trabalho de Carvalho et al. (2010), é feita uma discussão sobre sistemas de representação da informação em ambientes de produção e de colaboração na Web. Como o uso de palavras-chave tem sido um dos principais recursos para o refinamento de busca em sistemas de recuperação de informação, Ferreira et al. (2009) analisaram as palavras-chave encontradas nos artigos publicados nas revistas brasileiras e portuguesas que participam do Portal Univerciência.org ${ }^{3}$ - Revistas de Acesso Aberto em Ciências da Comunicação. Essa análise levou em consideração se as palavras-chave utilizadas nos artigos são adequadas para a recuperação de informação.

- Organização de informação visa auxiliar o trabalho feito a partir de coleções textuais, seja ele a obtenção de conhecimento ou busca de informação. Para se organizar informação pode-se utilizar taxonomias de tópicos construídas a partir das coleções textuais. No Projeto TopTAx (Moura et al., 2008a; Moura, 2009), o processo de Mineração de Textos é instanciado com o objetivo de extrair taxonomias de tópicos a partir de coleções textuais, visando organizar informação de domínios específicos. Para dar suporte a construção de taxonomias de forma não supervisionada, Marcacini e Rezende (2010) apresentaram um método incremental de construção de hierarquias de tópicos, que permite a atualização da taxonomia sem refazer o processo de agrupamento. Também se pode citar o trabalho de Murthy et al. (2010), no qual foi apresentada uma nova abordagem para gerar uma taxonomia de dados geográficas (registros de endereços) considerando a Frequência dos termos ocorridos nesses dados. Carvalho et al. (2014) utiliza agrupamento hierárquico para

${ }^{3}$ Portal Univerciência.org - http://www .revistas.univerciencia.org/ 
organizar os dados de redes sociais por meio da ferramenta TorchSR, que possibilita visualizar e explorar dados textuais.

- Extração de informação consiste em extrair a partir de documentos alguma informação relevante (Turmo et al., 2006). A extração de informação pode ser utilizada para diversos aplicativos, como em inteligência na Web, em motores de busca, em compreensão de textos. Por exemplo, Sun et al. (2003) utilizaram a extração de informação para identificar informação de terrorismo a partir de mensagens. Thomas et al. (2010) apresentaram um modelo de extração de informação que tem como entrada documentos manuscritos. Chiticariu et al. (2010) descrevem brevemente os avanços e desafios da atividade de extração de informação. Bellot et al. (2014) apresentam algumas abordagens estatísticas para a extração de informação e recuperação de informação, discutindo as limitações práticas de tais abordagens e os desafios para o futuro.

- Web semântica tem como "principal objetivo fornecer estruturas e dar significado semântico ao conteúdo das páginas da internet, favorecendo um ambiente no qual agentes de software e usuários possam trabalhar de forma cooperativa" (Aranha, 2007). As tendências da Web semântica são discutidas no trabalho de Bolinhas e Neves (2010), bem como são apresentados alguns projetos cujo foco é Web semântica. O projeto LARKC ${ }^{4}$ (Large scale semantic computing semantic Web technologies distributed reasoning probabilistic reasoning Web-scale inference information retrieval) é um exemplo desses projetos e tem como objetivo distribuir informação e métodos de recuperação e classificação da mesma contornando o problema de escalabilidade. Outro exemplo é o projeto KIWI ${ }^{5}$ (Knowledge in a Wiki), cujo objetivo é desenvolver um sistema avançado de gerenciamento de conhecimento (KIWI system). Esse sistema é baseado (i) na filosofia da wiki, na qual permite criar e compartilhar conhecimento colaborativo; (ii) na agregação de inteligência, por meio de raciocínio; (iii) e em métodos de Web semântica, por meio do uso de descrições semânticas.

- Análise de evolução de fluxos de textos objetiva encontrar padrões evolutivos nos dados temporais (Gama, 2010; Aggarwal, 2012a). Tais padrões evolutivos são úteis para uma ampla variedade de aplicações, como sumarizar eventos em artigos de notícias e descobrir tendências de pesquisa na literatura. Leskovec et al. (2009) criaram um framework para acompanhar frases curtas que persistentemente aparecem no texto on-line ao longo do tempo. Este framework rastreia novos tópicos, ideias e "memes" bais e as dinâmicas de propagação de informações entre os meios de comunicação e mídias sociais. Karkali et al. (2013) propuseram um algoritmo de detecção de novidades em fluxos de textos com base na frequência inversa de documento $(i d f)$.

Mostrando-se algumas das aplicações nas quais a Mineração de Textos pode ser utilizada é notável a importância da MT para os diversos objetivos.

\subsection{Considerações Finais}

Neste capítulo, foram abordados os principais conceitos das etapas do processo de Mineração de Textos. Uma das etapas destacadas foi o Pré-Processamento, na qual a

\footnotetext{
${ }^{4}$ LARKC - http://www.larkc.eu/

${ }^{5} \mathrm{KIWI}$ - http://www.kiwi-project.eu/

${ }^{6} \mathrm{O}$ termo "Meme" na Web é usado para descrever um conceito que se espalha via internet.
} 
extração de termos é realizada. Tradicionalmente, na literatura, são utilizadas medidas que tentam indicar quais candidatos a termos do domínio podem ser termos verdadeiros. Entretanto, não há indícios de valores ideais das medidas para a extração de termos.

Considerando tal problema, na pesquisa apresentada nesta tese, são exploradas técnicas de extração de padrões como meio para se realizar a extração automática de termos, especificamente, a classificação utilizando aprendizado indutivo supervisionado e transdutivo semissupervisionado. Uma das vantagens do uso dessa classificação é que esta evita a definição manual dos valores ideais usados pelas medidas para a extração de termos.

Ressalta-se que dependendo das escolhas feitas durante a extração de termos é possível amenizar o problema da alta dimensionalidade da representação dos candidatos. Diminuindo, assim, o espaço de armazenamento dos dados trabalhados e mantendo, em sua maioria, a qualidade dos mesmos. Além disso, pode ser possível diminuir o tempo de processamento e o espaço de armazenamento necessário para os dados.

No capítulo a seguir, é apresentada uma revisão da tarefa de extração de termos para a língua portuguesa do Brasil, uma vez que a extração realizada nesta pesquisa é aplicada para o português. 


\section{CAPÍTULO 3 \\ Extração (Semi)Automática de Termos para o Português do Brasil}

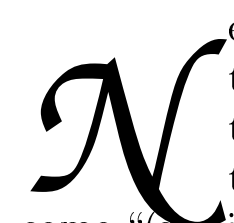

este capítulo, busca-se apresentar o cenário da extração (semi)automática de termos com foco principal na língua portuguesa do Brasil. A revisão da extração foi direcionada ao português porque os experimentos realizados neste trabalho utilizam corpora nessa língua. A extração discutida aqui é referida como "(semi)automática" devido ao fato que algumas pesquisas descritas neste capítulo não extraem termos de maneira totalmente automática. Um artigo que abrange grande parte dessa revisão foi aceito para publicação na revista JBCS (Conrado et al., 2014).

Na Seção 3.1, são mostrados exemplos de termos e introduzidas algumas dificuldades presentes durante a extração de termos. Na Seção 3.2, são detalhadas as abordagens utilizadas na tarefa de extração. Na Seção 3.3, são apresentadas as diferentes maneiras encontradas na literatura para avaliação de candidatos a termos extraídos. Os corpora disponíveis na língua portuguesa são descritos na Seção 3.4. Na Seção 3.5, é relatado o estado da arte da extração de candidatos a termos para a língua portuguesa, incluindo as medidas, ferramentas e recursos que podem ser utilizados para extrair candidatos a termos. Nessa mesma seção, é apresentada uma ideia geral sobre a extração de termos para as línguas inglesa e espanhola. Também são descritos os principais projetos que utilizam a tarefa de extração. Na Seção 3.7, discute-se sobre o estado da arte da tarefa de extração. Finalmente, na Seção 3.8, as considerações finais deste capítulo são apresentadas.

\subsection{Termos e as Dificuldades da sua Extração}

Apesar da importância da tarefa de extração de termos, ainda não há um consenso sobre a definição formal do que é "termo". Segundo a norma internacional ISO 1087, "termo" corresponde à "designação, por meio de uma unidade linguística, de um conceito definido em uma língua de especialidade" (_, 1990, p. 5). O verbo "designar", segundo o dicionário Michaelis ${ }^{1}$ online, significa "1 Apontar, indicar, nomear. 2 Assinalar, marcar. 3 Denominar, qualificar. 4 Escolher, nomear. 5 Determinar, fixar. 6 Ser o simbolo de; significar."

Uma definição bastante aceita de termo é a dada por Cabré e Vivaldi (2001), que

\footnotetext{
${ }^{1}$ Dicionário Michaelis online - michaelis.uol.com.br/
} 
é: "unidade terminológica obtida a partir de domínio especializado". Vivaldi (2001) também define "termo" como "unidade terminológica que é utilizada para designar conceitos em um âmbito tematicamente restrito".

Considerando que, de acordo com Barros (2004, p. 40), "unidade terminológica" já corresponde por si só ao termo, a mesma autora define "termo" como sendo "unidade lexical com um conteúdo específico dentro de um dominio específico". Para a autora, "unidade lexical" corresponde ao "símbolo linguístico, composto de expressão e de conteúdo, que pertence a uma das grandes classes gramaticais (substantivo, verbo, adjetivo ou advérbio)".

Com bases nas definições supra citadas, nesta tese, foi considerado que "termo" (ou unidade terminológica) é uma unidade lexical utilizada para designar conceito em um cenário tematicamente restrito.

$\mathrm{Na}$ maioria das pesquisas encontradas na literatura sobre termos, os autores afirmam que estes geralmente são unidades nominais, uma vez que designam conceitos (por exemplo, para denominar/dar um nome a um conceito) (Sager, 1990; Barros, 2004; Batista, 2011). Para outros autores, termos podem ser também substantivos ou adjetivos somente (Almeida e Vale, 2008), enquanto que outros pesquisadores consideram termos como substantivos, adjetivos ou verbos (Frantzi et al., 1998; Cabré e Sager, 1999; Zavaglia et al., 2007). Por exemplo, no domínio de Informática, o verbo "formatar" poderia ser considerado um termo. Mesmo que Cabré e Sager (1999) afirmam que termos são substantivos, adjetivos ou verbos, os autores também enfatizam que a quantidade de substantivos presentes em domínios específicos é extremamente desproporcional em relação aos adjetivos e verbos.

Na pesquisa apresentada nesta tese, são realizadas avaliações experimentais assumindo que termos podem ser tanto substantivos, adjetivos ou verbos (Seção 5.1 do Capítulo 5, página 73) como que termos podem ser somente substantivos (Seção 5.4 do Capítulo 5, página 93).

A dificuldade para encontrar uma definição única de termos na literatura tem origem na dificuldade que os especialistas de domínios e terminólogos têm para identificar termos nos textos. Consequentemente, a extração de termos se torna uma tarefa também não trivial mesmo quando realizada manualmente por terminólogos (Estopa et al., 2005). Essa dificuldade é devido às características ${ }^{2}$ das unidades terminológicas. Para ilustrar como termos podem ser extraídos, enfatizando sua dificuldade, foram considerados, a seguir, alguns exemplos de termos dos domínios de educação à distância $\left(\mathrm{EaD}^{3}\right)$, nanociência e nanotecnologia $\left(\mathrm{Nano}^{4}\right)$ e revestimentos cerâmicos $\left(\mathrm{RC}^{5}\right)$, que são mostrados, respectivamente, em (a), (b) e (c):

(a) "Um dos principais pontos que consideramos bem relevante para configuração de [[ambientes virtuais] de aprendizagem] é o design simples e fácil. (...) O [ciberespaço] é muito mais que um [meio de comunicação] ou mídia. (...) criar e produzir [material didático] impresso] para EAD é uma alternativa necessária".

(b) "Um [nanômetro] equivale à bilionésima parte de um metro e qualquer medida nessa escala é invisível a olho nu."

(c) "As [fritas] são utilizadas na atualidade como principais constituintes dos [esmaltes] empregados na fabricação nacional de [revestimentos cerâmicos]."

\footnotetext{
${ }^{2}$ As chamadas "características" são também chamadas de "atributos descritores" da área de aprendizado de máquina.

${ }^{3}$ Exemplos retirados do trabalho de Souza e Felippo (2010).

${ }^{4}$ Exemplos retirados do trabalho de Almeida e Vale (2008).

${ }^{5}$ Exemplos retirados do trabalho de Almeida et al. (2011).
} 
Uma das principais características das unidades em destaque é seus significados. Em revestimento cerâmico (subdomínio da engenharia de materiais), por exemplo, os termos "frita" e "esmalte" têm significado muito específico no discurso técnico. Nesse domínio, "frita" significa "vidro moido obtido a partir da fusão da mistura de diferentes ingredientes, como boratos, potássio, soda, cal, alumina, etc." 6 e "esmalte" significa "cobertura de aspecto semelhante ao vidro, impermeável, branca, colorida, transparente ou opaca, que é aplicada sobre a placa cerâmica como decoração e/ou proteção"7.

Quanto à estrutura mórfica, observa-se pelos exemplos (a), (b) e (c) que os termos podem ser: (i) lexias simples, isto é, formadas por apenas um radical, com ou sem afixos, ou (ii) lexias complexas, isto é, formadas por mais de um radical (_, 1990, p. 7). Na Tabela 3.1, são mostrados alguns exemplos de termos de diferentes domínios.

Tabela 3.1: Exemplos de termos simples e complexos de diferentes domínios.

\begin{tabular}{|c|c|c|}
\hline & & Domínios \\
\hline \multirow{6}{*}{ Termos Simples } & frita & \multirow{2}{*}{ revestimento cerâmico } \\
\hline & esmalte & \\
\hline & ciberespaço & \multirow{2}{*}{ educação à distância } \\
\hline & interatividade & \\
\hline & nanômetro & \multirow{2}{*}{ nanociência e nanotecnologia } \\
\hline & ácido & \\
\hline \multirow{6}{*}{ Termos Complexos } & revestimento cerâmico & \multirow{2}{*}{ revestimento cerâmico } \\
\hline & resistência mecânica & \\
\hline & meio de comunicação & \multirow{2}{*}{ educação à distância } \\
\hline & ambiente virtual (de aprendizagem) & \\
\hline & escala nanométrica & \multirow{2}{*}{ nanociência e nanotecnologia } \\
\hline & potência óptica & \\
\hline
\end{tabular}

Os termos que constituem lexias simples podem apresentar alguma característica morfológica que os diferencia das unidades lexicais que são usadas na língua geral ou em outro domínio especializado. No termo "ciberespaço" (a), por exemplo, identifica-se "ciber-", abreviatura de "Cibernética", utilizada na denominação de vários conceitos da EaD que se relacionam à internet, ou seja, mundo ou espaço virtual (Gianoti, 2012). O termo "nanômetro" (b) é outro exemplo paradigmático de lexia simples cuja estrutura morfológica revela seu estatuto terminológico. Esse estatuto se deve à presença do prefixo "nano-" 8 , empregado para indicar a escala $10^{-9}$ da medida indicada (metro) (Almeida e Vale, 2008). Já os termos da medicina, por sua vez, caracterizam-se pela presença de morfemas prefixais (p. ex.: "artri/o') e sufixais (p. ex.: "-patia") de origem grega (ou latina), como em "artrite" e "cardiopatia", respectivamente.

A denominação dos conceitos, no entanto, nem sempre é feita por unidades lexicais que apresentam alguma marca morfológica que caracteriza o domínio a que pertence. Muitas vezes, utilizam-se palavras com significado especializado que não manifestam particularidades mórficas. Nessa categoria, enquadram-se, por exemplo, os termos "frita" e "esmalte" (c). Apesar de não possuírem elementos formais de especificidade (sejam eles prefixos, sufixos, etc.), essas unidades são, do ponto de vista conceitual, portadoras de significados especializados muito precisos, como destacado no início deste texto.

Na língua geral, essas unidades são, comumente, genéricas e polissêmicas ("esmalte", por exemplo, é definido como "substância transparente que, aplicada em estado líquido, se transforma em película dura e brilhante depois da secagem" e tem três acepções em média

${ }^{6}$ Definição retirada de Almeida et al. (2011, p. 32).

${ }^{7}$ Definição retirada de Almeida et al. (2011, p. 27).

8"Nano-" (prefixo grego) remete a "nánnos" ("de excessiva pequenez") ou "nânos" ("anão") e equivale a um multiplicador $10^{-9}$ da unidade indicada. Assim, um "nanômetro" corresponde a $10^{-9}$ metros (1 $\mathrm{nm} 10^{-9} \mathrm{~m}$ ) (Houaiss e Villar, 2001). 
nos dicionários de língua portuguesa). Por outro lado, nos domínios de especialidade, essas mesmas unidades apresentam significado específico e comumente não são polissêmicas.

Os termos que constituem lexias complexas são os mais frequentemente utilizados na denominação dos conceitos nos domínios especializados. Essas unidades terminológicas são formadas por diferentes estruturas formais, denominadas padrões morfossintáticos (pos).

A estrutura mais frequente é substantivo+adjetivo. Esse é o caso dos termos "revestimento cerâmico" em (c), "ambiente virtual" em (a) e "material didático" em (a). Outros padrões morfossintáticos que comumente caracterizam os termos complexos são: (i) substantivo+adjetivo+preposição+substantivo (p.ex.: "ambiente virtual de aprendizagem" em (a)), (ii) substantivo+preposição+substantivo (p.ex.: "meio de comunicação" em (a)), e (iii) substantivo+adjetivo+adjetivo (p.ex.: "material didático impresso" em (a)), etc.

Outra característica dos termos do tipo lexia complexa é a expansão de caráter lexical que, na verdade, coincide com outra denominação, correspondente a uma especialização do termo genérico. Como exemplo, cita-se o termo "ambiente virtual", que se aplica aos sistemas computacionais que dispõem de uma interface avançada aos usuários e está sendo relacionado aos sistemas de aprendizagem, os quais são utilizados para mediar o processo de educação à distância. Essa expansão gerou o novo termo "ambiente virtual de aprendizagem". Exemplos de expansão à direta de um termo genérico são bastante comuns nas linguagens de especialidade e denominam um novo conceito correspondente a uma nova invenção ou tecnologia. Assim o termo "material didático", que denota o conjunto de objetos indispensáveis ao desempenho da atividade de ensino, passou a ser utilizado com a expansão "impresso" ("material didático impresso").

No que diz respeito às lexias simples, as dificuldades recaem principalmente na identificação de candidatos que não possuem marcas morfológicas de especificidade que indicam o seu potencial terminológico, ou seja, de candidatos que são utilizados também na língua geral por um não-especialista, como "esmalte".

Nesses casos, os terminólogos podem utilizar o critério de frequência, ou seja, o fato de se reencontrar sempre a unidade "esmalte" em textos do domínio dos RCs pode indicar que se trata de um candidato. Assim, a expressão linguística é por fim selecionada pelo terminólogo e enviada para apreciação de um especialista de domínio. Entretanto, o uso da frequência não obtém um resultado totalmente satisfatório, uma vez que, por exemplo, há alguns candidatos bastantes frequentes mas que não pertencem ao domínio em questão. Por exemplo, "se refere", "definido como" e "nós" podem aparecer frequentemente no corpus, mas provavelmente não são termos. Ou, ainda, há candidatos raros no corpus mas que pertencem ao domínio. Por exemplo, a sigla "LMS" (Ambiente Virtual de Aprendizagem, do inglês Learning Management System) aparece raramente no corpus do domínio de EaD e é considerada termo desse domínio.

Os especialistas comumente recebem os candidatos organizados em uma estrutura conceitual que reflete a realidade da área em questão. Nessa estrutura, os candidatos estão alocados em seus respectivos campos nocionais (conceitos de áreas específicas da ciência) de tal forma que o especialista avalia a relevância de um candidato/conceito frente às relações que este estabelece com os demais candidatos do próprio campo. Por exemplo, na estrutura conceitual do domínio dos RCs, o candidato "esmalte" compõe o campo nocional dos insumos (do inglês, input) e sua relevância terminológica será avaliada frente aos demais candidatos do campo (ou subcampo). Ao adotar esse procedimento, considera-se que os especialistas utilizam o critério semântico para a validação de um candidato.

No que diz respeito às lexias complexas, a dificuldade reside em distinguir os candida- 
tos desse tipo dos sintagmas livres. Enquanto uma lexia complexa é uma combinatória de elementos, constituindo uma unidade léxico-semântica e, por isso, expressando um conceito específico (p.ex.: "material didático impresso"), um sintagma livre apresenta, por sua vez, uma frágil estabilidade no sistema lexical (p.ex.: "intercâmbio didático dirigido" que também pode ser "intercâmbio dirigido didático").

Normalmente, os critérios propostos para a identificação e delimitação dos termos complexos baseiam-se no grau de lexicalização, que, por sua vez, determina os limites da unidade sintagmática. Os candidatos a termos complexos podem ser identificados pelos terminólogos por algumas de suas características. Segundo Barros (2004, p. 103), essas características são:

"(a) não autonomia de um componente em relação aos outros que compõem a unidade léxico-semântica sem que haja modificação de sentido; ex.: "quinta" e "feira" em "quinta-feira";

(b) impossibilidade de comutação de um componente sem acarretar mudança de sentido; ex.: "mesa-redonda" (tipo de debate) / "mesa quadrada";

(c) não-separabilidade dos componentes; ex.: "terra fina" / "esta terra é fina";

(d) particularidade da estrutura interna; ex.: ausência de determinação significa integração dos elementos constitutivos: "ter medo", "fazer justiça"."

Além dessas características, outros critérios podem ser aplicados, como a comutação sinonímica. Segundo esse critério, a possibilidade de comutar "estrada de ferro" por "ferrovia" indica que "estrada de ferro" é uma unidade terminológica em potencial. Outro critério importante para a verificação do grau de lexicalização de um sintagma é a frequência de coocorrências, ou seja, o fato de se reencontrar sempre a mesma associação de palavras no domínio de estudo é normalmente uma pista de lexicalização do sintagma. Por fim, os candidatos identificados com base em ao menos um dos critérios mencionados são selecionados e enviados ao especialista juntamente com os candidatos a termos simples.

Entretanto, os casos cuja extração (semi)automática é problemática devem-se principalmente à limitação computacional de lidar com unidades lexicais cujos critérios de identificação não residem em aspectos formais das línguas, mas sim em aspectos abstratos, no caso, semânticos e mesmo enunciativos. Essas unidades que não apresentam elementos formais que as especificam em relação às de língua geral, também são portadoras de significado especializado (no caso, intervenção não significa "ação ou resultado de intervir", mas sim "procedimento médico"). Porém, a identificação dessas unidades como termos requer que a máquina lide com conhecimento linguístico abstrato e essa tarefa é bastante complexa do ponto de vista computacional.

Nesta seção foram elencados alguns dos desafios da extração de termos. Na próxima seção, são descritas e discutidas as abordagens nas quais a extração de termos podem ser baseadas.

\subsection{Abordagens de Extração de Candidatos a Termos}

A extração de termos é tradicionalmente baseada em três abordagens: estatística, linguística e híbrida. As abordagens caracterizam-se pelo tipo primordial de conhecimento utilizado na referida tarefa. Na sequência, apresenta-se cada uma das abordagens com mais detalhes (Cabré e Vivaldi, 2001; Pazienza et al., 2005). 


\subsubsection{Abordagem Estatística}

A abordagem puramente estatistica utiliza conhecimento obtido por meio da aplicação de medidas estatísticas. Para tanto, o corpus passa por um pré-processamento, que comumente envolve a identificação dos tokens ${ }^{9}$, a remoção das stopwords e a representação dos textos em uma tabela. Nessa tabela, cada linha representa um documento $\left(D_{i}\right)$ e cada coluna representa um n-grama ${ }^{10}$ do documento $\left(N_{j}\right)$, sendo que a célula $D_{i} N_{j}$ pode ser preenchida com alguma medida, por exemplo, pela frequência absoluta do n-grama $N_{j}$ no documento $D_{i}$. A essa representação dos textos é dada a denominação bag-of-words (BOW). Nesse sentido, a aplicação de medidas estatísticas por meio de uma BOW ignora qualquer informação estrutural sobre as sentenças dos textos, como a ordem em que os n-gramas ocorrem. A partir dos valores obtidos pela medida escolhida, os candidatos a termos são ranqueados. Nesse ranqueamento, considera-se que os candidatos com pontuação mais elevada têm maior probabilidade de serem termos do domínio (Pazienza et al., 2005).

As medidas comumente utilizadas no desenvolvimento de extratores (semi)automáticos segundo a abordagem estatística são independentes de língua. A independência de língua é uma característica vantajosa do ponto de vista computacional, pois a aplicação das medidas não requer a especificação (manual ou automática) de qualquer tipo de conhecimento (p.ex.: morfológico, sintático, etc.) sobre a língua dos textos em processamento, o que torna a extração (semi)automática mais simples e rápida. Em comparação à extração humana, a independência de língua não reflete o processo realizado pelos especialistas do domínio, já que estes utilizam o conhecimento linguístico para identificar termos. Um tipo de conhecimento linguístico é o morfológico, utilizado, por exemplo, para identificar termos compostos por morfemas greco-latinos (p.ex.: $\operatorname{artr}(i / o) \rightarrow$ "artrite" e "osteoartrite").

O principal problema dos extratores de termos desenvolvidos segundo a abordagem estatística é o "silêncio", ou seja, a não identificação e seleção de termos reais em um texto ou corpus. Um exemplo desse problema é quando a medida escolhida utiliza a frequência de cada termo no corpus como base para a extração de termos e, por isso, um determinado termo (p. ex., "polinização", do domínio de ecologia) não é extraído por possuir uma baixa frequência.

Segundo Kageura e Umino (1996), as medidas estatísticas buscam identificar duas propriedades terminológicas: unithood e termhood. As medidas que expressam unithood revelam a força ou estabilidade de expressões complexas (isto é, formadas por dois ou mais elementos separados por espaços em branco). As medidas que expressam termhood revelam, por sua vez, o grau de relação entre uma expressão linguística e um domínio do conhecimento. Em outras palavras, termhood expressa o quanto uma expressão linguística (seja ela simples, como "polaridade", ou complexa, como "molécula orgânica" e "molécula de água") está relacionada a um domínio.

As principais medidas estatísticas são formalmente descritas a seguir. Três dessas medidas $(t v, t v q$ e $t c)$ são tradicionalmente aplicadas à área de seleção de características, mas foram descritas aqui porque também poderiam ser utilizadas para extrair termos. Essas medidas são identificadas por *.

Menciona-se "candidatos a termos" (representado por $t$ ) ao invés de "termos", porque um candidato somente é considerado um termo depois de ser validado por pelo menos um especialista do domínio em questão. As medidas apresentadas a seguir retornam uma lista de candidatos ordenados por valores obtidos por cada medida. Então, deve-se

\footnotetext{
${ }^{9}$ Os tokens são sequências de caracteres separadas por espaços em branco. Assim, um token pode representar uma palavra, numeral ou sinal de pontuação.

${ }^{10} \mathrm{Na}$ abordagem estatística, um n-grama é uma sequência de $n$ tokens (por exemplo, unigrama, bigrama, trigrama, etc.)
} 
escolher um valor mínimo que os candidatos devem ter para serem considerados como possíveis termos. Ressalta-se também que algumas medidas quantificam a relevância dos candidatos a termos de um domínio específico com base em corpora de outros domínios. Esses últimos são conhecidos como corpora contrastantes. Na descrição das medidas apresentadas a seguir, considera-se $D$ o número de documentos em um corpus.

\section{Medidas que Expressam Unithood}

Para expressar a propriedade unithood, utilizam-se medidas de associação, uma vez que o objetivo é identificar a força ou estabilidade de expressões complexas (Pazienza et al., 2005). As principais medidas estatísticas são formalmente descritas a seguir.

(a) Logaritmo da Razão de Máxima Verossimilhança $(l l)$

O logaritmo da razão de máxima verossimilhança visa detectar se as combinações são mais do que simples coocorrências casuais nos documentos, fornecendo, para isso, uma lista de todas as combinações dos tokens $(k)$. Segundo Manning e Schutze (2001), para a elaboração dessa lista (para o caso de bigramas $k_{1} k_{2}$, por exemplo), é necessária a formulação das duas hipóteses mostradas a seguir. Sendo que $h=$ hipótese, $P=$ probabilidade, que pertence a um grama composto do token $1\left(k_{1}\right)$ e token $2\left(k_{2}\right)$.

$$
\begin{aligned}
& h_{1}: P\left(k_{1} \mid k_{2}\right)=P\left(k_{1} \mid \neg k_{2}\right) \\
& h_{2}: P\left(k_{1} \mid k_{2}\right) \neq P\left(k_{1} \mid \neg k_{2}\right)
\end{aligned}
$$

A hipótese $1\left(h_{1}\right)$ é a formalização da independência, isto é, a ocorrência de $k_{2}$ é independente da ocorrência de $k_{1}$. A hipótese $2\left(h_{2}\right)$ é a formalização da dependência. Quando a $h_{2}$ é satisfeita, significa que pode ter sido encontrada uma combinação interessante.

(b) Informação Mútua Pontual ( $m i)$

A informação mútua pontual (do inglês, pointwise mutual information) (Church e Hanks, 1989) mede a quantidade de informação que dois tokens compartilham. A definição formal da $m i$ é:

$$
m i_{\left(k_{i}, k_{j}\right)}=\log _{2} \frac{P\left(k_{i}, k_{j}\right)}{P\left(k_{i}\right) \times P\left(k_{j}\right)}
$$

na qual $k_{i}$ e $k_{j}$ são tokens que formam um candidato a termo de um corpus com $N$ palavras, $P\left(k_{i}\right)$ e $P\left(k_{j}\right)$ são, respectivamente, as probabilidades de $k_{i}$ e $k_{j}$ e correspondem às frequências desses tokens no mesmo corpus, e $P\left(k_{i}, k_{j}\right)$ é a probabilidade de que os tokens $k_{i}$ e $k_{j}$ ocorram juntos.

(c) Coeficiente de Dice (dice)

O coeficiente de Dice (Dice, 1945) apresenta uma interpretação similar à mi. Conforme explicado por Teline (2004), a diferença entre as medidas é que, ao contrário da mi, o coeficiente de Dice não depende do tamanho da amostra (o corpus), conforme mostrado na Equação 3.3.

$$
\operatorname{dice}_{\left(k_{i}, k_{j}\right)}=\frac{2 \times f_{k_{i}, k_{j}}}{f_{k_{i}}+f_{k_{j}}}
$$


na qual $k_{i}$ e $k_{j}$ são tokens de um corpus de tamanho $N, f_{k_{i}}$ e $f_{k_{j}}$ são, respectivamente, as frequências de $k_{i}$ e $k_{j}$ no corpus, e $f_{k_{i}, k_{j}}$ é a frequência em que os tokens $k_{i}$ e $k_{j}$ ocorrem juntos.

\section{Medidas que Expressam Termhood}

Para a identificação da propriedade denominada termhood, normalmente se utilizam as medidas estatísticas descritas a seguir.

(a) Frequência de Termo $(t f)$

Conhecida como term frequency, essa medida contabiliza a frequência absoluta de um determinado candidato ao longo de um corpus. A especificação formal dessa medida pode ser observada na Equação 3.4.

$$
t f_{t_{j}}=\sum_{x=1}^{D} f_{d_{x}, t_{j}}
$$

na qual $f_{d_{x}, t_{j}}$ é a frequência do $t_{j}$ ( $j$-ésimo candidato) no $d_{x}$ ( $x$-ésimo documento).

(b) Frequência Relativa $(r f)$

A frequência relativa (em inglês, relative frequency) é usada para calcular a razão entre a frequência absoluta de um candidato em um corpus e a frequência de todas as palavras no mesmo corpus, conforme mostrado na Equação 3.5.

$$
r f_{t_{j}}=\frac{t f_{t_{j}}}{N}
$$

na qual $t f_{t_{j}}$ é a frequência absoluta de $t_{j}$ ( $j$-ésimo candidato) e $N$ é o número total de palavras no corpus.

(c) Frequência de Documentos $(d f)$

Conhecida como document frequency, essa medida contabiliza o número de documentos em que um candidato aparece, conforme mostrado na Equação 3.6.

$$
d f_{t_{j}}=\sum_{x=1}^{D}\left(1 \mid f_{d_{x}, t_{j}} \neq 0\right)
$$

na qual $f_{d_{x}, t_{j}}$ é a frequência do $t_{j}$ ( $j$-ésimo candidato) no $d_{x}$ ( $x$-ésimo documento).

(d) Frequência Média de Termo (atf)

Conhecida como average term frequency, essa medida contabiliza a razão entre a frequência do candidato no corpus e a frequência de documentos desse mesmo candidato, de acordo com a Equação 3.7.

$$
a t f_{t_{j}}=\frac{t f_{t_{j}}}{d f_{t_{j}}}
$$

na qual $t f_{t_{j}}$ é a frequência absoluta de $t_{j}$ ( $j$-ésimo candidato) e $d f_{t_{j}}$ é a frequência de documentos desse candidato no mesmo corpus. 
(e) Frequência Inversa Residual de Documento (ridf)

Frequência inversa residual de documento (Manning e Schütze, 1999) (em inglês, residual inverse document frequency) corresponde à diferença entre os logs da frequência de documentos do candidato e frequência de documentos considerando a distribuição de Poisson, como mostrado na Equação 3.8.

$$
r i d f_{t_{j}}=i d f_{t_{j}}-\log _{2}\left(\frac{1}{1-p\left(0 ; \lambda_{j}\right)}\right)
$$

na qual $i d f_{t_{j}}$ corresponde ao $\log _{2}\left(\frac{D}{d f_{t_{j}}}\right)$ e $p$ é a distribuição de Poisson com parâmetro $\lambda_{j}=\frac{t f_{t_{j}}}{D}$, o número médio de ocorrências do $t_{j}$ em cada documento. $1-p\left(0 ; \lambda_{j}\right)$ é a probabilidade de Poisson de um documento com pelo menos uma ocorrência.

(f) Frequência de Termo - Frequência Inversa de Documento ( $t f-i d f)$

Conhecida como term frequency inverse document frequency (Salton e Buckley, 1987), essa medida pondera a frequência de um candidato $(t f)$ em função de sua distribuição ao longo do corpus, atribuindo menor peso àqueles candidatos que aparecem em muitos documentos $(i d f)$, conforme mostrado na Equação 3.9.

$$
t f-i d f_{t_{j}}=\underbrace{t f_{d_{x}, t_{j}}}_{\text {parte } t f} \times \underbrace{\log \left(\frac{D}{d f_{t_{j}}}\right)}_{\text {parte } i d f}
$$

na qual $t f_{d_{x}, t_{j}}$ é a frequência de $t_{j}$ ( $j$-ésimo candidato) no $x$-ésimo documento $\left(d_{x}\right)$ e $d f_{t_{j}}$ é a frequência de documentos do $j$-ésimo candidato.

Witten et al. (1999) adaptam a $t f$ - $i d f$ supra citada para evitar que o valor dessa medida seja igual a zero no caso em que um candidato ocorra em todos os documentos de um corpus, como observado na Equação 3.10.

$$
t f-i d f_{d_{x}, t_{j}}=\underbrace{\left(1+\log \left(t f_{d_{x}, t_{j}}\right)\right)}_{\text {parte } t f} \times \underbrace{\log \left(1+\frac{D}{d f_{t_{j}}}\right)}_{\text {parte } i d f}
$$

(g) Contribuição do Termo $(t c)$

Conhecida como term contribution (Liu et al., 2003), essa medida considera que a importância de um candidato pode ser vista como a contribuição dele para a similaridade de documentos. Dessa forma, a contribuição do candidato provê maior pontuação àqueles candidatos que aparecem em poucos documentos, não considerando candidatos muito raros ou muito frequentes no corpus, conforme mostrado na Equação 3.11.

$$
t c_{t_{j}}=\sum_{x=1}^{D} \sum_{y=1}^{D} f_{d_{x}, t_{j}} \times i d f_{t_{j}} \times f_{d_{y}, t_{j}} \times i d f_{t_{j}}
$$

considerando o $x$-ésimo e $y$-ésimo documento de um corpus, $f_{d_{x}, t_{j}}$ é a frequência do $t_{j}$ (j-ésimo candidato) no $x$-ésimo documento $\left(d_{x}\right)$ e $i d f_{t_{j}}$ é o inverso da frequência de documentos do $j$-ésimo candidato. 
(h) Variância do Termo $(t v)$

Conhecida como term variance (Liu et al., 2005), essa medida considera que os candidatos importantes são aqueles que não aparecem com uma frequência baixa nos documentos e mantêm uma distribuição não uniforme ao longo do corpus (maior variância). Para isso, a variância de todos os candidatos do corpus é calculada (Equação 3.12).

$$
t v_{t_{j}}=\sum_{x=1}^{D}\left[f_{d_{x}, t_{j}}-\overline{f_{t_{j}}}\right]^{2}
$$

na qual $f_{d_{x}, t_{j}}$ é a frequência absoluta do $t_{j}$ ( $j$-ésimo candidato) no $x$-ésimo documento $\left(d_{x}\right)$ e $\overline{f_{t_{j}}}$ é média das frequências do $j$-ésimo candidato nos documentos de um corpus.

(i) Qualidade da Variância do Termo (tvq)

Conhecida como term variance quality (Liu et al., 2005), essa medida é uma adaptação da medida $t v$, mas tendo como objetivo quantificar a qualidade da variância dos candidatos. Essa medida considera que os candidatos com pouca variação apresentam pequeno poder discriminante, já que ocorrem de maneira uniforme ao longo de toda coleção. Veja a descrição formal na Equação 3.13.

$$
t v q_{t_{j}}=\sum_{x=1}^{D} f_{d_{x}, t_{j}}^{2}-\frac{1}{D}\left[\sum_{x=1}^{D} f_{d_{x}, t_{j}}\right]^{2}
$$

na qual $f_{d_{x}, t_{j}}$ é a frequência do $t_{j}$ ( $j$-ésimo candidato) no $x$-ésimo documento $\left(d_{x}\right)$.

(j) Zone-Scored Term Frequency (zstf)

A medida zstf (Nogueira, 2009), descrita formalmente na Equação 3.14, assume que algumas partes no documento (como resumo e conclusão) trazem maior informação relevante sobre o conteúdo do documento do que outras partes. Diante dessa consideração, atribui maiores pesos aos candidatos que ocorrem nas partes de maior impacto dos documentos ou que naquelas onde se concentra maior informação relativa ao conteúdo do documento.

$$
z s t f_{t_{j}}=\sum_{x=1}^{D} \sum_{z=1}^{Z} f_{d_{x}, t_{j}} \times \text { peso }_{z}
$$

na qual $f_{d_{x}, t_{j}}$ é a frequência do $t_{j}$ ( $j$-ésimo candidato) no $x$-ésimo documento $\left(d_{x}\right)$ e peso $_{z}$ é o peso aferido à z-ésima zona dos documentos do corpus. Esse peso deve seguir a restrição mostrada na Equação 3.15.

$$
\sum_{z=1}^{Z} \text { peso }_{z}=1 \mid 0<\text { peso }_{z} \leq 1
$$




\subsubsection{Abordagem Linguística}

Segundo essa abordagem, os candidatos a termos são identificados e extraídos de um corpus com base em suas características ou propriedades linguísticas, as quais podem ser de diferentes tipos ou níveis.

Os manuais de PLN, como o de Jurafsky e Martin (2000), baseiam-se em uma hierarquia de tipos de conhecimento linguístico, elaborada com base em uma escala de abstração e complexidade, ou seja, quanto mais alto for o nível nessa escala, mais complexos serão a modelagem e o tratamento computacional do conhecimento, conforme ilustrado na Figura 3.1. No nível mais inferior dessa escala, está o conhecimento morfológico, seguido pelos conhecimentos sintático, semântico e pragmático-discursivo.

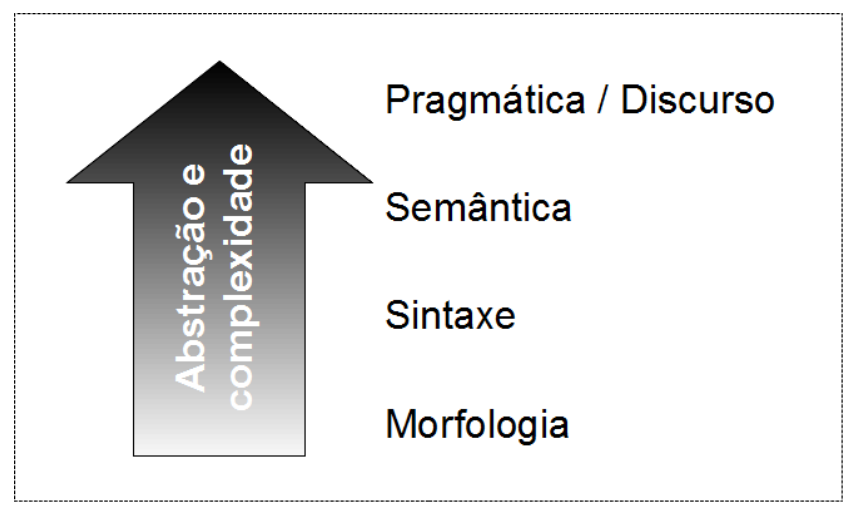

Figura 3.1: Níveis linguísticos de conhecimento - Adaptada de Jurafsky e Martin (2000)

O conhecimento de nível morfológico (isto é, referente à estrutura interna dos termos) resume-se a morfemas greco-latinos ou típicos do domínio que indicam a ocorrência de um possível termo. Na extração de termos da medicina e de domínios correlatos, por exemplo, geralmente se busca identificar morfemas, tanto radicais quanto afixos, de origem grega ou latina, como $\operatorname{artr}(i / o)$ (do gr. árthron) em "artrite" (p.ex.: Vivaldi e Rodríguez (2007)). $\mathrm{Na}$ EAT, a partir de textos do domínio da nanociência e nanotecnologia, é possível detectar candidatos a termos com base na identificação de morfemas como nano-, pois esse prefixo compõe inúmeros termos simples (p.ex.: "nanotubo") e complexos (p. ex.: "nanotubo de carbono") desse domínio (Almeida e Vale, 2008).

A extração com base em conhecimento sintático (isto é, referente à ordem e função dos termos nas sentenças) é feita comumente por meio da identificação da estrutura sintagmática das sentenças, a partir da qual os sintagmas nominais são selecionados como candidatos a termos. Por exemplo, na sentença "Moléculas de ácido silícico condensam com formação de água.", "molécula", por ser núcleo de um sintagma nominal, é identificada como um candidato a termo.

Para a extração de candidatos com base em conhecimento de nível semântico (isto é, referente ao significado ou conceito subjacente aos termos), os extratores da abordagem linguística buscam identificar o tipo semântico (p.ex.: "mundo" <concreto.lugar >), dos candidatos ou o conceito a eles subjacente. Na literatura geral, há poucos trabalhos que utilizam conhecimento mais abstrato, como o de nível semântico (p.ex.: Vivaldi (2001)).

Quanto ao conhecimento de nível pragmático, desconhecem-se trabalhos que buscam identificar candidatos a termos por meio de propriedades referentes ao uso.

De um modo geral, a extração de termos segundo a abordagem linguística pauta-se com frequência em conhecimento de nível morfossintático (Pazienza et al., 2005). No caso, busca-se realizar a EAT por meio de (i) a categoria sintática dos n-gramas (p.ex.: verbo, substantivo, adjetivo, etc.) do corpus e/ou (ii) padrões morfossintáticos (p.ex.: substantivo+adjetivo, substantivo+preposição+substantivo). Quanto às 
categorias, muitos dos trabalhos pautam a EAT na identificação de candidatos da categoria dos nomes, posto que as terminologias são compostas, em sua maioria, por termos dessa categoria. Os padrões morfossintáticos, por sua vez, são bastante utilizados porque as terminologias tendem a concentrar um volume grande de termos nominais que apresentam estrutura interna como as ilustradas pelos padrões substantivo+adjetivo (p.ex: "material nanoestruturado"), substantivo+preposição+substantivo (p.ex.: "nanotubo de carbono").

Tendo em vista a utilização de conhecimento linguístico, o pré-processamento dos corpora para a EAT envolve outros processos, além da delimitação sentencial, tokenização e remoção das stopwords. Se baseados na identificação da categoria sintática e de padrões morfossintáticos, os extratores podem realizar diferentes processos durante o préprocessamento, como: etiquetação morfossintática (do inglês, part-of-speech tagging), que consiste na associação, a cada palavra do corpus, de uma etiqueta que indica a sua categoria sintática (p.ex.: "nanotubo_substantivo de_preposição carbono_substantivo") (Voutilainen, 2004) e normalização das palavras dos textos, que consiste em uniformizálas por meio da redução de suas variações. Na literatura, são encontradas três técnicas de normalização, a saber: radicalização, lematização e substantivação.

A radicalização, também conhecida como "stemmização" ou "stemming", visa reduzir as palavras às suas formas inflexionáveis e às vezes reduzir às suas derivações (Lovins, 1968; Sparck-Jones e Willett, 1997; Manning et al., 2008a). A radicalização reduz cada palavra do texto ao seu provável radical, ou seja, palavra raiz (radical ou stem), em que cada palavra é analisada isoladamente. Por exemplo, "casamos $\rightarrow$ cas" / "latas $\rightarrow$ lat".

A técnica de lematização, também conhecida como "redução à forma canônica", consiste na redução de cada palavra de um texto ao seu lema ou forma canônica, ou seja, formas não-marcadas, desprovidas de flexões (Sparck-Jones e Willett, 1997; Arampatzis et al., 2000). Nessa técnica, os verbos são reduzidos ao infinitivo (p.ex.: "casamos $\rightarrow$ casar") e os substantivos e adjetivos ao masculino singular (p.ex.: "latas $\rightarrow$ lata" / "feias $\rightarrow$ feio").

A substantivação (Gonzalez et al., 2006), também conhecida por "nominalização", é uma técnica na qual as palavras passam a exibir um comportamento sintático/semântico semelhante àquele próprio de um nome ${ }^{11}$. Deve-se ressaltar que a maioria das palavras do português podem ser nominalizadas com o uso de artigos. Por exemplo, o verbo trabalhar na primeira pessoa do singular, trabalho, pode ser substantivado com o artigo: $\underline{o}$ trabalho. Por exemplo, "casamos $\rightarrow$ casa" / "latas $\rightarrow$ lata".

Conrado (2009) e Conrado et al. (2009a,b, 2012) apresentam experimentos que utilizam e comparam, de forma objetiva e subjetiva, o uso dessas três técnicas para a extração de termos.

Quando a utilização de conhecimento linguístico é baseada na identificação de sintagmas, os extratores comumente realizam o reconhecimento da estrutura sintática (do inglês, parsing) das sentenças, atribuindo funções sintáticas aos constituintes reconhecidos (Carroll, 2003), por exemplo, sujeito e predicado, sintagma nominal e sintagma verbal.

Em resumo, os extratores linguísticos podem fazer uso de ferramentas de processamento de língua natural como os sentenciadores, tokenizadores, etiquetadores morfossintáticos (em inglês, taggers), lematizadores, radicalizadores (do inglês, stemmer), substantivadores e analisadores sintáticos (do inglês, parsers).

Independentemente do tipo de conhecimento empregado, os resultados obtidos pelos extratores baseados nessa abordagem são em geral melhores do que os obtidos pela abordagem estatística. No entanto, a abordagem linguística também não está livre de problemas. No caso, a extração é dependente de língua, pois a identificação dos candidatos requer a

\footnotetext{
${ }^{11}$ Texto sobre Gramática Tradicional e Categorização Lexical - http://www . dacex .ct.utfpr.edu .br/ paulo3.htm
} 
especificação de algum tipo de conhecimento linguístico (p.ex.: a categoria sintática das palavras) que é obtida por meio da utilização de ferramentas como os taggers, parsers, lematizadores, etc, as quais geram erros frequentes que afetam as tarefas de identificação e extração de candidatos a termos. Quando manual, a especificação linguística necessária torna a extração de candidatos mais cara e lenta.

De um modo geral, os principais problemas dos extratores desenvolvidos segundo a abordagem linguística dizem respeito ao "silêncio", já mencionado, e ao "ruído", ou seja, à identificação/extração de um número elevado de candidatos que são descartados na fase de avaliação. Como exemplo de ruído, se considerar que substantivos podem ser termos e adjetivos não podem, se um adjetivo (p. ex., "ecológico" do domínio de ecologia) for erroneamente marcado como um substantivo, o mesmo seria equivocadamente extraído como um termo do domínio.

\subsubsection{Abordagem Híbrida}

A abordagem híbrida pauta-se em propriedades estatísticas e linguísticas para a identificação e extração dos candidatos a termos.

Nos extratores que seguem essa abordagem, a ordem de utilização do conhecimento pode variar. Em alguns extratores, o conhecimento estatístico é utilizado antes do linguístico e, em outros, o conhecimento estatístico é utilizado depois do linguístico.

Segundo Teline (2004) e Pazienza et al. (2005), os melhores resultados são obtidos quando as medidas estatísticas são aplicadas sobre uma lista de candidatos que foram previamente extraídos com base em alguma propriedade linguística, pois a confiabilidade das medidas estatísticas é maior quando estas são aplicadas a candidatos a termo linguisticamente "justificados". Uma das razões para esse fato é que os termos normalmente seguem um padrão pré-definido para cada domínio (substantivos, principalmente). Esse padrão é identificado ao analisar morfossintaticamente o candidato a termo, porém o padrão pode ser diferente dependendo do contexto que o candidato aparece. Por exemplo, a palavra "segundo" pode ser um substantivo "Alguns segundos são suficientes...") ou um numeral ordinal ("O segundo ano..."). Os métodos estatísticos normalmente não consideram esse contexto e é essa uma das razões pelas quais se aconselha primeiramente identificar as propriedades linguísticas dos candidatos e, em seguida, aplicar métodos estatísticos. Além disso, os métodos estatísticos são mais rígidos e podem eliminar os termos que têm baixa frequência, mas que são importantes para o domínio.

Como exemplos de medidas/métodos híbridos, ou seja, que utilizam conhecimento estatístico e linguístico, podem-se citar c-value e nc-value. Nesta tese, um corpus contrastante ou de língua geral é considerado como um recurso linguístico. Portanto, as medidas que utilizam algum desses corpora são consideradas aqui como medidas híbridas, a saber:glossEx,tds, thd, TF-IDF, tf-dcf e weirdness.

\section{(a) C-value}

Na medida c-value (Frantzi et al., 1998), o recurso linguístico auxilia na geração de uma lista de candidatos a termos ${ }^{12}$ de acordo com um filtro linguístico baseado na busca de padrões sintáticos pré-determinados. Em seguida, o cálculo do potencial de um candidato ser termo ou não-termo é realizado baseando-se na frequência do candidato no corpus e em seu comprimento em gramas (se é bigrama, trigrama, etc.).

\footnotetext{
${ }^{12}$ Nessa medida, consideram-se como candidatos a termos somente os sintagmas nominais.
} 


$$
\text { c-value } t_{j}=\left\{\begin{array}{lc}
\log _{2}\left|t_{j}\right| \times t f\left(t_{j}\right), & \text { se } t_{j} \notin \text { a } V \\
\log _{2}\left|t_{j}\right|\left(t f\left(t_{j}\right)-\frac{1}{P\left(T_{t_{j}}\right)} \sum_{b \in T} t f(b)\right), & \text { caso contrário. }
\end{array}\right.
$$

Para a descrição formal do c-value (Equação 3.16), $t_{j}$ é o $j$-ésimo candidato a termo (sintagma nominal), $\left|t_{j}\right|$ é o comprimento em gramas de $t_{j}, t f\left(t_{j}\right)$ é a frequência de $t_{j}$ no corpus, $T_{t_{j}}$ é o conjunto de candidatos com comprimento em gramas maior que o de $t_{j}$ e que contém $t_{j}, P\left(T_{t_{j}}\right)$ é o número desses candidatos (tipos) incluindo o próprio tipo do $t_{j}, \sum t f(b)$ é a quantidade total de $t_{j}$ como subcadeia do candidato $b$ tal que $\left|t_{j}\right|<|b|$ e $V$ é o conjunto de vizinhos de $t_{j}$.

A c-value foi inicialmente proposta para expressar a propriedade unithood e, por isso, trabalha com expressões complexas. Barrón-Cedeño et al. (2009) adaptaram essa medida para que seja possível expressar a termhood e, assim, aplicá-la a unigramas (veja a Equação 3.17).

$$
\text { c-value }_{t_{j}}=\left\{\begin{array}{lc}
\mathrm{c} \times \log _{2}\left|t_{j}\right| \times t f\left(t_{j}\right), & \text { se } t_{j} \notin \text { a } V \\
c \times \log _{2}\left|t_{j}\right|\left(t f\left(t_{j}\right)-\frac{1}{P\left(T_{t_{j}}\right)} \sum_{b \in T} f(b)\right), & \text { caso contrário. }
\end{array}\right.
$$

na qual $c=i+\log _{2}\left|t_{j}\right|$. Os autores afirmam que utilizando $i=1$ é possível obter resultados experimentalmente melhores.

(b) Nc-value

A nc-value (Frantzi et al., 1998) expressa tanto a unithood como a termhood. Essa medida assume que o contexto em que os candidatos aparecem é significativo para determinar se eles são termos ou não. Nesse sentido, a nc-value considera que a vizinhança de cada um dos candidatos pode favorecer a qualidade dessa determinação. Essa vizinhança são as palavras ao redor do candidato, chamadas de "palavras de contexto". Para identificá-las, deve-se definir previamente o tamanho da janela e somente considerar as palavras que possuem as classes gramaticais de substantivos, adjetivos ou verbos. Então, para cada uma dessas palavras $(w)$, é calculado um peso Peso(w) (Equação 3.18).

$$
\operatorname{peso}_{w}=\frac{t(w)}{n c}
$$

no qual $t(w)$ é o número de candidatos onde aparece a palavra $w$ e $n c$ é o número total de candidatos considerados no corpus.

Em seguida, é possível calcular a medida nc-value, que é expressa formalmente na Equação 3.19 .

$$
\text { nc-value }_{t_{j}}=0.8 \text { c-value }_{t_{j}}+0.2 \sum_{b \in C_{t_{j}}} f_{t_{j}}(b) \text { peso }_{b}
$$

Nessa equação, $t_{j}$ é o candidato a termo, $C_{t_{j}}$ é o conjunto de palavras de contexto do candidato $t_{j}, b$ é uma palavra de contexto do candidato $t_{j}, f_{t_{j}}(b)$ é a frequência de ocorrência de $b$ como palavra de contexto do candidato $t_{j}$ e peso(b) é o peso calculado para $b$ como palavra de contexto. 


\section{(c) GlossEx}

O método glossEx (Kozakov et al., 2004b) considera a probabilidade dos candidatos ocorrerem no corpus de domínio dividido pela probabilidade desses mesmos candidatos ocorrerem em um corpus de língua geral, considerando também a frequência desse candidato no corpus de domínio. A representação formal desse método é:

$$
\text { glossE } x_{t_{j}}=a * t d\left(t_{j}\right)+b * t c\left(t_{j}\right), \text { default } \mathrm{a}=0.9, \mathrm{~b}=0.1 .
$$

na qual $t d\left(t_{j}\right)$ é considerada como a especificidade do candidato $t_{j}, t c\left(t_{j}\right)$ é a coesão do candidato $t_{j}$ e $a$ e $b$, sendo $a+b=1$, são constantes que determinam as contribuições relativas de $t d$ e $t c$.

(d) Índice de Especificidade de Domínio $(t d s)$

O tds (do inglês, term domain specificity) (Park et al., 2008) assume que um candidato relevante para um domínio é mais frequente no corpus desse domínio do que em outros corpora. Com base nessa consideração, os autores ressaltam a relevância dos candidatos em um corpus de domínio baseada na probabilidade de ocorrência desses candidatos e considerando corpora contrastantes. Essa medida é formalmente descrita na Equação 3.21.

$$
t d s_{t_{j}}^{(c)}=\frac{P\left(t_{j}^{(c)}\right)}{P\left(t_{j}{ }^{(g)}\right)}=\frac{\frac{t f_{t_{j}}^{(c)}}{N^{(c)}}}{\frac{t f_{t_{j}}^{(g)}}{N^{(g)}}}=\frac{\text { prob. no domain } c}{\text { prob. no corpus } g}
$$

considerando $P_{t_{j}}^{(c)}$ corresponde a probabilidade de ocorrência do candidato $t_{j}$ no corpus $c, N^{c}$ é o número total de palavras do corpus c e $g$ é um corpus contrastante.

(e) Índice Termhood $(t h d)$

Assim como $t d s$, o thd (Kit e Liu, 2008) assume que um candidato relevante para um domínio é mais frequente no corpus desse domínio do que em outros corpora. Para verificar a relevância do candidato no domínio, o thd se baseia na ordenação do candidato considerando todas as palavras do corpus, conforme mostrado na Equação 3.22 .

$$
\operatorname{th} d_{t_{j}}^{(c)}=\frac{r_{t_{j}}^{(c)}}{N^{(c)}}-\frac{r_{t_{j}}^{(g)}}{N^{(g)}}
$$

na qual $N^{(c)}$ é a quantidade de palavras do corpus $c, r_{t_{j}}^{(c)}$ é o valor de ordenação do candidato $t_{j}$ em $c$ e $g$ é um corpus contrastante.

(f) Frequência de Termo - Frequência Inversa de Domínio (TF-IDF)

A TF-IDF (do inglês, term frequency, inverse domain frequency) (Kim et al., 2009), descrita formalmente na Equação 3.23, é referenciada nesta tese com letras maiúsculas $(T F-I D F)$ para diferenciá-la da medida $t f-i d f$ (term frequency inverse document frequency). A TF-IDF é baseada na medida frequência de termo frequência inversa de documento $(t f-i d f)$, mas em vez de considerar as ocorrências de termos em documentos individualmente, a TF-IDF faz uso de corpora contrastantes, 
além do corpus do domínio, e considera as ocorrências de candidatos em cada corpus individualmente.

$$
T F-I D F_{t_{j}}^{(c)}=\underbrace{\frac{t f_{t_{j}}^{(c)}}{N^{(c)}}}_{\text {parte } T F} \times \underbrace{\log \left(\frac{\left|G^{*}\right|}{\left|G_{t_{j}}^{*}\right|}\right)}_{\text {parte } I D F}
$$

na qual $t f_{t_{j}}^{(c)}$ é a frequência absoluta do candidato $t_{j}$ no corpus $c, G^{*}$ é o conjunto de todos os corpora contrastantes e o corpus $c$, e $G_{t_{j}}^{*}$ é o subconjunto de $G^{*}$ no qual o candidato $t_{j}$ aparece pelo menos uma vez.

(g) Frequência de Termo - Frequência de Disjunção de Corpora $(t f-d c f)$

A $t f$-dcf (do inglês, term frequency - disjoint corpora frequency) (Lopes, 2012) penaliza um candidato proporcionalmente ao número de corpora contrastantes em que ele aparece e também ao número de ocorrências desse candidato em cada um desses corpora, conforme mostrado na Equação 3.24.

$$
t f-d c f_{t_{j}}^{(c)}=\frac{t f_{t_{j}}^{(c)}}{\prod_{\forall g \in \mathcal{G}} 1+\log \left(1+t f_{t_{j}}^{(g)}\right)}
$$

considerando $t_{j}$ como o candidato do corpus $c, g$ como um corpus contrastante e $\mathcal{G}$ como o conjunto de corpora contrastantes.

(h) Weirdness

Weirdness (Ahmad et al., 1999) foi inicialmente proposta para sistemas de recuperação de informação. Essa medida considera que a distribuição dos candidatos em um corpus de domínio específico é diferente da distribuição desse candidato em um corpus de língua geral. Weirdness é formalmente definida na Equação 3.25.

$$
\text { weirdness }_{t_{j}}^{(c)}==\frac{t f_{t_{j}}^{(c)} / N^{(c)}}{t f_{t_{j}}^{(g)} / N^{(g)}}
$$

na qual $N^{(c)}$ é o número de palavras de um corpus de domínio específico $(c), t f_{t_{j}}^{(c)}$ é a frequência do candidato $t_{j}$ no corpus $c$ e $g$ é um corpus contrastante.

\subsection{Medidas de Avaliação para Extração de Candidatos a Termos}

Conforme citado anteriormente, a extração de termos pode ser a base de diversas tarefas. Por esse motivo, não há um padrão para a realização da avaliação dos termos extraídos. Por exemplo, caso os termos sejam utilizados em uma taxonomia, os mesmos devem ser avaliados quanto a sua representatividade em relação ao domínio trabalhado, a posição de cada termo na taxonomia, entre outros.

Vivaldi e Rodríguez (2007) ressaltam uma questão relacionada à avaliação de termos que é difícil de ser respondida: "Quem determina quais são os termos relevantes em um dado texto de teste?". Nesse sentido, antes de efetuar a avaliação dos termos, deve-se considerar em qual tarefa os termos extraídos serão utilizados, ou seja, se serão empregados 


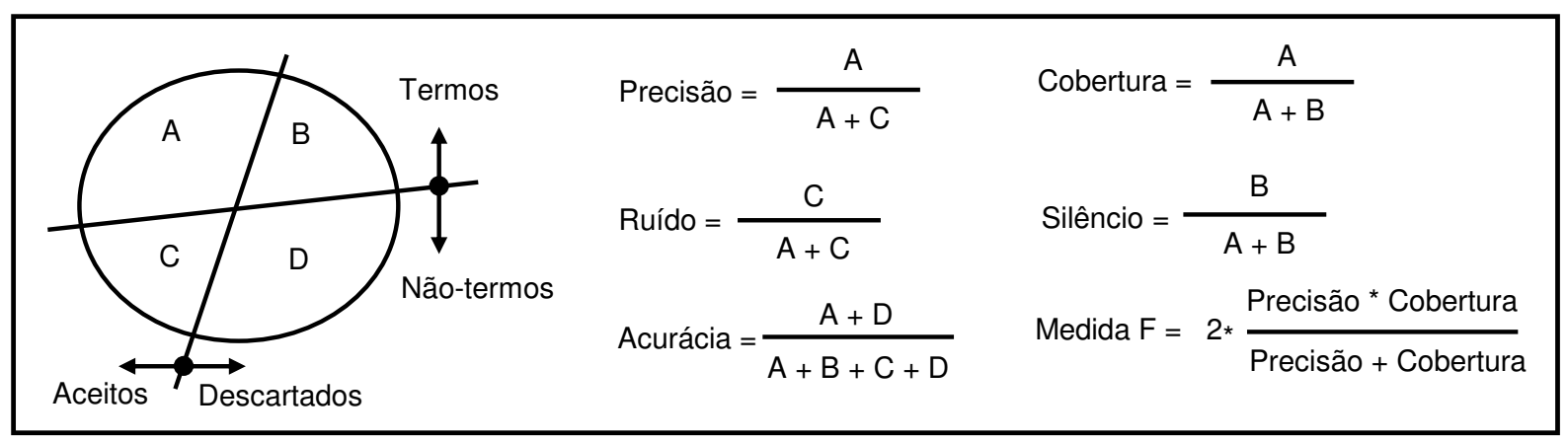

Figura 3.2: Medidas de avaliação de termos. Adaptada de Vivaldi e Rodríguez (2007)

para a construção de taxonomias, recuperação de informação, etc. Com base nisso, devese definir o significado de "qualidade" dos mesmos por meio das necessidades envolvidas na tarefa final. Então, a avaliação deve ser realizada para verificar tal qualidade dos termos.

Segundo Almeida e Vale (2008), a avaliação pode ser feita de três formas diferentes, a saber: a análise objetiva da lista de candidatos a termos; a análise subjetiva feita por especialistas do domínio em questão; e a combinação dessas duas primeiras formas de avaliar.

A primeira forma de avaliação compreende a comparação da lista de candidatos a termos contra uma lista de termos de referência, isto é, uma lista de termos considerada como a padrão do domínio em questão. Na maioria das vezes, a lista de referência é elaborada por especialistas do mesmo domínio, uma vez que os mesmos detêm o conhecimento acerca do domínio. Essa tarefa dos especialistas pode ser auxiliada por algum processo automático. Sendo assim, a construção dessas listas demanda tempo, esforço e carrega a subjetividade dos especialistas. Adicionalmente, pode não haver uma concordância entre os especialistas se um dado candidato a termo é ou não termo do domínio. Essa falta de concordância, pode ser explicada pela dificuldade de definir um conjunto de propriedades mesuráveis que contribuem para avaliar a qualidade da extração de termos (Vivaldi e Rodríguez, 2007).

Essa forma de avaliação utilizando lista de termos de referência pode ser feita por meio das medidas de: precisão, cobertura, ruído, silêncio e medida F. A precisão (precision) mede o grau de corretude dos candidatos a termos. A cobertura (recall) mede o grau de abrangência dos candidatos a termos. A Medida F ( $F$ measure) é uma média harmônica entre a precisão e a cobertura. O ruído (noise) é o complemento da precisão. O silêncio (silence) é o complemento da cobertura.

As descrições formais dessas medidas são apresentadas na Figura 3.2. Nessa figura, $A$ corresponde aos candidatos a termos que foram extraídos corretamente como sendo termos; $C$ corresponde aos candidatos a termos que foram aceitos incorretamente como termos (os que não deveriam ter sido extraídos); $B$ corresponde aos termos que deveriam ter sido extraídos, mas não foram; e $D$ corresponde aos "não-termos" que, de maneira correta, não foram extraídos como termos. Sendo assim, $A$ e $B$ pertencem à lista de termos de referência. A medida $\mathrm{F}$ é a média harmônica entre a cobertura e a precisão que penaliza alta divergência entre essas duas medidas.

Ainda, essa primeira forma de avaliação pode ser feita trocando-se a lista de termos de referência por um corpus da língua geral. Essa troca possibilita avaliar se os candidatos a termos extraídos são ou não pertencentes à língua geral. Caso sejam, provavelmente não são candidatos a termos específicos do domínio.

Além dessas medidas apresentadas, pode-se aplicar aos termos a medida ctw (context term weight) (Maynard e Ananiadou, 1999). Essa medida avalia a quantidade de vezes em que um candidato a termo aparece em um determinado contexto (corpus). Para aplicar 
essa medida aos termos, pode-se considerar como contexto a lista de termos de referência. Então, para a avaliação dos candidatos, os mesmos são recuperados na lista. A descrição formal da medida $c t w$ adaptada para a avaliação de termos e apresentada no trabalho de Conrado (2009) é:

$$
c t w\left(t_{j}\right)=\sum_{i \in T} f_{t_{j}}\left(t_{i}\right)
$$

na qual $t_{j}$ é o $j$-ésimo candidato a termo; $T$ é o conjunto dos termos da lista de referência que coincide com os candidatos a termos extraídos; $i$ é o $i$-ésimo termo de $T$; e $f_{t_{j}}\left(t_{i}\right)$ é a frequência de $t_{i}$ no corpus como um candidato a termo $t_{j}$, que é obtida durante a extração dos candidatos a termos.

A segunda forma de avaliação corresponde à submissão da lista de candidatos à análise subjetiva de especialistas do domínio. Contar com o apoio desses especialistas para a avaliação subjetiva, que demanda grande esforço manual, é muitas vezes um processo caro e muito mais demorado que a avaliação objetiva, o que pode refletir em um atraso no término do processo.

A última forma de avaliação considerada é o uso sequencial das duas formas de avaliação citadas, ou seja, primeiro a lista de candidatos a termos é comparada contra a lista de termos de referência (ou ao corpus de língua geral) e, em seguida, os especialistas analisam o resultado obtido.

\subsection{Corpora da Língua Portuguesa}

A quantidade de corpora na língua portuguesa brasileira tem aumentado significativamente. Em geral, esses corpora podem ser obtidos no Centro de Recursos - distribuído para a língua portuguesa (Linguateca ${ }^{13}$ ), no "Portal de Ontologia" (OntoLP ${ }^{14}$ ) (Ribeiro Junior, 2008), ambos descritos a seguir, no Grupo de Estudos e Pesquisas em Terminologia $\left(\right.$ GETerm $^{15}$ ), no Grupo de Processamento de Linguagem Natural (PLN ${ }^{16}$ ), no Laboratório de Inteligência Computacional $\left(\mathrm{LABIC}^{17}\right)$ e no Núcleo Interinstitucional de Linguística Computacional (NILC $\left.{ }^{18}\right)$.

Na Tabela 3.2, são descritos os 16 corpora encontrados na língua portuguesa do Brasil que são utilizados na tarefa de extração de termos. Nessa tabela, também são indicados os responsáveis por cada corpus, o número de textos e de classes presentes no corpus, se o mesmo possui lista de termos de referência e de qual domínio pertence. Além desses, há corpora disponíveis na página Web da Linguateca, que são voltados para outras tarefas e são classificados, segundo a Linguateca, como corpora de aprendizagem, de fala, de português escrito, de português falado transcrito e paralelos/comparáveis.

O corpus do CIMM $^{19}$ (Centro de Informação Metal Mecânica) possui 3.326 textos pertencentes à dissertações, notícias e teses relacionadas à área da Metal mecânica.

$\mathrm{O}$ CorpusDT $^{20}$ (Feltrim et al., 2001) foi desenvolvido no NILC da Universidade de São Paulo $\left(\mathrm{USP}^{21}\right)$. Esse corpus possui 52 textos originados de teses e de dissertações

\footnotetext{
${ }^{13}$ Linguateca - www. linguateca.pt

${ }^{14}$ OntoLP - www.inf.pucrs.br/ ontolp/index.php

${ }^{15}$ GETerm - www.geterm.ufscar.br

${ }^{16} \mathrm{PLN}$ - www.inf .pucrs.br/ linatural

${ }^{17} \mathrm{LABIC}$ - www.labic.icmc.usp.br/

${ }^{18} \mathrm{NILC}$ - www.nilc.icmc.usp.br

${ }^{19}$ CIMM - www.cimm.com.br

${ }^{20}$ CorpusDT - www.nilc.icmc.usp.br/nilc/projects/scipo.htm

${ }^{21}$ USP-ICMC - www.icmc.usp.br/
} 
Capítulo 3. Extração (Semi)Automática de Termos para o Português do Brasil

Tabela 3.2: Corpora na língua portuguesa do Brasil

\begin{tabular}{|c|c|c|c|c|c|}
\hline Nomes & Responsáveis & \# textos & \# classes & Listas de referência & Dominios \\
\hline CIMM & CIMM & 3.326 & 3 & Não & $\begin{array}{c}\text { Metal } \\
\text { mecânica }\end{array}$ \\
\hline CorpusDT & NILC-USP & 52 & 2 & Não & $\begin{array}{l}\text { Ciência da } \\
\text { computação }\end{array}$ \\
\hline Corpus.EaD & GETerm-UFSCar & 347 & 2 & Sim & $\begin{array}{l}\text { Educação à } \\
\text { distância }\end{array}$ \\
\hline CSTNews & NILC-USP & 140 & 50 & Não & Geral \\
\hline $\mathrm{ECO}$ & NILC-USP & 390 & - & Sim & Ecologia \\
\hline Embrapa & $\begin{array}{c}\text { CNPTIA-Embrapa } \\
\text { LABIC-USP }\end{array}$ & 2.149 & 8 & Não & Agronegócio \\
\hline Folha-RIcol & PLN-PUCRS & 5.090 & 18 & Não & Geral \\
\hline Geologia & PLN-PUCRS & 234 & - & Não & Geologia \\
\hline IFM2 & LABIC-USP & 134 & - & Não & $\begin{array}{l}\text { Engenharia } \\
\text { de produção }\end{array}$ \\
\hline JPED & Coulthard (2005) & 283 & - & Sim & Pediatria \\
\hline Mineração de Dados & PLN-PUCRS & 53 & - & No & Mineração de Dados \\
\hline $\begin{array}{l}\text { Modelagem } \\
\text { estocástica }\end{array}$ & PLN-PUCRS & 88 & - & No & $\begin{array}{l}\text { Modelagem } \\
\text { estocástica }\end{array}$ \\
\hline Muniz & NILC-USP & 50 & 5 & Não & Eletrodomésticos \\
\hline $\begin{array}{c}\text { Nanociência e } \\
\text { Nanotecnologia }\end{array}$ & GETerm-UFSCar & 1.057 & 5 & Sim & $\begin{array}{c}\text { Nanociência e } \\
\text { Nanotecnologia }\end{array}$ \\
\hline $\begin{array}{c}\text { Processamento } \\
\text { paralelo }\end{array}$ & PLN-PUCRS & 62 & - & Não & $\begin{array}{c}\text { Processamento } \\
\text { paralelo }\end{array}$ \\
\hline $\begin{array}{l}\text { Revestimento } \\
\text { cerâmico }\end{array}$ & NILC-USP & 164 & - & Sim & $\begin{array}{l}\text { Revestimento } \\
\text { cerâmico }\end{array}$ \\
\hline
\end{tabular}

pertencentes à área da ciência da computação. Além dessas categorias, os documentos são classificados em oito diferentes subáreas da computação, que são: banco de dados, inteligência computacional, engenharia de software, hipermídia, sistemas digitais, sistemas distribuídos e programação concorrente, computação gráfica e processamento de imagens e computação de alto desempenho. Esse corpus foi criado para servir de base para um estudo realizado sobre a estrutura de textos científicos do tipo teses e dissertações na língua portuguesa.

O Corpus.EaD (Souza e Felippo, 2010) foi desenvolvido no GETerm da Universidade Federal de São Carlos (UFSCar ${ }^{22}$ ). O corpus possui 347 textos sobre a área de educação à distância obtidos na internet. Esses textos foram divididos em dois subcorpora, sendo 307 textos considerados - Técnico e 40 textos considerados + Técnico. O subcorpora - Técnico foi classificado em (i) científico de divulgação, que são textos provenientes de artigos de divulgação; (ii) informativo, textos provenientes de livro-textos e apostilas; e (iii) instrucional, textos provenientes de notícias/reportagens. O subcorpora + Técnico recebeu o rótulo de técnico-científico, já que contém textos provenientes de teses, dissertações, projetos de pesquisa e artigos científicos. Para a elaboração das listas de termos de referências, consideraram-se como candidatos a termos os sintagmas nominais (sn) que satisfizeram as seguintes condições: (i) tinham no mínimo uma frequência absoluta pré-especificada no corpus EaD; e (ii) não foram excluídos manualmente por serem, por exemplo, nomes próprios ou sn sem valor terminológico (p. ex.: "século XIX"); e (iii) no caso de candidatos a termos simples, não ocorreram em um corpus de língua geral. Então, um especialista decidiu quais desses candidatos são termos do domínio, formando-se, assim, as listas de referências, sendo 59 termos unigramas, 102 bigramas, 63 trigramas e 5 quadrigramas (Gianoti e Felippo, 2011).

O CSTNews (Cardoso et al., 2011) foi desenvolvido no NILC. O corpus possui 140 textos jornalísticos divididos em quatro subtemas: cotidiano, esporte, mundo e política. Esse corpus foi criado para servir de base para pesquisas sobre sumarização multidocumento.

${ }^{22}$ UFSCar - www2.ufscar.br/ 
O corpus $\mathrm{ECO}^{23}$ (Zavaglia et al., 2007) foi desenvolvido no NILC. O corpus contém 390 documentos pertencentes ao domínio de ecologia. O objetivo da construção desse corpus foi auxiliar na criação de uma base de conhecimento com informações ontológicas para os termos pertencentes ao domínio de ecologia. As listas de termos de referências foram confeccionadas considerando os termos presentes ao mesmo tempo em 2 livros, 2 glossários especializados, 1 dicionário online, todos relacionados com o domínio de ecologia, e o corpus ECO. Após eliminação dos termos duplicados, as listas totalizaram 322 termos unigramas, 136 bigramas e 62 trigramas.

O corpus Embrapa é proveniente de documentos do Centro Nacional de Pesquisa Tecnológica em Informática para a Agricultura $\left(\mathrm{CNPTIA}^{24}\right)$ da Empresa Brasileira de Pesquisa Agropecuária (Embrapa) (Conrado, 2009) foi desenvolvido no LABIC da USP com parceria com a CNPTIA da Embrapa. O corpus possui 2.149 textos do área de Agronegócio referentes a 8 produtos: milho, cana, feijão, leite, maçã, caupi, eucalipto e caju. Esse corpus foi criado para a tarefa de extração de termos, já que no referido trabalho contava com o apoio de especialistas desse domínio na avaliação dos termos extraídos.

O corpus Folha-RIcol ${ }^{25}$ foi desenvolvido no grupo de PLN da Pontifícia Universidade Católica do Rio Grande do Sul (PUCRS) para avaliação e treino de sistemas de recuperação de informação. Esse corpus é composto por 5.090 artigos provenientes do corpus do NILC, sendo que estes, por sua vez, foram extraídos do Jornal Folha de São Paulo. O Folha-RIcol possui 18 assuntos pesquisados, que são: Acidente de automóvel, Tráfico de drogas, Música brasileira, Ensino, Jogo de futebol, Comércio de telefone, Aposentadoria, Campanha eleitoral, Fenômenos da natureza, Frutas tropicais, Viagem de avião, Doença grave, Animal doméstico, Aumento de salário, Aluguel de imóvel, Viagem internacional, Uso de computador, Professor universitário e Outros assuntos.

O corpus IFM2 ${ }^{26}$ (Instituto Fábrica do Milênio) (Oliveira et al., 2008) foi desenvolvido no LABIC da USP e possui 134 artigos da área de engenharia de produção que podem ser divididos em 5 classes: WP01, WP02, WP03, WP04 e WP05.

JPED (Coulthard, 2005) contém 283 textos do domínio de pediatria publicados online no Jornal de Pediatria $\left(\mathrm{JPED}^{27}\right)$. Ele foi organizado para estudar padrões de tradução português-inglês. As listas de referências desse corpus foram elaboradas no projeto TEXTQUIM/TEXTECC, anteriormente citado, e possuem 1534 termos bigramas e 2647 trigramas.

Os corpora de geologia, mineração de dados, modelagem estocástica e processamento paralelo possuem 221, 94, 53 e 86 textos, respectivamente. Esses corpora são compostos por teses, dissertações e artigos científicos. A criação desses corpora foi destinada ao processamento computacional para aplicações como elaboração de glossários, extração de informação e construção de ontologias (Martins et al., 2009). Posteriormente, eles foram descritos em Lopes e Vieira (2010, 2013b).

O corpus de Muniz (2011), desenvolvido no NILC, possui 50 textos referentes a manuais técnicos provenientes de 5 categorias de eletrodomésticos, consideradas como classes, que foram: centrífuga de alimentos, ferro de passar roupa, fogão, secador de cabelo e televisão. O total de palavras do corpus é 182.100. A criação desse corpus foi destinada à extração de termos voltada para manuais técnicos.

O corpus de nanociência e nanotecnologia (Coleti et al., 2008), desenvolvido no GE-

\footnotetext{
${ }^{23} \mathrm{ECO}$ - www.nilc.icmc.usp.br/nilc/projects/bloc-eco.htm

${ }^{24}$ CNPTIA-Embrapa - www . cnptia.Embrapa.br/

${ }^{25}$ Folha-RIcol - www. linguateca.pt/Repositorio/Folha-RIcol/

${ }^{26} \mathrm{IFM}$ - www. ifm.org.br

${ }^{27}$ JPED - www. jped.com.br
} 
Term da UFSCar, possui 1.057 textos divididos em 5 categorias: científico, científico-divulgação, informativo, técnico-administrativo e Outros (prospectos de empresas e instituições de pesquisas, slides de palestras, etc.). Esse corpus foi construído no âmbito do projeto NANOTERM (Aluísio, 2005). Para a elaboração das listas de termos de referências, após remoção de stopwords, os candidatos a termos foram identificados por meio do uso de métodos estatísticos. Alguns desses candidatos foram excluídos manualmente por um linguista e, então, um especialista decidiu quais desses candidatos são termos do domínio, formando-se, assim, as listas de referências, sendo 1794 termos unigramas, 586 bigramas, 590 trigramas e 151 quadrigramas (Coleti et al., 2008, 2009).

O corpus de revestimento cerâmico (Teline, 2004) foi desenvolvido no NILC da USP. O corpus possui 164 artigos provenientes da Revista Cerâmica Industrial ${ }^{28}$, totalizando 448.352 palavras. Cada texto possui uma média de 4 a 8 páginas (aproximadamente 4000 palavras). As listas de referências possuem 264 termos unigramas, 74 bigramas e 43 trigramas. A elaboração desse corpus possibilitou a avaliação de métodos para a extração (semi)automática de termos em um trabalho de mestrado (Teline, 2004).

Nesta seção, foram descritos 16 corpora encontrados até o momento na língua portuguesa do Brasil. Entre esses corpora, somente quatro (ver Tabela 3.2) contêm lista de termos de referência. Logo, somente com esses quatro corpora é possível avaliar objetivamente a tarefa de extração de termos.

Na próxima seção, é detalhado o estado da arte da extração de termos na língua portuguesa do Brasil.

\subsection{Estado da Arte da Extração de Candidatos a Termos no Por- tuguês do Brasil}

Nesta seção, são detalhadas as principais contribuições encontradas na literatura que são relacionadas com a extração de termos a partir de corpora da língua portuguesa do Brasil. Na Figura 3.3, ilustra-se a organização dessas pesquisas em função da abordagem e do tipo de conhecimento linguístico.

Nessa figura, observa-se que a maioria dos trabalhos utilizou uma abordagem híbrida para a extração de termos, levando em consideração propriedades linguísticas dos candidatos a termos nos níveis de sintaxe e morfologia e utilizando medidas estatísticas. Somente alguns poucos trabalhos consideraram as propriedades semânticas e outros poucos não utilizaram nenhuma medida estatística. Resumidamente, há trabalhos que investigaram a aplicação de diversas medidas estatísticas para a extração (semi)automática de termos em corpora do PB (Almeida et al., 2003; Teline et al., 2003). Outro trabalho investigou a aplicação unicamente de conhecimento linguístico (no caso, morfológico) (Almeida e Vale, 2008). Algumas pesquisas compararam a extração de termos segundo as abordagens estatística e linguística (Lopes et al., 2009a, 2010a) e outras exploraram a extração (semi)automática de termos segundo a abordagem híbrida (Conrado, 2009; Conrado et al., 2009b; Honorato e Monard, 2008; Lopes, 2012; Lopes et al., 2012; Lopes e Vieira, 2012, 2013a; Lopes et al., 2009b, 2010b; Muniz e Aluísio, 2010; Muniz et al., 2011; Muniz, 2011; Ribeiro Junior, 2008; Ribeiro Junior e Vieira, 2008; Teline, 2004; Zavaglia et al., 2007, 2005).

A seguir, esses trabalhos são classificados de acordo com seus objetivos. O primeiro grupo de trabalhos (Subseção 3.5.1) corresponde aos que visaram primordialmente à comparação, adaptação ou desenvolvimento de métodos de extração de termos. Mais especificamente, esses trabalhos são descritos em função da abordagem (linguística, estatística

${ }^{28}$ Revista Cerâmica Industrial - www.ceramicaindustrial.org.br/ 


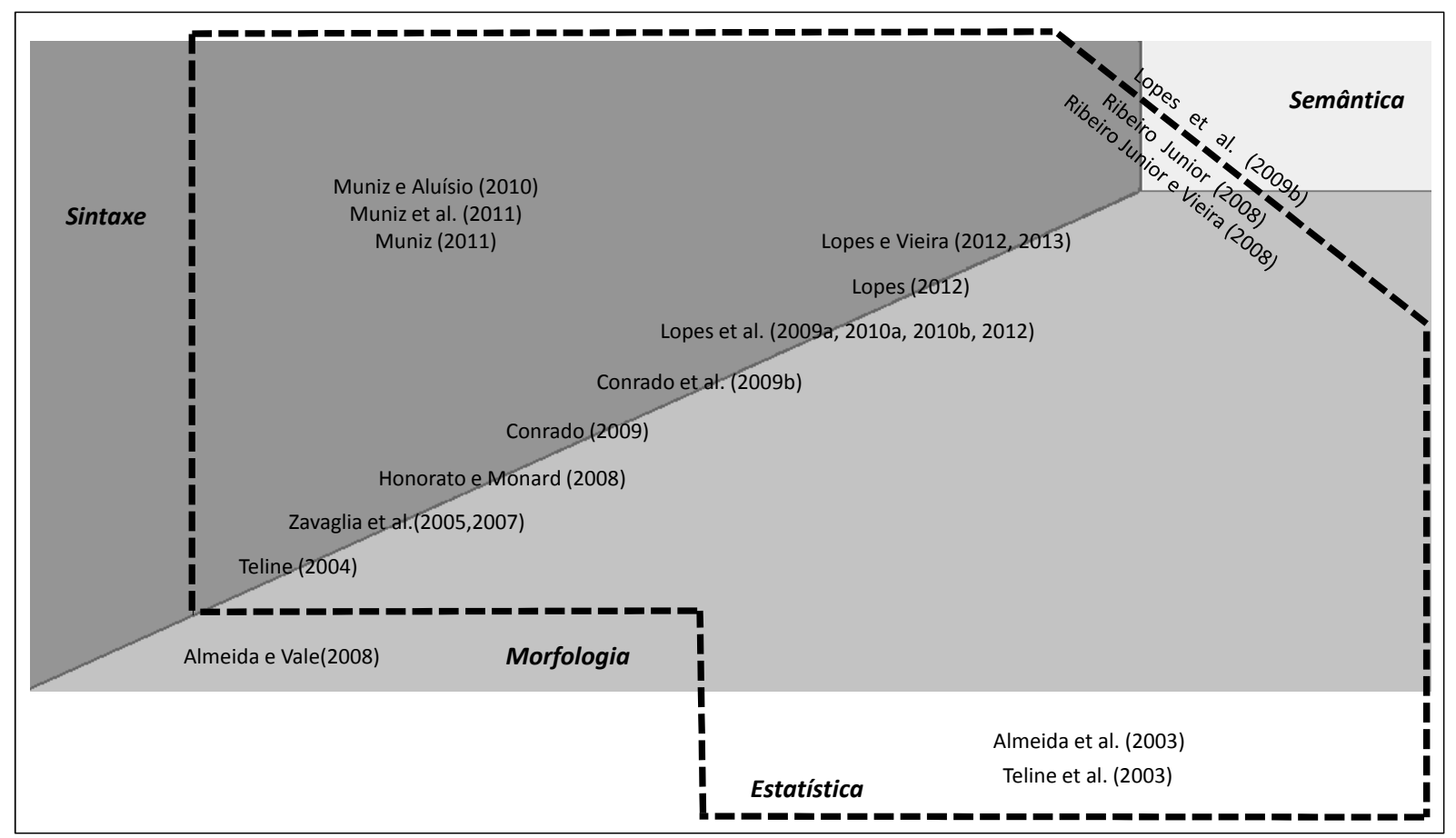

Figura 3.3: Organização dos trabalhos relacionados com a extração de termos para a língua portuguesa do Brasil.

e híbrida) na qual se pauta a extração (semi)automática de termos. Para aqueles que são baseados em conhecimento linguístico, explicita-se ainda o nível do conhecimento empregado (isto é, nível morfológico, sintático e/ou semântico). O segundo grupo é formado pelos trabalhos que objetivaram à avaliação de medidas, ferramentas e recursos na extração de termos (Subseção 3.5.2). Adicionalmente, na Subseção 3.5.3, os principais projetos encontrados na literatura relacionados à extração de termos são descritos.

\subsubsection{Pesquisas Desenvolvidas para a Extração de Candidatos a Termos no Português do Brasil}

Teline et al. (2003) avaliaram o uso de medidas estatísticas aplicadas ao corpus da Revista Cerâmica Industrial, descrita na Seção 3.4, página 34. As medidas avaliadas foram: para termos simples, frequência; para termos bigramas, frequência, informação mútua, logaritmo da razão de máxima verossimilhança e coeficiente de Dice; para termos trigramas, frequência, mi e $l l$. A avaliação, separadamente, dessas medidas na extração de termos bigramas a partir desse corpus apresentou resultados bastante semelhantes. Por essa razão, os autores concluíram que não foi possível identificar quais dessas medidas utilizadas são melhores para essa extração. Já para o caso de termos trigramas, a medida frequência absoluta apresentou um resultado melhor do que as medidas informação mútua e logaritmo da razão de máxima verossimilhança. Com base nos resultados apresentados pelos autores, foi possível calcular os seguintes valores de medida F: 26\%, 9\% e 0,62\% 
para termos unigramas, bigramas e trigramas, respectivamente.

Zavaglia et al. (2005) e Zavaglia et al. (2007) avaliaram a extração de termos segundo as abordagens linguística, estatística e híbrida. Para as três abordagens, foram removidas stopwords e foram utilizadas algumas expressões indicativas, por exemplo "definido como" e "chamado". Mais especificamente, para a abordagem linguística, foram considerados padrões morfossintáticos para a extração de termos. Para a abordagem estatística, foram utilizadas, separadamente, medidas estatísticas implementadas no NSP (frequência absoluta, informação mútua, logaritmo da razão de máxima verossimilhança e coeficiente de Dice) e seus resultados foram comparados. Já para a abordagem híbrida (que correspondeu ao uso das citadas medidas estatísticas e linguísticas juntas), os conhecimentos obtidos por essas medidas utilizadas foram combinados. Para os experimentos, foi utilizado o corpus ECO, que contém 390 documentos textuais em português do domínio de ecologia. Os autores observaram que a abordagem híbrida foi a que obteve melhores resultados, embora a quantidade de candidatos a termos extraídos tenha sido mediana, como as outras duas abordagens. Como resultados, os melhores valores de medida $\mathrm{F}$ foram: para termos unigramas, $16,48 \%$; para bigramas, $16,88 \%$; para trigramas, $5,77 \%$.

No trabalho de Honorato e Monard (2008), foi desenvolvido um ambiente para extrair terminologia de forma híbrida para laudos médicos, denominado Term Pattern Discover (TP-Discover). Tal ambiente, resumidamente, seleciona palavras e frases que aparecem com uma determinada frequência absoluta (método estatístico) e, para isso, a técnica de lematização (método linguístico) é aplicada utilizando o lematizador TreeTagger (Schmid, 1994). Então, selecionam-se os termos que seguem padrões morfossintáticos pré-definidos (p.ex.: o termo "terço distal" segue o padrão substantivo+adjetivo). Como não foi possível ter acesso às medidas exatas de precisões e coberturas, assumiu-se que o melhor valor de medida $\mathrm{F}$ obtido foi $59 \%$.

Ribeiro Junior (2008) e Ribeiro Junior e Vieira (2008) realizaram a extração de termos utilizando a abordagem híbrida e seguindo três etapas, a saber: (i) seleção de grupos semânticos, (ii) extração de termos simples, (iii) extração de termos compostos. A seleção de grupos semânticos consiste na remoção de stopwords e na utilização das informações semânticas disponibilizadas pelo parser Palavras (Bick, 2000). Essas são informações prototípicas que classificam nomes comuns em classes gerais, por exemplo, a tag " $<a n>$ " atribuída ao substantivo "olho", indica que a palavra pertence à classe Anatomia. Dessa forma, os substantivos etiquetados com uma mesma tag são agrupados em conjuntos semânticos. A lista de tags semânticas obtida é apresentada ao especialista do domínio ordenada pela frequência relativa de cada tag. Então, o especialista exclui os grupos semânticos que considera não ter relação com o domínio em questão. Para a extração de termos simples e composto, foram utilizados as medidas estatísticas de frequência relativa, tf-idf (Salton e Buckley, 1987) e nc-value (Frantzi et al., 1998). Ainda, para a extração dos termos compostos, foi utilizado também o método estatístico c-value (Frantzi et al., 1998). Também, para a extração dos termos simples, somente foram extraídos os candidatos que pertencem a determinadas classes gramaticais definidas pelo especialista, bem como foram considerados somente os núcleos dos sintagmas nominais. Já para os candidatos a termos compostos, foram considerados somente aqueles que consistem de determinados padrões morfossintáticos e que constituem sintagmas nominais. Por fim, esses métodos linguísticos e estatísticos foram combinados, originando os métodos híbridos. Todos esses métodos foram utilizados para extrair termos a partir de dois corpora em português: nanociência e nanotecnologia (Coleti et al., 2008), que possui 1.057 textos desse domínio, e JPED, que é composto por 283 documentos textuais do domínio de pediatria $\left(\mathrm{JPED}^{29}\right)$. Para o primeiro corpus, foram calculadas as precisões dos termos extraídos e, para o corpus JPED, foram

\footnotetext{
${ }^{29}$ Os documentos do JPED foram extraídos do Jornal de Pediatria - www.jped.com.br
} 
calculadas também as medidas $\mathrm{F}$, sendo que os melhores valores obtidos foram 22,39\%, $10,04 \%$ e $5,46 \%$ para termos unigramas, bigramas e trigramas, respectivamente.

Conrado (2009) e Conrado et al. (2009b) efetuaram a extração de termos unigramas, bigramas e trigramas utilizando a abordagem híbrida. Os autores aplicaram técnicas de normalização de palavras (radicalização, lematização e substantivação) no domínio de agronegócio. Foram removidas stopwords padrão para o português disponível na PRETEXT (Soares et al., 2008), juntamente com as conjugações do verbo SER e as palavras compostas por apenas um caractere. Em seguida, foram aplicadas medidas estatísticas, a saber: para candidatos a termos unigramas, bigramas e trigramas, utilizaram frequência de documentos $(d f>=2)$ e, para os bigramas e trigramas, aplicaram o logaritmo da razão de máxima verossimilhança. Os termos simples que foram removidos a partir da $d f$ formam uma nova lista de palavras, denominada "stoplist da coleção" ou "stoplist de domínio", e esta é incorporada à stoplist padrão e utilizada para formar os n-gramas. Os termos extraídos utilizando essas diferentes técnicas foram avaliados pelos autores de forma objetiva - utilizando, por exemplo, a medida ctw (Maynard e Ananiadou, 1999) - e de forma subjetiva com o apoio de especialistas do domínio. Essa abordagem de extração de termos foi focada para ser utilizada no Projeto TopTAx (Moura et al., 2008b), que será explicado ainda neste capítulo, embora possa ser utilizada para outros objetivos.

Há também um trabalho (Lopes et al., 2009b) que utilizou a ferramenta OntoLP (Ribeiro Junior, 2008) para comparar três formas de extração de termos bigramas e trigramas com base na abordagem linguística. A primeira forma considerou somente n-gramas, a segunda utilizou padrões morfossintáticos pré-estabelecidos e a terceira considerou somente os sintagmas nominais. Tanto para a identificação de padrões morfossintáticos quanto de sintagmas nominais, foi utilizado o parser Palavras (Bick, 2000). Essas três formas foram comparadas entre si. Ainda, informações sobre grupos semânticos foram adicionadas à cada uma dessas formas, gerando, agora, 3 novas formas de extrair semiautomaticamente os termos, que foram comparadas com as formas que não utilizaram informações semânticas. Esses grupos semânticos são informações prototípicas fornecidas pelo parser Palavras e disponibilizadas pela ferramenta OntoLP. Tais informações classificam nomes comuns em classes gerais. Um exemplo dado pelos próprios autores é a tag "<an>" atribuída ao substantivo "músculo", indica que a palavra pertence à classe Anatomia. Como resultado, os melhores valores de medida $\mathrm{F}$ foram $11,51 \%$ para termos bigramas e $8,41 \%$ para trigramas, obtidos com o corpus JPED considerando os sintagmas nominais, com exclusão de termos por grupos semânticos.

Nos trabalhos de Lopes et al. (2009a) e Lopes et al. (2010a), foi realizada uma análise comparativa da extração de termos bigramas e trigramas utilizando uma abordagem linguística e uma estatística. Esses termos foram extraídos de um corpus do domínio de pediatria (JPED). Na abordagem linguística, foi utilizada a ferramenta E $\chi \mathrm{ATO} L P$ para identificar sintagmas nominais a partir de um corpus previamente anotado pelo parser Palavras (Bick, 2000). Na abordagem estatística foi adotado o pacote NSP para identificar os termos que continham uma Frequência Absoluta superior a um determinado valor. Ainda para a abordagem estatística, foram removidos stopwords, as palavras de demarcação estrutural do texto, como "Introdução", "Referências", "Bibliografia", e os candidatos a termos cujas palavras iniciavam com maiúsculas, visando remover substantivos próprios, como "São Paulo". Os termos extraídos foram avaliados com o apoio de uma lista de referência de n-gramas. Como resultado, os autores afirmam que a abordagem estatística tem grande simplicidade em sua execução. Porém, obtiveram melhores resultados quando utilizada a abordagem linguística. Os valores de medida $\mathrm{F}$ alcançados pela ferramenta, para um corpus do domínio de pediatria, foram $34,48 \%$ para termos bigramas e $=38,37 \%$ para trigramas (Lopes et al., 2010a). 
Lopes et al. (2010b) extraíram termos bigramas e trigramas a partir do corpus JPED. Essa extração usou a ferramenta OntoLP (Ribeiro Junior, 2008), que considera três diferentes maneiras de se extrair termos: (i) os $n$-gramas mais frequentes; (ii) os candidatos que seguem algum padrão morfossintáticos $(\mathrm{pm})$; e (iii) os sintagmas nominais. Adicionalmente, os autores avaliaram diferentes pontos de corte para a escolha dos candidatos que seriam considerados termos. Os melhores valores de medida $\mathrm{F}$ foram, para termos bigramas, $56,84 \%$ quando usando $p m$ e, para trigramas, $52,11 \%$ quando usando a frequência dos $n$-gramas, ambos valores foram alcançados considerando thresholds de $5 \mathrm{E}-6$ e $6 \mathrm{E}-6$ para pontos de corte absolutos.

Em outros trabalhos (Muniz e Aluísio, 2010; Muniz et al., 2011; Muniz, 2011), termos foram extraídos utilizando a abordagem híbrida a partir de manuais de instruções, como manuais de eletrodomésticos. A extração foi realizada com a ferramenta NorMan Extractor $^{30}$ e foi baseada em relações específicas existentes no gênero trabalhado. Ou seja, os manuais de instrução possuem duas relações procedimentais básicas: relação "gera" (generation), quando uma ação $A$ gera automaticamente uma ação $B$, e a relação "habilita" (enablement), quando a realização de uma ação $A$ permite a realização da ação $B$. Os passos realizados para a extração de termos são: primeiramente, o usuário seleciona um manual de instruções a ser utilizado. Há também a possibilidade do usuário submeter um corpus de domínio para que este seja utilizado no cálculo da medida c-value (Frantzi et al., 1998). Essa medida é utilizada para a extração de candidatos a termos compostos. Então, o manual de instrução é anotado pelo parser Palavras (Bick, 2000). A partir dessa anotação, é possível extrair os termos utilizando as relações "gera" e "habilita". Por fim, as listas de candidatos a termos unigramas, bigramas e n-gramas extraídos são apresentadas ao usuário, permitindo que o mesmo faça algum corte utilizando os valores oferecidos pela medida c-value para cada termo extraído. Considerando que não há uma lista de termos de referência de manuais de instruções, os autores não apresentaram resultados utilizando medida F, mas os resultados foram comparados com outros métodos de extração voltados para artigos científicos e também foi utilizada a medida estatística kappa (Carletta, 1996), que é uma medida que indica a concordância entre anotadores ao mesmo tempo em que desconta a concordância por sorte.

Lopes e Vieira (2012) extraíram termos utilizando conhecimento linguístico. Para isso, foram considerados somente os sintagmas nominais $(s n \mathrm{~s})$ que se enquadravam em uma das 11 heurísticas linguísticas propostas. Um exemplo dessas heurísticas é a remoção de sns que começam com um advérbio. Os melhores valores de medida $\mathrm{F}$ obtidos nos experimentos realizados com o corpus JPED foram $64 \%$ para termos bigramas e $50 \%$ para trigramas.

Outros trabalhos (Lopes, 2012; Lopes et al., 2012) extraíram termos bigramas e trigramas baseando-se nos mesmos métodos linguísticos de Lopes e Vieira (2012) e os ordenaram utilizando os valores numéricos obtidos pela aplicação das medidas estatísticas: $t f$, $t f-i d f$, $t d s$, $t h d$, frequência do termo e frequência inversa de domínio ( TF-IDF). Lopes (2012) também propôs e usou a medida frequência de termo - frequência de disjunção de corpora $(t f-d c f)$. Tal medida, segundo a autora, considera a frequência absoluta de termo como indicação primária da relevância de um termo e penaliza os termos que aparecem nos corpora contrastantes (corpora de outros domínios) dividindo a frequência absoluta do termo no corpus de domínio pela composição geométrica da sua frequência absoluta em cada um dos corpora contrastantes. Após a ordenação dos termos por cada uma dessas medidas, foram escolhidos e aplicados pontos de corte às listas ordenadas de termos. Para os experimentos, foi utilizado o corpus JPED e, como corpora contrastantes, foram criados quatro outros corpora (Lopes e Vieira, 2010): Modelagem estocástica (88 textos),

${ }^{30}$ NorMan - http://nilc.icmc.usp.br/norman/extractor/ 
Mineração de dados (53 textos), Processamento paralelo (62 textos) e Geologia (234 textos). Foram avaliadas as precisões de termos bigramas e trigramas extraídos do corpus JPED nos seguintes cenários: (i) comparação das heurísticas linguísticas adotadas para seleção ou remoção dos sns, sendo possível mostrar que o uso das heurísticas propostas melhora significativamente os resultados; (ii) comparação das medidas estatísticas utilizadas, sendo que, para esse corpus, as precisões são superiores quando a medida $t f-d c f$ foi usada; e (iii) comparação da variação dos corpora contrastantes utilizando a $t f-d c f$, o que foi possível mostrar que quando se utiliza os quatro corpora contrastantes juntos obtêm-se melhores resultados. Como resultados e considerando cortes nos números de candidatos a termos, a autora obteve medida $\mathrm{F}$ igual a $81 \%$ para termos bigramas e $84 \%$ para trigramas.

Os trabalhos descritos anteriormente utilizaram diferentes corpora e, em alguns casos, os autores utilizaram diferentes medidas de avaliação dos resultados ou avaliaram somente uma parte da lista de candidatos a termos. Mesmo considerando tais diferenças, com o objetivo de fornecer uma visão geral dos resultados dos trabalhos sobre extração de termos para a língua portuguesa apresentam-se, na Tabela 3.3, um resumo dos mesmos e seus melhores valores de medida $\mathrm{F}$.

Tabela 3.3: Síntese dos trabalhos sobre extração de termos

\begin{tabular}{|c|c|c|c|c|}
\hline \multirow{2}{*}{ Trabalhos } & \multirow{2}{*}{ Domínios } & \multicolumn{3}{|c|}{ Valores de Medida F para os termos } \\
\hline & & Unigramas & Bigramas & Trigramas \\
\hline Almeida et al. (2003) & Revestimento cerâmico & - & - & - \\
\hline Almeida e Vale (2008) & $\begin{array}{l}\text { Revestimento cerâmico, } \\
\text { Fisioterapia e Nano- } \\
\text { ciência e Nanotecnologia }\end{array}$ & - & - & - \\
\hline Conrado (2009) e Conrado et al. (2009b) & Agronegócios & - & - & - \\
\hline Honorato e Monard (2008) & Medicina (laudos médicos) & & $59,00 \%$ & \\
\hline Lopes (2012) e Lopes e Vieira (2013a) & Pediatria & - & $81,00 \%$ & $84,00 \%$ \\
\hline Lopes et al. (2012) & Pediatria & - & - & - \\
\hline Lopes et al. (2009a, 2010a) & Pediatria & - & $51,42 \%$ & $41,26 \%$ \\
\hline Lopes e Vieira (2012) & Pediatria & - & $64,00 \%$ & $50,00 \%$ \\
\hline Lopes et al. (2009b) & Pediatria & - & $11,50 \%$ & $8,40 \%$ \\
\hline Lopes et al. (2010b) & Pediatria & - & $56,84 \%$ & $52,11 \%$ \\
\hline $\begin{array}{c}\text { Muniz e Aluísio (2010), } \\
\text { Muniz et al. (2011) e Muniz (2011) }\end{array}$ & $\begin{array}{c}\text { Eletrodomésticos } \\
\text { (manuais de instruções) }\end{array}$ & - & - & - \\
\hline $\begin{array}{c}\text { Ribeiro Junior (2008) e } \\
\text { Ribeiro Junior e Vieira (2008) }\end{array}$ & Pediatria & $22,39 \%$ & $10,04 \%$ & $5,46 \%$ \\
\hline Teline (2004) & Revestimento cerâmico & $11,00 \%$ & $17,00 \%$ & $46,00 \%$ \\
\hline Teline et al. (2003) & Revestimento cerâmico & $26,00 \%$ & $9,00 \%$ & $0,62 \%$ \\
\hline Zavaglia et al. $(2007,2005)$ & Ecologia & $16,48 \%$ & $16,88 \%$ & $5,77 \%$ \\
\hline
\end{tabular}

\subsubsection{Pesquisas relacionadas à Extração de Termos na Língua Portuguesa do Brasil}

Algumas pesquisas encontradas na literatura discutem a extração de termo na língua portuguesa do Brasil.

Almeida et al. (2003) discutiram os processos manual e semiautomático de extração de termos a partir de um corpus do domínio de revestimento cerâmico. As autoras afirmam que a extração manual feita por especialistas do domínio em questão, na qual os mesmos indicam quais são os termos do domínio, é considerada como um critério semântico. Além disso, as autoras analisaram os candidatos a termos obtidos na extração considerando os três seguintes casos: com e sem a remoção de stopwords e com a correção de possíveis erros no corpus utilizado. Para a extração de candidatos a termos unigramas, a medida de frequência foi utilizada e, para bigramas, as medidas de informação mútua, logaritmo da razão de máxima verossimilhança e frequência foram comparadas. 
No trabalho de Teline (2004) foi feito um levantamento bibliográfico sobre os pontos fortes e fracos de métodos de extração de termos nessas três abordagens - estatística, linguística e híbrida. Para a abordagem estatística, foram comparadas as medidas de frequência, informação mútua, logaritmo da razão de máxima verossimilhança e coeficiente de Dice. Para a abordagem linguística, foram removidas stopwords e foram utilizadas algumas expressões indicativas, como "definido(a)(s) como", "caracterizado(a)", "conhecido(a)(s) como", "significa (m)", bem como foram utilizados padrões morfossintáticos. Na abordagem híbrida, a abordagem linguística foi combinada com a medida de frequência para a extração de termos unigramas, bigramas e trigramas separadamente. Ainda para a extração de termos bigramas e trigramas separadamente, a abordagem linguística foi combinada com a medida de informação mútua. Cada uma dessas extrações foi avaliada no domínio de revestimentos cerâmicos. A abordagem híbrida (parte linguística com a frequência) apresentou melhores valores de medida F, que foram 11\%, 17\% e 33\% para, respectivamente, termos unigramas, bigramas e trigramas. Considerando uma seleção manual (um linguista e a autora) feita nos candidatos a termos, foram alcançados $58 \%$ de medida $\mathrm{F}$ na extração de termos unigramas também ordenados pela frequência e atingiram $26 \%$ de medida F para a extração de termos trigramas utilizando o coeficiente de Dice.

Almeida e Vale (2008) discutiram sobre os padrões morfológicos específicos que acontecem em três domínios, a saber: revestimento cerâmico, fisioterapia e nanociência e nanotecnologia. Como resultados, no domínio de revestimento cerâmico, foi observada uma alta frequência de combinações, como "argila refratária aluminosa" e "análise granulométrica por peneiramento", e de palavras simples acompanhadas de morfemas que podem servir como identificadores de termos, como os sufixos derivacionais -agem, -ção, tendo como exemplo "secagem" e "moagem". No domínio de fisioterapia, têm-se muitas formações eruditas, de origem grega ou latina, devido ao fato que essa terminologia tem muitos termos provenientes da medicina, como o $\operatorname{artr}(i / o)$ - que pode formar, por exemplo, os termos "artralgia" e "artrite". Já no domínio de nanociência e nanotecnologia, a característica mais marcante é a alta frequência absoluta do prefixo nano-, que pode dar origem, por exemplo, aos termos "nanocristais" e "nanossistema biológico".

A maneira mais comum de se extrair termos é atribuir um valor para cada candidato a termo de acordo com alguma medida e, então, os candidatos são ordenados considerando esses valores. Entretanto, é necessário saber como escolher um limiar no qual candidatos que tenham valores fornecidos pela medida usada superiores ao limiar são considerados termos. Lopes e Vieira (2013a) discutiram e compararam três diferentes formas de obtenção desse limiar, que foram: (i) ponto de corte absoluto, no qual os autores criaram um ranking de candidatos usando a medida $t f$ - $d c f$ e forneceram pontos de corte considerando intervalos entre os 100 e 3500 primeiros candidatos; (ii) ponto de corte utilizando threshold, no qual eles consideraram as frequências dos candidatos no corpus JPED (de 0 até 15) como pontos de corte; e (iii) pontos de corte relativos, no qual eles também utilizaram $t f$ - $d c f$ e removeram porcentagem dos candidatos (de 1 até $30 \%$ ). Finalmente, eles analisaram esses três pontos de corte e sugeriram o uso da combinação de threshold com pontos de corte relativos, na qual mantiveram candidatos que têm $t f-d c f>2$ e estão entre os $15 \%$ candidatos mais bem ranqueados.

\subsubsection{Projetos Relacionados à Extração de Termos na Língua Portuguesa do Brasil}

Nesta seção, são apresentados alguns dos principais projetos que são relacionados com a extração de termos na língua portuguesa do Brasil, a saber: NANOTERM, TEXT- 
QUIM/TEXTECC, Bio-C, E-TERmos e TermiNet. Na descrição de cada projeto, é destacado em negrito onde os termos extraídos são aplicados. Também são descritos o portal OntoLP e o repositório da Linguateca, nos quais os pesquisadores da área podem encontrar recursos para realizar a extração de termos. Uma síntese desses projetos, portal e repositório é apresentada na Tabela 3.4, e suas características principais são destacadas.

Tabela 3.4: Síntese dos projetos, portal e repositório relacionados com a extração de termos

\begin{tabular}{|c|c|c|c|c|}
\hline Nomes & Responsáveis & Períodos & Objetivos & Dominios \\
\hline Bio-C & $\begin{array}{l}\text { GETerm } \\
\text { e NILC }\end{array}$ & $2007-2009$ & $\begin{array}{c}\text { Gerar a terminologia } \\
\text { sistematizada da área } \\
\text { de Biocombustíveis. }\end{array}$ & Biocombustível \\
\hline E-TERMos & $\begin{array}{l}\text { Embrapa, } \\
\text { GETerm } \\
\text { e NILC }\end{array}$ & 2009 - Atual & Gestão terminológica. & Diversos \\
\hline NANOTERM & $\begin{array}{l}\text { NILC } \\
\text { e IFSC }\end{array}$ & $2006-2008$ & $\begin{array}{l}\text { Constituir corpus; } \\
\text { criar ontologia; elaborar } \\
\text { dicionário-piloto. }\end{array}$ & $\begin{array}{c}\text { Nanociência e } \\
\text { Nanotecnologia }\end{array}$ \\
\hline TermiNet & $\begin{array}{l}\text { GETerm } \\
\text { e NILC }\end{array}$ & 2009 - Atual & $\begin{array}{l}\text { Divulgar ontologias, } \\
\text { Desenvolver bases tex- } \\
\text { tuais terminológicas e } \\
\text { construir uma WordNet. }\end{array}$ & Diversos \\
\hline $\begin{array}{l}\text { TEXTQUIM/ } \\
\text { TEXTECC }\end{array}$ & UFRGS & 2003 - Atual & $\begin{array}{l}\text { Desenvolver dicionário } \\
\text { para tradução. }\end{array}$ & $\begin{array}{c}\text { Química, Física, } \\
\text { Pediatria, Cardiologia, } \\
\text { Enfermagem e Veterinária }\end{array}$ \\
\hline TopTax & $\begin{array}{l}\text { LABIC e } \\
\text { Embrapa }\end{array}$ & 2005 - Atual & $\begin{array}{l}\text { Organizar e manter } \\
\text { informação de } \\
\text { domínios específicos. }\end{array}$ & Diversos \\
\hline OntoLP & PUCRS & 2008 & $\begin{array}{c}\text { Divulgar ferramentas } \\
\text { e recursos. }\end{array}$ & Diversos \\
\hline Linguateca & $\begin{array}{l}\text { IST-UTL, UC } \\
\text { e PUC-Rio }\end{array}$ & 1998 & $\begin{array}{l}\text { Manter recursos } \\
\text { linguísticos. }\end{array}$ & Diversos \\
\hline
\end{tabular}

\section{Projeto NANOTERM}

O projeto denominado "Terminologia em língua portuguesa da Nanociência e Nanotecnologia: Sistematização do Repertório Vocabular e Elaboração de Dicionário-Piloto" (NANOTERM) (Aluísio, 2005) foi desenvolvido entre os anos 2006 e 2008 no laboratório do Grupo de Estudos e Pesquisas em Terminologia (GETerm) da Universidade Federal de São Carlos (UFSCar) com a colaboração do NILC da Universidade de São Paulo.

Os objetivos desse projeto foram: 1) a constituição de um corpus em língua portuguesa do domínio de nanociência e nanotecnologia; 2) a busca de equivalentes em português (língua de chegada) a partir de uma nomenclatura em inglês (língua de partida); 3) a criação de uma ontologia em língua portuguesa do domínio de nanociência e nanotecnologia e 4) a elaboração do primeiro dicionário-piloto de nanociência e nanotecnologia em língua materna.

A extração semiautomática de termos nesse projeto diz respeito à obtenção do conjunto terminológico que comporá a nomenclatura do glossário ou dicionário e é feita de forma semiautomática, pois nessa tarefa está sempre previsto o papel do linguista, além do trabalho automático realizado com o pacote NSP. Entende-se por nomenclatura o conjunto de unidades léxicas ${ }^{31}$ que vão constituir as entradas do glossário ou dicionário. Para a extração de termos, é utilizado o ambiente computacional E-TERMos, que é descrito posteriormente. Por fim, os termos extraídos são inseridos na ontologia em língua portuguesa do domínio de nanociência e nanotecnologia.

\section{Projeto TEXTQUIM/TEXTECC}

\footnotetext{
${ }^{31} \mathrm{Na}$ área de linguística, é utilizado de forma mais específica o conceito de "unidade lexical". Neste trabalho, usa-se genericamente "unidade lexical" como sinônimo de "item lexical".
} 
O projeto denominado TEXTQUIM ${ }^{32}$ (Textos de Química), que teve início no ano de 2003 e é desenvolvido pela Universidade Federal do Rio Grande do Sul (UFRGS), está se transformando no projeto TEXTECC ${ }^{33}$ (Textos Técnicos e Científicos), visando abranger, além da área de química, também as áreas de física, pediatria, cardiologia, enfermagem e veterinária.

O objetivo desse projeto é desenvolver um dicionário para apoiar os estudantes de tradução, inicialmente no domínio de pediatria. Para isso, Coulthard (2005) construiu um corpus, o JPED, que é composto por 283 textos (785.448 palavras) na língua portuguesa extraídos do Jornal de Pediatria, visando estudar padrões de tradução português-inglês. Então, no âmbito do projeto TEXTQUIM-TEXTECC, foi realizado um trabalho manual de extração de termos (sem anotação linguística) a partir desse mesmo corpus e foram considerados somente os n-gramas que ocorreram mais de 4 vezes no corpus. Em seguida, uma filtragem foi feita baseada em heurísticas que resultou em uma nova lista de ngramas considerados possivelmente relevantes para integrar o glossário. Esses n-gramas foram avaliados quanto à relevância e refinados manualmente por estudantes de tradução com conhecimento do domínio. Com esse processo, originaram-se as listas de termos de referências do corpus JPED que têm sido utilizadas em experimentos de extração de termos compostos e candidatos a conceitos, como o caso do projeto OntoLP (Ribeiro Junior, 2008).

\section{Projeto Bio-C}

O projeto denominado "Terminologia de Biocombustíveis: descrição semântica e morfológica com vistas à sistematização" (Bio-C ${ }^{34}$ ) foi desenvolvido entre o ano de 2007 e 2009, pelo Grupo de Estudos e Pesquisas em Terminologia (GETerm) da Universidade Federal de São Carlos (UFSCar) juntamente com o apoio do Núcleo Interinstitucional de Linguística Computacional (NILC) da Universidade de São Paulo (USP).

Esse projeto tem como objetivo gerar a terminologia sistematizada da área de Biocombustíveis, contendo os termos fundamentais da referida área, o que inclui os subdomínios do etanol e do biodiesel, de forma a dar subsídios para a criação, a posteriori, do primeiro glossário desse domínio do conhecimento na língua portuguesa do Brasil.

Para a extração semiautomática de termos nesse projeto foi utilizado o pacote NSP para gerar listas de candidatos a termos unigramas, bigramas, trigramas, quadrigramas e pentagramas. As stopwords foram removidas dos textos de entrada visando diminuir o excesso de ruído na lista de candidatos a termos. Em seguida, essas listas foram limpas manualmente por um linguista, bem como os candidatos foram validados posteriormente por especialistas de domínio. Como resultado, tem-se uma lista dos termos validados que integrarão o glossário da área.

\section{Projeto E-TERMOS}

O Projeto "Termos Eletrônicos" (E-TERmos ${ }^{35}$ ) (Oliveira, 2009) foi oriundo da transformação do projeto TermEx para o E-TERMOS. É um ambiente computacional colaborativo $W e b$ de acesso livre e gratuito dedicado à gestão terminológica. Esse projeto foi desenvolvido no Núcleo Interinstitucional de Linguística Computacional (NILC) da Universidade de São Paulo (USP) com a colaboração do Grupo de Estudos e Pesquisas em Terminologia

\footnotetext{
${ }^{32}$ TEXTQUIM - www.ufrgs.br/textquim/

${ }^{33}$ TEXTECC - www6.ufrgs.br/textecc/

${ }^{34}$ Bio-C - www.geterm.ufscar.br/geterm2/?page_id=111

${ }^{35} \mathrm{E}$-TERmos está disponível em: www.etermos .ufscar .br/index.php
} 
(GETerm) da Universidade Federal de São Carlos (UFSCar) e da Empresa Brasileira de Pesquisa Agropecuária (EMBRAPA).

O principal objetivo do E-TERMOS é viabilizar a criação de produtos terminológicos, sejam eles para os fins de pesquisa acadêmica ou de divulgação, por meio da (semi)automatização das etapas do trabalho terminológico.

A extração semiautomática de termos desse projeto visa obter os candidatos a termos a partir dos corpora de especialidade em questão. Para efetuar a extração, primeiramente, pode-se optar pelo tamanho do grama a ser utilizado, que pode ser de 2 a 7. Então, pode-se remover stopwords com o uso de uma lista de stopwords fornecida, sendo esta resultante do trabalho de Teline (2004). Após a remoção das stopwords, os termos são extraídos com auxílio de conhecimento estatístico e/ou linguístico. Segundo o autor, estão previstos a incorporação de medidas estatísticas (logaritmo da razão de máxima verossimilhança, informação mútua e coeficiente de Dice) pertencentes ao pacote NSP, de conhecimento linguístico (a ser definido) e híbrido (junção do conhecimento estatístico e linguístico). Atualmente, está disponível a medida estatística de Frequência Simples.

Para a edição do mapa conceitual e categorização de termos, no E-TERMOS são permitidas a criação, a edição e a visualização dos mapas conceituais e recursos computacionais para a inserção e avaliação dos termos pelos especialistas. Então, tem-se o gerenciamento da base de dados terminológicos, no qual a ficha terminológica é criada e preenchida e a base definicional é elaborada, com o auxílio de ferramentas que gerenciam a base de dados terminológica.

Por fim, na etapa de intercâmbio e difusão de termos, os verbetes são editados e a difusão, intercâmbio e consulta dos produtos terminológicos podem ser efetuadas por meio de ferramentas de exportação de dados terminológicos, possibilitando que os verbetes sejam consultados pelos usuários.

\section{Projeto TermiNet}

O projeto TermiNet (Terminological WordNet) (Di Felippo, 2010) vem sendo desenvolvido, desde o ano de 2009, no laboratório do Grupo de Estudos e Pesquisas em Terminologia (GETerm) da Universidade Federal de São Carlos (UFSCar) com a colaboração do Núcleo Interinstitucional de Linguística Computacional (NILC) da Universidade de São Paulo (USP).

Esse projeto possui dois objetivos principais. O primeiro é desenvolver uma metodologia genérica, semiautomática e baseada em corpus, para a construção de bases lexicais no formato WordNet. O segundo objetivo é validar essa metodologia por meio da construção de uma terminet.

A extração de candidatos a termos do TermiNet utiliza a abordagem linguística por meio das ferramentas E $\chi$ ATO $L P$ (Lopes et al., 2009a) e OntoLP (Ribeiro Junior e Vieira, 2008), bem como abordagem estatística com o uso do pacote NSP (Ngram Statistics Package) (Banerjee e Pedersen, 2003). A avaliação dos candidatos a termos extraídos é feita por meio de uma validação manual realizada por especialistas do domínio em questão. Os candidatos a termos também são comparados com uma lista de unidades lexicais pertencentes à corpora de contraste.

\section{Metodologia TOPTAX}

A metodologia TopTAX ${ }^{36}$ (Topic Taxonomy Environment) (Moura et al., 2008b) tem como objetivo organizar e manter informação de domínios específicos. Isso é possível

\footnotetext{
${ }^{36}$ TopTAX- http://labic.icmc.usp.br/projects/toptax
} 
devido à criação de uma taxonomia de tópicos sobre o conhecimento do domínio representado pela coleção de textos. A taxonomia considerada é uma organização hierárquica de tópicos extraídos de uma coleção de textos, na qual os tópicos superiores são pais dos inferiores, ou seja, os inferiores são especializações dos tópicos superiores. Além disso, a cada nível da taxonomia, podem-se associar recursos da base textual referentes ao seu domínio, facilitando, assim, a organização da informação sob essa taxonomia.

A TopTax, para atingir seus objetivos, segue as etapas do processo de Mineração de Textos (Ebecken et al., 2003), que são Identificação do Problema, Pré-Processamento, Extração de Padrões, Pós-Processamento e Uso do Conhecimento.

A etapa de Identificação do Problema deve delimitar o problema a ser abordado por selecionar e recuperar os documentos que formam a coleção textual a ser trabalhada.

Na etapa do Pré-Processamento, os documentos da base textual obtida são preparados para servirem de entrada para as ferramentas que serão utilizadas. Nessa etapa, quatro atividades são realizadas: (i) a padronização dos documentos; (ii) a extração de termos; (iii) a seleção de termos; e (iv) a representação dos documentos em matriz atributo-valor. $\mathrm{Na}$ atividade de padronização, os documentos são convertidos para o forma de texto plano sem formatação. Na atividade de extração de termos, as palavras dos documentos são normalizadas utilizando-se uma das técnicas de normalização de palavras (radicalização, lematização ou substantivação). Em seguida, as stopwords são removidas e métodos para auxiliar na extração de termos são utilizados. Os termos extraídos descrevem a base de textos e são representados em uma matriz atributo-valor, conforme detalhado em Conrado (2009). Mas, devido à alta dimensionalidade da matriz, passa-se para a atividade de seleção de termos, com o objetivo de diminuir a quantidade de termos a ser trabalhada. Para isso, pode-se utilizar os métodos de Luhn, Salton e term variance, que são detalhados no trabalho de Nogueira (2009).

Na etapa de Extração de Padrões, efetua-se o processo de agrupamento hierárquico de documentos visando a construção de uma taxonomia de tópicos. Com a hierarquia, os agrupamentos obtidos retêm tópicos ou sub tópicos aos quais os documentos se referem. Em seguida, conforme descrito em Moura et al. (2008b), identifica-se os descritores para cada grupo encontrado pela obtenção dos termos mais significativos, sendo possível adicionar a cada nó recursos de informação de tópicos, como documentos, vídeos e imagens associadas.

Na etapa do Pós-Processamento, esta hierarquia obtida é visualizada e validada. O conhecimento acerca do domínio em questão representado nessa hierarquia é, então, utilizado para dar suporte às decisões e organização da informação ali contida (etapa do Uso do Conhecimento).

\section{Portal OntoLP}

O "Portal de Ontologia" OntoLP"37 (Ribeiro Junior, 2008) é desenvolvido pelo Grupo de Processamento da Língua Natural da Pontifícia Universidade do Rio Grande do Sul (PUCRS) e tem como objetivo divulgar ontologias disponíveis na língua portuguesa, bem como bases terminológicas, vocabulários controlados, até ontologias mais complexas do tipo OWL-DL (Web Ontology Language-Description Logics), e ferramentas e recursos relacionados à pesquisa na área.

\section{Repositório Linguateca}

O Repositório Linguateca ${ }^{38}$ é formalmente chamada de Centro de Recursos - distribuído - para a língua portuguesa e foi criada oficialmente no ano de 2002, mas os primeiros

\footnotetext{
${ }^{37}$ OntoLP - www.inf.pucrs.br/ ontolp/index.php

${ }^{38}$ Linguateca - www. linguateca.pt
} 
trabalhos relacionados a mesma tiveram início em 1998. A Linguateca consiste em um repositório de recursos linguísticos voltados à língua portuguesa. A responsabilidade pela Linguateca, desde o seu início (em 1998) era passada de polo em polo de diversas faculdades. Já a partir de 2009, foi estabelecido que a responsabilidade sobre a mesma seria apenas dada ao polo de Oslo operacional. Os responsáveis desse polo são quatro pesquisadores de Portugal (Diana Santos, Cristina Mota, Rosário Silva e Fernando Ribeiro) do Instituto Superior Técnico da Universidade de Lisboa (IST-UTL ${ }^{39}$ ) e da Universidade de Coimbra $\left(\mathrm{UC}^{40}\right.$ ), dois doutorandos de Portugal (Nuno Cardoso e Hugo Oliveira) do IST-UTL, todos situados em Portugal, e uma pesquisadora do Brasil (Maria Cláudia de Freitas) da Pontifícia Universidade Católica do Rio de Janeiro (PUC-Rio ${ }^{41}$ ).

Na próxima seção, é apresentado um resumo dos principais trabalhos encontrados na literatura sobre a extração de termos nas línguas inglesa e espanhola.

\subsection{Ideia Geral da Extração de Termos para o Inglês e o Espanhol}

Nesta seção, é apresentada uma visão geral da extração de termos realizada a partir de documentos nas línguas inglesa e espanhola. Para isso, os principais trabalhos encontrados na literatura são descritos a seguir, desconsiderando os diferentes cenários adotados por essas pesquisas, como a variação dos corpora de teste e medidas de avaliação dos resultados.

Para o inglês, Zhang et al. (2008) propuseram um medida (chamada pelos autores de "esquema de votação") que, com base nas medidas $t f$-idf, weirdness, c-value e termex, calcula o valor de cada candidato a termo. Eles alcançaram precisão ${ }^{42}$ de $97 \%$ na extração de termos simples e complexos juntos pertencentes ao domínio de medicina ao considerar os 100 primeiros candidatos mais bem ranqueados.

Knoth et al. (2009) calcularam valores para candidatos a termos utilizando medidas estatísticas ( $t f, t f-i d f$, ridf e $l l$ ), medidas híbridas (c-value e weirdness) e método híbrido (glossEx), bem como a soma dos valores de algumas dessas medidas. Uma das considerações de weirdness e glossEx é, respectivamente, a distribuição e a probabilidade dos candidatos em um corpus de língua geral. Diante disso, os autores também avaliaram o impacto causado por utilizar corpora de língua geral de dois diferentes tamanhos. Foram calculadas a precisão ${ }^{42}$ da extração de termos complexos a partir de um corpus inglês do domínio biomédico considerando os 20, 200 e 2000 candidatos mais bem ranqueados de acordo com os valores calculados. Atingiu-se $100 \%$ de precisão quando considerados os 20 candidatos mais bem ranqueados.

Zhang et al. (2010) utilizaram informação sintática dos candidatos a termos ${ }^{43}$ para que um algoritmo identifique quais desses são termos de um corpus do domínio biomédico na língua inglesa. Esse algoritmo constrói um grafo não direcionado a partir dos candidatos e suas informações sintáticas. Exemplos dessas informações são: se os candidatos pertencem à padrões morfossintáticos pré-definidos e se estes são candidatos simples ou fazem parte de candidatos complexos. Segundo os autores, a média de precisão alcançada na extração foi $90,10 \%$, de cobertura foi $59,80 \%$ e de medida $\mathrm{F}$ foi $71,12 \%$.

\footnotetext{
${ }^{39} \mathrm{IST}-\mathrm{UTL}$ - www . ist .utl . pt/

${ }^{40} \mathrm{UC}-\mathrm{www} \cdot \mathrm{uc} \cdot \mathrm{pt} /$

${ }^{41}$ PUC-Rio - http: //www.puc-rio.br/

${ }^{42}$ Nos artigos de Zhang et al. (2008) e Knoth et al. (2009) não estão disponíveis os valores de cobertura e medida $F$.

${ }^{43}$ Não está claro se Zhang et al. (2010) extraíram termos simples ou complexos.
} 
Nazar (2011) treinou um algoritmo para identificar termos simples e complexos juntos pertencentes ao domínio médico na língua inglesa. Para isso, o autor utilizou a frequência relativa dos elementos léxicos ( $r f$ das palavras), morfológicos ( $r f$ das 3 , 4 e 5 primeiras e últimas letras das palavras e de seus lemas) e sintáticos ( $r f$ dos padrões sintáticos). Todas essas frequências foram calculadas tanto para as palavras de um corpus de língua geral como para as de um corpus de medicina, no qual se pretende extrair os termos. Em seguida, o autor calculou valores para os candidatos utilizando essas frequências e removeu àqueles cujos valores estão abaixo de um threshold definido manualmente. Foram calculadas precisões $(\mathrm{P})$ e coberturas $(\mathrm{C})$ da extração dos candidatos não removidos por esses thresholds, sendo que o melhor balanço entre elas foi $\mathrm{P}=75 \%$ e $\mathrm{C}=80 \%$. Considerando esses dados, é possível calcular a medida $\mathrm{F}$ da extração, que foi $77,42 \%$.

Para o espanhol, Vivaldi et al. (2001) usaram um algoritmo de votação para avaliar diferentes formas de se extrair termos utilizando conhecimento linguístico, desde morfemas greco-latinos até conhecimento semântico obtido da WordNet, e medidas estatísticas, como logaritmo da razão de máxima verossimilhança e informação mútua. Um dos resultados da extração de termos simples e complexos a partir de um corpus do domínio de medicina foi a precisão de $99,10 \%$ e cobertura de $32 \%$. Considerando esses valores, é possível calcular a medida $\mathrm{F}$ da extração, que foi $48,38 \%$.

O extrator híbrido YATE (Vivaldi e Rodríguez, 2007) atribui um valor para cada candidato a termo que é calculado pelo uso de conhecimento linguístico variado, como o morfológico, sintático e semântico, juntamente com medidas estatísticas. A obtenção do conhecimento semântico, em especial, advém da consulta a recursos externos, como dicionários especializados (em formato digital) e bases de dados lexicais de língua geral que armazenam certo conhecimento terminológico. A extração de termos simples e complexos realizada pelo YATE, a partir de corpora em espanhol do domínio médico, atingiu precisão de $98,03 \%$ e cobertura de $51,90 \%$. Considerando esses valores, é possível calcular a medida F da extração, que foi $67,93 \%$.

Ainda para a língua espanhola, Gelbukh et al. (2010) propuseram uma medida que calcula a distância baseada na logaritmo da razão de máxima verossimilhança entre as palavras do domínio de computação e as de um corpus de língua geral. Os autores removeram (aparentemente de maneira manual) os 31 verbos contidos dentre os 270 primeiros unigramas mais bem ranqueadas de acordo com essa medida. O 239 unigramas restantes foram considerados como candidatos a termos extraídos. Em seguida, 19 candidatos que claramente não são termos (p.ex.: "sofware" que deveria ser "software") foram considerados como ruído da extração. Considerando isso, a precisão da extração ${ }^{44}$ foi calculada assim: (239-19)/239 = 92,05\%. Os autores também agruparam esses candidatos em 19 classes com o uso do algoritmo $k$-means. Esse agrupamento teve como objetivo visualizar os candidatos extraídos.

As principais diferenças entre os trabalhos apresentados nesta seção e a pesquisa descrita nesta tese são elencadas a seguir. Um diferença é que a pesquisa desta tese extrai termos simples da língua portuguesa do Brasil. Outra diferença é o não uso de conhecimento morfológico e semântico como adotado por Vivaldi et al. (2001) e Vivaldi e Rodríguez (2007). Um exemplo de conhecimento semântico seria a WordNet, porém o português dispõe somente da WordNet de verbos (Bento Carlos Dias-da-Silva e Nunes, 2008). Um exemplo de conhecimento morfológico é considerar a identificação de candidatos a termos com base em prefixos ou sufixos comuns em domínios específicos. Outra diferença é que na extração de termos realizada nesta pesquisa não é necessário definir manual ou semiautomaticamente os valores ideais usados pelas medidas durante a extração de termos

\footnotetext{
${ }^{44}$ Não estão disponíveis os valores de cobertura e medida F da extração realizada por Gelbukh et al. (2010).
} 
para escolher os melhores candidatos a termos. Por exemplo, considerar somente os candidatos cujos valores estão acima de um threshold definido manualmente (Nazar, 2011) ou considerar um número fixo de candidatos mais bem ranqueados por alguma medida (Zhang et al., 2008; Knoth et al., 2009; Gelbukh et al., 2010). Já a diferença do trabalho de Zhang et al. (2010) é que esta pesquisa utiliza diferentes técnicas de aprendizado de máquina juntamente um conjunto de características dos candidatos a termos pertencentes a diferentes níveis de conhecimento (linguístico, estatístico e híbrido).

Na próxima seção, tece-se uma discussão à respeito do estado da arte sobre a extração de termos, a qual abrange também o desempenho dos extratores e um mapeamento geográfico de todos os trabalhos direta e indiretamente relacionadas à extração no $\mathrm{PB}$.

\subsection{Discussão sobre o Estado da Arte da Extração de Candidatos a Termos na Língua Portuguesa do Brasil}

Conforme observado na Figura 3.3 da Seção 3.5, página 38, 77\% dos trabalhos apresentados utilizaram somente a abordagem estatística ou a combinaram com algum informação linguística não muito sofisticada, como sintagma nominal e padrão morfossintático. Até o momento, foram encontrados somente dois trabalhos que utilizaram conhecimento linguístico do nível da semântica, Lopes et al. (2009b) e a dissertação de Ribeiro Junior (2008) publicada em Ribeiro Junior e Vieira (2008). Não foi encontrado nenhum trabalho utilizando conhecimento do nível pragmático. O maior uso de conhecimento estatístico em relação ao linguístico é devido a falta de recursos eficientes e avançados de PLN para o processamento da língua portuguesa. A tarefa de extração de termos em línguas como inglês e espanhol faz mais uso de recursos avançados, como WordNet, ontologias de domínios específicos e diferentes parsers e recursos de desambiguação. Alguns dos recursos para língua portuguesa estão disponíveis no portal de ontologias (OntoLP) e na Linguateca.

Dentre os 22 trabalhos relacionados com a extração de termos na língua portuguesa que foram descritos nas Subseções 3.5.1 (página 38) e 3.5.2 (página 42), ressalta-se que o trabalho de Teline et al. (2003) alcançou um maior valor de medida $\mathrm{F}$ para termos unigramas, 26\%, no domínio de revestimento cerâmico, e o trabalho de Lopes (2012) conseguiu maiores valores de medida $\mathrm{F}$ para termos bigramas, $81 \%$, e para trigramas, $84 \%$, ambos no domínio de pediatria. Deve-se salientar que essa comparação foi realizada desconsiderando as diferenças existentes entre cada trabalho como, por exemplo, o uso de diferentes corpora e a avaliação realizada somente utilizando parte da lista de candidatos a termos. A comparação realizada teve o objetivo de fornecer uma visão geral dos resultados dos trabalhos. Claramente, para afirmar quais métodos de extração utilizados pelos autores são melhores ou piores, deve-se realizar uma comparação de todos os trabalhos utilizando o mesmo cenário, ou seja, mesmos corpora e mesmas medidas e condições de avaliação. Essa comparação com o mesmo cenário é uma lacuna existente na língua portuguesa, que dificulta a escolha de algum método como baseline. Essa lacuna é abordada na pesquisa apresentada nesta tese (Seção 4.1 do Capítulo 4, página 55).

Adicionalmente, é possível realizar observações relacionadas aos corpora descritos na Seção 3.4, página 34, quando se consideram os trabalhos que apresentaram valores obtidos pela medida $\mathrm{F}$ ou que possibilitaram os seus cálculos.

A primeira observação é que esses trabalhos utilizaram somente um corpus para avaliar seus resultados, sendo que na língua portuguesa foram encontrados 5 corpora que poderiam ser utilizados por possuírem listas de termos de referências (ver Tabela 3.2, página 35). Além disso, esses trabalhos, como um todo, concentram-se somente em três domínios: revestimento cerâmico, ecologia e pediatria. 
A segunda observação é que 95\% desses 22 trabalhos (Subseções 3.5.1 e 3.5.2) realizaram extração de termos bigramas e trigramas, mas somente $64 \%$ deles extraíram também (ou somente) os termos simples. Conclui-se que para o português, a extração de termos limita-se em termos simples, bigramas e trigramas, já que geralmente são os termos mais comuns nos documentos e os que estão presentes nas listas de termos de referências.

A terceira observação é referente ao conhecimento utilizado por cada um desses trabalhos. A frequência é a medida mais utilizada para obtenção de conhecimento estatístico, sendo que $45 \%$ dos 22 trabalhos a aplicaram para extrair termos simples, $38 \%$ para termos bigramas e $47 \%$ para trigramas. As outras medidas mais utilizadas foram: para termos unigramas, $24 \%$ usaram a medida $d f$, para bigramas, $30 \%$ usaram $m i$ e logaritmo da razão de máxima verossimilhança, e para trigramas $35 \%$ aplicaram logaritmo da razão de máxima verossimilhança. Com relação à obtenção do conhecimento linguístico, a informação sobre padrão morfossintático é a mais utilizada, estando presente em $45 \%$ dos trabalhos que extraíram termos unigramas e em $28 \%$ dos que extraíram bigramas e trigramas. As expressões indicativas foram utilizadas em $19 \%$ dos trabalhos e os sintagmas nominais foram considerados em $9 \%$ dos trabalhos que extraíram termos unigramas e em $23 \%$ dos que extraíram bigramas e trigramas. Por fim, a medida c-value foi utilizada em $19 \%$ dos trabalhos para a obtenção de conhecimento híbrido (estatístico e linguístico).

Observa-se uma lacuna considerável com relação ao uso de recursos híbridos, além da falta do uso de WordNets e Wikipédia para auxiliar a extração, sendo que esses recursos já são utilizados em línguas como espanhol, francês e inglês. Outra lacuna existente, também presente nas línguas citadas, é a avaliação dos termos. O problema relacionado à avaliação é que a lista de termos de referência que se utiliza é construída de maneira subjetiva e, consequentemente, essa subjetividade continuará na avaliação.

Analisando os recursos utilizados nos trabalhos, observa-se uma tendência nos trabalhos atuais em considerar conhecimentos provindos de domínio, seja do próprio domínio no qual se está realizando a extração de termos, que é o caso da "stoplist de domínio", seja de domínios contrastantes ao utilizado na extração, que é caso das medidas $t d s, t f-d c f$, TF-IDF e thd.

Na Figura 3.4, é mostrado um mapeamento dos trabalhos, projetos e corpora relacionados com a extração de termos na língua portuguesa do Brasil. Para tal mapeamento, considerou-se somente o estado onde o primeiro autor estava vinculado.

Considerando os trabalhos encontrados na literatura durante essa revisão da área de extração (semi)automática de termos, nessa figura, observa-se que e a maioria dos trabalhos, projetos e corpora citados concentra-se nos estados de São Paulo e Rio Grande do Sul. Foram encontrados dois projetos e um corpus criados por pesquisadores do estado de Santa Catarina. É importante comentar que esse fato não indica que nos outros estados do Brasil não haja trabalhos relacionados com a extração de termos, pois podem haver trabalhos ainda não publicados em conferências ou revistas ou também os autores de pesquisas dos demais estados podem ter parcerias de pesquisa com os autores citados.

\subsection{Considerações Finais}

Neste capítulo, foi apresentada uma revisão atual do estado da arte da extração de termos voltada à língua portuguesa. Há cinco características principais que foram observadas com essa revisão do estado da arte.

A primeira característica é a diversidade em que a atividade de extração de termos se insere. Observou-se que a extração é de grande importância para tarefas de diferentes áreas. Quando se realiza a extração de termos, tem-se normalmente um objetivo específico, 


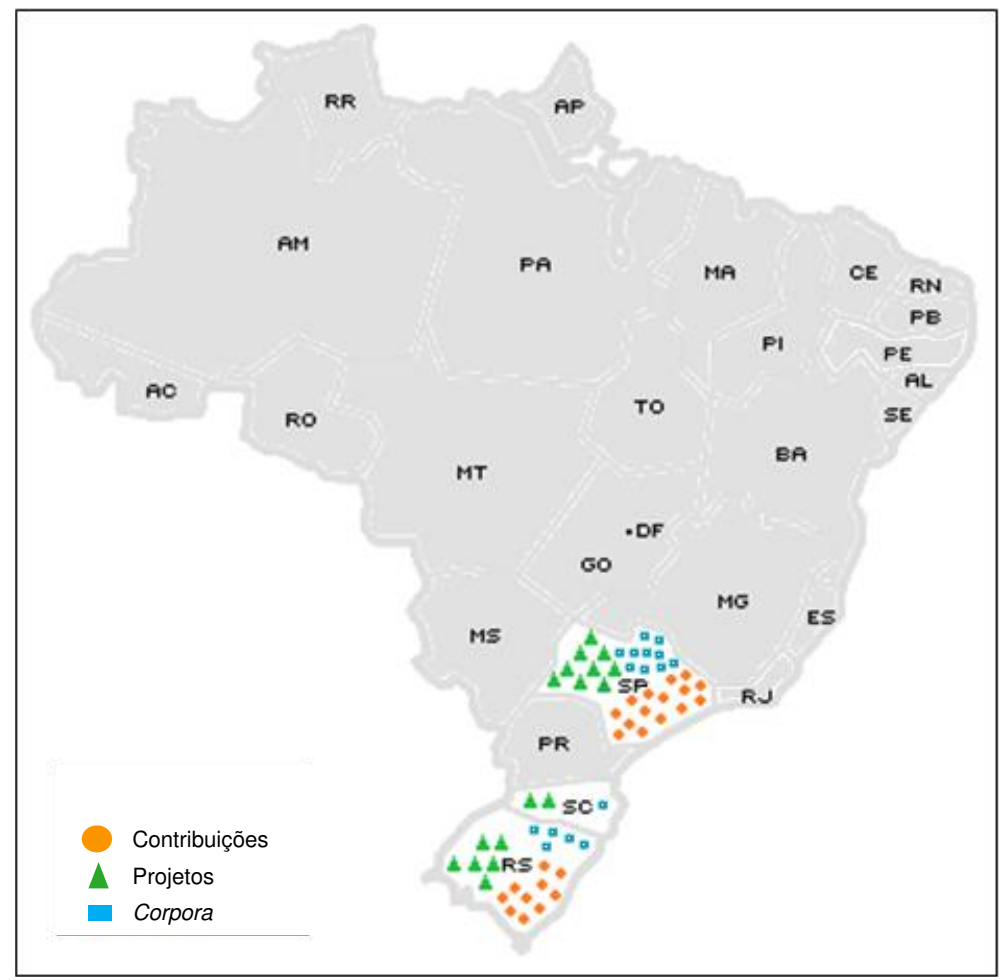

Figura 3.4: Mapeamento dos trabalhos, projetos e corpora relacionados à extração de termos na língua portuguesa do Brasil.

como a construção de taxonomias e ontologias, a elaboração de dicionários, a tradução, a organização e a recuperação de dados textuais.

A diversidade em que a tarefa de extração de termos se encontra pode ser observada pelo fato de que há trabalhos que não realizam diretamente a extração de termos, porém utilizam os termos para alcançar seus objetivos finais. Um exemplo é o trabalho de Tagnin (2007), que utilizou os termos para demonstrar como a área de Linguística de Corpus pode auxiliar o tradutor a encontrar equivalentes para termos técnicos em diversas áreas. Como esse trabalho não realizou a extração de termos e sim fez uso dos termos, o mesmo não foi considerado como um trabalho especificamente de extração de termos. Porém, há trabalhos que realizaram a extração de termos para alcançar objetivos específicos, por exemplo o agrupamento de textos (Ribeiro et al., 2008), classificação textual (Santos, 2005; Conrado et al., 2012), além de diferentes projetos, descritos na Subseção 3.5.3, página 43.

A segunda característica concentra-se na maneira pela qual os trabalhos citados extraíram termos e como esses trabalhos foram organizados de acordo com o conhecimento utilizado para extrair os termos. Deve-se considerar aqui o trabalho de Lima et al. (2007), no qual foi ressaltado que até o ano de 2007 as abordagens híbridas geralmente trabalhavam mais com os níveis lexical, morfossintático e sintático quando se tratava da língua portuguesa do Brasil. Para línguas cujas pesquisas nessa área estavam mais desenvolvidas, como o inglês, encontram-se alguns trabalhos utilizando o nível sintático e semântico. Em geral, há uma indicação de carência de pesquisas mais profundas nessas áreas, principalmente na língua portuguesa. No entanto, até a data atual, não foi encontrado na literatura uma organização e um mapeamento dos trabalhos na língua portuguesa, bem como uma síntese de todos os trabalhos. Diante desse fato, na pesquisa apresentada nesta tese, os trabalhos de extração para o português do Brasil, os corpora disponíveis para realizar tal tarefa e os projetos relacionados com a extração foram identificados, descritos e mapeados. 
Ainda em relação às abordagens adotadas para a extração, o uso de métodos estatísticos para realizá-la agrega uma grande vantagem no método de extração que é a independência da língua trabalhada. Entretanto, quando os especialistas extraem termos de determinado domínio, (sub)conscientemente utilizam seu conhecimento do domínio e de linguística para indicar as palavras ou colocações que realmente são termos. Essa última é a explicação para o fato de que o uso de conhecimento linguístico aumenta a qualidade da extração. Portanto, o melhor caminho é utilizar métodos estatísticos junto com linguísticos, tendo assim um método híbrido.

A terceira característica observada é referente aos avanços alcançados na tarefa de extração de termos. Ao analisar os trabalhos voltados para a língua portuguesa do Brasil, nota-se uma divisão dos mesmos com relação aos recursos que utilizam. Normalmente, eles utilizam métodos que contêm dois níveis linguísticos de conhecimento: morfológico e sintático, sendo que alguns poucos trabalhos fazem uso somente do nível da morfologia ou recursos puramente estatísticos. Com isso, conclui-se que, para o português, ainda faltam avanços com relação aos demais níveis linguísticos de conhecimento. Esse futuro avanço permitirá a melhoria da qualidade dos termos extraídos. Além disso, observa-se um avanço recente em corpora que possuem listas de termos de referências, o que também auxilia tal melhoria.

A quarta característica é a existência de uma tendência nos trabalhos atuais em considerar conhecimentos provindos de domínio, seja do próprio domínio no qual se está realizando a extração de termos, que é o caso da "stoplist de domínio", seja de domínios contrastantes ao utilizado na extração, que é caso das medidas $t d s, t f-d c f$, TF-IDF e thd.

Como quinta característica, observou-se a ausência de uma comparação prática dos trabalhos existentes para a extração voltados à língua portuguesa. Considerando isso, na pesquisa apresentada nesta tese, as medidas e os métodos estatísticos e híbridos, bem como as formas de obtenção de conhecimento linguístico descritos neste capítulo e que podem ser aplicadas à extração de termos simples, que é o foco desta tese, são avaliadas frente a um mesmo cenário, ou seja, utilizando os mesmos corpora, a mesma maneira de pré-processar os textos desses corpora e a mesma forma de avaliar os resultados. Essa avaliação é descrita na Seção 4.1 do Capítulo 4, página 55.

Finalmente, com esta revisão, os interessados na sistematização de terminologias por meio da extração (semi)automática de termos podem encontrar uma descrição detalhada dos principais paradigmas de extração (estatístico, linguístico e híbrido) e seus recursos/ferramentas linguístico-computacionais, dos tipos de conhecimento (estatísticos e linguísticos) que podem ser utilizados na extração (semi)automática de termos, além de uma organização e um mapeamento dos principais trabalhos, métodos e projetos relacionados ao português do Brasil. 



\section{MATE-ML: um Método para Extração Automática de Termos Baseado em Aprendizado de Máquina}

$\mathcal{A}$

extração de termos tem sido investigada por mais de 20 anos devido a sua importância tanto na área de linguística como na de computação. Apesar disso, ainda há desafios a serem enfrentados. Na Seção 3.1 do Capítulo 3, página 17, foram discutidos os desafios da extração de termos devidos às características das unidades terminológicas. Neste capítulo, são apresentados os desafios da EAT em relação ao elevado número de candidatos a termos presente na extração de termos e a escolha manual ou semiautomática para identificar os candidatos a termos durante o processo de extração. Esses desafios são as motivações para a proposta do MATE-ML, um método para extração automática de termos descrito nas Seções 4.1 e 4.2. Na Seção 4.3, é detalhado o método para avaliação utilizado na análise dos candidatos a termos extraídos pelo método MATE-ML. Por fim, as considerações finais deste capítulo são apresentadas na Seção 4.4.

\subsection{Motivações para a Proposta do Método MATE-ML para Ex- tração Automática de Termos}

O foco da pesquisa apresentada nesta tese é: redução do elevado número de candidatos a termos presente na extração de termos e automatização da identificação dos candidatos a termos durante o processo de extração.

Trabalhar com um número reduzido dos candidatos é essencial em função da complexidade de tempo e de recursos computacionais durante a EAT. Essa redução também afeta a validação dos candidatos extraídos em aplicações reais, em especial, aquelas que não se têm listas de termos de referências para realizar a validação dos candidatos, que, nesse caso, é realizada de maneira manual, o que demanda um enorme esforço humano. Para tanto, o método MATE-ML faz uso de filtros visando reduzir o número de candidatos a termos.

Normalmente os métodos de extração de termos selecionam candidatos a termos com base em algum conhecimento linguístico (Pazienza et al., 2005). Depois disso, eles aplicam 
a esses candidatos medidas ou combinação de medidas (e/ou heurísticas) para gerar um ranking com tais candidatos (Frantzi et al., 1998; Kozakov et al., 2004b; Kit e Liu, 2008; Vivaldi et al., 2012). Quanto mais ao topo desse ranking os candidatos estão, maior a chance de que eles sejam termos. Então, especialistas do domínio e/ou terminólogos analisam manual ou semiautomaticamente o ranking para escolher um limiar no qual os candidatos que têm valores acima dele são considerados termos. Essa análise é subjetiva porque depende da interpretação pessoal do humano e conhecimento do domínio, além de requerer tempo para ser realizada. Essa forma de extração é denominada nesta tese de "extração tradicional de termos".

Para demonstrar empiricamente o quão difícil é escolher os candidatos do ranking que devem ser considerados termos, nesta seção, é apresentada uma comparação de diferentes medidas, métodos e formas de obtenção de conhecimento que podem ser utilizados para a extração de termos. Nessa comparação, duas questões principais são abordadas.

\section{Primeira questão: como saber quais candidatos do ranking devem ser con- siderados termos?}

Teoricamente, os candidatos que têm um valor mínimo, limiar, no ranking devem ser considerados como possíveis termos de um domínio específico. Esse limiar define um ponto de corte a ser seguido. A decisão de qual limiar deve ser adotado pode ser feita (i) manualmente por um especialista do domínio e/ou terminólogo que analisa o ranking e decide até qual posição deverá ser considerada, ou (ii) de maneira semi-automática por um especialista do domínio e/ou terminólogo que escolhe um número fixo ou percentual de candidatos a ser considerado. A escolha do limiar feita manualmente não é a melhor opção uma vez que demanda alto custo humano. Já a escolha do limiar feita de maneira semi-automática, mesmo não sendo ótima, requer menos a presença do humano.

Dentre os métodos semi-automáticos que podem ser utilizados, destacam-se o método de Luhn (Luhn, 1958) e LuhnDF (Nogueira, 2009) que plotam histogramas a partir de candidatos a termos baseados, respectivamente, em suas frequências $(t f)$ e frequências nos documentos $(d f)$. Tais histogramas facilitam a visualização de algum padrão que os candidatos possam seguir, auxiliando, portanto, na determinação do limiar a ser considerado. Também há o método de Salton (Salton et al., 1975) que sugere considerar candidatos que apresentam $d f$ entre 1 e $10 \%$ do total de documentos do corpus. Ainda na linha semiautomática, pode-se citar a abordagem TRUCKS (Maynard e Ananiadou, 2000), na qual um de seus passos para extrair termos é considerar somente os $30 \%$ primeiros candidatos mais bem ranqueados de acordo com a medida nc-value (Frantzi et al., 1998). Também há trabalhos que consideram diferentes valores absolutos de candidatos (Frantzi et al., 1998; Pantel e Lin, 2001; Zavaglia et al., 2007; Lopes e Vieira, 2013a); outros trabalhos mostram diferentes combinações de seus resultados (precisão e cobertura, normalmente) (Vivaldi e Rodríguez, 2007; Vivaldi et al., 2012).

Segunda questão: qual é a melhor medida, método ou forma de obtenção de conhecimento para criar o ranking de candidatos a termos?

$\mathrm{Na}$ maneira semi-automática para se escolher um limiar do ranking, os candidatos a termos são ordenados de acordo com o valor obtido para cada candidato a partir da aplicação de medidas estatísticas, como a frequência do candidato no corpus, ou medidas/métodos híbridos, que, por exemplo, verificam a distribuição (medida weirdness) ou a probabilidade de ocorrência (método glossEx) do candidato no corpus de domínio e em um corpus de língua geral. Outra opção é utilizar conhecimento linguístico para considerar, por exemplo, somente candidatos que são sintagmas nominais ou substantivos.

Dentre os trabalhos descritos na Seção 3.5 (página 37) e Seção 3.6 (página 48) do Capítulo 3, é possível perceber que alguns deles abordam essas duas questões citadas anteriormente. Knoth et al. (2009) avaliaram as seguintes medidas: $t f$, tf-idf, ridf, weirdness, 
logaritmo da razão de máxima verossimilhança e c-value, bem como o método glossEx para a extração de termos complexos. Por outro lado, Zhang et al. (2008) avaliaram as medidas $t f$-idf, weirdness, c-value e os métodos glossEx e Termex para a extração de termos simples e termos complexos juntos. Ambos utilizaram dois corpora em inglês e pontos de corte absolutos. Lopes e Vieira (2012) compararam as medidas $t f$, $t f-i d f$, $t d s$, $t h d, t f-i d f$ e $t f$ - $d c f$ e Lopes e Vieira (2013a) avaliaram diferentes pontos de corte para o ranking de candidatos construído a partir da medida $t f$ - $d c f$. Em ambos trabalhos foram extraídos termos complexos a partir de 1 corpus em português.

É importante notar que os trabalhos encontrados na literatura utilizaram diferentes maneiras para escolha do limiar no ranking de candidatos a termos, porém o foco desses trabalhos não são termos simples a partir de corpora em português, que é o foco desta tese. Adicionalmente, até o momento, não foi encontrada na literatura uma maneira totalmente automática para saber quais termos do ranking devem ser selecionados, ou seja, para definição automática do limiar (ou ponto de corte).

Considerando as lacunas apresentadas anteriormente, foi realizada uma avaliação experimental para identificação dos métodos, medidas e formas de obtenção de conhecimento visando criar o ranking dos candidatos a termos e saber se há algum padrão a ser seguido para escolha dos candidatos desses rankings. Para facilitar a leitura deste texto, os métodos, medidas e formas de obtenção de conhecimento utilizados são aqui denominados de "características", uma vez que têm o objetivo de identificar características distintas em termos em relação a não-termos.

Para atingir o objetivo dessa avaliação experimental, as principais características encontradas na literatura que podem ser aplicadas à extração de termos simples para o português foram implementadas e avaliadas em um mesmo cenário, isto é, utilizando os mesmos corpora, o mesmo pré-processamento dos textos e a mesma forma de avaliação de resultados. Essas características são apresentadas na Tabela 4.1.

Foram implementadas dez medidas estatísticas para extração de termos simples. Quatro dessas medidas são parte da contribuição desta pesquisa, pois essas medidas foram adaptadas de outras áreas para serem usadas na EAT. Elas são: três medidas usualmente aplicadas para seleção de características ${ }^{1}$ ( $t v$, $t v q$ e $t c$ ), identificadas pelo símbolo * na Tabela 4.1 e detalhadas na Subseção 3.2.1 do Capítulo 3, página 24, e uma medida estatística (comGram) que conta o número de caracteres do $n$-grama e normalmente usada na tarefa de reconhecimento de entidades nomeadas, identificada pelo símbolo ${ }^{* *}$ na tabela. As medidas $t v, t v q$ e $t c$ foram avaliadas aqui pois obtiveram resultados satisfatórios na tarefa de seleção de características (Nogueira, 2009). Já a medida comGram foi utilizada nesta pesquisa porque termos de um domínio específico podem ter tamanhos (em caracteres) diferentes de palavras da língua geral ou de termos de outro domínio. Por exemplo, o maior termo do domínio de ecologia (territorialidade) contém 16 caracteres e é seguido dos termos protocooperação e reflorestamento com 15 caracteres. Já no domínio de nanociência e nanotecnologia, o maior termo (hidroxipropilmetilcelulose) contém 26 caracteres, seguido do termo aminopropiltrietoxisilano com 25 caracteres e do termo micro-fotoluminescência com 23 caracteres.

As medidas estatísticas $t f, r f$, atf ${ }^{2}, r i d f^{2}$, $d f$ e $t f-i d f$ foram apresentadas na Subseção 3.2.1, página 24. As medidas $t f$, $r f$, atf, ridf e $t f-i d f$ foram utilizadas nesta avaliação experimental com o objetivo de que elas possam ajudar na identificação dos termos frequentes do domínio, uma vez essas medidas consideram a frequência dos candidatos em relação ao corpus. Já a $d f$ foi avaliada pois contabiliza os documentos do corpus nos quais os candidatos aparecem. O uso da $d f$ visou identificar os candidatos que representam o

\footnotetext{
${ }^{1}$ Em aprendizado de máquina, a seleção de características também é chamada de seleção de atributos.

${ }^{2}$ Foi utilizada a implementação disponível em https://code.google.com/p/jatetoolkit/
} 
Tabela 4.1: Medidas, métodos e formas de obtenção de conhecimento utilizados na extração tradicional de termos.

\begin{tabular}{|c|c|}
\hline Sigla & Caracteristica \\
\hline \multicolumn{2}{|r|}{ Medidas Estatísticas } \\
\hline 1. $\operatorname{comGram}^{* *}$ & comprimento do $n$-grama \\
\hline 2. $t f$ & frequência de termo \\
\hline 3. $r f$ & frequência relativa de termo \\
\hline 4. atf & frequência média de termo \\
\hline 5. ridf & frequência residual inversa de documento (Church, 1995) \\
\hline 6. $d f$ & frequência de documentos \\
\hline 7. $t f-i d f$ & frequência de termo - frequência inversa de documento (Salton e Buckley, 1987) \\
\hline 8. $t v^{*}$ & variância do termo (Liu et al., 2005) \\
\hline 9. $t v q^{*}$ & qualidade da variância do termo (Dhillon et al., 2003) \\
\hline 10. $t c^{*}$ & contribuição do termo (Liu et al., 2003) \\
\hline \multicolumn{2}{|r|}{ Medidas/Métodos Híbridos } \\
\hline 1. freq_cg & frequência do termo em um corpus de língua geral \\
\hline 2. weirdness & $\begin{array}{l}\text { distribuição do candidato no corpus de domínio e } \\
\text { em um corpus de língua geral (Ahmad et al., 1999) }\end{array}$ \\
\hline 3. thd & $\begin{array}{l}\text { índice termhood: frequência ponderada do termo no corpus de domínio e } \\
\text { em um corpus de língua geral (Kit e Liu, 2008) }\end{array}$ \\
\hline 4. $t d s$ & índice de especificidade de domínio (Park et al., 2008) \\
\hline 5. glossEx & $\begin{array}{l}\text { probabilidade de ocorrência do candidato no corpus de domínio } \\
\text { e em um corpus de língua geral (Kozakov et al., 2004b) }\end{array}$ \\
\hline 6. c-value & frequência e tamanho em gramas do candidato (Frantzi et al., 1998) \\
\hline 7. nc-value & contexto no qual o candidato aparece (Frantzi et al., 1998) \\
\hline \multicolumn{2}{|r|}{ Formas de Obtenção de Conhecimento Linguístico } \\
\hline 1. sintagma & sintagma nominal \\
\hline 2. núcleo_sintagma & núcleo do sintagma nominal (Estopa et al., 2005) \\
\hline 3. $p m$ & classe gramatical \\
\hline 4. $e i$ & expressão indicativa \\
\hline
\end{tabular}

domínio do corpus ao assumir que esses aparecem em pelo menos uma quantidade mínima dos documentos. Dentre as medidas descritas na Subseção 3.2.1, a medida estatística zstf não foi considerada nesse experimento, uma vez que ela necessita de marcações de seções (resumo, introdução, etc.) e os textos utilizados nesse experimento não as contêm.

Assim como pode haver termos frequentes no corpus, pode também haver termos raros ou que têm a mesma frequência de não-termos. As medidas estatísticas não são capazes de identificar essas diferenças. Por essa razão, foram também avaliadas quatro formas de obtenção de conhecimento linguístico, usadas tradicionalmente na EAT (sintagma, núcleo_sintagma, pm e ei). Assumindo que a maioria dos termos segue algum padrão (por exemplo, ser unidade nominal), a extração de termos que considera somente os candidatos que fazem parte de sintagmas nominais (característica sintagma) foi avaliada, bem como a que assume que os substantivos são termos (característica $p m$ ). Também foi avaliada a extração na qual foram considerados somente os candidatos que são núcleos de sintagmas nominais (núcleo_sintagma), uma vez que eles representam o núcleo significativo dos termos, conforme discutido por Estopa et al. (2005) e utilizado por Ribeiro Junior (2008); Ribeiro Junior e Vieira (2008). Por exemplo, no sintagma nominal "Os autótrofos terrestres", pertencente a um texto do corpus de ecologia, o especialista do domínio considerou como termo somente o núcleo desse sintagma, "autótrofos". Assume-se também que os candidatos definidos ou descritos no decorrer dos textos do corpus são considerados importantes pelo autor desses textos. Por essa razão, tais candidatos têm chance de serem termos. Por exemplo, em "A segunda possibilidade de coalescência é descrita por...", o termo "coalescência" do domínio de nanociência e nanotecnologia aparece perto da expressão indicativa "é descrita por". Por essa razão, avaliou-se a extração de termos feita com os candidatos que estão perto de alguma expressão indicativa (característica ei).

Ao considerar somente medidas estatísticas, não é possível identificar termos com, 
por exemplo, frequências similares aos não-termos. Da mesma maneira que considerar somente as medidas linguísticas, os termos que seguem os mesmos padrões linguísticos dos não-termos não são identificados. A avaliação dos candidatos considerando tanto o nível estatístico como o linguístico otimiza a identificação de termos. Por exemplo, o verbo propor pode ser bastante frequente em textos técnicos de um domínio específico, mas se assumir que um termo deve seguir tanto um padrão linguístico (p.ex., ser substantivo) como um estatístico (p.ex., ser frequente no corpus), esse verbo, mesmo que frequente, será corretamente identificado como não-termo. É por essa razão que, nesta pesquisa, também foram avaliadas seis medidas híbridas e um método híbrido encontrados na literatura. As medidas híbridas weirdness ${ }^{2}$, thd, tds, c-value e nc-value e o método híbrido glossEx ${ }^{2}$ são descritos na Seção 3.2 do Capítulo 3, página 21. Também foi considerada a frequência do candidato em um corpus de língua geral, denominada freq_cg. A medida freq_cg facilita a identificação dos termos com base em um corpus de língua geral. Para isso, assume-se que candidatos com frequências muito altas no corpus de língua geral não são termos e os que têm frequências muito baixas ou que não aparecem nesse corpus são termos.

As medidas híbridas TF-IDF e tf-dcf (descritas na Subseção 3.2.1) originalmente utilizam um conjunto de corpora contrastantes e por essa razão não foram consideradas nesta avaliação experimental, uma vez que se optou por utilizar as medidas que necessitam somente de um corpus, além do corpus do domínio no qual se pretende extrair os termos. Entretanto, como trabalho futuro, pode-se avaliá-las utilizando somente um corpus contrastante.

Ressalta-se que foi considerada a adaptação da medida c-value (Barrón-Cedeño et al., 2009), uma vez que esta pode ser aplicada a unigramas. Já para o cálculo das características freq_cg, $t d s$, thd, glossEx e weirdness foi utilizado o corpus de língua geral do NILC (ver Seção 3.4, página 34) por conter 40 milhões de palavras de língua geral para que o experimento não seja influenciado pela escolha de diferentes corpora contrastantes. Por fim, a característica $e i$ indica se o candidato aparece perto de alguma expressão indicativa ${ }^{3}$.

Para os experimentos, foram considerados três corpora no português do Brasil pertencentes a diferentes domínios. Tais corpora são apresentados na Tabela 4.2 e foram detalhados na Seção 3.4, página 34. O pré-processamento dos textos desses corpora consistiu em anotar linguisticamente os textos utilizando o parser Palavras ${ }^{4}$ (Bick, 2000); eliminar os caracteres especiais dos textos; normalizar as palavras dos textos usando a técnica de radicalização; e remover stopwords em inglês e português. O pré-processamento é detalhado na Seção 5.4 do Capítulo 5, página 93.

Tabela 4.2: Corpora utilizados nos experimentos

\begin{tabular}{c|c|c|c}
\hline Nomes & \# textos & \# palavras & Domínios \\
\hline ECO & 390 & 260.921 & Ecologia \\
\hline Corpus.EaD (EaD) & 347 & 1.350 .683 & Educação à distância \\
\hline Nanociência e Nanotecnologia (Nano) & 1.057 & 2.565 .490 & Nanociência e Nanotecnologia \\
\hline
\end{tabular}

A identificação dos sintagmas (característica sintagma) usados para o cálculo do $c$ value e do nc-value e para a identificação dos núcleos dos sintagmas (núcleo_sintagma) e das classes gramaticais as quais os candidatos pertencem $(\mathrm{pm})$ foram realizadas a partir dos corpora anotados pelo parser Palavras. Ao final do pré-processamento, obteve-se

\footnotetext{
${ }^{3}$ As 40 expressões indicativas utilizadas estão disponíveis em http://sites.labic.icmc.usp.br/ merleyc/ThesisData/.

${ }^{4}$ Como todas as ferramentas de PLN para domínios gerais, o Palavras não é excelente para domínios específicos. No entanto, tal parser foi adotado aqui, mesmo que haja alguns erros de anotação, uma vez que seria caro (em tempo e trabalho manual) personalizá-lo para cada domínio específico utilizado na pesquisa apresentada nesta tese.
} 
9.997, 16.013, 41.335 radicais dos candidatos para, respectivamente, os corpora ECO, EaD e Nano.

Cada unigrama pré-processado de cada corpus é considerado um candidato a termo. Para cada candidato, foram calculadas as 21 características anteriormente descritas. A extração de termos realizada utilizando cada uma dessas características foi avaliada pelo cálculo da precisão, cobertura e medida F com relação às listas de termos de referências. As listas de termos dos corpora ECO, EaD e Nano, contêm, respectivamente, um total de 322, 118 e 1794 termos simples originais que, após sua radicalização, passou para 300, $112,1.543$ radicais. Ressalta-se que, na pesquisa apresentada nesta tese, foram utilizados 118 termos simples fornecidos pelos pesquisadores que criaram o corpus ECO, sendo esses uma expansão da lista de referência original apresentada em Gianoti e Felippo (2011).

Para as características estatísticas e híbridas, as quais resultam em um valor numérico (conhecidas como atributos contínuos), os candidatos foram ranqueados em ordem decrescente a sua chance de serem termos de acordo com o valor obtido no cálculo de cada característica. Assim, aqueles que possuem valores melhores de acordo com uma determinada característica estão no topo do ranking. Logo, foram calculadas medidas de avaliação (precisão, cobertura e medida F, descritas na Seção 3.3) com relação às listas de termos de referências para pontos de corte que começam com os 50 primeiros candidatos ranqueados, depois para os 100 candidatos, para os 150, 200 e assim sucessivamente até o número total de candidatos do corpus.

Na Tabela 4.3, são apresentados os resultados ${ }^{5}$ obtidos com o uso da característica tf considerando o corpus ECO. Nessa Tabela, observa-se que os resultados mais altos de precisão $(\mathrm{P}(\%))$, cobertura $(\mathrm{C}(\%))$ e medida $\mathrm{F}(\mathrm{MF}(\%)$ alcançados pelo uso da $t f$ foram, respectivamente, $42,00 \%, 99,67 \%$ e $24,29 \%$ considerando os $50,9.950$ e 400 candidatos mais bem ranqueados (\#Cand.).

As características linguísticas utilizadas nesse experimento são discretas, resultando em um valor binário (0 ou 1). Por exemplo, se o candidato pertence a alguma classe gramatical pré-estabelecida, $p m=1$, caso contrário, $p m=0$. Para essas características discretas, foram considerados candidatos extraídos aqueles que têm valor 1 . Assim, tem-se um total fixo e único de candidatos extraídos com o qual as medidas de avaliação foram calculadas. Por exemplo, se foram identificados 5.030 sintagmas nominais no corpus, esses sintagmas são considerados os candidatos extraídos com os quais são calculadas as medidas de avaliação.

Nas Tabelas 4.4, 4.5 e 4.6, encontram-se os resultados ${ }^{5}$ mais altos de precisão, cobertura e medida $\mathrm{F}$ obtidos por cada característica utilizada considerando os diferentes limiares para o ranking de candidatos. Nessas tabelas, são apresentados, para cada característica utilizada (coluna Característica), a quantidade de candidatos considerados (preditos) como termos para cada resultado (\#Cand.), o número de termos corretamente extraídos (\#TE), os valores obtidos de precisão, cobertura e medida F. Os resultados mais altos de cada medida de avaliação estão destacados nas tabelas.

Considerando a Tabela 4.4, ao analisar os 50 primeiros candidatos ("\#Cand.") mais bem ranqueados pela característica $t f$ ("Característica"), observa-se que 21 desses candidatos ("\#TE") aparecem na lista de termos de referência do domínio. Logo, para esse caso, tem-se uma precisão de $42 \%$, cobertura ("C(\%)") de $7 \%$ e medida F ("MF(\%)") de $12 \%$.

A seguir, é apresentado um detalhamento do valor mais alto de precisão; separadamente, do valor mais alto de cobertura; e do mais alto de medida $\mathrm{F}$ porque dependendo da tarefa na qual os termos extraídos serão utilizados, será importante maximizar uma

\footnotetext{
${ }^{5}$ Todos os resultados dos três corpora utilizados nos experimentos podem ser apreciados em http: //sites.labic.icmc.usp.br/merleyc/ThesisData/.
} 
Capítulo 4. MATE-ML: um Método para Extração Automática de Termos Baseado em Aprendizado de Máquina

Tabela 4.3: Ordenação de candidatos utilizando a característica $t f$ - Corpus ECO.




Tabela 4.4: Resultados mais altos obtidos pela ordenação de candidatos utilizando diferentes características - Corpus ECO.

\begin{tabular}{|c|c|c|c|c|c|}
\hline Característica & \#Cand. & $\# \mathbf{T E}$ & $\mathbf{P}(\%)$ & $\mathrm{C}(\%)$ & $\operatorname{MF}(\%)$ \\
\hline \multirow{2}{*}{ comGram } & 9850 & 296 & 3,01 & 98,67 & 5,83 \\
\hline & 9950 & 298 & 2,99 & 99,33 & 5,81 \\
\hline \multirow{3}{*}{$t f$} & 50 & 21 & 42,00 & 7,00 & 12,00 \\
\hline & 400 & 85 & 21,25 & 28,33 & 24,29 \\
\hline & 9950 & 299 & 3,01 & 99,67 & 5,83 \\
\hline \multirow{3}{*}{$r f$} & 50 & 21 & 42,00 & 7,00 & 12,00 \\
\hline & 400 & 85 & 21,25 & 28,33 & 24,29 \\
\hline & 9900 e 9950 & 299 & 3,01 e 3,02 & 99,67 & 5,86 e 5,83 \\
\hline \multirow{2}{*}{ atf } & 800 & 121 & 15,13 & 40,33 & 22,00 \\
\hline & 9950 & 299 & 3,01 & 99,67 & 5,83 \\
\hline ridf & 9950 & 283 & 2,84 & 94,33 & 5,52 \\
\hline \multirow{3}{*}{$d f$} & 50 & 14 & 28,00 & 4,67 & 8,00 \\
\hline & 450 & 75 & 16,67 & 25,00 & 20,00 \\
\hline & 9950 & 299 & 3,01 & 99,67 & 5,83 \\
\hline \multirow{3}{*}{$t f-i d f$} & 50 & 25 & 50,00 & 8,33 & 14,29 \\
\hline & 300 & 78 & 26,00 & 26,00 & 26,00 \\
\hline & 9950 & 299 & 3,01 & 99,67 & 5,83 \\
\hline \multirow{3}{*}{$t v$} & 50 & 25 & 50,00 & 8,33 & 14,29 \\
\hline & 500 & 109 & 21,80 & 36,33 & 27,25 \\
\hline & 9950 & 299 & 3,01 & 99,67 & 5,83 \\
\hline \multirow{3}{*}{$t v q$} & 50 & 24 & 48,00 & 8,00 & 13,71 \\
\hline & 400 & 103 & 25,75 & 34,33 & 29,43 \\
\hline & 9950 & 299 & 3,01 & 99,67 & 5,83 \\
\hline \multirow{3}{*}{$t c$} & 50 & 26 & 52,00 & 8,67 & 14,86 \\
\hline & 400 & 90 & 22,50 & 30,00 & 25,71 \\
\hline & 9950 & 299 & 3,01 & 99,67 & 5,83 \\
\hline \multirow{2}{*}{ freq_cg } & 3300 & 155 & 4,70 & 51,67 & 8,61 \\
\hline & 8850 a 9950 & 300 & 3,02 a 3,39 & 100,00 & 5,85 a 6,56 \\
\hline \multirow{3}{*}{ weirdness } & 50 & 11 & 22,00 & 3,67 & 6,29 \\
\hline & 950 & 67 & 7,05 & 22,33 & 10,72 \\
\hline & 9700 a 9950 & 300 & 3,02 a 3,09 & 100,00 & 5,85 a 6,00 \\
\hline \multirow{3}{*}{ thd } & 50 & 19 & 38,00 & 6,33 & 10,86 \\
\hline & 450 & 75 & 16,67 & 25,00 & 20,00 \\
\hline & 9850 a 9950 & 300 & 3,02 a 3,05 & 100,00 & 5,85 a 5,91 \\
\hline \multirow{3}{*}{$t d s$} & 50 & $2 \mathrm{a} 4$ & 4,00 & 0,67 a 1,33 & 1,14 a 2,00 \\
\hline & 5800 & 220 & 3,79 & 73,33 & 7,21 \\
\hline & 9550 a 9950 & 298 & 2,99 a 3,12 & 99,33 & 5,81 a 6,05 \\
\hline \multirow{3}{*}{ glossEx } & 50 & $2 \mathrm{a} 4$ & 4,00 & 0,67 a 1,33 & 1,14 a 2,00 \\
\hline & 6550 & 251 & 3,83 & 83,67 & 7,33 \\
\hline & 9550 a 9950 & 298 & 2,99 a 3,12 & 99,33 & 5,81 a 6,05 \\
\hline \multirow{3}{*}{ c-value } & 50 & 21 & 42,00 & 7,00 & 12,00 \\
\hline & 400 & 85 & 21,25 & 28,33 & 24,29 \\
\hline & 9350 a 9950 & 299 & 3,01 a 3,20 & 99,67 & 5,83 a 6,20 \\
\hline \multirow{3}{*}{ nc-value } & 50 & 14 & 28,00 & 4,67 & 8,00 \\
\hline & 1150 & 114 & 9,91 & 38,00 & 15,72 \\
\hline & 9700 a 9950 & 300 & 3,02 a 3,09 & 100,00 & 5,85 a 6,00 \\
\hline sintagma & 5030 & 279 & 5,55 & 93,00 & 10,47 \\
\hline núcleo_sintagma & 5113 & 280 & 5,48 & 93,33 & 10,35 \\
\hline$p m$ & 5147 & 281 & 5,46 & 93,67 & 10,32 \\
\hline Corpus inteiro & 9950 & 300 & 3,02 & 100,00 & 5,85 \\
\hline
\end{tabular}


Tabela 4.5: Resultados mais altos obtidos pela ordenação de candidatos utilizando diferentes características - Corpus EaD.

\begin{tabular}{|c|c|c|c|c|c|}
\hline Caracteristica & \#Cand. & $\# \mathbf{T E}$ & $\mathbf{P}(\%)$ & $\mathbf{C}(\%)$ & $\mathrm{MF}(\%)$ \\
\hline \multirow{3}{*}{ comGram } & 300 & 4 & 1,33 & 3,57 & 1,94 \\
\hline & 1600 & 18 & 1,13 & 16,07 & 2,10 \\
\hline & 15000 & 104 & 0,69 & 92,86 & 1,38 \\
\hline \multirow{3}{*}{$t f$} & 50 & 9 & 18,00 & 8,04 & 11,11 \\
\hline & 150 & 16 & 10,67 & 14,29 & 12,21 \\
\hline & 11305 a 15000 & 112 & 0,75 a 0,99 & 100,00 & 1,39 a 1,95 \\
\hline \multirow{3}{*}{$r f$} & 50 & 9 & 18,00 & 8,04 & 11,11 \\
\hline & 150 & 16 & 10,67 & 14,29 & 12,21 \\
\hline & 11100 a 15000 & 112 & 0,75 a 1,01 & 100,00 & 1,48 a 2,00 \\
\hline \multirow{3}{*}{ atf } & 50 & 7 & 14,00 & 6,25 & 8,64 \\
\hline & 150 & 16 & 10,67 & 14,29 & 12,21 \\
\hline & 11305 a 15000 & 112 & 0,75 a 0,99 & 100,00 & 1,39 a 1,95 \\
\hline ridf & 15000 & 64 & 0,43 & 57,14 & 0,85 \\
\hline \multirow{2}{*}{$d f$} & 100 & 10 & 10,00 & 8,93 & 9,43 \\
\hline & 11305 a 15000 & 112 & 0,75 a 0,99 & 100,00 & 1,48 a 1,95 \\
\hline \multirow{3}{*}{$t f-i d f$} & 50 & 11 & 22,00 & 9,82 & 13,58 \\
\hline & 100 & 15 & 15,00 & 13,39 & 14,15 \\
\hline & 11305 a 15000 & 112 & 0,75 a 0,99 & 100,00 & 1,48 a 1,95 \\
\hline \multirow{2}{*}{$t v$} & 50 & 10 & 20,00 & 8,93 & 12,35 \\
\hline & 11305 a 15000 & 112 & 0,75 a 0,99 & 100,00 & 1,48 a 1,95 \\
\hline \multirow{2}{*}{$t v q$} & 50 & 10 & 20,00 & 8,93 & 12,35 \\
\hline & 11305 a 15000 & 112 & 0,75 a 0,99 & 100,00 & 1,48 a 1,95 \\
\hline \multirow{3}{*}{$t c$} & 50 & 11 & 22,00 & 9,82 & 13,58 \\
\hline & 100 & 15 & 15,00 & 13,39 & 14,15 \\
\hline & 11305 a 15000 & 112 & 0,75 a 0,99 & 100,00 & 1,48 a 1,95 \\
\hline \multirow{2}{*}{ freq_cg } & 150 & 5 & 3,33 & 4,46 & 3,82 \\
\hline & 14850 a 15000 & 112 & 0,75 & 100,00 & 1,48 a 1,50 \\
\hline \multirow{3}{*}{ weirdness } & 100 & 9 & 9,00 & 8,04 & 8,49 \\
\hline & 300 & 19 & 6,33 & 16,96 & 9,22 \\
\hline & 15000 & 111 & 0,74 & 99,11 & 1,47 \\
\hline \multirow{3}{*}{ thd } & 50 & 6 & 12,00 & 5,36 & 7,41 \\
\hline & 200 & 15 & 7,50 & 13,39 & 9,62 \\
\hline & 15000 & 111 & 0,74 & 99,11 & 1,47 \\
\hline \multirow{2}{*}{$t d s$} & 50 & 18 & 36,00 & 16,07 & 22,22 \\
\hline & 15000 & 110 & 0,73 & 98,21 & 1,46 \\
\hline \multirow{2}{*}{ glossEx } & 50 & 18 & 36,00 & 16,07 & 22,22 \\
\hline & 15000 & 110 & 0,73 & 98,21 & 1,46 \\
\hline \multirow{3}{*}{ c-value } & 50 & 9 & 18,00 & 8,04 & 11,11 \\
\hline & 150 & 16 & 10,67 & 14,29 & 12,21 \\
\hline & 13350 a 15000 & 112 & 0,75 a 0,84 & 100,00 & 1,48 a 1,66 \\
\hline \multirow{3}{*}{ nc-value } & 50 & 4 & 8,00 & 3,57 & 4,94 \\
\hline & 500 & 20 & 4,00 & 17,86 & 6,54 \\
\hline & 15000 & 110 & 0,73 & 98,21 & 1,46 \\
\hline sintagma & 8008 & 108 & 1,35 & 96,43 & 2,66 \\
\hline núcleo_sintagma & 7908 & 108 & 1,37 & 96,43 & 2,69 \\
\hline$p m$ & 7249 & 105 & 1,45 & 93,75 & 2,85 \\
\hline Corpus inteiro & 16000 & 112 & 0,70 & 100,00 & 1,39 \\
\hline
\end{tabular}


Tabela 4.6: Resultados mais altos obtidos pela ordenação de candidatos utilizando diferentes características - Corpus Nano.

\begin{tabular}{|c|c|c|c|c|c|}
\hline Caracteristica & \#Cand. & $\# \mathbf{T E}$ & $\mathbf{P}(\%)$ & $\mathrm{C}(\%)$ & $\mathrm{MF}(\%)$ \\
\hline \multirow{2}{*}{ comGram } & 14150 a 14250 & 560 a 564 & 3,99 & 36,55 a 36,88 & 7,19 a 7,21 \\
\hline & 15000 & 595 & 3,97 & 38,56 & 7,19 \\
\hline \multirow{3}{*}{$t f$} & 50 & 24 & 48,00 & 1,56 & 3,01 \\
\hline & 3200 & 844 & 26,38 & 54,70 & 35,59 \\
\hline & 15000 & 1452 & 9,68 & 94,10 & 17,55 \\
\hline \multirow{3}{*}{$r f$} & 50 & 24 & 48,00 & 1,56 & 3,01 \\
\hline & 3200 & 844 & 26,38 & 54,70 & 35,59 \\
\hline & 14900 a 15000 & 1452 & 9,68 a 9,74 & 94,10 & 17,55 a 17,66 \\
\hline \multirow{3}{*}{$a t f$} & 200 & 53 & 26,50 & 3,43 & 6,08 \\
\hline & 3150 & 615 & 19,52 & 39,86 & 26,21 \\
\hline & 14650 a 15000 & 1344 & 8,96 a 9,17 & 87,10 & 16,25 a 16,60 \\
\hline \multirow{2}{*}{ ridf } & 14950 & 16 & 0,11 & 1,04 & 0,19 \\
\hline & 15000 & 16 & 0,11 & 1,04 & 0,19 \\
\hline \multirow{3}{*}{$d f$} & 100 & 30 & 30,00 & 1,94 & 3,65 \\
\hline & 3400 & 770 & 22,65 & 49,90 & 31,16 \\
\hline & 15000 & 1400 & 9,33 & 90,73 & 16,93 \\
\hline \multirow{3}{*}{$t f-i d f$} & 50 & 29 & 58,00 & 1,88 & 3,64 \\
\hline & 3150 & 850 & 26,98 & 55,09 & 36,22 \\
\hline & 14900 a 15000 & 1451 & 9,67 a 9,74 & 94,04 & 17,54 a 17,65 \\
\hline \multirow{3}{*}{$t v$} & 50 & 32 & 64,00 & 2,07 & 4,02 \\
\hline & 2150 & 661 & 30,74 & 42,84 & 35,80 \\
\hline & 14900 a 15000 & 1446 & 9,64 a 9,84 & 93,71 & 17,48 a 17,80 \\
\hline \multirow{3}{*}{$t v q$} & 50 & 33 & 66,00 & 2,14 & 4,14 \\
\hline & 2850 & 793 & 27,82 & 51,39 & 36,10 \\
\hline & 15000 & 1437 & 9,58 & 93,13 & 17,37 \\
\hline \multirow{3}{*}{$t c$} & 50 & 29 & 58,00 & 1,88 & 3,64 \\
\hline & 3100 & 832 & 26,84 & 53,92 & 35,84 \\
\hline & 15000 & 1400 & 9,33 & 90,73 & 16,93 \\
\hline \multirow{3}{*}{ freq_ $c g$} & 200 & 25 & 12,50 & 1,62 & 2,87 \\
\hline & 8300 & 504 & 6,07 & 32,66 & 10,24 \\
\hline & 15000 & 820 & 5,47 & 53,14 & 9,91 \\
\hline \multirow{3}{*}{ weirdness } & 50 & 16 & 32,00 & 1,04 & 2,01 \\
\hline & 1750 & 233 & 13,31 & 15,10 & 14,15 \\
\hline & 14950 a 15000 & 811 & 5,41 a 4,42 & 52,56 & 9,80 a 9,83 \\
\hline \multirow{3}{*}{ thd } & 50 & 22 & 44,00 & 1,43 & 2,76 \\
\hline & 2550 & 725 & 28,43 & 46,99 & 35,43 \\
\hline & 14900 a 15000 & 1230 & 8,20 a 8,26 & 79,71 & 14,87 a 14,96 \\
\hline \multirow{3}{*}{$t d s$} & 50 & 30 & 60,00 & 1,94 & 3,77 \\
\hline & 1600 & 269 & 16,81 & 17,43 & 17,12 \\
\hline & 14650 a 15000 & 423 & 2,82 a 2,89 & 27,41 & 5,11 a 5,22 \\
\hline \multirow{3}{*}{ glossEx } & 50 & 30 & 60,00 & 1,94 & 3,77 \\
\hline & 1600 & 269 & 16,81 & 17,43 & 17,12 \\
\hline & 14650 a 15000 & 423 & 2,82 a 2,89 & 27,41 & 5,11 a 5,22 \\
\hline \multirow{3}{*}{ c-value } & 50 & 24 & 48,00 & 1,56 & 3,01 \\
\hline & 3200 & 845 & 26,41 & 54,76 & 35,63 \\
\hline & 14900 a 15000 & 1448 & 9,65 a 9,72 & 93,84 & 17,51 a 17,61 \\
\hline \multirow{3}{*}{ nc-value } & 250 & 79 & 31,60 & 5,12 & 8,81 \\
\hline & 2850 & 550 & 19,30 & 35,64 & 25,04 \\
\hline & 15000 & 1074 & 7,16 & 69,60 & 12,98 \\
\hline sintagma & 17218 & 1368 & 7,95 & 88,32 & 14,58 \\
\hline núcleo_sintagma & 16886 & 1366 & 8,09 & 88,19 & 14,82 \\
\hline$p m$ & 17888 & 1329 & 7,43 & 85,80 & 13,67 \\
\hline Corpus inteiro & 41335 & 1543 & 0,04 & 100,00 & 0,07 \\
\hline
\end{tabular}


dessas medidas. Entretanto, para a análise dos resultados somente da extração de termos, é relevante analisar cada uma dessas medidas juntamente com os valores que a acompanham obtidos pelas outras duas medidas restantes. Por isso, mesmo que é ressaltado aqui o valor separado por medidas, nas tabelas a seguir, são mostrados os seus valores correspondentes das outras medidas.

Ao analisar os resultados mais altos de cada medida de avaliação, observou-se que, para o corpus ECO (Tabela 4.4), a precisão mais alta (52\%) foi atingida ao utilizar os primeiros 50 candidatos mais bem ranqueados pela característica tc. A cobertura mais alta (100\%), foi alcançada com freq_cg, weirdness e thd quando se utiliza acima de 8850 candidatos, tendo o corpus um total de 9950 candidatos. Já a medida F mais alta $(29,43 \%)$ foi alcançada com os 400 primeiros candidatos ordenados pela característica $t v q$.

Para o corpus EaD (Tabela 4.5), a precisão mais alta (36\%) foi atingida ao utilizar os primeiros 50 candidatos mais bem ranqueados pela característica $t d s$. O valor mais alto de cobertura (100\%), foi alcançada com tf, rf, atf, $d f$, tf-idf, tv, tvq, tc, freq_cg e c-value utilizando acima de 11305 candidatos, tendo o corpus um total de 16000 candidatos. Enquanto que a medida $\mathrm{F}$ mais alta $(22,22 \%)$ foi obtida com o uso dos 50 primeiros candidatos ordenados pela característica $t d s$.

Para o corpus Nano (Tabela 4.6), o valor mais alto de precisão (66\%) foi obtido com os primeiros 50 candidatos mais bem ranqueados pela característica $t v q$. A cobertura mais alta $(94,10 \%)$, foi alcançada com tf e rf utilizando acima de 14.900 candidatos, sendo que o corpus inteiro possui 41.335 candidatos. Por fim, a medida F mais alta $(36,22 \%)$ foi atingida com os 3.150 primeiros candidatos ordenados pela característica $t f-i d f$.

Nas Figuras 4.1, 4.2 e 4.3, é mostrada a relação entre os valores de precisão, cobertura e medida $\mathrm{F}$ (eixo da direita) e o número de candidatos extraídos (eixo da esquerda) na obtenção desses valores. Observa-se que as precisões mais altas são alcançadas utilizando a mesma quantidade de candidatos (\#Cand.), que é 50, para os três corpora. Os valores de cobertura dos três corpora atingem ou se aproximam de 100\%, porém, na maioria desses casos, para se alcançar esses valores é preciso utilizar praticamente todos os candidatos. Logo, os resultados de cobertura não são considerados bons uma vez que, se simplesmente utilizasse todo o corpus, eles seriam similares ou iguais.

Ressalta-se que, para resumir os resultados dos experimentos, na Figura 4.3, o máximo de candidatos apresentado para o corpus Nano foi 15000 (36\% do número total de candidatos desse corpus) para as características estatísticas e híbridas. Ainda para o corpus Nano, nota-se que as características que obtiveram valores mais altos de cobertura, mesmo utilizando até $36 \%$ dos candidatos do corpus, foram: $t f, d f$, tf-idf, tv, tvq, tc, thd e c-value, além das características linguísticas, que utilizaram em torno de 17000 candidatos (aprox. 41\%). Já para a medida F, há características que alcançam resultados aproximados de 20 a $30 \%$ para os corpora ECO e EaD quando utilizada uma quantidade razoável de candidatos (entre 50 e 450, ou seja, de 0,31 a 4,5\% dos corpora). Para o corpus Nano, é preciso utilizar $7,62 \%$ do corpus (3150 candidatos) para se obter a medida F mais alta $(36,22 \%)$.

Em relação ao nível de conhecimento (linguístico, estatístico e híbrido) das características utilizadas, em geral, os resultados mais altos de precisão foram obtidos utilizando características estatísticas e algumas poucas características híbridas, como tds e c-value. É interessante notar que não foram encontrados trabalhos na literatura que utilizaram as medidas $t c$ e $t v q$ para EAT, porém estas se mostraram boas alternativas para identificação de termos se considerados somente valores de precisão. A cobertura é bem similar para as características estatísticas e híbridas, uma vez que seus altos valores são atingidos somente com quase $100 \%$ dos candidatos, o que a torna praticamente independente da característica utilizada. Uma exceção à afirmação sobre a independência da cobertura 


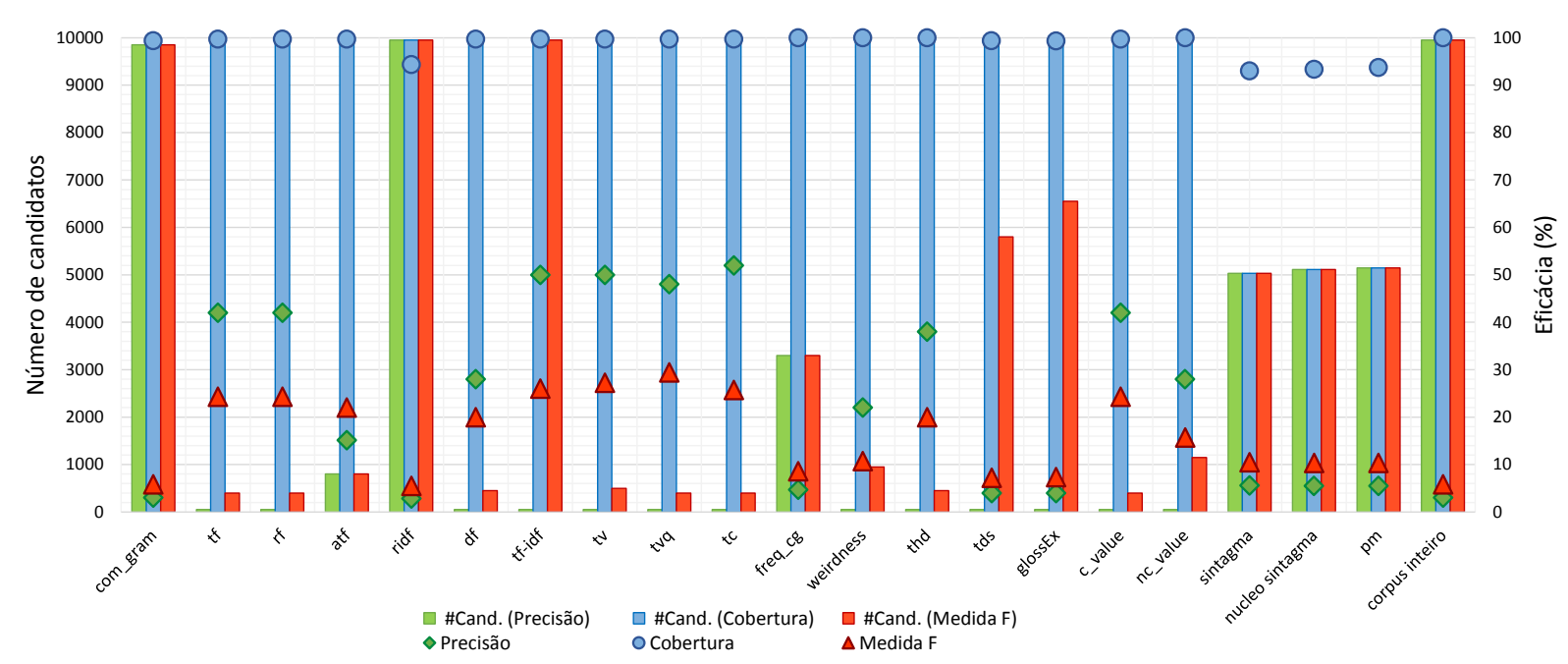

Figura 4.1: Relação entre os resultados mais altos de precisão, cobertura e medida F com seus respectivos números de candidatos extraídos - Corpus ECO.

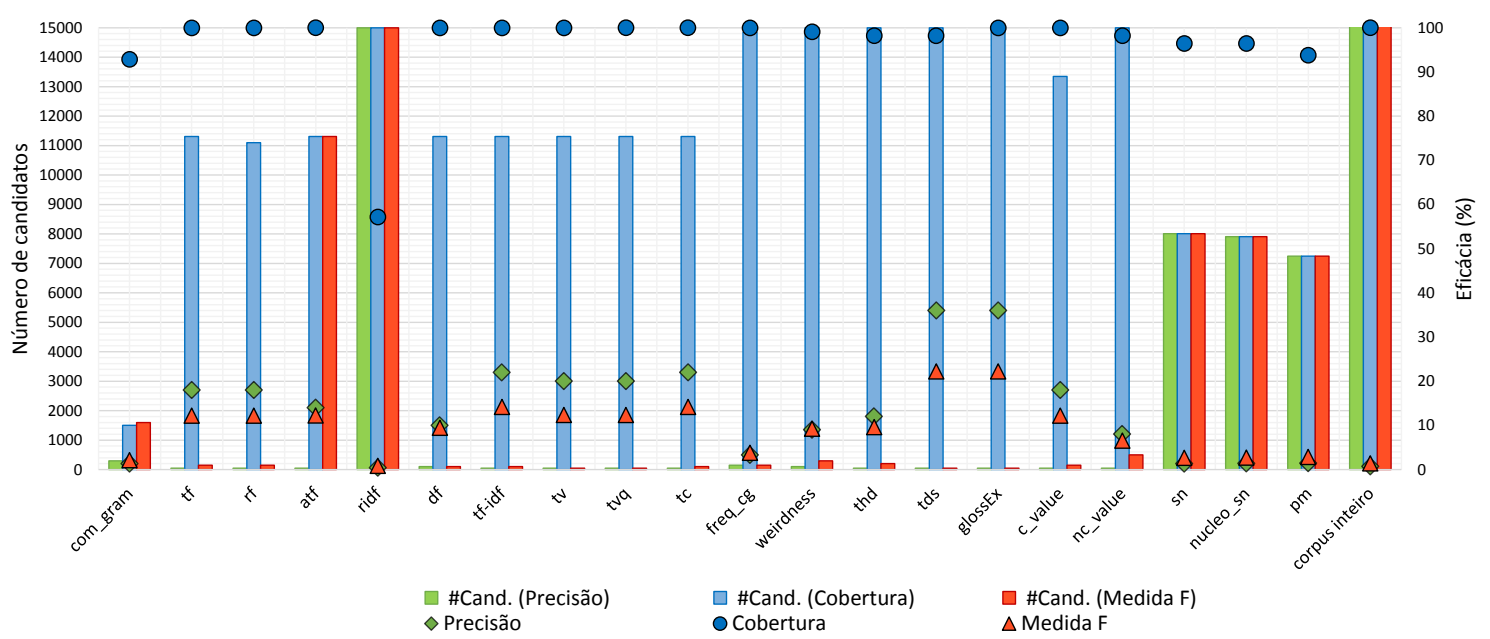

Figura 4.2: Relação entre os resultados mais altos de precisão, cobertura e medida F com seus respectivos números de candidatos extraídos - Corpus EaD.

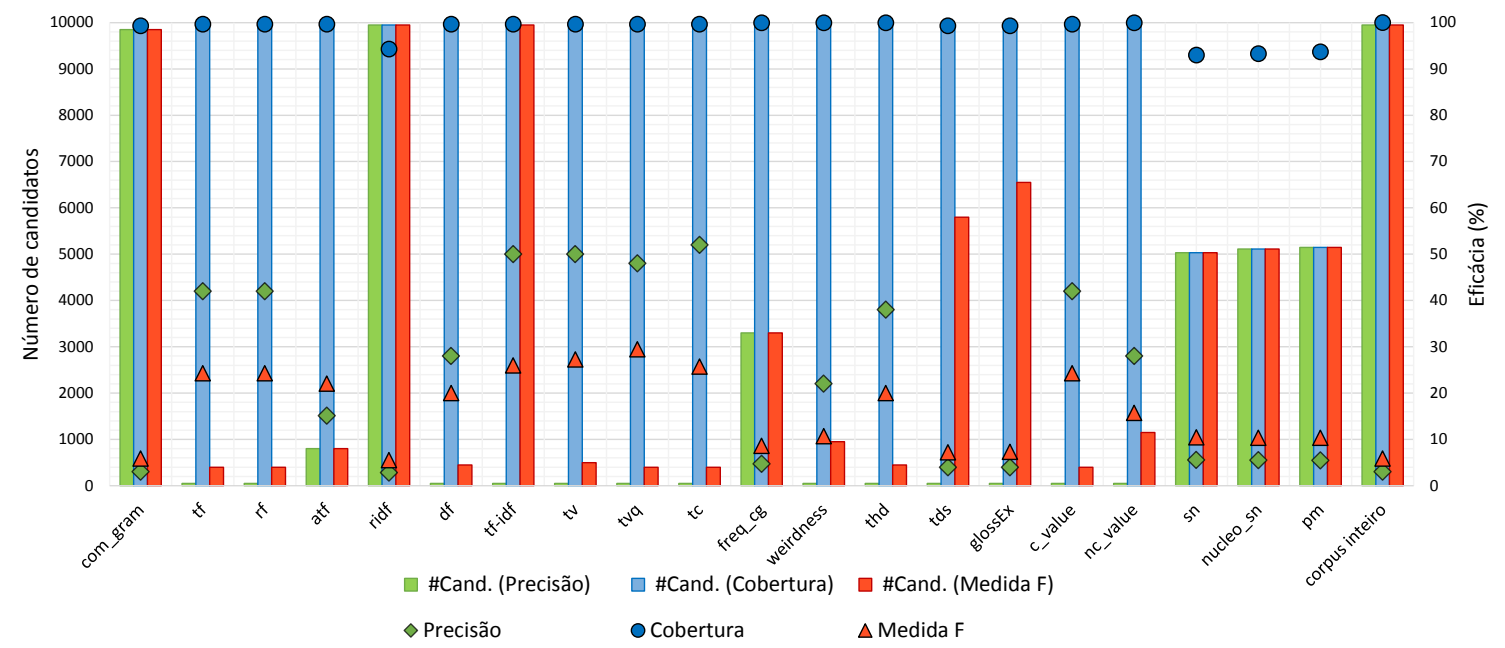

Figura 4.3: Relação entre os resultados mais altos de precisão, cobertura e medida F com seus respectivos números de candidatos extraídos - Corpus Nano. 
em relação à característica é o uso das medidas/métodos linguísticos, uma vez que suas coberturas mais altas atingem $93,67 \%, 96,43 \%$ e 88,32\% utilizando $51 \%, 49 \%$ e $42 \%$ do número total de candidatos, respectivamente, para os corpora ECO, EaD e Nano.

A medida F mantém geralmente o mesmo padrão quando utilizadas características estatísticas e híbridas. Ressalta-se que quando se utilizaram características puramente linguísticas, os resultados de precisão e medida $\mathrm{F}$ foram baixos (entre 1,35 a 8,09\%), dando indícios que estas devem ser utilizadas juntamente com características de outros níveis de conhecimento. Ainda, tais características linguísticas alcançam altos resultados de cobertura (entre 85 e 96\%), o que significa que conseguem remover parte dos nãotermos, sem excluir muitos termos. Logo, se tais características são combinadas com outras não-linguísticas, intuitivamente será possível aumentar a medida F. Dessa maneira, corrobora-se a ideia de Teline (2004) e Pazienza et al. (2005) de que os resultados mais altos são obtidos quando as medidas estatísticas são aplicadas sobre uma lista de candidatos que foram previamente extraídos com base em alguma propriedade linguística.

Retoma-se, então, às questões levantadas no início dessa seção. Em relação a "como saber quais candidatos do ranking devem ser considerados termos", levando em conta os três corpora utilizados, ao analisar os resultados da extração de termos obtidos usando diferentes limiares para o ranking de candidatos a termos, conclui-se que há um padrão a ser seguido para escolher o melhor limiar para a precisão; entretanto, não há um limiar exato a ser adotado para se alcançar bons valores de cobertura e medida F.

Com base nessa avaliação experimental, a seguir são listadas algumas sugestões sobre a extração tradicional de termos. Para alcançar bons valores de precisão (de no máximo $66 \%$, sendo que nesse caso a cobertura correspondente foi de $2,14 \%$ ), sugere-se considerar os 50 primeiros candidatos mais bem ranqueados por alguma das medidas estatísticas e híbridas. Já para a cobertura, não há uma característica melhor ou um limiar aconselhável para se utilizar, uma vez que os altos valores de cobertura somente são atingidos utilizando (quase) todo o corpus, o que não é recomendado. Entretanto, com base nos resultados dos experimentos realizados nesta pesquisa, sugere-se utilizar as características linguísticas por utilizar aproximadamente metade do corpus e alcançar altos valores de cobertura. Para atingir valores de medida $\mathrm{F}$ entre 20 a 30\%, aconselha-se utilizar alguma medida estatística ou híbrida considerando 50 a 450 candidatos (de 0,31 a 4,5\%) dos corpora ECO e EaD e, para o corpus Nano, sugere-se utilizar aprox. 3150 candidatos (7,62\% do corpus) para se obter medida $\mathrm{F}$ perto de $36,22 \%$.

Sobre a segunda questão: "qual é a melhor medida, método ou forma de obtenção de conhecimento para criar um ranking de candidatos a termos?", considerando os três corpora utilizados, é possível concluir por meio dos experimentos realizados que não há uma única medida que seja melhor para todos eles. No entanto, com relação à definição do limiar dos rankings, as medidas estatísticas e híbridas são mais aconselháveis quando o objetivo é alcançar valores mais altos de precisão e medida F. Mas essa afirmação tem suas exceções, que são as medidas estatísticas comGram e ridf e a híbrida freq_cg, que para todos os corpora atingem resultados piores que as demais medidas. Assim, baseado nos resultados dos experimentos apresentados nesta pesquisa, sugere-se utilizar as características linguísticas com características estatísticas ou características linguísticas com híbridas, uma vez que somente as coberturas das características linguísticas são boas.

Em relação as quatro medidas ( $t v, t v q$, tc e comGram) que foram, pela primeira vez, aplicadas à tarefa de extração de termos, observou-se que $t v$, $t v q$ e $t c$ foram responsáveis por pelo menos um dos resultados mais altos de cada corpus. Logo, assim como esperado, essas três medidas são boas opções para a EAT. Entretanto, comGram obteve resultados bem inferiores comparados com as demais características utilizadas no experimento. Conclui-se, então, que, ao contrário do esperado, os termos dos domínios usados 
no experimento não têm tamanhos (em caracteres) diferentes das demais palavras dos corpora.

Com essa avaliação experimental, pode-se perceber o quão difícil e subjetivo é determinar um limiar a ser considerado no ranking dos candidatos a termos. Também, ainda são necessárias melhorias nesse processo de extração, por exemplo, a combinação dessas características. Nesse sentido, nesta tese, é proposto um método, apresentado a seguir, para extração automática de termos utilizando técnicas da área de aprendizado de máquina.

\subsection{Descrição do Método MATE-ML}

O MATE-ML é um método para extração automática de termos baseado em aprendizado de máquina, do inglês, $\underline{\boldsymbol{M}}$ ethod for $\underline{\boldsymbol{A}}$ utomatic $\underline{\boldsymbol{T}}$ erm $\underline{\boldsymbol{E}} x$ traction based on $\underline{\boldsymbol{M}}$ achine L earning.

O MATE-ML trata a extração automática de termos como uma tarefa de classificação, uma vez que o objetivo da extração pode ser visto como classificar candidatos em termos ou não-termos. Na Figura 4.4, são mostradas as quatro etapas do método MATE-ML, que são automatizadas e permitem realizar adaptações dependendo da aplicação na qual os termos extraídos serão utilizados.

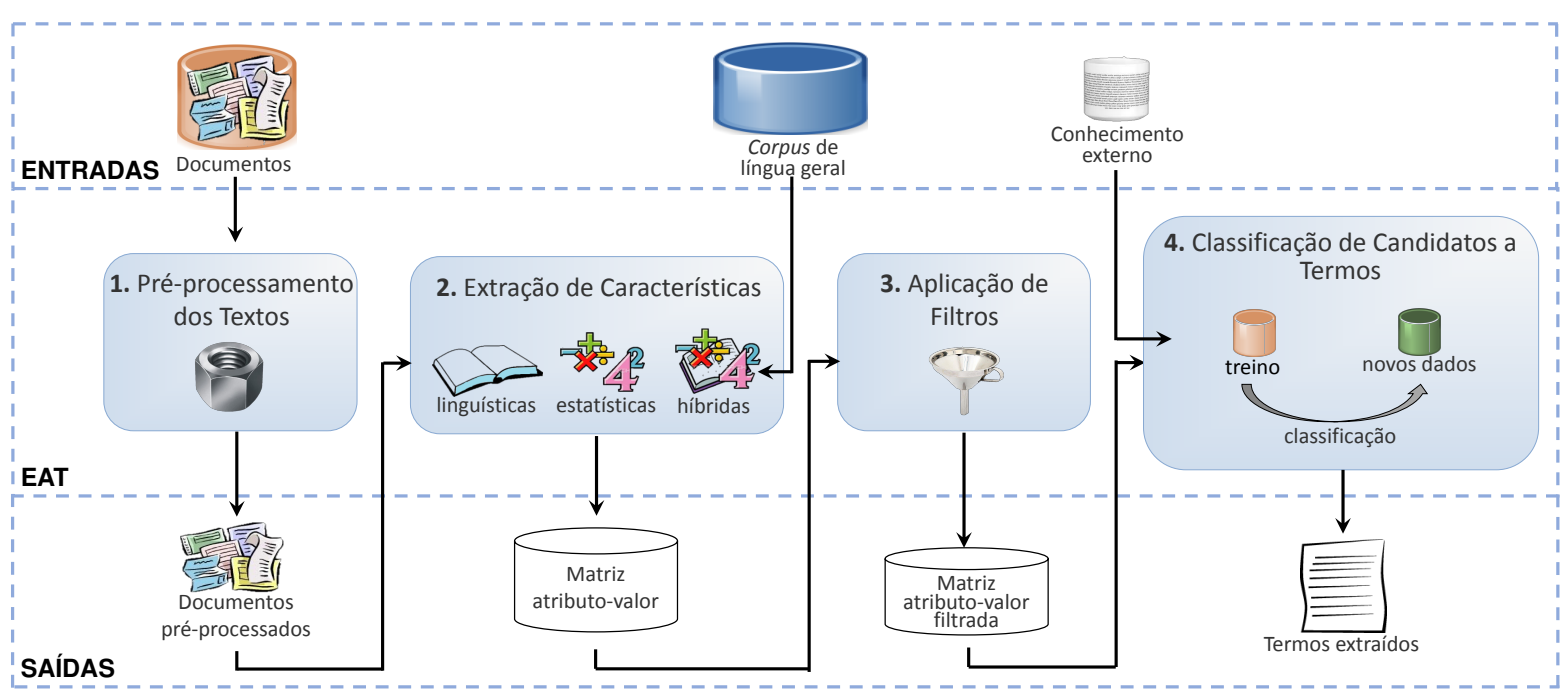

Figura 4.4: Etapas do MATE-ML - método para extração automática de termos baseada em aprendizado de máquina.

\subsubsection{Pré-processamento dos Textos}

Os documentos de um corpus de domínio do qual se pretende extrair termos constitui a entrada do método proposto para EAT. A primeira etapa do MATE-ML consiste do pré-processamento dos documentos, que visa realizar transformações nos dados e eliminar os que não ajudam na identificação dos termos. Como esses documentos podem estar em diferentes formatos, é necessário transformá-los em textos planos para que seja possível realizar esse pré-processamento. Outros tipos de transformações também podem ser feitas, como eliminar caracteres especiais e colocar todas as letras em minúsculas.

Nessa etapa, dependendo de quais critérios serão adotados para identificar os termos do domínio (por exemplo, considerar que termos, entre outros critérios, devem ser substantivos ou sintagmas nominais), pode ser necessário anotar linguisticamente os textos. Essa anotação é feita de maneira automática utilizando algum parser. 
Ainda, são removidas as stopwords (i) padrão, (ii) de domínio e (iii) do tipo de texto. As stopwords padrão são, por exemplo, os advérbios e as preposições. As stopwords de domínio ${ }^{6}$, segundo Moura (2009), correspondem aos unigramas que são descartados em um filtro feito com a aplicação de alguma medida. Por exemplo, os unigramas que têm frequência menor que um valor específico poderiam ser considerados stopwords de domínio.

Na pesquisa apresentada nesta tese, outras palavras que podem manualmente ser identificadas como frequentes no domínio, mas que não são termos, podem também fazer parte da stoplist de domínio. Por exemplo, se o domínio do corpus não for de exatas, os números também poderiam ser removidos, porque dificilmente seriam termos. Dependendo do tipo de textos que compõe o corpus, também é útil remover as palavras que normalmente são usadas no vocabulário desses textos. Essas palavras são denominadas nesta tese de "stopwords do tipo de texto". Por exemplo, para os artigos científicos, podem-se remover palavras como introdução, trabalhos relacionados, conclusões, figuras e tabelas.

Também se pode normalizar as palavras dos textos para que suas variações sejam reduzidas, mas mantendo seus significados essenciais. O uso da normalização permite trabalhar com uma quantidade menor de candidatos a termos. As técnicas encontradas na literatura são: radicalização, lematização e substantivação. Essas técnicas foram detalhadas na Seção 3.2 do Capítulo 3, página 21.

\subsubsection{Extração de Características}

A partir dos textos pré-processados, busca-se por indícios de que uma palavra é termo ou não-termo do domínio em questão. Para isso, o MATE-ML sugere a extração de características dos candidatos na qual diferentes níveis de conhecimento são considerados, sendo eles linguístico, estatístico e híbrido.

Cada uma das palavras dos textos pré-processados é considerada como candidato a termo do domínio. Para cada candidato, são extraídas características que variam desde medidas estatísticas (por exemplo, a frequência do candidato) e formas de obtenção de conhecimento linguístico (por exemplo, considerar palavras que pertencem a alguma classe gramatical pré-estabelecida ou considerar os sintagmas nominais) até conhecimento híbrido mais sofisticado. Por exemplo, pode-se obter o conhecimento híbrido analisando o contexto do candidato ou utilizando textos que não pertencem a domínio específico (chamado de corpus de língua geral), uma vez que esse tipo de corpus pode ajudar a diferenciar um termo do domínio de uma palavra de língua geral.

Considerando as pesquisas da literatura sobre extração automática de termos descritas na Seção 3.5 do Capítulo 3, página 37, esse método tem como diferencial o uso, adaptação, avaliação e proposta de um rico conjunto de características que utiliza diferentes níveis de conhecimento (linguístico, estatístico e híbrido) ao mesmo tempo. No decorrer do texto, as demais contribuições desta pesquisa são listadas.

\subsubsection{Aplicação de Filtros}

Após a extração de características para cada candidato a termo, os candidatos são representados no formato de matriz atributo-valor, no qual os candidatos se encontram nas linhas de uma matriz e as características nas colunas.

Entretanto, essa matriz tem um elevado número de candidatos a termos, uma vez que todas as palavras do corpus não removidas durante o pré-processamento dos textos são consideradas candidatos. Então, com o objetivo de remover os candidatos que têm menos

${ }^{6} \mathrm{Na}$ tese de Moura (2009), as stopwords de domínio foram chamadas de stopwords da coleção. 
chance de ser termos, é realizada a aplicação de filtros. Um exemplo de critério que pode ser adotado pelos filtros é remover os candidatos que aparecem em apenas um documento do corpus, uma vez que esses possivelmente não representam o domínio.

Após a aplicação de filtros, tem-se uma matriz atributo-valor filtrada, ou seja, contendo apenas os candidatos, e suas características, que não são removidas pelos filtros.

\subsubsection{Classificação de Candidatos a Termos}

O MATE-ML é proposto para obtenção de uma lista de (candidatos a) termos de domínios específicos sem lidar com o problema da escolha manual ou semiautomática dos candidatos presente na tarefa de extração tradicional de termos. Para automatizar essa escolha, MATE-ML utiliza aprendizado de máquina.

Uma das motivações do uso de AM é a existência de trabalhos na literatura que alcançaram bons resultados de precisão ao utilizar AM para a extração de termos de línguas como o inglês e o espanhol (Vivaldi et al., 2001; Zhang et al., 2010). Outra motivação é que AM facilita o uso de um grande número de candidatos a termos, que normalmente é o cenário do mundo real, e de várias características desses candidatos, uma vez que técnicas de AM podem aprender por si só como reconhecer um termo, economizando, assim, tempo na extração de termos.

No MATE-ML, cada candidato a termo é considerado como um exemplo utilizado no aprendizado e as características desse candidato são os atributos descritores desse exemplo. Então, a classificação é aplicada como meio para predizer quais desses candidatos são termos e não-termos de domínios específicos. Para isso, a matriz atributo-valor filtrada é a entrada de um algoritmo de classificação para que este gere automaticamente uma lista de (candidatos a) termos do domínio em questão. Essa lista corresponde à saída do MATE-ML.

Ressalta-se que o método proposto é independente de domínio e aplicação, entretanto ele pode ser direcionado para atender especificidades de diferentes domínios e aplicações, p. ex., utilizar stopwords para domínio específicos. Nesse sentido, as decisões tomadas durante o pré-processamento podem ser direcionadas ao problema e domínio considerados, bem como as demais etapas do método podem fazer uso de diferentes características dos candidatos, critérios para filtragem dos candidatos e algoritmos de classificação.

Uma vez aplicado o método para extração de termos de um domínio específico, é necessário avaliar os candidatos a termos extraídos. A seguir, é apresentado o método utilizado para essa avaliação.

\subsection{Método Utilizado para Avaliação dos Termos Extraídos}

Após a extração dos candidatos a termos, é necessário avaliá-los quanto à sua precisão e cobertura. O método para avaliação adotada nesta pesquisa é ilustrado na Figura 4.5.

Os termos extraídos utilizando o método para EAT proposto nesta pesquisa são comparados aos termos da lista de referência do domínio em questão. Tal comparação é realizada pelo cálculo de medidas de avaliação objetiva normalmente utilizadas na literatura, a saber: precisão, cobertura e medida F. O cálculo dessas medidas é baseado na matriz de contingência apresentada na Tabela 4.7. O significado das células dessa matriz é: número de não-termos preditos como não-termos (TN - true non-terms), número de não-termos preditos como termos ( $F T$ - false terms), número de termos preditos como não-termos (FN - false non-terms), e número de termos preditos como termos (TT - true terms). 


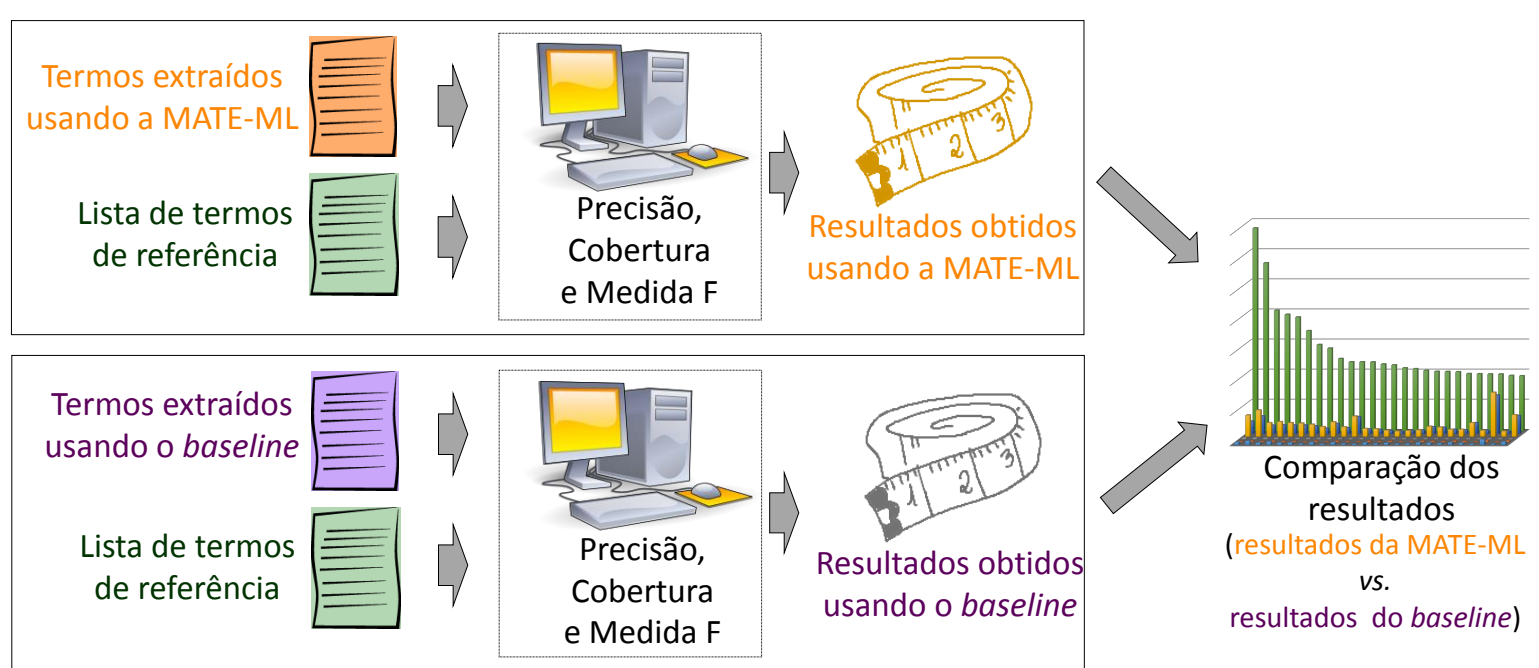

Figura 4.5: Método para avaliação dos termos extraídos.

Tabela 4.7: Matriz de Contingência

\begin{tabular}{|c|c|c|c|}
\cline { 3 - 4 } \multicolumn{2}{c|}{} & \multicolumn{2}{c|}{ Predito } \\
\cline { 3 - 4 } \multicolumn{2}{c|}{ Real } & Não-Tero-Termo & Termo \\
\cline { 2 - 4 } & Termo & $T N$ & $F T$ \\
\hline
\end{tabular}

Considerando a matriz de contingência, o cálculo da precisão é $P=\frac{T T}{T T+F T}$, da cobertura é $C=\frac{T T}{T T+F N}$ e da medida $\mathrm{F}$ é $M F=\frac{2 * P * C}{P+C}$. Essas medidas são calculadas considerando somente a classificação dos termos, uma vez que estes são o foco desta pesquisa, ou seja, são utilizados somente o valor de TT como classificação correta.

Por fim, os resultados dessas medidas de avaliação são contrastados com resultados de trabalhos baselines e de trabalhos encontrados na literatura.

\subsection{Considerações Finais}

Automatizar a forma de escolha dos candidatos a termos durante o processo de extração de termos é uma das motivações da proposta do método para EAT. A dificuldade de escolher esses candidatos foi mostrada empiricamente ao se avaliar 21 métodos, medidas e formas de obtenção de conhecimento encontrados na literatura que utilizam diferentes limiares do ranking de candidatos a termos para escolher quais destes devem ser considerados termos. Esse experimento extraiu termos simples, que é o foco desta pesquisa, utilizando os mesmos corpora e realizando o mesmo pré-processamento que serão considerados no decorrer do trabalho. Dessa maneira, além de serem experimentos motivadores, são também meios para se comparar os resultados dos experimentos mostrados nos próximos capítulos.

A outra motivação para a proposta do método MATE-ML é reduzir o elevado número de candidatos a termos presente na extração de termos ao propor o uso de filtros. Assim, possivelmente, os extratores de termos podem gerar listas menores de candidatos a termos extraídos, demandando, assim, menos tempo dos especialistas para avaliar esses candidatos.

Adicionalmente, neste capítulo, foram detalhados tanto o método para extração automática de termos proposto quanto o método para avaliação de termos a ser utilizado nos experimentos descritos nos capítulos seguintes. 
Ao considerar a extração de termos simples na língua portuguesa do Brasil, conforme detalhado na Seção 3.5 do Capítulo 3, página 37, observa-se que seus resultados ainda são inferiores se comparados com a extração de outras línguas como a inglesa e a espanhola, descrito na Seção 3.6, página 48. Visando melhorar o estado da arte da extração de termos simples no português, o MATE-ML é aplicado a esse tipo de extração.

A avaliação do método MATE-ML foi realizada com duas instanciações, sendo que uma é a proposta da abordagem ILATE, descrita no Capítulo 5, página 73, que utiliza classificação indutiva, e a outra é a proposta da abordagem TLATE, descrita no Capítulo 6, página página 113, que utiliza classificação transdutiva. Nesses capítulos, são apresentados também os experimentos realizados com cada instanciação e seus resultados. Ressalta-se que, nos Capítulos 5 e 6, ao analisar os resultados dos experimentos, são consideradas precisão, cobertura e medida $\mathrm{F}$ da extração de termos. Para melhor descrever os resultados, detalha-se o valor mais alto de precisão; separadamente, do valor mais alto de cobertura; e do mais alto de medida F porque dependendo da tarefa na qual os termos extraídos serão utilizados, será importante maximizar uma dessas medidas. Entretanto, para a análise dos resultados somente da extração de termos, é relevante analisar cada uma dessas medidas juntamente com os valores que a acompanham obtidos pelas outras duas medidas restantes. Por essa razão, mesmo que seja ressaltado o valor separado por medidas, são também apresentados os seus valores correspondentes das outras medidas. 


\section{CAPÍTUlo 5 \\ ILATE: uma Abordagem para Extração Automática de Termos Utilizando Aprendizado Indutivo}

o Capítulo 4, página 55, foi descrito o método proposto para extração auto-
mática de termos - MATE-ML - que aplica classificação para extrair termos
de domínios específicos. Uma das vantagens desse método é que o uso do
aprendizado de máquina automatiza a escolha dos candidatos a termos antes feita de maneira manual ou semiautomática durante a extração tradicional de termos. Outra vantagem em se aplicar AM é que seu uso tem obtido altos valores de precisão (acima de 90\%) na extração de termos para as línguas inglesa e espanhola (Vivaldi et al., 2001; Zhang et al., 2010). Por fim, AM facilita a utilização de um grande número de candidatos a termos, sendo esse o cenário do mundo real, desde que tenta aprender como reconhecer um termo no domínio.

Um diferencial do método MATE-ML proposto nesta tese em relação aos trabalhos de extração de termos encontrados na literatura é que o método proposto utiliza, adapta, avalia e propõe um conjunto de características dos candidatos que faz uso ao mesmo tempo de diferentes níveis de conhecimento: linguístico, estatístico e híbrido. O objetivo da aplicação desse rico conjunto de características é diminuir o silêncio e o ruído da EAT.

Neste capítulo, é apresentada uma abordagem proposta para EAT (descrita a seguir) que instancia as etapas do método MATE-ML utilizando aprendizado indutivo supervisionado. A avaliação experimental realizada com a abordagem proposta é detalhada na Seção 5.2 e seus resultados são discutidos na Seção 5.3. Com base nos resultados obtidos, é realizada a segunda avaliação experimental visando melhorar os resultados da EAT, conforme descrito na Seção 5.4. Ambas avaliações experimentais utilizaram três corpora de domínios diferentes na língua portuguesa do Brasil. Na Seção 5.5, são apresentadas as comparações dos resultados obtidos pelas duas avaliações experimentais. Por fim, as considerações finais deste capítulo são apresentadas na Seção 5.6.

\subsection{Descrição da Abordagem ILATE}

A abordagem proposta para a extração automática de termos instancia o método MATE-ML, apresentado no Capítulo 4. Devido ao fato de essa abordagem utilizar a 
classificação indutiva, ela é denominada "aprendizado indutivo para a extração automática de termos", do inglês, Inductive $\underline{\boldsymbol{L}}$ earning for $\underline{\boldsymbol{A}}$ utomatic $\underline{\boldsymbol{T}}$ erm $\underline{\boldsymbol{E} x t r a c t i o n}$ - ILATE (Conrado et al., 2013c).

As etapas da abordagem ILATE são ilustradas na Figura 5.1 e descritas a seguir.

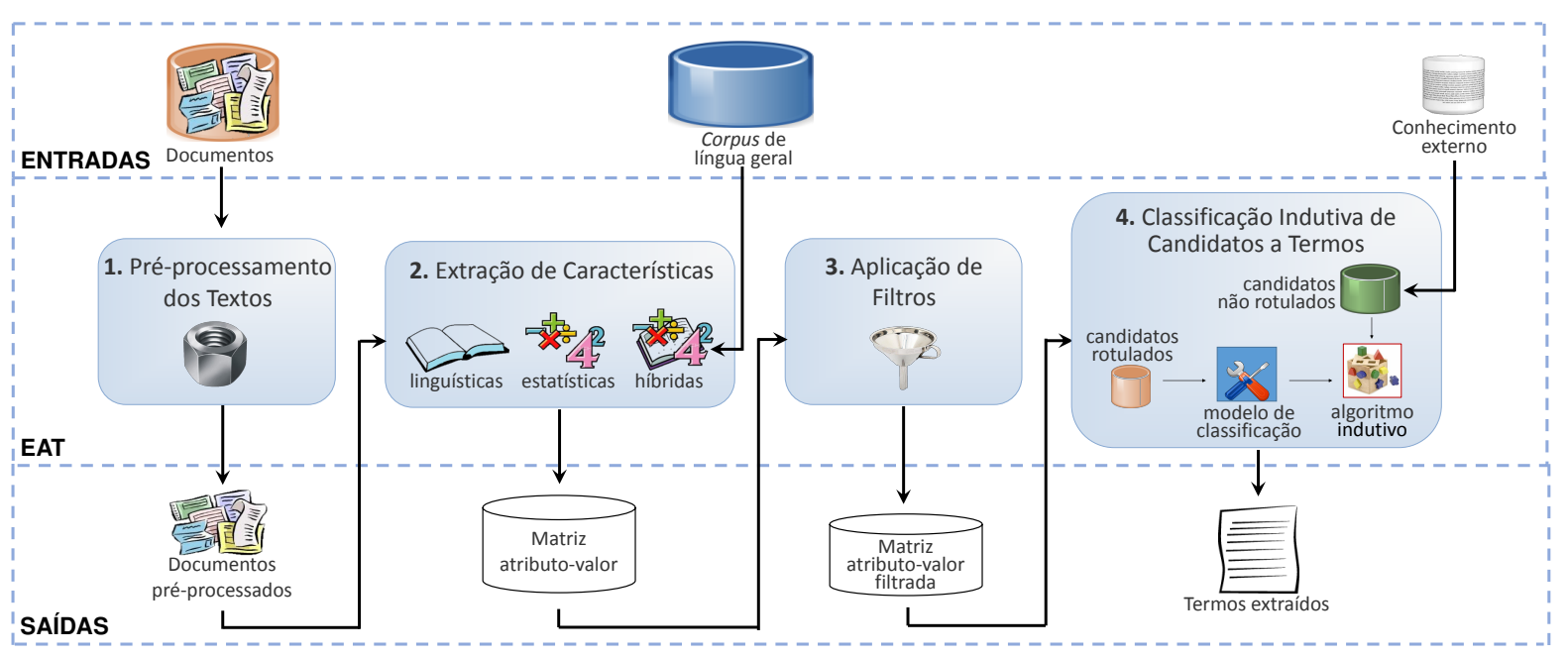

Figura 5.1: ILATE - abordagem para extração automática de termos utilizando aprendizado indutivo.

\subsubsection{Pré-processamento dos Textos}

Assim como em MATE-ML, os documentos de um corpus de domínio do qual se pretende extrair termos constitui a entrada da abordagem proposta para EAT. A primeira etapa da ILATE consiste do pré-processamento desses documentos visando realizar transformações nos dados e eliminar os irrelevantes para a identificação dos termos, conforme detalhado em MATE-ML (Capítulo 4, página 55).

\subsubsection{Extração de Características}

A partir dos textos pré-processados, busca-se indícios de que uma palavra é termo ou não-termo do domínio em questão. Cada uma das palavras dos textos pré-processados é considerada candidato a termo do domínio. Para cada candidato, são extraídas características pertencentes aos níveis de conhecimento linguístico, estatístico e híbrido.

\subsubsection{Aplicação de Filtros}

Os candidatos e suas características estão representados no formato de matriz atributovalor, na qual os candidatos se encontram nas linhas da matriz e as características nas colunas.

Como essa matriz tem diferentes características desses candidatos, para avaliar quais delas são mais relevantes para auxiliar a identificar termos, é realizado um filtro sugerido na ILATE. Esse filtro consiste da seleção de características dos candidatos que, por sua vez, tem dois subobjetivos: (i) identificar qual nível de conhecimento (linguístico, estatístico ou híbrido) é melhor para a EAT e (ii) identificar quais características, independentemente do nível de conhecimento, são melhores para distinguir termos de não-termos.

Para identificar o melhor nível de conhecimento para a EAT, a extração utilizando ILATE é feita separadamente e considerando quatro conjuntos de características diferen- 
tes: (i) todas as características extraídas, (ii) somente as características linguísticas, (iii) somente as estatísticas e (iv) somente as características híbridas.

Já para identificar quais características, independentemente do nível de conhecimento do qual elas pertencem, são melhores para distinguir termos de não-termos, são utilizados métodos de seleção de características baseados em aprendizado de máquina. Esses métodos avaliam o conjunto total de características para selecionar quais delas são melhores para identificar termos e não-termos. Na ILATE, sugere-se o uso de métodos de seleção de características que seguem a abordagem filtro, a qual é independente de algoritmo de classificação, e que avaliam a importância das características considerando a informação da classe. Dessa maneira, sem ter a influência de desempenho de classificadores, é possível identificar a relevância das características em relação à classe dos candidatos (termo ou não-termo).

A matriz dos candidatos a termos tende a ter um elevado número de candidatos porque possui todas as palavras do corpus que não são removidas durante o pré-processamento dos textos. Consequentemente, a extração de termos pode gastar um tempo considerável para ser executada. Visando reduzir essa quantidade de candidatos, o segundo filtro sugerido na ILATE é a seleção de candidatos, que tem o objetivo de remover aqueles com menos chance de serem termos. Dessa maneira, pode-se diminuir o tempo necessário para realizar a extração dos termos.

Essa seleção de candidatos pode ser realizada utilizando um dos dois filtros: Filtro $D F$ ou Filtro $D F \_S N_{-} P M$. O Filtro $D F$ preserva apenas os candidatos que ocorrem em pelo menos dois documentos no corpus $(d f)$, já que os candidatos que aparecem em apenas um documento provavelmente não são representativos do domínio em questão. $\mathrm{O}$ Filtro $D F \_S N_{-} P M$ mantém os candidatos que não são removidos pelo Filtro $D F$, que fazem parte de sintagmas nominais ou preposicionais $(s n)$ e que, ao mesmo tempo, são anotados por um parser automático como sendo substantivos, nomes próprios, verbos ou adjetivos $(p m)$. A ideia do Filtro $D F_{-} S N_{-} P M$ é remover os candidatos que não são representativos do domínio (os que aparecem em apenas um documento) e não seguem os possíveis padrões básicos de termo, ou seja, os que não são substantivos, nomes próprios, verbos ou adjetivos e, consequentemente, não são sintagmas nominais e preposicionais.

\subsubsection{Classificação Indutiva de Candidatos a Termos}

Assim como no método MATE-ML, a abordagem ILATE trata a extração de termos como uma solução de aprendizado de máquina. Dessa maneira, cada candidato a termo é considerado um exemplo utilizado no aprendizado e as características desse candidato são os atributos descritores desse exemplo.

Na ILATE, a classificação supervisionada utilizando aprendizado indutivo é aplicada como meio para rotular novos candidatos como termos e não-termos do domínio em questão. Esse tipo de classificação tem como objetivo induzir um classificador que é obtido ao apresentar um conjunto de candidatos de treinamento $X$, com classes $C$ representando termo ou não-termo, a um algoritmo de aprendizado. Dado um novo candidato $x \in X$, o classificador obtido atribui uma classe $c \in C$ ao candidato $x$. Normalmente, quanto maior a quantidade de candidatos usada pelo algoritmo na indução de um classificador, melhor será o desempenho do classificador.

Algum conhecimento externo é necessário para rotular o subconjunto de candidatos de treinamento. Por exemplo, especialistas do domínio podem fazer a rotulação dos candidatos. Para a criação do subconjunto rotulado considerado na avaliação experimental apresentada nesta tese, utilizou-se a lista de termos de referência do domínio em questão.

Ao final da aplicação da ILATE, tem-se como saída uma lista de (candidatos a) termos 
do domínio em questão gerada pelo classificador.

\subsection{Primeira Avaliação Experimental da ILATE}

Para a avaliação experimental da ILATE, foram utilizadas três corpora na língua portuguesa pertencentes a diferentes domínios: ecologia (ECO), educação à distância (EaD) e nanociência e nanotecnologia (Nano). A escolha de tais corpora foi baseada no fato de pertencerem a domínios variados e serem compostos por diferentes quantidades de textos, segundo a revisão literária feita na área de EAT. Além disso, não foram encontrados outros corpora na língua portuguesa do Brasil que possuíssem listas de termos simples de referências, que é o foco desta pesquisa.

Esses corpora estão detalhados na Subseção 3.4 do Capítulo 3, página 34. Resumidamente, o corpus ECO possui 390 textos (260.921 palavras) e 322 termos simples em sua lista de referência; o corpus EaD é composto por 347 textos (1.350.683 palavras) e 118 termos simples em sua lista de referência; já o corpus Nano tem 1.057 textos $(2.565 .490$ palavras) e 1.794 termos simples em sua lista de referência.

A seguir, os experimentos são detalhados considerando cada etapa da ILATE.

\subsubsection{Pré-processamento dos Textos}

O pré-processamento dos textos de cada corpus consistiu em:

1. Transformar os documentos do corpus Nano que estavam em formato .xml para texto plano. Os documentos dos corpora ECO e EaD já estavam em texto plano.

2. Anotar linguisticamente os textos utilizando o parser Palavras.

3. Eliminar caracteres especias dos textos, como \, |, @ $\mathrm{e}^{\wedge}$, entre outros.

4. Transformar todas as letras para minúsculas.

5. Normalizar as palavras dos textos usando a técnica de radicalização. Para isso, adotou-se a implementação disponível em PTStemmer ${ }^{1}$.

6. Remover stopwords em português - nas quais foram adicionadas às stopwords tradicionais o verbo "ser", pontuação, números, acentos, as palavras compostas de apenas um caractere e as palavras não significativas para o corpus de domínio, como "que", "figura" e "introdução". Também foram removidas stopwords em inglês, uma vez que os textos têm, por exemplo, muitos nomes de livros em inglês que contêm palavras como "and" e "the".

Ao final do pré-processamento, obteve-se 10.524, 14.385, 46.203 radicais (candidatos) para os corpora ECO, EaD e Nano, respectivamente. Devido a diferença do préprocessamento realizada aqui e na extração tradicional de termos (Subseção 4.1 do Capítulo 4, página 55), a quantidade de radicais é diferente em ambos experimentos.

\footnotetext{
${ }^{1}$ Foi utilizado o PTStemmer, que é um conjunto de ferramentas para radicalização da língua portuguesa. - http://code.google.com/p/ptstemmer/
} 


\subsubsection{Extração de Características}

Cada unigrama pré-processado de cada corpus foi considerado como um candidato a termo. Para cada candidato, foram extraídas características que correspondem a métodos, medidas e formas de obtenção de conhecimento que podem ser aplicados à extração de termos simples para o português. Na avaliação experimental do ILATE, foram consideradas 19 características, sendo que 5 foram propostas nessa avaliação e 14 foram utilizadas no experimento apresentado na Seção 4.1 do Capítulo 4, página 55. Essas características são mostradas na Tabela 5.1.

Tabela 5.1: Medidas, métodos e formas de obtenção de conhecimento utilizados na ILATE.

\begin{tabular}{|c|c|c|}
\hline Sigla & Caracteristica & $\begin{array}{c}\text { Valor } \\
\text { resultante }\end{array}$ \\
\hline \multicolumn{3}{|c|}{ Medidas Estatísticas } \\
\hline 1. $\operatorname{com~Gram}^{* *}$ & comprimento do $n$-grama & numérico \\
\hline 2. $t f$ & frequência de termo & numérico \\
\hline 3. $d f$ & frequência de documentos & numérico \\
\hline 4. $t f-i d f$ & frequência de termo - frequência inversa de documento (Salton e Buckley, 1987) & numérico \\
\hline 5. $t v^{*}$ & variância do termo (Liu et al., 2005) & numérico \\
\hline 6. $t v q^{*}$ & qualidade da variância do termo (Dhillon et al., 2003) & numérico \\
\hline 7. $t c^{*}$ & contribuição do termo (Liu et al., 2003) & numérico \\
\hline \multicolumn{3}{|c|}{ Medidas/Métodos Híbridos } \\
\hline 1. $c g$ & se o candidato aparece em um corpus de língua geral & binário \\
\hline 2. freq_cg & frequência do termo em um corpus de língua geral & numérico \\
\hline 3. c-value & frequência e tamanho em gramas do candidato (Frantzi et al., 1998) & numérico \\
\hline 4. nc-value & contexto no qual o candidato aparece (Frantzi et al., 1998) & numérico \\
\hline \multicolumn{3}{|c|}{ Formas de Obtenção de Conhecimento Linguístico } \\
\hline 1. sintagma & sintagma nominal, verbal ou adjetival & binário \\
\hline 2. núcleo_sintagma & núcleo de sintagma nominal, verbal ou adjetival (Estopa et al., 2005) & binário \\
\hline 3. $p m$ & classe gramatical & binário \\
\hline 4. $e i$ & expressão indicativa & binário \\
\hline 5. $n \_$subst. $\Delta$ & número de substantivos & numérico \\
\hline 6. $n-a d j . \Delta$ & número de adjetivos & numérico \\
\hline 7. $n \_$verbo ${ }^{\Delta}$ & número de verbos & numérico \\
\hline 8. $n_{-}$po $\Delta$ & total de palavras que deram origem ao candidato radicalizado & numérico \\
\hline
\end{tabular}

Neste trabalho, foram propostas cinco características linguísticas relacionadas com o radical do candidato, sendo estas identificadas pelo símbolo ${ }^{\Delta}$ na Tabela 5.1. Para explicar tais características, consideram-se as palavras educativo, educadores, educação e educar que dão origem a um mesmo radical, que é educ. Assim, o candidato educ teria como característica $n_{-}$subst. $=2$ (porque há dois substantivos: educadores e educação), $n_{-} a d j$. $=1$ (pelo adjetivo educativo, $n_{-}$verbo $=1$ (pelo verbo educar) e $n_{-}$po $=4$ (porque educ tem 4 palavras originais). O uso dessas cinco características teve como objetivo verificar se os candidatos radicalizados que foram originados a partir de um maior número de substantivos do que adjetivos ou verbos têm mais chance de serem termos.

Conforme detalhado na Seção 4.1 do Capítulo 4, página 55, quatro medidas estatísticas específicas de outras áreas são avaliadas na EAT. A avaliação dessas medidas estatísticas é um dos diferenciais deste trabalho. Três dessas medidas são aplicadas para a tarefa de seleção de características ( $t v$, tvq e $t c$ ), identificadas pelo símbolo * na Tabela 5.1, e uma medida estatística (comGram) que conta o número de caracteres do $n$-grama, normalmente utilizada na tarefa de reconhecimento de entidades nomeadas, identificada pelo símbolo $* *$ na tabela. As medidas $t v$, $t v q$ e $t c$ foram adotadas aqui pois obtiveram resultados satisfatórios na tarefa de seleção de características. A partir do cálculo dessas medidas são retornados valores para cada candidato, o que permite sua aplicação na tarefa de extração de termos. Já a medida comGram foi utilizada nesta pesquisa com o objetivo de que ela verifique se termos de um domínio específico têm tamanhos (em caracteres) 
diferentes de palavras da língua geral ou de termos de outro domínio.

As medidas $t f$, $t f-i d f$ e $d f$ foram escolhidas por serem amplamente utilizadas para a tarefa de extração de termos. As medidas $t f$ e $t f-i d f$ foram utilizadas nesta pesquisa com o objetivo de que elas possam ajudar na identificação dos termos frequentes do domínio, uma vez essas medidas consideram a frequência dos candidatos em relação ao corpus. Já a $d f$ foi avaliada nesta pesquisa com o objetivo de que ela identifique os candidatos que representam o domínio do corpus ao assumir que eles aparecem em pelo menos uma quantidade mínima dos documentos.

Na extração tradicional de termos realizada na Seção 4.1 do Capítulo 4, página 55, a medida $r f$ (frequência relativa de termo) alcançou resultados bem similares à $t f$ (frequência de termo). Como tf está sendo considerada nesse experimento, a rf não foi utilizada.

As medidas híbridas c-value e nc-value (descritas no 3.2.3 do Capítulo 3, página 29), que usualmente são utilizadas na EAT, foram consideradas nessa avaliação experimental. Também foram utilizadas duas medidas híbridas simples, sendo que uma verifica a presença ou ausência do candidato em um corpus de língua geral $(c g)$ e a outra conta a frequência do candidato em um corpus de língua geral (freq_ $c g$ ). A medida $c g$ foi utilizada para verificar se os candidatos que aparecem no corpus de língua geral são termos de domínio específico. A medida $f r e q \_c g$ foi consideradas para verificar se a frequência na qual os candidatos aparecem no corpus de língua geral auxilia na distinção entre termos e não-termos, uma vez que se assume que candidatos com frequências muito altas não são termos e os que têm frequências muito baixas ou zero nesse corpus geral são termos. Para calcular essas duas últimas medidas, utilizou-se o corpus NILC, que contém 40 milhões de palavras no português.

Em relação as formas de obtenção de conhecimento linguístico para a EAT, nesse experimento, assumiu-se que os termos fazem parte de sintagmas nominais, adjetivais e verbais (característica sintagma), uma vez que se assume que termos também podem ser adjetivos (Almeida e Vale, 2008), além de substantivos e verbos (Frantzi et al., 1998; Cabré e Sager, 1999; Zavaglia et al., 2007). Logo, para a característica pm, foram considerados os candidatos que são adjetivos, substantivos ou verbos (Zavaglia et al., 2007). Para ei, foram utilizadas as mesmas expressões indicativas adotadas no experimento descrito na Seção 4.1 do Capítulo 4. Considerando "Todos os organismos são compostos de uma ou mais células", os unigramas "organismos" e "células" seriam considerados candidatos a termos, uma vez que aparecem perto da expressão indicativa "são compostos de".

Por fim, também foi considerado como uma forma de obtenção de conhecimento linguístico o núcleo do sintagma (núcleo_sintagma) uma vez que ele representa o núcleo significativo do termo, conforme discutido por Estopa et al. (2005) e utilizado por Ribeiro Junior (2008) e Ribeiro Junior e Vieira (2008). Por exemplo, considerando o sintagma nominal "Os autótrofos terrestres" pertencente a um texto do corpus de ecologia, o especialista do domínio considerou como termo somente o núcleo desse sintagma, que é "autótrofos".

Desse modo, como citado anteriormente, um total de 19 características foram consideradas. Para mais detalhes sobre elas, exceto as propostas aqui, ver Subseção 3.2 do Capítulo 3, página 21. Ainda na Tabela 5.1, também é indicado se a característica resulta em um valor numérico (conhecida como atributo contínuo na área de aprendizado de máquina) ou em um valor binário (0 ou 1), conhecida como atributo discreto. Um exemplo de atributo contínuo é a frequência de um candidato, que pode ser qualquer número inteiro menor que a quantidade de palavras do corpus. Já como atributo discreto tem-se a possibilidade de um candidato pertencer a alguma classe gramatical pré-estabelecida ( $\mathrm{pm}$ $=1)$ ou não $(p m=0)$.

Após a extração das características para cada candidato a termo, os candidatos foram 
representados em um formato de matriz atributo-valor. Essa matriz de candidatos é chamada de Todos CTs - Todas Caract., uma vez que possui todos os candidatos préprocessados do corpus (Todos CTs) e todas as características extraídas (Todas Caract.).

\subsubsection{Aplicação de Filtros}

Para a seleção de características que visa identificar o melhor nível de conhecimento (linguístico, estatístico ou híbrido) para a EAT, foram consideradas também matrizes de candidatos contendo: somente as características linguísticas (Ling.), somente as estatísticas (Estat.) e somente as características híbridas (Híbrido).

Para a seleção que tem como objetivo identificar quais características, independentemente do nível de conhecimento, são melhores para distinguir termos de não-termos, foram utilizadas quatro combinações de métodos de seleção de características baseados em aprendizado de máquina para escolher o conjunto dessas características que, segundo eles, são mais relevantes para a EAT. A combinação, neste caso, refere-se a um algoritmo para avaliação das características e outro para busca por subconjuntos de características. Esses métodos de seleção de características, disponíveis na ferramenta WEKA (Hall et al., 2009), avaliam o conjunto total de características em relação à consistência e correlação delas com sua classe (termo ou não-termo).

O primeiro algoritmo de seleção de características utilizado foi o Consistency-based Filter (CBF) (Liu e Setiono, 1996). Ele é um algoritmo probabilístico que avalia o subconjunto de características de acordo com sua consistência em relação à classe, ou seja, prioriza a escolha das características que têm valores similares para exemplos com a mesma classe, podendo, portanto, facilitar a classificação (Arauzo-Azofra et al., 2008). Dessa maneira, esse algoritmo procura por combinações de características cujos valores particionem os dados em subconjuntos com alguma classe majoritária.

O segundo algoritmo foi o Correlation-based Feature Selection (CFS) (Hall, 1998), que considera como subconjunto desejado aquele no qual as características tenham pouca correlação com outras características e bastante correlação com a classe.

Conforme comentado anteriormente, esses algoritmos de seleção de características foram escolhidos para ser utilizados porque seguem a abordagem filtro, a qual é independente de algoritmo de classificação e geralmente tem um custo computacional mais baixo em relação aos métodos dependentes de algoritmo de classificação (p. ex., método que busca um subconjunto que maximiza o desempenho de classificadores SVM) (Liu e Motoda, 2007). Esses métodos foram escolhidos porque eles realizam a seleção de características supervisionada, assim, eles são capazes de avaliar a importância das características considerando a informação da classe, seja para avaliar consistência ou para avaliar correlação entre características e suas classes.

Como os algoritmos CBF e CFS avaliam subconjuntos de características, é necessário definir como a busca das características será realizada e qual será o critério de parada da busca por esses subconjuntos. Nesta pesquisa, tanto para o CBF como para o CFS, utilizou-se o método de busca bastante conhecido na literatura, o Best First (BF), e um método de busca randômica chamando Random Search (RS).

O Best First (Russell e Norvig, 2003) realiza uma busca gulosa no espaço dos subconjuntos de características com backtracking. O espaço de busca dos subconjuntos de características corresponde a todas as combinações de subconjuntos possíveis. Nesta pesquisa, o critério de parada da busca seguiu o padrão da WEKA, que é finalizar a busca quando não há ganhos ao utilizar o subconjunto de características considerando 5 passos consecutivos do backtracking. Já o Random Search (Liu e Setiono, 1996) percorre randomicamente o espaço dos subconjuntos de características. Neste trabalho, o critério de 
parada da busca seguiu o padrão utilizado pela WEKA para o RS, que é finalizar a busca quando já percorreu uma porcentagem do espaço de busca a ser explorado (25\%).

Então, as quatro combinações de métodos de seleção de características utilizadas nesta pesquisa foram: CBF usando o Random Search como método de busca ( $\left.C B F \_R S\right)$; CBF com o Best First como método de busca $\left(C B F_{-} B F\right)$; CFS utilizando o método de busca Random Search $\left(C F S_{-} R S\right)$; e CFS com o Best First como método de busca $\left(C F S_{-} B F\right)$.

Com o uso desses quatro métodos foram geradas mais quatro matrizes de candidatos contendo as características que os métodos de seleção consideraram melhores para extrair termos.

A representação dos candidatos a termos (matrizes de candidatos) tem um elevado número de candidatos a termos e, consequentemente, a extração de termos pode gastar um tempo considerável para ser executada. Para diminuir o número de candidatos, uma seleção de candidatos foi realizada utilizando, para isso, dois filtros diferentes. O Filtro $D F$ preserva apenas os candidatos que ocorrem em pelo menos dois documentos no corpus, uma vez que os candidatos que aparecem em apenas um documento provavelmente não são representativos do domínio em questão. O Filtro $D F_{-} S N_{-} P M$ mantém os candidatos que não foram removidos pelo Filtro $D F$, que fazem parte de sintagmas nominais ou preposicionais e que, ao mesmo tempo, foram anotados pelo parser como sendo substantivos, nomes próprios, verbos ou adjetivos. A ideia do Filtro $D F_{-} S N_{-} P M$ é remover os candidatos que não são representativos do domínio (os que aparecem em apenas um documento) e não seguem os padrões básicos de termo normalmente assumidos pela comunidade, ou seja, os que não são substantivos, nomes próprios, verbos ou adjetivos e, consequentemente, não são sintagmas nominais e preposicionais.

A seleção de candidatos foi realizada a partir dessas 8 matrizes de candidatos citadas anteriormente e consistiu da aplicação dos Filtro DF e Filtro $D F \_S N_{-} P M$. Tem-se, então, um total de 24 matrizes de candidatos a termos para cada corpus, conforme mostrado na Figura 5.2. Por exemplo, a primeira linha na esquerda da figura corresponde à matriz composta por todos os candidatos (Todos CTs) com todas as suas características (Todas Caract.), a segunda matriz contém todos os candidatos (Todos CTs) com somente suas características linguísticas (Ling.) e assim sucessivamente.

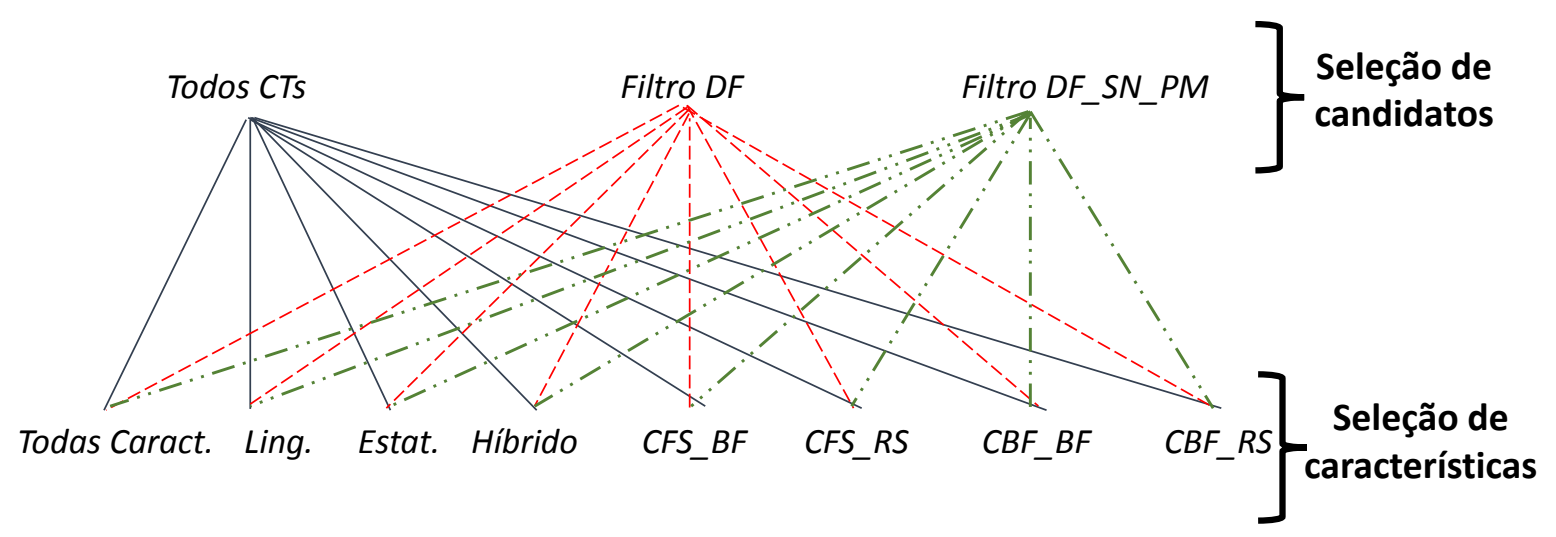

Figura 5.2: Matrizes dos candidatos a termos.

Acredita-se que a redução do número de candidatos é uma das contribuições desta pesquisa. Para exemplificar tal redução, considera-se a seguir a matriz com todas as características dos candidatos (Todas Caract).

O número de candidatos (radicais) obtidos inicialmente para Todos CTs foi 10.524 , 14.385 e 46.203, para os corpora, respectivamente, ECO, EaD e Nano. Ao usar o Filtro DF, esse número diminuiu $55,15 \%, 45,83 \%$ e $57,05 \%$, e ao usar o Filtro $D F \_S N_{-} P M$ diminuiu $63,10 \%, 63,18 \%, 66,95 \%$ em relação a quantidade de todos os candidatos inicialmente 
obtidos (Todos CTs). Claramente ao filtrar candidatos é possível que se remova também termos verdadeiros. Na Figura 5.3 são mostradas as quantidades de candidatos para cada filtro e quantos termos verdadeiros foram removidos durante cada filtragem. Esses valores correspondem aos radicais dos candidatos a termos e dos termos da lista de referência.

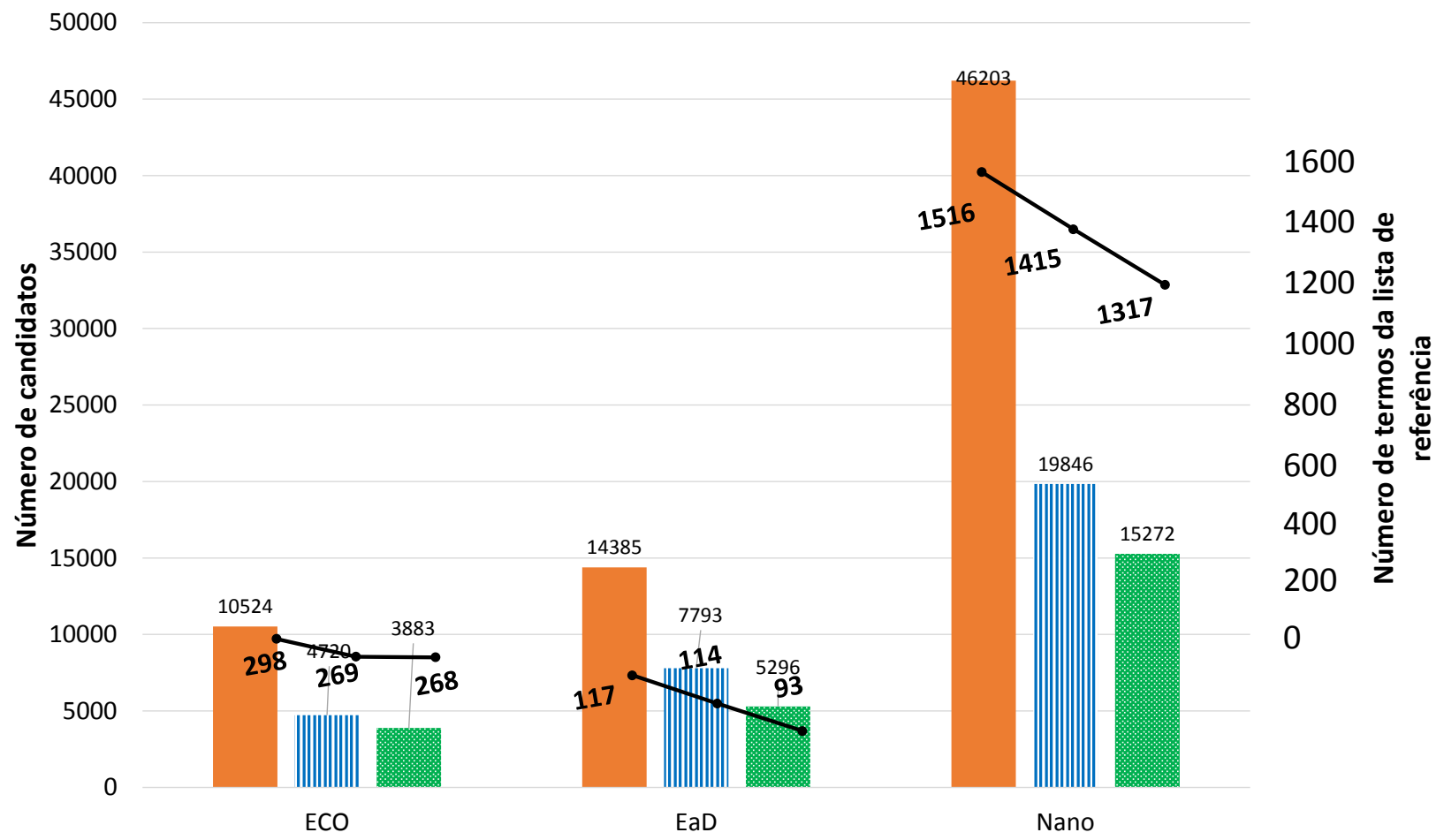

\section{Legenda:}

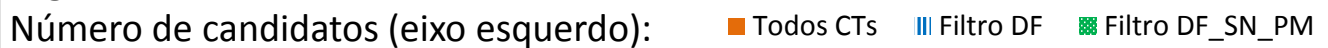
Número de termos da lista de referência (eixo direito): $\bullet$ Termos da lista de referência

Figura 5.3: Número de candidatos considerados por cada filtro aplicado vs. número de termos da lista de referência mantidos por cada filtro.

Para exemplificar a análise dos dados da Figura 5.3, considera-se o corpus ECO. Ao observar o eixo à esquerda ("Número de candidatos") e a primeira barra alaranjada (correspondente à Todos CTs), observa-se que esse corpus tem 10524 radicais em seu total. Nesse caso, ao observar o eixo à direita ("Número de termos da lista de referência") e o primeiro ponto da linha negra, verifica-se que a lista de referência, que originalmente tem 322 termos simples, foi reduzida a 298 radicais após seu pré-processamento e sua radicalização. Após a aplicação do Filtro DF, reduziu-se o número de candidatos para 4720 (44,85\% a menos do total), sendo que 29 desses candidatos eram termos verdadeiros (removendo assim 9,73\% dos termos verdadeiros).

Como esperado, observa-se que o Filtro $D F_{-} S N_{-} P M$ reduz mais o número de candidatos para os três corpora. Para o corpus EaD, essa diminuição é ainda mais notável uma vez que o uso do Filtro $D F_{-} S N_{-} P M$ removeu 837 candidatos $(17,35 \%)$ a mais do que o Filtro DF sendo que, desse total, somente 1 candidato era termo verdadeiro do domínio.

Na Figura 5.4, são mostrados os resultados da seleção de características considerando a seleção de candidatos. Ou seja, os conjuntos de características selecionados por cada um dos métodos de seleção de características $\left(C F S_{-} R S, C F S_{-} B F, C B F_{-} R S\right.$ e $\left.C B F_{-} B F\right)$ utilizando cada uma das matrizes de candidatos obtidas por diferentes filtragens ( $\bar{T}$ Todos CTs, Filtro DF e Filtro DF_SN_PM) de cada corpus (ECO, EaD e Nano).

Para os corpora ECO e EaD, os métodos de seleção de características $C F S_{-} R S$ e $C F S_{-} B F$ elegeram o mesmo conjunto de características quando utilizaram como entrada 


\begin{tabular}{|c|c|c|c|c|}
\hline & $\begin{array}{l}\text { Método/ } \\
\text { Corpus }\end{array}$ & ECO & EaD & Nano \\
\hline \multirow{4}{*}{$\begin{array}{l}\mathscr{\omega} \\
0 \\
0 \\
0 \\
0 \\
0\end{array}$} & CFS_RS & $\begin{array}{l}\text { tf-idf, tv, tvq, tc, núcleo_sintagma, } \\
\text { pm, n_subst., n_adj., n_po }\end{array}$ & tv, ei, nc-value, n_subst., n_adj. & $\begin{array}{c}\text { tf, df, tvq, ei, núcleo_sintagma, } \\
\text { n_subst., n_adj., n_po }\end{array}$ \\
\hline & CFS_BF & $\begin{array}{l}\text { tf-idf, tvq, tc, sintagma, pm, n_subst., } \\
\text { n_adj., n_po }\end{array}$ & $\begin{array}{c}\text { idem ao CFS_RS usando Todas } \\
\text { Caract. }\end{array}$ & $\begin{array}{c}\text { tf-idf, tvq, ei, núcleo_sintagma, } \\
\text { n_subst., n_adj., n_po }\end{array}$ \\
\hline & CBF_RS & $\begin{array}{l}\text { comGram, tf, df, tf-idf, tv, tvq, cg, ei, } \\
\text { c-value, } \\
\text { nc-value, sintagma, pm, n_subst., } \\
\text { n_adj., n_verbo, n_po }\end{array}$ & $\begin{array}{l}\text { comGram, tf, df, tf-idf, tv, tvq, tc, cg, } \\
\text { freq_cg, ei, c-value, nc-value, } \\
\text { núcleo_sintagma, pm, n_subst., n_adj., } \\
\text { n_verbo, n_po }\end{array}$ & $\begin{array}{c}\text { comGram, df, tf-idf, tv, tvq tc, freq_cg, } \\
\text { ei, nc-value, núcleo_sintagma, } \\
\text { n_subst., n_adj., n_verbo, n_po }\end{array}$ \\
\hline & CBF_BF & $\begin{array}{c}\text { comGram, tf, df, tf-idf, tv, tvq, cg, ei, } \\
\text { nc-value, sintagma, pm, n_subst., } \\
\text { n adj., n verbo, n po }\end{array}$ & $\begin{array}{c}\text { tf, df, tf-idf, tv, tvq, tc, cg, freq_cg, ei, } \\
\text { nc-value, sintagma, pm, n_subst., } \\
\text { n adj., n verbo, n po }\end{array}$ & $\begin{array}{l}\text { comGram, tf, df, tf-idf, tv, tvq, tc, } \\
\text { freq_cg, ei, nc-value, núcleo_sintagma, } \\
\text { pm, n subst., n adj., n verbo, n po }\end{array}$ \\
\hline \multirow{4}{*}{$\begin{array}{l}\text { 늠 } \\
\text { 은 } \\
\frac{1}{2}\end{array}$} & CFS_RS & tv, tvq, tc, pm, n_subst. & $\begin{array}{l}\text { comGram, tf-idf, tvq, ei, n_subst., } \\
\text { n_adj., n_verbo }\end{array}$ & $\begin{array}{l}\text { df, tf-idf, tvq, ei, c-value, pm, n_subst., } \\
\text { n_adj., n_po }\end{array}$ \\
\hline & CFS_BF & tf-idf, tvq, tc, pm, n_subst. & $\begin{array}{l}\text { comGram, tf-idf, tvq, cg, ei, n_subst., } \\
\text { n_adj., n_verbo }\end{array}$ & $\begin{array}{c}\text { tf, tf-idf, tvq, ei, pm, n_subst., n_adj., } \\
\text { n_po }\end{array}$ \\
\hline & CBF_RS & $\begin{array}{l}\text { tf, df, tf-idf, tv, tvq, cg, freq_cg, ei, nc- } \\
\text { value, sintagma, núcleo_sintagma, } \\
\text { pm, n_subst., n_adj., n_verbo, n_po }\end{array}$ & $\begin{array}{l}\text { comGram, tf, df, tf-idf, tv, tvq, tc, cg, } \\
\text { freq_cg, ei, nc-value, sintagma, } \\
\text { núcleo_sintagma, pm, n_subst., n_adj., } \\
\text { n_verbo, n_po }\end{array}$ & $\begin{array}{c}\text { comGram, tf, df, tf-idf, tv, tvq, tc, cg, } \\
\text { freq_cg, ei, nc-value, sintagma, } \\
\text { núcleo_sintagma, pm, n_subst., n_adj., } \\
\text { n_verbo, n_po }\end{array}$ \\
\hline & CBF_BF & $\begin{array}{c}\text { tf, df, tf-idf, tv, tvq, cg, ei, nc-value, } \\
\text { sintagma, núcleo_sintagma, pm, } \\
\text { n subst., n adj., n po }\end{array}$ & $\begin{array}{l}\text { comGram, tf, df, tf-idf, tvq, tc, cg, ei, } \\
\text { nc-value, sintagma, núcleo_sintagma, } \\
\text { pm, n subst., n adj., n verbo, n po }\end{array}$ & $\begin{array}{c}\text { tf, df, tf-idf, tv, tvq, tc, cg, ei, nc-value, } \\
\text { sintagma, núcleo_sintagma, pm, } \\
\text { n subst., n adj., n verbo, n po }\end{array}$ \\
\hline \multirow{4}{*}{ 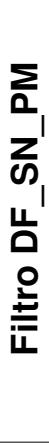 } & CFS_RS & tf-idf, tv, tvq, tc, n_subst. & tf-idf, tv, tvq, ei, n_subst., n_adj. & $\begin{array}{c}\text { tf, df, tf-idf, tc, ei, c-value, nc-value, } \\
\text { n_subst., n_adj., n_po }\end{array}$ \\
\hline & CFS_BF & $\begin{array}{c}\text { idem ao CFS_RS usando candidatos } \\
\text { resultantes do Filtro DF_SN_PM }\end{array}$ & $\begin{array}{c}\text { idem ao CFS_RS usando candidatos } \\
\text { resultantes do Filtro DF_SN_PM }\end{array}$ & $\begin{array}{l}\text { tf, tf-idf, tvq, ei, c-value, nc-value, } \\
\text { n_subst., n_adj., n_po }\end{array}$ \\
\hline & CBF_RS & $\begin{array}{l}\text { tf, df, tf-idf, tv, tvq, tc, cg, ei, nc-value, } \\
\text { núcleo_sintagma, pm, n_subst., } \\
\text { n_adj.,n_verbo, n_po }\end{array}$ & $\begin{array}{l}\text { tf, df, tf-idf, tv, tvq, tc, cg, freq_cg, ei, c- } \\
\text { value, nc-value, pm, n_subst., n_adj., } \\
\text { n_verbo, n_po }\end{array}$ & $\begin{array}{l}\text { comGram, df, tf-idf, tv, tvq, tc, cg, } \\
\text { freq_cg, ei, c-value, nc-value, } \\
\text { sintagma, núcleo_sintagma, pm, } \\
\text { n_subst., n_adj., n_verbo, n_po }\end{array}$ \\
\hline & CBF_BF & $\begin{array}{c}\text { tf, df, tf-idf, tv, tvq, tc, cg, ei, nc-value, } \\
\text { núcleo_sintagma, pm, n_subst., } \\
\text { n_adj., n_po }\end{array}$ & $\begin{array}{l}\text { tf, df, tf-idf, tv, cg, ei, nc-value, } \\
\text { núcleo_sintagma, n_subst., n_adj., } \\
\text { n_verbo, n_po }\end{array}$ & $\begin{array}{c}\text { comGram, tf, df, tf-idf, tv, tvq, tc, cg, ei, } \\
\text { nc-value, núcleo_sintagma, pm, } \\
\text { n_subst., n_adj., n_verbo, n_po }\end{array}$ \\
\hline
\end{tabular}

Figura 5.4: Seleção de características considerando diferentes filtragens de candidatos.

os candidatos que se mantiveram durante o uso do Filtro $D F_{-} S N_{-} P M$. Para o corpus EaD, tais métodos $\left(C F S_{-} R S\right.$ e $\left.C F S_{-} B F\right)$ também selecionaram o mesmo conjunto de características quando usaram como entrada todos os candidatos.

Em relação à seleção de características feita por quatro métodos diferentes a partir dos 3 corpora, a característica que foi escolhida como relevante para a classificação em todos os casos foi a $n_{-}$subst. (proposta na pesquisa apresentada nesta tese). Esse resultado já era esperado, uma vez que os especialistas dos domínios tendem a escolher substantivos como termos. Em 88,89\% dos casos, $t f-i d f$, $t v q$ e $n_{-} a d j$. também foram indicadas como características relevantes e em $88,33 \%$ dos casos, ei foi selecionada. As características propostas nesta pesquisa, que são $n_{-}$subst., $n_{-} a d j$., $n_{-}$po e $n_{-}$verbo, foram selecionadas por, respectivamente, $100 \%, 88,89 \overline{\%}, 77,22 \%$ e $50 \%$ dos casos. Já as características de outra área, que são $t v q$, $t v$, tc e comGram foram indicadas como relevantes por, respectivamente, $88,89 \%, 69,44 \%, 55,56 \%$ e $33,33 \%$ dos casos. Esses dados podem ser observados na Figura 5.5. Ao considerar a quantidade de características selecionada por cada método para cada caso, - por exemplo, o CFS_RS escolheu 9 características considerando Todos CTs do corpus ECO - calcula-se que esses métodos de seleção de características escolheram, em média, 34 características. 


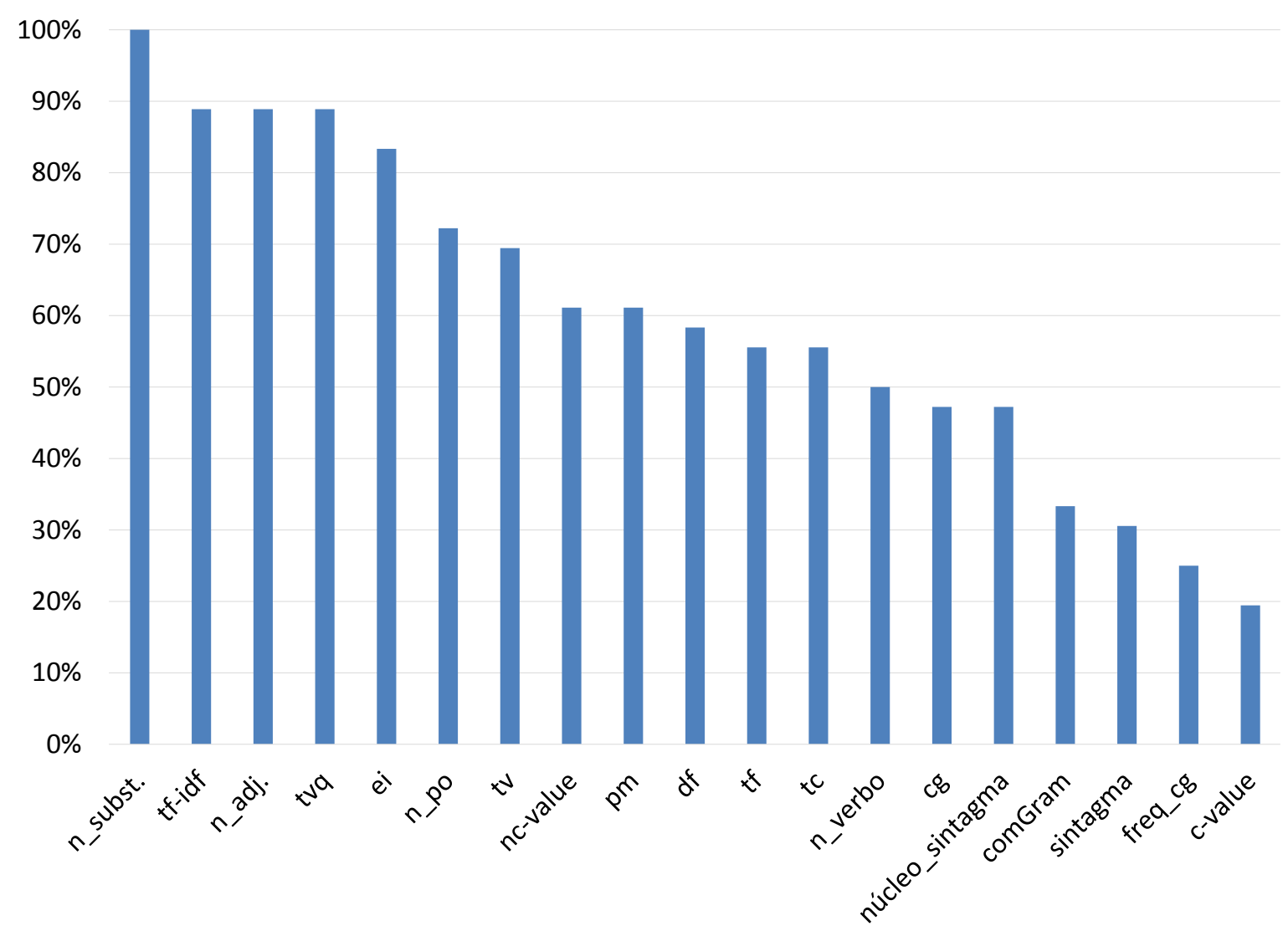

Figura 5.5: Porcentagem da escolha de cada característica considerando todos os métodos de seleção de características e os três corpora utilizados.

\subsubsection{Classificação Indutiva de Candidatos a Termos}

Para que a classificação dos candidatos a termos não seja influenciada pelo desempenho dos classificadores, nesta pesquisa, foram utilizados algoritmos tradicionais de classificação que se baseiam em diferentes paradigmas (Feldman e Sanger, 2006; Sebastiani, 2002). Os algoritmos, juntamente com seus paradigmas, são: i) Nä̈ve Bayes (NB), paradigma probabilístico; ii) $\mathrm{J}_{4} 8^{2}$ e $\mathrm{JRIP}^{3}$, ambos pertencentes ao paradigma simbólico; iii) $K$ Nearest Neighbors (KNN), aprendizado baseado em instâncias; e iv) Sequential Minimal Optimization $\left(\mathrm{SMO}^{4}\right)$, aprendizado estatístico. A seguir, descreve-se brevemente tais algoritmos e seus respectivos paradigmas. Todos esses algoritmos estão disponíveis na ferramenta computacional WEKA.

- No paradigma probabilístico, os classificadores verificam a probabilidade $P(c \mid x)$ de um exemplo $x$ pertencer a uma classe $c$ e calcula essa probabilidade utilizando o teoria de Bayes (Feldman e Sanger, 2006): $P(c \mid x)=\frac{P(x \mid c) P(c)}{P(x)}$. Entre os algoritmos probabilísticos, destacam-se os bayesianos. Tais algoritmos fazem uso de evidências durante a inferência que permitem associar uma probabilidade a hipótese gerada, sendo assim, esses algoritmos tentam modelar a probabilidade de um novo exemplo pertencer a uma certa classe. Eles seguem a pressuposição de independência dada a classe entre as características que descrevem os exemplos, o que diminui bastante o número de parâmetros que deve ser estimado (Mitchell, 1997). Dentre as várias

\footnotetext{
${ }^{2} \mathrm{~J} 48$ corresponde à implementação do algoritmo de classificação C4.5.

${ }^{3}$ JRIP corresponde à implementação do algoritmo Repeated Incremental Pruning to Produce Error Reduction (RIPPER).

${ }^{4}$ SMO pertence à família dos algoritmos de classificação de Máquinas de Vetores de Suporte (SVMs).
} 
implementações dos algoritmos bayesianos, nesta pesquisa, utilizou-se o Naïve Bayes (John e Langley, 1995). Uma descrição mais detalhada sobre esse algoritmo pode ser apreciada em Mitchell (1997).

- No paradigma simbólico, o objetivo é aprender construindo representações simbólicas de um conceito por meio da análise de exemplos e contra-exemplos desse conceito (Monard e Baranauskas, 2003). Os classificadores simbólicos constroem modelos mais facilmente interpretáveis por humanos do que os demais (Feldman e Sanger, 2006). As representações simbólicas normalmente fazem uso de árvore de decisão e regras. Nesta pesquisa, foram utilizados os algoritmos JRIP (Cohen, 1995), baseado em regras, e J48 (Quinlan, 1993), baseado em árvore de decisão. O algoritmo JRIP ordena as classes de acordo com a prevalência crescente da classe (iniciar com a classe que contém a menor quantidade de exemplos ou padrões), aprende primeiro o conjunto de regras para a classe minoritária (menor número de exemplos), considerada como classe positiva, e segue repetindo o aprendizado com a seguinte menor classe até que não existam mais exemplos a serem classificados positivamente, ou até que uma regra gerada possua uma taxa de erro alta. Mais detalhes podem ser vistos em Feldman e Sanger (2006). O algoritmo J48 gera, a partir de um conjunto de treinamento, uma árvore de decisão utilizando regras do tipo SE < condição $>$ ENTÃO < conclusão $>$ para classificar os novos exemplos. Uma descrição mais detalhada sobre J48 pode ser apreciada em Witten et al. (2011).

- No paradigma baseado em instâncias, os classificadores medem a semelhança entre o exemplo a ser classificado e cada exemplo de treinamento para induzir a classe desse exemplo. Um dos algoritmos baseados em instâncias mais utilizados é o KNN, o qual foi adotado nesta pesquisa. Esse algoritmo decide se um exemplo $x$ pertence à classe $c$, se os $k$ exemplos de treino mais similares à $x$ pertencem à $c$. Essa similaridade é calculada utilizando alguma medida de distância. Mais detalhes sobre o KNN podem ser apreciados em Yavuz e Guvenir (1998) e Feldman e Sanger (2006). Mesmo que o KNN é um algoritmo tradicional, há diversas implementações do mesmo. Nesta pesquisa, foi utilizado o algoritmo IBk (Aha et al., 1991), que é uma implementação do KNN.

- No paradigma estatístico, utilizam-se modelos estatísticos para encontrar uma aproximação considerada boa do conceito induzido (Mitchell, 1997). SVM forma uma conjunto de algoritmos aplicados para a obtenção de classificadores lineares e binários, ou seja, que separam exemplos em duas classes por meio de uma fronteira linear (hiperplano) posicionada entre os exemplos dessas classes. Uma descrição mais detalhada sobre SVM está disponível em Cristianini e Shawe-Taylor (2000). Entretanto, existem adaptações do SVM original para que este possa trabalhar com mais de duas classes (Lorena, 2006). Nesta pesquisa, foi adotado o algoritmo SMO (Keerthi et al., 2001), que é uma implementação do SVM disponível no WEKA. A ideia geral do SMO é construir um hiperplano com maior margem de separação entre os exemplos de classes distintas e, então, os novos exemplos são classificados de acordo com sua posição no hiperplano.

Uma vez que o objetivo da pesquisa apresentada nesta tese não é a comparação do desempenho dos algoritmos de classificação, mas sim utilizá-los como meio para a extração automática de termos, foram adotados os parâmetros padrões desses algoritmos que são sugeridos pela WEKA. Considerando essas sugestões, para o algoritmo KNN foi adotada a distância cosseno, que é aconselhável para medir a similaridade de documentos representados no espaço vetorial, e o valor de $k$ foi definido em 7 , seguindo as indicações de 
Batista e Furtado (2009). Foram utilizadas as classes em Java, disponíveis na página Web da WEKA, que implementam esses algoritmos de classificação. Para o treinamento dos algoritmos, considerou-se 10-fold cross validation. Para os diferentes algoritmos utilizados, os folds continham os mesmos candidatos rotulados que foram inicialmente escolhidos de forma aleatória.

Os cinco algoritmos foram executados para cada matriz de candidatos a termos de cada corpus visando gerar automaticamente uma lista de candidatos considerados termos do domínio em questão (termos extraídos) segundo o algoritmo de classificação utilizado.

\subsection{Apresentação, Análise e Discussão dos Resultados da Primeira Avaliação Experimental da ILATE}

Para analisar os termos extraídos, adotou-se o método para avaliação descrito anteriormente na Seção 4.3 do Capítulo 4, página 70. Para cada lista de termos extraídos, foram calculadas precisão, cobertura e medida F. A matriz de contingência utilizada para se calcular as medidas de precisão, cobertura e medida $\mathrm{F}$ foi obtida por meio da soma dos resultados obtidos pelos 10 folds de teste.

Para facilitar o entendimento da avaliação, as discussões sobre os resultados foram divididas em três partes: (i) discussão sobre os resultados da ILATE, (ii) comparação e discussão sobre os resultados da ILATE com outras medidas/métodos de extração de termos, e (iii) discussão acerca da junção de características de diferentes níveis de conhecimento para a extração de termos.

\subsubsection{Discussão sobre os Resultados da ILATE}

Os valores obtidos por cada uma das medidas de avaliação utilizadas (precisão, cobertura e medida F) são mostrados nas Figuras de 5.6 a 5.14 .

Para cada corpus (ECO, EaD e Nano), os resultados são apresentados separadamente para cada conjunto de características selecionado por cada um dos métodos de seleção de características $\left(C F S_{-} R S, C F S_{-} B F, C B F_{-} R S\right.$ e $\left.C B F_{-} B F\right)$ utilizando cada uma das matrizes de candidatos obtidas por diferentes filtragens (Todos CTs, Filtro DF e Filtro $\left.D F_{-} S N_{-} P M\right)$. Para os experimentos, também foram consideradas todas as características juntas (Todas Caract.), somente as características linguísticas (Ling.), somente as estatísticas (Estat.) e as características híbridas (Híbrido).

Ressalta-se que para o cálculo da cobertura de cada corpus foi descontado o número de termos verdadeiros removidos durante a seleção de candidatos (previamente explicada). Por exemplo, para o corpus Nano, 101 termos verdadeiros foram removidos durante a seleção de candidatos utilizando o Filtro DF. Na ILATE, foram extraídos corretamente 420 termos, mas deveria ter extraído 995 termos verdadeiros, além dos 420 . Então, o cálculo da cobertura foi: Cobertura $=\frac{420}{101+995+420}=27,70 \%$ (veja quinta linha da Tabela 5.4).

Ao analisar os valores obtidos pelas medidas de avaliação, observa-se que a precisão varia de 0 a $100 \%$ para os corpora ECO e EaD e, para o corpus Nano, os valores atingem de 0 até levemente superior a $80 \%$. Os valores de cobertura para os 3 corpora alcançam quase $40 \%$. A medida F é sempre inferior a 20, 30 e 40\% para, respectivamente, os corpora EaD, ECO e Nano; tendo como exceção o valor de $21,05 \%$ para o corpus EaD quando se utiliza o indutor J48 com somente as características híbridas e os candidatos mantidos pelo Filtro $D F_{-} S N_{-} P M$ (ver Hibrido - DF_SN_PM - J48 na Tabela 5.3).

Em relação a seleção de características dos candidatos utilizadas na extração de termos, para o corpus ECO, os resultados mais baixos de precisão foram atingidos quando se 


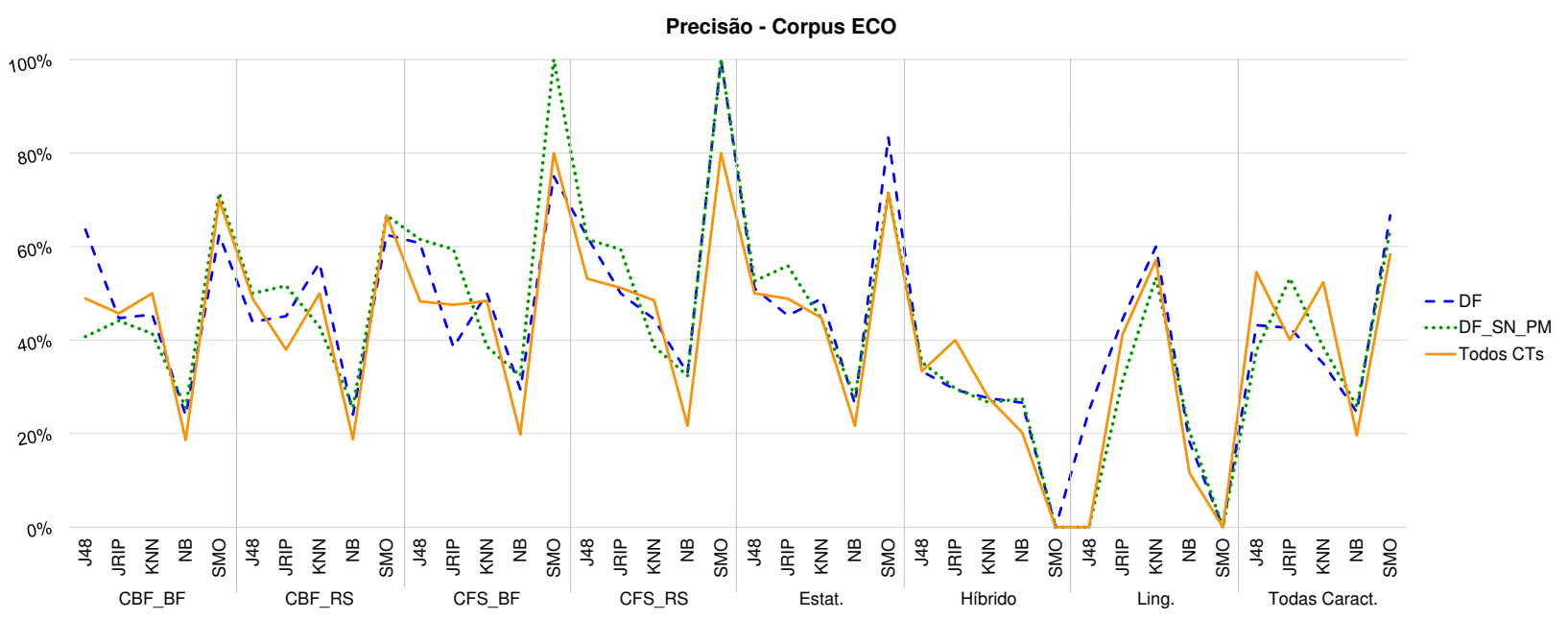

Figura 5.6: Resultados de precisão - Corpus ECO.

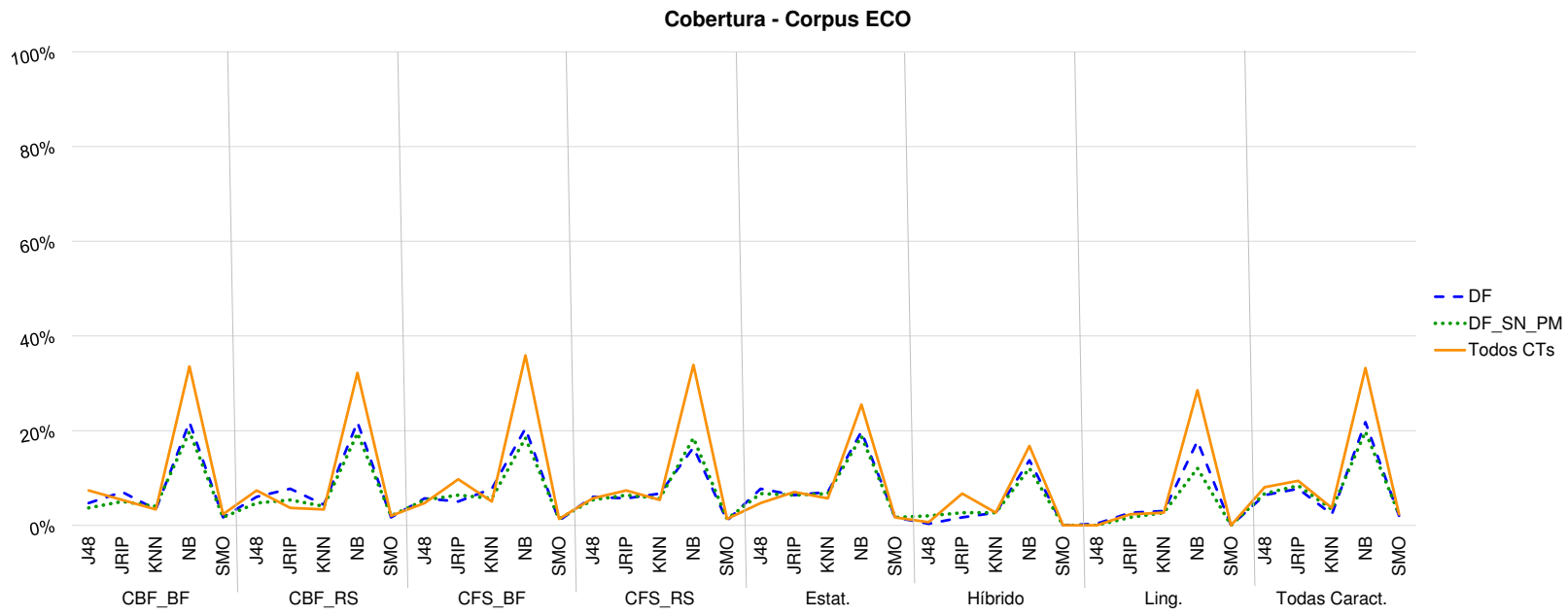

Figura 5.7: Resultados de cobertura - Corpus ECO.

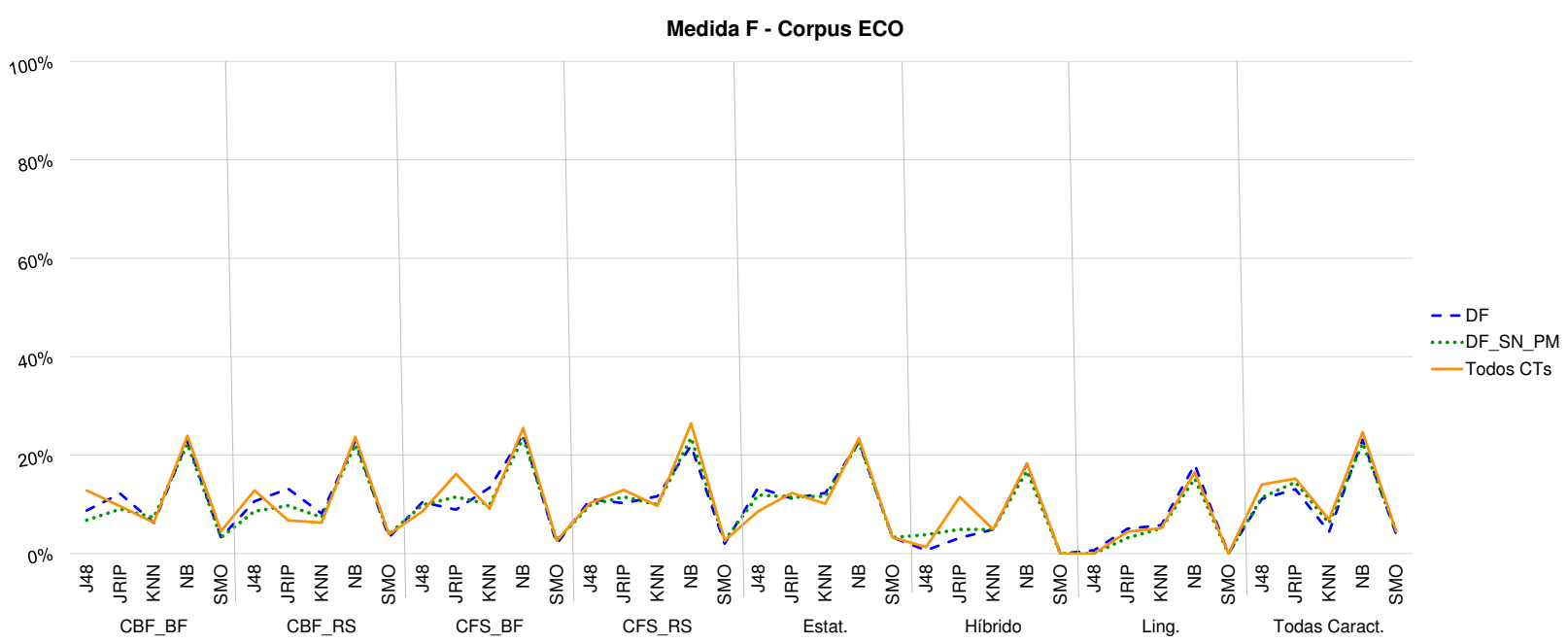

Figura 5.8: Resultados de medida F - Corpus ECO.

utiliza somente características híbridas e, para o corpus EaD, quando se utiliza somente características linguísticas, embora os valores mais altos dessas características se aproximam de $80 \%$. Para o corpus Nano, os resultados inferiores de precisão foram obtidos 


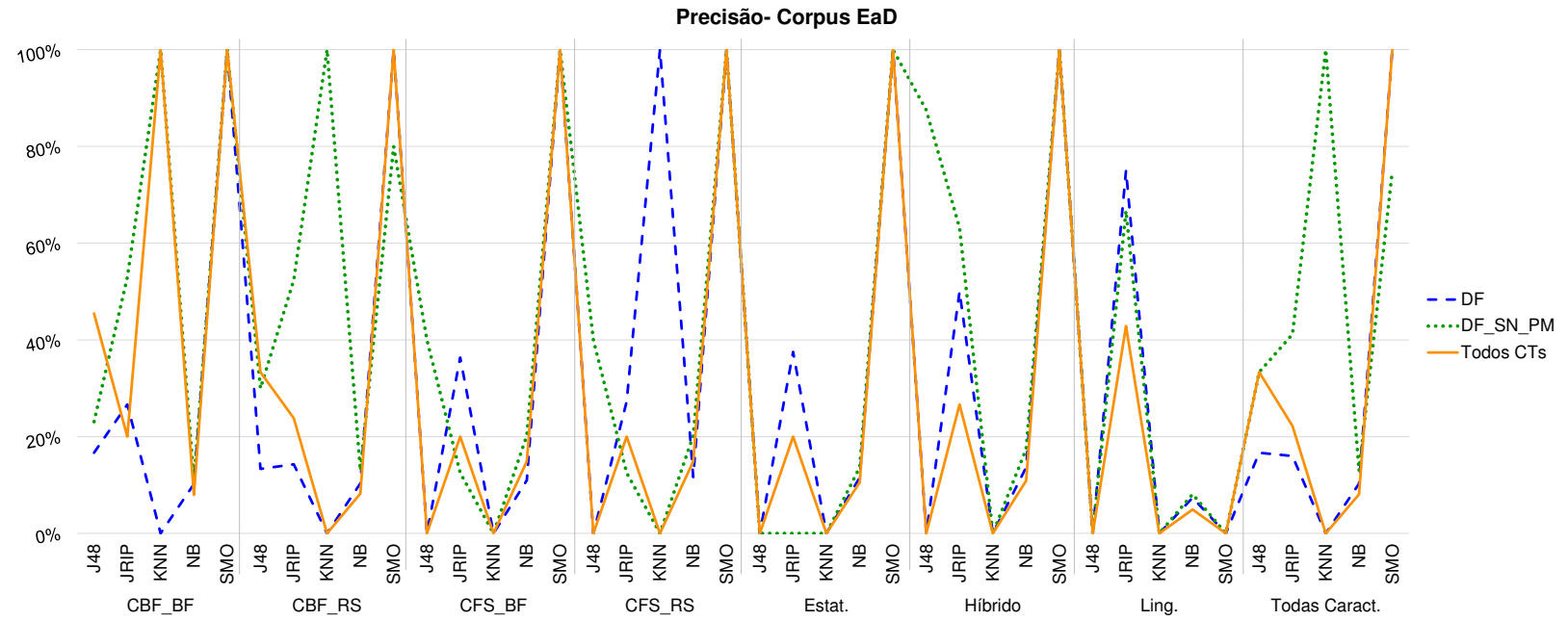

Figura 5.9: Resultados de precisão - Corpus EaD.

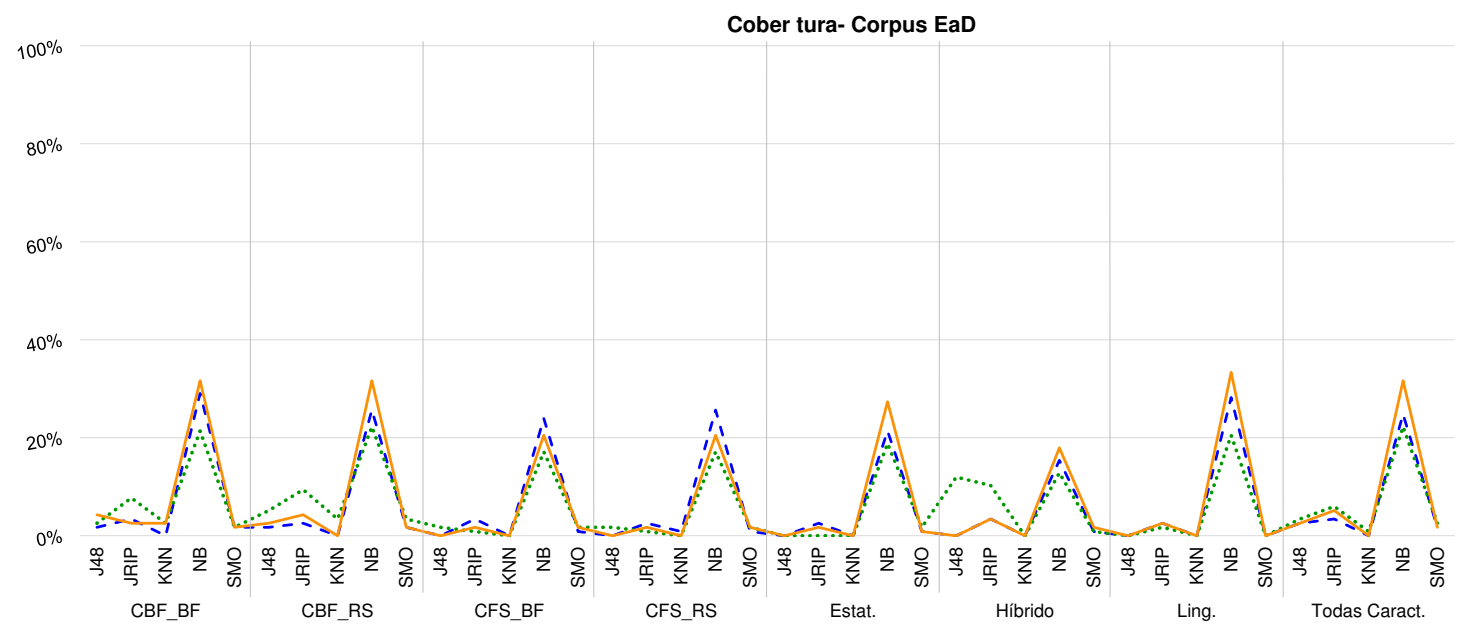

Figura 5.10: Resultados de cobertura - Corpus EaD.

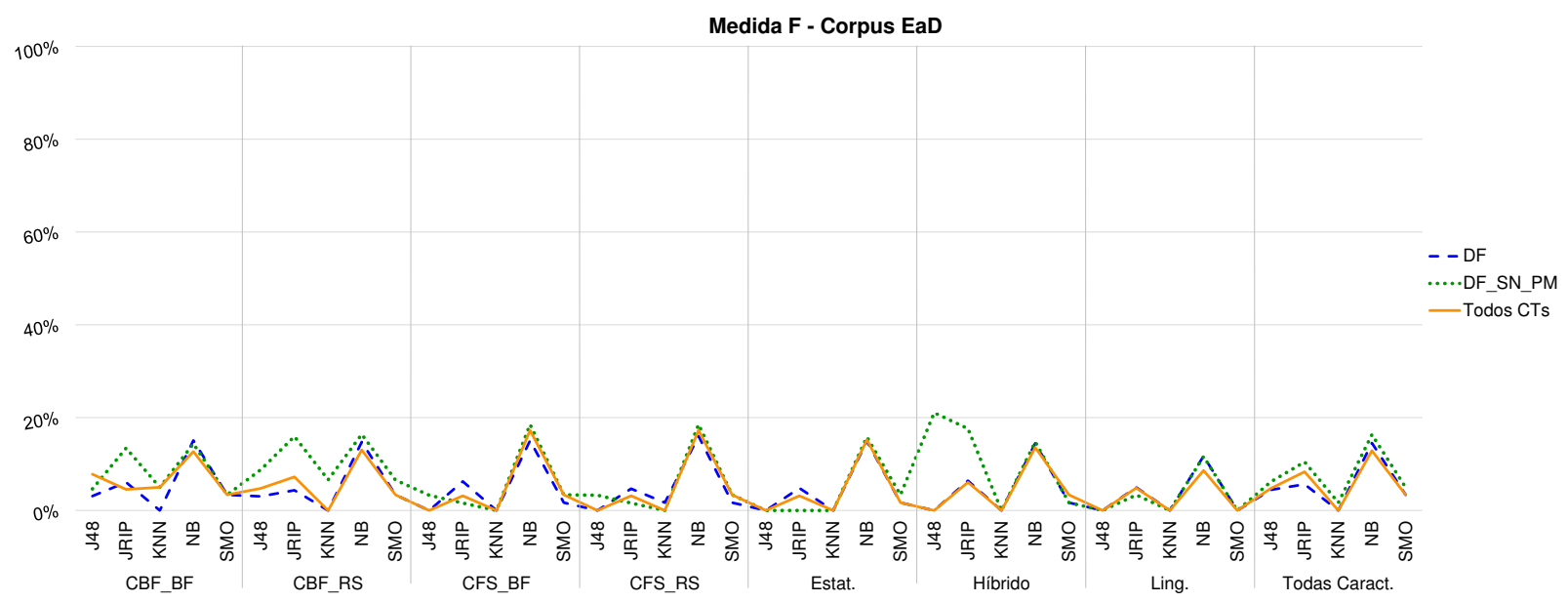

Figura 5.11: Resultados de medida F - Corpus EaD.

tanto pelo uso de somente de características híbridas como linguísticas. Já os valores de precisão mais altos para o corpus ECO foram obtidos com o uso das características selecionadas pelos métodos CFS_BF e CFS_RS, bem como quando se utilizam somente 


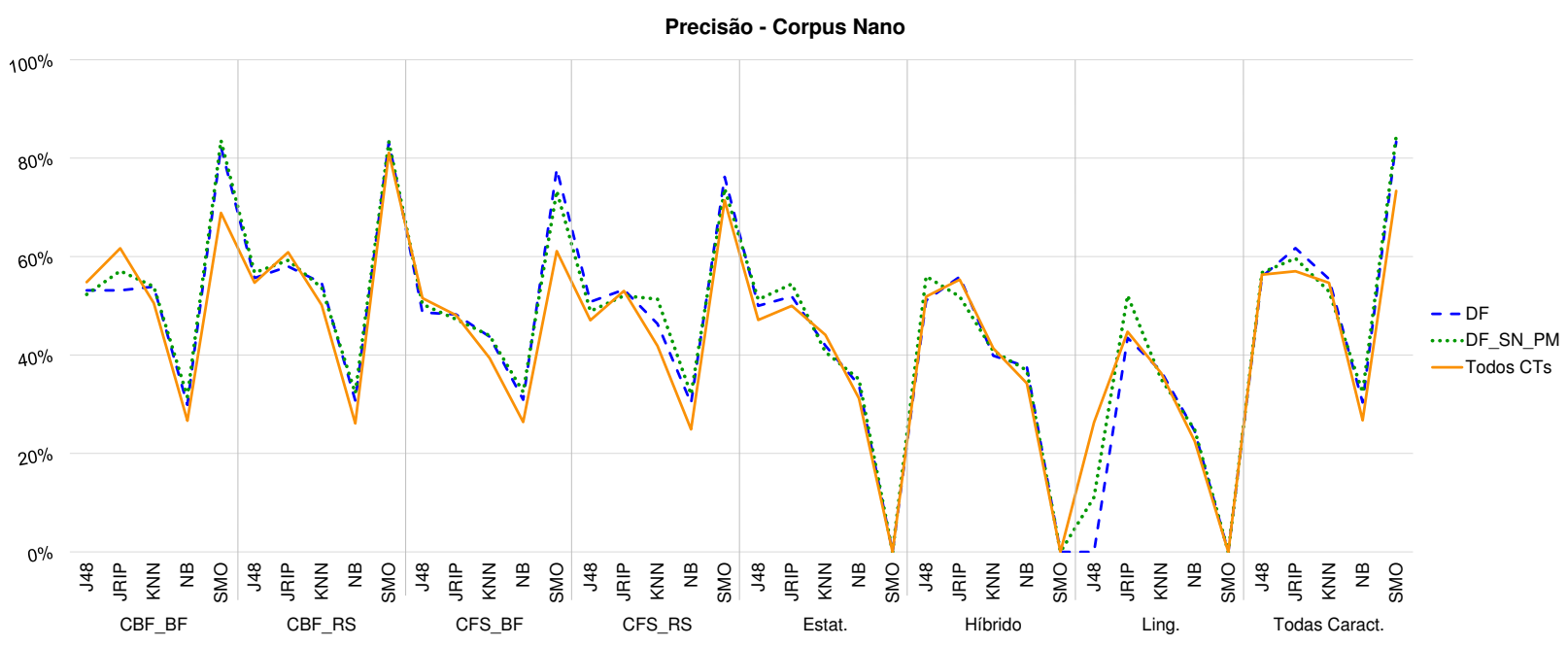

Figura 5.12: Resultados de precisão - Corpus Nano.

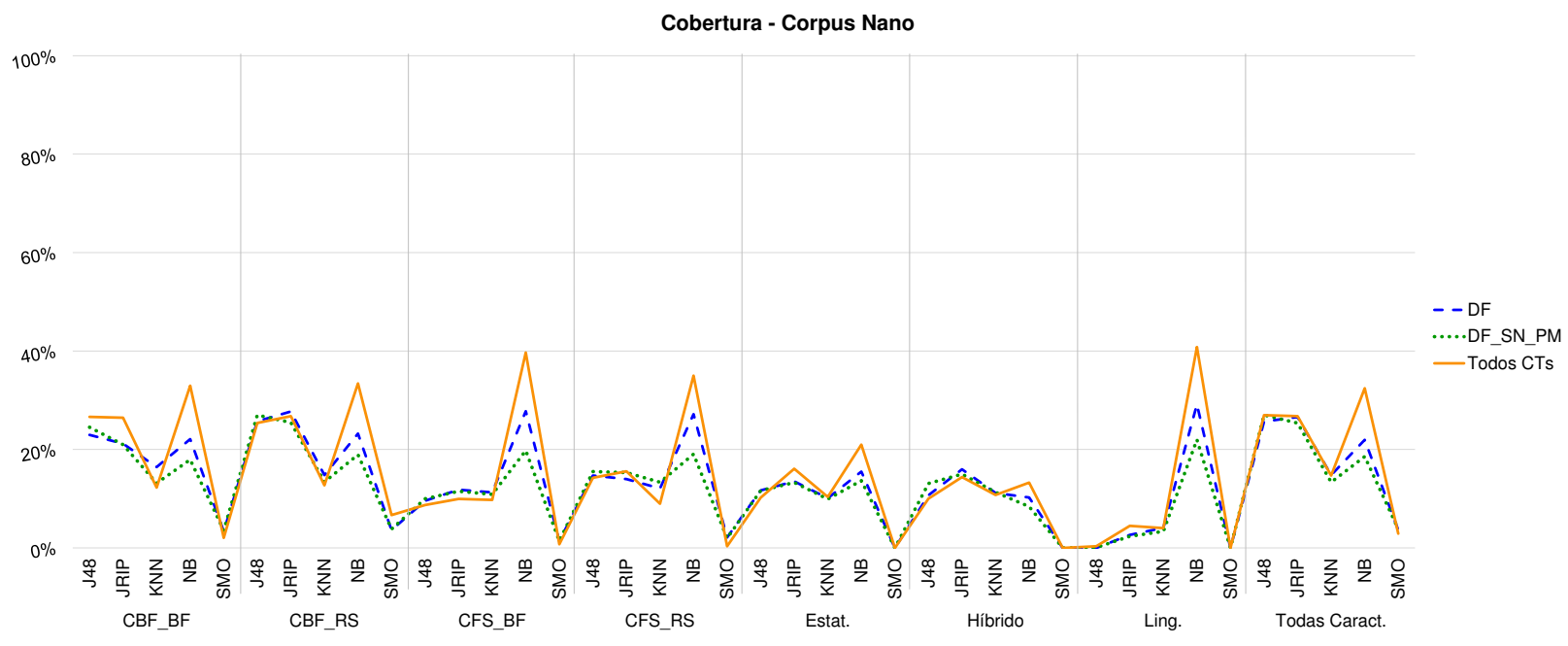

Figura 5.13: Resultados de cobertura - Corpus Nano.

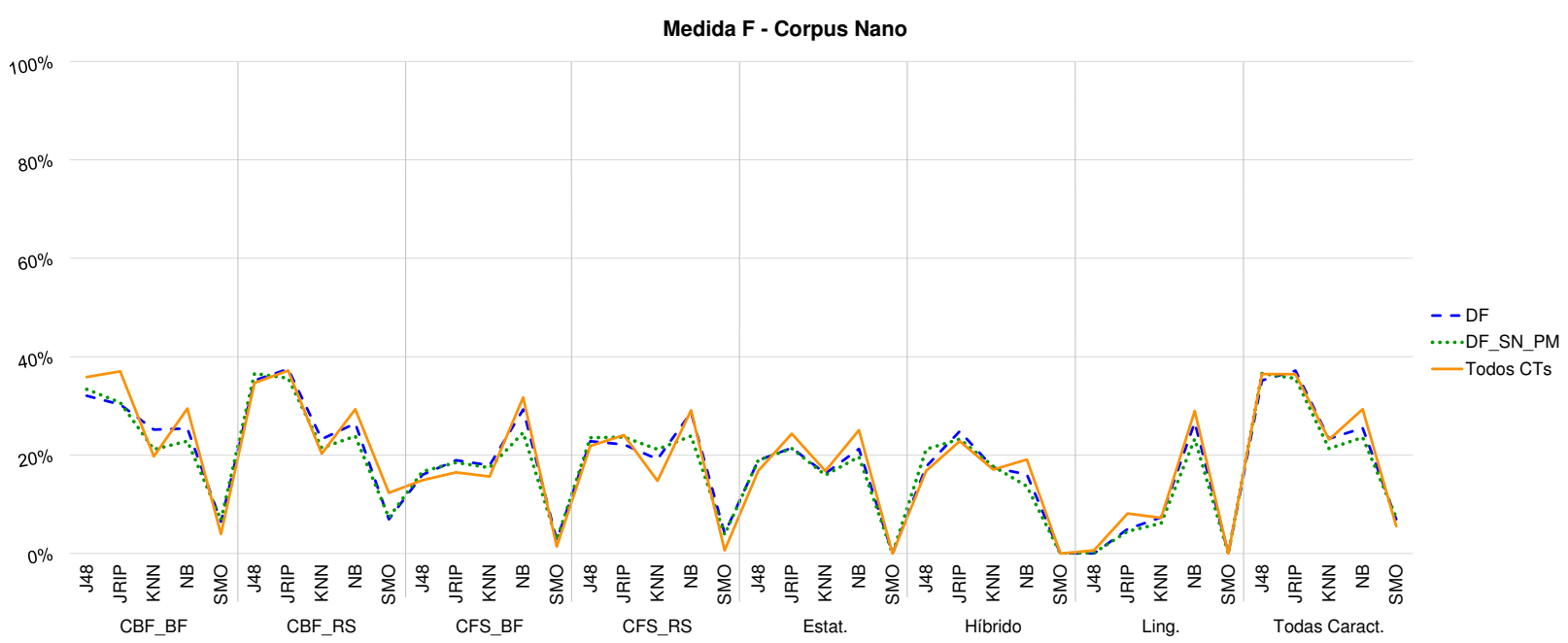

Figura 5.14: Resultados de medida F - Corpus Nano.

características estatísticas. Não obstante, para os corpora EaD e Nano, os valores de precisão variam para as diferentes seleções de características. As características híbridas também foram responsáveis pelos resultados mais baixos de cobertura e, para o corpus 
Nano, as características estatísticas também contribuem para os baixos resultados.

Em relação a seleção de candidatos, não foi observado nenhum padrão em relação aos valores de precisão dos corpora ECO e EaD. Para o corpus Nano, ao utilizar todos os seus candidatos (Todos CTs), a precisão é levemente inferior do que quando se filtra tais candidatos. Entretanto, para os 3 corpora, ao usar todos os candidatos, em geral, a cobertura é mais alta (mesmo que levemente) do que quando se filtra os candidatos.

Tanto a seleção de característica como a de candidatos, em geral, não têm forte impacto nos resultados de medida $\mathrm{F}$ dos 3 corpora, uma vez que seus valores foram bastante similares. Somente para o corpus EaD, ao utilizar o Filtro $D F_{-} S N_{-} P M$ para selecionar candidatos, em alguns casos, têm-se resultados de medida $\mathrm{F}$ levemente superiores aos demais resultados. Para os 3 corpora, há também uma leve diferença entre os valores de medida F obtidos utilizando as diferentes seleções de candidatos, sendo que Todos CTs atingem resultados levemente superiores do que o Filtro DF e este, por sua vez, alcança resultados levemente mais altos do que o Filtro $D F_{-} S N_{-} P M$.

\subsubsection{Comparações entre ILATE e outros Trabalhos de Extração de Termos}

Para uma análise minuciosa dos termos extraídos, os resultados alcançados pela ILATE foram comparados com os resultados obtidos utilizando diferentes formas de extração de termos, a saber:

1. "Baselines", que são as medidas $t f$ e $t f-i d f$;

2. Extração tradicional de termos (referenciada como "Comparações extras"), que corresponde ao uso individual das principais características encontradas na literatura. Nos experimentos deste capítulo, entretanto, são mostradas as características que têm os resultados mais altos de precisão, de cobertura e de medida F, uma vez que os resultados de todas as características foram apresentados na Subseção 4.1 do Capítulo 4, página 55; e

3. Os métodos ExPorTer_linguístico e ExPorTer_híbrido (Zavaglia et al., 2007), que realizam extração de termos simples para o português do Brasil. Esses métodos são referenciados como "Estado da arte" e são descritos na Subseção 3.5.1 do Capítulo 3 , página 38 .

O método ExPorTer_linguístico considera como termos os candidatos que pertencem a alguma classe gramatical pré-estabelecida (substantivo (nome e nome próprio), adjetivo e verbo) e que ocorrem perto de expressões indicativas (p. ex., é definido como). Já o método ExPorTer_híbrido gera um subcorpus com sentenças que palavras pertencentes a alguma das classes gramaticais citadas anteriormente. Então, a extração de termos é realizada a partir desse subcorpus usando o método ExPorTer_linguístico e considerando como termos os candidatos que têm frequência de até um limiar (20). Ambos consideraram somente os 150 primeiros candidatos mais bem ranqueados por cada método.

Os métodos ExPorTer_linguístico e ExPorTer_híbrido foram originalmente avaliados para o corpus ECO utilizando a técnica de lematização para normalizar as palavras dos textos. Como a técnica de radicalização foi adotada na ILATE, a implementação feita dos métodos ExPorTer_linguístico e ExPorTer_híbrido também utilizaram a radicalização. Outra diferença é que ExPorTer utilizou o tagger MXPOST (Ratnaparkhi, 1996) para etiquetar morfossintaticamente os textos e, na implementação feita aqui, a anotação linguística foi feito com o parser Palavras (Bick, 2000), uma vez que ILATE também a utiliza. 
Nas três tabelas apresentadas a seguir, é mostrada a comparação dos resultados mais $\operatorname{altos}^{5}$ de cada uma das formas de extração de termos. Nessas tabelas, a coluna "Descrição" corresponde à classificação de cada "Método" de extração utilizado para obtenção dos valores mais altos de Precisão $(\mathrm{P}(\%))$, Cobertura $(\mathrm{C}(\%))$ e Medida $\mathrm{F}(\mathrm{MF}(\%))$.

Ainda, nessas tabelas, os resultados mais altos são destacados com a cor cinza. Entretanto, quando o maior resultado é atingido utilizando (praticamente) todo o corpus, destaca-se também o segundo resultado mais alto correspondente a mesma medida. Por exemplo, para o corpus ECO (Tabela 5.2), o valor mais alto de cobertura (100\%) foi alcançado pelas medidas freq_cg, weirdness, thd e nc-value considerando (praticamente) o corpus inteiro (8850 a 9950 candidatos). Tal resultado era esperado uma vez que os termos obrigatoriamente devem estar contidos no corpus do domínio em questão. Sendo assim, também se destacou o segundo resultado mais alto de cobertura (99,67\%) atingido pelas medidas $t f$ e $t f$ - $i d f$ ao utilizar também todo o corpus (9950 candidatos), o que não é uma vantagem. Então, o terceiro valor mais alto de cobertura $(89,18 \%)$ também foi destacado, sendo que este utilizou os 150 candidatos mais bem ranqueados pelo método ExPorTer_linguístico. Com base nessa análise, considera-se $89,18 \%$ o valor mais alto de cobertura para o corpus ECO.

Tabela 5.2: Comparação dos resultados mais altos - Corpus ECO.

\begin{tabular}{|c|c|c|c|c|}
\hline Descrição & Método & $P(\%)$ & $C(\%)$ & $M F(\%)$ \\
\hline \multirow{3}{*}{ ILATE } & $\begin{array}{l}\text { CFS RS - DF - SVM ou CFS RS/ } \\
\text { CFS }- \text { BF - DF SN PM - SVM }\end{array}$ & 100.00 & 1,01 a 1,34 & 1.99 a 2.65 \\
\hline & CFS BF - Todos CTs - NB & 19,81 & 35,91 & 25,54 \\
\hline & CFS RS - Todos CTs - NB & 21,67 & 33,89 & 26,44 \\
\hline \multirow{5}{*}{ Baselines } & $\operatorname{tf}$-idf $(50)$ & 50,00 & 8,33 & 14,29 \\
\hline & tf-idf $(300)$ & 26,00 & 26,00 & 26,00 \\
\hline & tf e tf-idf (9950) & 3,01 & 99,67 & 5,83 \\
\hline & $\mathrm{tf}(50)$ & 42,00 & 7,00 & 12,00 \\
\hline & $\mathrm{tf}(400)$ & 21,25 & 28,33 & 24,29 \\
\hline \multirow{2}{*}{ Estado da arte } & ExPorTer_linguístico & 2,74 & 89,18 & 5,32 \\
\hline & ExPorTer híbrido & 12,76 & 23,25 & 16,48 \\
\hline \multirow{4}{*}{$\begin{array}{l}\text { Comparações } \\
\text { extras }\end{array}$} & tc $(50)$ & 52,00 & 8,67 & 14,86 \\
\hline & $\begin{array}{l}\text { freq_cg, weirdness, } \\
\text { thd e nc-value ( } 8850 \text { a } 9950)\end{array}$ & 3,02 a 3,39 & 100,00 & 5,85 a 6,56 \\
\hline & $\operatorname{tvq}(400)$ & 25,75 & 34,33 & 29,43 \\
\hline & Corpus inteiro (9950) & 3,02 & 100,00 & 5,85 \\
\hline
\end{tabular}

Na Tabela 5.2, são apresentados os resultados para o corpus ECO. O uso da ILATE alcançou precisão de $100 \%$ utilizando 3 matrizes de candidatos diferentes, a saber: (i) $C F S_{-} R S-D F-S V M$, ou seja, uma matriz contendo os candidatos que se mantiveram após a aplicação do Filtro $D F$ nas características selecionadas pelo método $C F S_{-} R S$; (ii) $C F S_{-} R S-D F_{-} S N_{-} P M-S V M$, isto é, uma matriz contendo os candidatos que se mantiveram após a aplicação do Filtro $D F_{-} S N_{-} P M$ nas características selecionadas pelo método $C F S_{-} R S$; ou (iii) $C F S_{-} B F-D F_{-} S N_{-} P M-S V M$, que utilizou também o Filtro $D F \_S N_{-} P M$ mas com o método de seleção de características chamado $C F S_{-} B F$. As três matrizes de candidatos utilizaram o indutor SVM. A cobertura mais alta alcançada foi de 89,18\% pelo método ExPorTer_linguístico. O resultado mais alto de medida $\mathrm{F}$ foi $29,43 \%$ utilizando os 400 primeiros candidatos a termos mais bem ranqueados pela medida $t v q$. Esse resultado também é considerando uma das contribuições desta tese uma vez que, de acordo com a pesquisa literária realizada, pela primeira vez a $t v q$ foi aplicada à tarefa de extração de termos. Destaca-se também que a ILATE alcançou resultados parecidos de medida F, sendo 26,44\% (CFS_RS - Todos CTs - NB) e 25,54\% (CFS_BF - Todos $C T s-N B)$; assim como as medidas $t f-i d f$ e $t f$, que atingiram 26 e $24,29 \% \overline{\text { de cobertura }}$

\footnotetext{
${ }^{5}$ Todos os resultados desses experimentos podem ser apreciados em http://sites.labic.icmc.usp. $\mathrm{br} / \mathrm{merleyc} /$ ThesisData/.
} 
utilizando, respectivamente, os 300 e 400 candidatos mais bem ranqueados por cada uma dessas medidas.

Na Tabela 5.3, são apresentados os resultados para o corpus EaD. Observa-se que o uso da ILATE obteve precisão de $100 \%$ com diferentes configurações (ver $1^{\text {a }}$ linha da Tabela 5.3). Quando se utiliza a ILATE somente com as características híbridas e os candidatos selecionados pelo Filtro $D F_{-} S N_{-} P M$ com o indutor J48 (Hi̋rido - DF_ SN_PM - J48), obtém-se também um alto valor de precisão (87,50\%). Essa mesma configuração da ILATE (Híbrido - DF_SN_PM - J48) também atinge um bom valor de medida F $(21,05 \%)$ combinado com uma alta precisão $(87,50 \%)$, sendo que a medida $\mathrm{F}$ mais alta foi praticamente similar $(22,22 \%)$ combinada com uma precisão bem mais inferior $(36 \%)$, alcançada ao utilizar os 50 primeiros candidatos mais bem ranqueados pela medida $t d s$ ou glossEx. Considera-se, então, que a ILATE com configuração Híbrido - DF_SN_PM $J_{4} 8$ é a melhor opção para extrair termos do domínio de educação à distância quando em casos que se deseja ser mais conservador, ou seja, quando não é preciso identificar todos os termos, mas necessário que essa identificação tenha alta confiança devido sua precisão mais alta. Além disso, essa configuração da ILATE é capaz de extrair cerca de $11 \%$ dos termos (cobertura), o que também não está muito abaixo dos $16 \%$ alcançado pelo $t d s$ e glossEx. Assim como para o corpus ECO, a cobertura mais alta $(89,70 \%)$ foi alcançada pelo método ExPorTer_linguístico.

Tabela 5.3: Comparação dos resultados mais altos - Corpus EaD.

\begin{tabular}{|c|c|c|c|c|}
\hline Descrição & Método & $P(\%)$ & $C(\%)$ & $M F(\%)$ \\
\hline \multirow[t]{3}{*}{ ILATE } & $\begin{array}{l}\text { CBF_BF/CFS_BF/CFS_RS/Estat./Híbrido } \\
\text { - DF/DF_SN_PM - SVM ou CBF_BF/ } \\
\text { CBF_RS/CFS_BF/Estat./Híbrido/ } \\
\text { Todas Caract. - Todos CTs - SVM ou } \\
\text { Todas Caract./CBF_RS/CBF_BF - } \\
\text { DF_SN_PM - KNN ou CFS_RS - DF - } \\
\text { KNN ou Todas Caract./CBF_RS - DF - } \\
\text { SVM ou CBF BF - Todos CTs - KNN }\end{array}$ & 100,00 & 0,85 a 3,42 & 1,69 a 6,61 \\
\hline & Ling. - Todos CTs - NB & 4,94 & 33,33 & 8,60 \\
\hline & Híbrido-DF_SN_PM - J48 & 87,50 & 11,97 & 21,05 \\
\hline \multirow{5}{*}{ Baselines } & tf-idf $(50)$ & 22,00 & 9,82 & 13,58 \\
\hline & tf-idf $(100)$ & 15,00 & 13,39 & 14,15 \\
\hline & tf e tfidf (11100 a 15000) & 0,75 a 1,01 & 100,00 & 1,48 a 2,00 \\
\hline & tf $(50)$ & 18,00 & 8,04 & 11,11 \\
\hline & tf $(150)$ & 10,67 & 14,29 & 12,21 \\
\hline \multirow{2}{*}{ Estado da arte } & ExPorTer_linguístico & 0,33 & 89,70 & 0,66 \\
\hline & ExPorTer_híbrido & 0,07 & 17,64 & 0,15 \\
\hline \multirow[t]{3}{*}{$\begin{array}{l}\text { Comparações } \\
\text { extras }\end{array}$} & $\begin{array}{l}\text { rf, atf, df, tv, tvq, freq_cg, } \\
\text { tc, c-value (11100 a } 15000)\end{array}$ & 0,75 a 1,01 & 100,00 & 1,48 a 2,00 \\
\hline & tds e glossEx (50) & 36,00 & 16,07 & 22,22 \\
\hline & Corpus inteiro (16000) & 0,70 & 100,00 & 1,39 \\
\hline
\end{tabular}

Na Tabela 5.4, são apresentados os resultados para o corpus Nano. A precisão mais alta (84,51\%) foi alcançada com a ILATE, especificamente com Todas Caract. - DF_SN_PM $S V M$, ou seja, utilizando o indutor SVM com todas as características (Todas Caract.) dos candidatos mantidos após a aplicação do Filtro $D F_{-} S N_{-} P M$. Essa precisão acompanha uma cobertura ruim $(3,81 \%)$, mas há outras formas de extração que têm coberturas ainda inferiores, como a medida clássica da literatura $t$ - $i d f(1,88 \%)$. A vantagem da EAT utilizando a ILATE com configuração Todas Caract. - DF_ $S N_{-} P M-S V M$ é que quando esta classifica um candidato como termo, este realmente é termo para quase $85 \%$ dos casos.

Ainda, para o corpus Nano, o valor mais alto de cobertura (94,10\%) foi obtido pelas medidas $t f$ e $r f$ ao considerar de 14900 a 15000 primeiros candidatos a termos mais bem ranqueados por tais medidas. Com o mesmo número de candidatos (14900 a 15000), a medida $t f-i d f$ atingiu uma cobertura bem similar (94,04\%). Em seguida, o método 
ExPorTer_linguístico conseguiu $89,40 \%$ de cobertura. A medida $\mathrm{F}$ mais alta $(37,50 \%)$ foi alcançada por ILATE com configuração $C B F_{-} R S$ - DF - JRIP. Considera-se que a ILATE com essa configuração é a melhor opção para extrair termos do domínio de nanociência e nanotecnologia quando comparada com os demais resultados, uma vez que ILATE consegue atingir a medida $\mathrm{F}$ mais alta para esse domínio combinada com uma boa precisão $(58,01 \%)$ e uma cobertura não tão baixa $(27,70 \%)$. Valores de medida $\mathrm{F}$ próximos aos da ILATE foram obtidos pelas medidas $t f-i d f(36,22 \%)$ e $t f(35,59 \%)$ quando utilizaram, respectivamente, os 3150 e 3200 primeiros candidatos mais bem ranqueados por cada medida. Dependendo do objetivo, se a aplicação na qual os termos extraídos serão utilizados não se importar em recuperar candidatos que não são termos, $t f-i d f$ pode ser boa opção para a extração porque consegue extrair 55,09\% dos termos, apesar de também extrair muito ruído, porém menos do que tf (14900 a 15000). Entretanto, a ILATE com configuração $C B F_{-} R S-D F-J R I P$ continua sendo a mais aconselhada para ser utilizada porque, ao contrário da ILATE, $t f-i d f$ e $t f$ não extraem termos de maneira totalmente automática.

Tabela 5.4: Comparação dos resultados mais altos - Corpus Nano.

\begin{tabular}{|c|c|c|c|c|}
\hline Descrição & Método & $P(\%)$ & $C(\%)$ & $M F(\%)$ \\
\hline \multirow{3}{*}{ ILATE } & Todas Caract. - DF_SN_PM - SVM & 84,51 & 3,81 & 7,29 \\
\hline & Ling. - Todos CTs - NB & 22,47 & 40,80 & 28,98 \\
\hline & CBF_RS - DF - JRIP & 58,01 & 27,70 & 37,50 \\
\hline \multirow{6}{*}{ Baselines } & tf-idf $(50)$ & 58,00 & 1,88 & 3,64 \\
\hline & tf-idf $(3150)$ & 26,98 & 55,09 & 36,22 \\
\hline & tf-idf (14900 a 1500$)$ & 9,67 a 9,74 & 94,04 & 17,54 a 17,65 \\
\hline & $\mathrm{tf}(50)$ & 48,00 & 1,56 & 3,01 \\
\hline & tf $(3200)$ & 26,38 & 54,70 & 35,59 \\
\hline & $\mathrm{tf}(14900$ a 15000$)$ & 9,68 а 9,74 & 94,10 & 17,55 a 17,66 \\
\hline \multirow{2}{*}{ Estado da arte } & ExPorTer_linguístico & 3,75 & 89,40 & 7,20 \\
\hline & ExPorTer_híbrido & 1,68 & 35,35 & 3,22 \\
\hline \multirow{3}{*}{$\begin{array}{l}\text { Comparações } \\
\text { extras }\end{array}$} & $\operatorname{tvq}(50)$ & 66,00 & 2,14 & 4,14 \\
\hline & rf $(14900$ a 15000$)$ & 9,68 a 9,74 & 94,10 & 17,55 a 17,66 \\
\hline & Corpus inteiro (41335) & 0,04 & 100,00 & 0,07 \\
\hline
\end{tabular}

Em suma, ao analisar os resultados dos 3 corpora, observa-se que a ILATE sempre alcança resultados mais altos de precisão em relação a todos os métodos e medidas comparados. Ao contrário dos demais métodos de extração de termos comparados, a ILATE alcançou $100 \%$ de precisão para os corpora ECO e EaD e a melhor precisão para o corpus Nano (84,51\%). A ILATE atinge valores de medida F bem similares ou superiores (o mais alto é $37,50 \%$ ) aos resultados das medidas que necessitam utilizar um limiar subjetivo para cortar o ranking de candidatos usado na extração (o mais alto é 36,22\%). Tais medidas são: $t f, t f-i d f, t v q, t d s$ e glossEx. Assim, considera-se que ILATE é vantajosa também para a extração de termos quando o objetivo principal for alcançar bons resultados de medida F, uma vez que sua extração é feita de maneira totalmente automática, ao contrário das medidas referenciadas como "Baselines" e "Comparações extras".

\subsubsection{Discussão acerca da Junção de Características de Diferentes Níveis de Conhecimento para a Extração de Termos Utilizando ILATE}

Uma das contribuições desta pesquisa são os resultados de precisão e medida F superiores (ou similares) ao do estado da arte. Adicionalmente, considera-se como uma outra contribuição o uso da medida estatística tvq que é tradicionalmente utilizada para a tarefa de seleção de características e, aqui, foi aplicada para a tarefa de extração de termos, obtendo o resultado mais alto de medida F para o corpus ECO. 
Considerando o fato de que a ILATE utiliza diferentes características dos candidatos, comprova-se a hipótese inicialmente levantada de que a junção de características pertencentes a diferentes níveis de conhecimento melhora os resultados de EAT, uma vez que a ILATE obtém resultados superiores (ou similares) aos valores alcançados por medidas e métodos de extração encontrados na literatura. Por exemplo, para o corpus Nano, a precisão mais alta $(84,51 \%)$ foi atingida pela ILATE quando utilizadas todas as características dos candidatos com o indutor SVM. A única exceção para tal afirmação é em relação aos valores de cobertura, porque os resultados mais altos de cobertura foram alcançados geralmente pelo método ExPorTer_linguístico.

Em relação aos níveis de conhecimento nos quais cada característica dos candidatos pertence, observa-se que 69,44\% dos casos mostrados anteriormente na Tabela 5.4 possuem características linguísticas, estatísticas e híbridas ao mesmo tempo. Os demais casos possuem características linguísticas e estatísticas ao mesmo tempo. Afirma-se então que, com base nesses experimentos, segundo os métodos de seleção de características, é necessário se ter pelo menos dois tipos de conhecimento juntos (linguístico e estatístico).

\subsection{Segunda Avaliação Experimental da ILATE}

Ao analisar os resultados obtidos pela ILATE, percebeu-se que alguns ruídos eram provenientes da etapa de pré-processamento da extração de termos, conforme será detalhado nessa subseção. Visando melhorar ainda mais os resultados da extração, foram implementadas mais características dos candidatos, tendo, portanto, alteração na etapa de extração de características também. Consequentemente, as matrizes compostas por esses novos candidatos são a entrada da etapa de aplicação de filtros. Dessa maneira, tal etapa também foi alterada.

Sendo assim, foi realizada a segunda avaliação experimental na qual se reproduziu a abordagem ILATE (Figura 5.1) mas com alterações nas etapas de pré-processamento, extração de características e aplicação de filtros. As mudanças realizadas nessas etapas são listadas a seguir.

\subsubsection{Pré-processamento dos Textos}

Os mesmos corpora utilizados anteriormente foram também considerados nessa segunda avaliação experimental, a saber: ECO, EaD e Nano. Também se realizou o mesmo pré-processamento dos textos, porém para a segunda avaliação experimental, os seguintes refinamentos foram incorporados:

\section{Tratamento automático dos termos compostos antes da normalização}

Os termos compostos são formados por dois ou mais radicais em situação de nãoautonomia representada graficamente pela utilização do hífen (Barros, 2004, p. 100). Os especialistas dos domínios dos corpora que foram utilizados nos experimentos realizados nesta tese consideraram os termos compostos como termos simples. Por exemplo, anteriormente, o termo composto "bate-papo" do domínio de EaD era considerado pela ILATE como 2 candidatos a termos ("bate" e "papo"). Com isso, três problemas eram gerados:

(a) O sentido da palavra poderia ser perdido, uma vez que, segundo o dicionário Michaelis online, "bate" pode ser a terceira pessoa do verbo bater ou um substantivo que significa "Raqueta com cabo, própria para receber a bola, em certos jogos". Já a palavra "papo" pode significar: 
"1 Bolsa que existe nas aves, formada por uma dilatação do esôfago, na qual os alimentos permanecem algum tempo, antes de passarem à moela. 2 Bócio, papeira. 3 pop Estômago. 4 Saco formado pela distensão dos músculos faciais de alguns macacos e roedores do Antigo Continente, e onde eles guardam a comida antes de a engolir; bolsa facial. 5 Parte do vestuário, em geral formando tufo ou grandes pregas, e que cobre o peito. 6 Bolso ou fole em roupa malfeita".

Contudo, o termo composto "bate-papo" tem o significado de "1 Cavaco, cavaqueira. 2 Conversa animada", segundo o dicionário Michaelis.

(b) Intuitivamente pode-se afirmar que considerar o termo "bate-papo" como sendo dois candidatos a termos, aumentaria erroneamente o número de candidatos a termos.

(c) O extrator de termos não seria capaz de extrair os termos compostos, diminuindo, assim, a cobertura.

Considerando tais problemas, nessa segunda avaliação experimental da ILATE, os candidatos a termos compostos foram considerados candidatos simples. Essa decisão foi utilizada para corrigir alguns erros previamente embutidos no corpus de entrada, seja eles por quebra de linha (o que se introduz um hífen para separar as sílabas das palavras nesse local) ou por erro gerado no momento de transformar do formato .pdf para texto plano. Por exemplo, no corpus EaD, é possível resgatar de "himenopteros" a palavra correta, que é "himenópteros".

Já no caso da presença de hifens em verbos, nessa segunda avaliação experimental, foi realizada uma limpeza de pronomes. Por exemplo, o verbo "tornam-se" se transformaria em "tornam"; "poder-se-ia" para "poderia". Desse modo, os pronomes foram removidos, não atrapalhando a EAT uma vez que eles não são termos. Além disso, o parser Palavras trata o verbo e o pronome separadamente.

Entretanto, há alguns casos não tratados. Por exemplo, seria interessante que um especialista de cada domínio indicasse como alguns casos específicos deveriam ser tratados, por exemplo "não-sustentável" e "ñ̃a-queimado". Adicionalmente, no futuro, espera-se tratar os pronomes oblíquos átonos (me, te, se, o, a, lhe, nos, vos, os, as, lhes) em relação ao seu posicionamento perante o verbo. Exemplos de casos ainda não tratados são: "fá-lo-ei", que deveria ser mudado para "farei e "trazê-las" para "trazer".

\section{Tratamento automático da codificação do arquivo de entrada}

Inicialmente considerou-se que todos os arquivos de entrada utilizavam a codificação UTF-8. Entretanto, em uma análise manual, constatou-se que alguns dos arquivos utilizavam outra codificação. Ao assumir que todos arquivos usavam a mesma codificação, poderia haver casos em que, por exemplo, o termo "pós-teste", se lido incorretamente pelo extrator de termos, poder-se-ia tornar " $p$ " e "s-teste", o que geraria ruído nos resultados da extração, além de impossibilitar a identificação do termo correto ("pós-teste"), uma vez que este não mais existiria nos dados de entrada. Nessa segunda avaliação experimental, antes da leitura de cada arquivo de entrada, verifica-se qual é a codificação que este utiliza e, então, o arquivo é aberto considerando sua própria codificação. Infelizmente, nem todos os arquivos são possíveis de identificação da codificação. Nesse caso, optou-se por realizar a leitura do arquivo utilizando UTF-8, que é a codificação mais comum. 


\section{Não-normalização das stopwords}

A stopword (vós) "sede" (original do verbo ser conjugado no imperativo afirmativo da segunda pessoa do plural (vós)), após radicalização seria "sed", que coincidiria com o radical "sed" que, por sua vez, é originado do termo "sedimento" do domínio de ecologia. A radicalização da stoplist diminuiria a cobertura uma vez que eliminaria termos cujos radicais coincidem com os radicais de stopwords. Portanto, nessa segunda avaliação experimental, a stoplist foi utilizada não normalizada.

No momento de criar a matriz de atributo-valor dos candidatos a termos, é necessário identificar a classe de cada candidato (termo ou não termos) para que a classificação seja realizada. Nessa segunda avaliação experimental, não se considerou como stopwords os candidatos que coincidem com algum termo da lista de termos de referência.

\section{Conserto manual de erros}

Ao analisar manualmente os arquivos de entrada, nessa segunda avaliação experimental, foram consertados os seguintes erros:

(a) Padronização dos nomes dos arquivos. Por exemplo, o parser utilizado para anotar linguisticamente os textos não processa arquivos cujos nomes contêm 6. Por isso, esse caractere foi removido dos nomes dos arquivos de entrada.

(b) Limpeza dos textos. Por exemplo, "humanos1" foi mudado para "humanos", o que mantém tal palavra como candidato a termo. "que_a" foi alterada para "que" e " $a$ ", o que possibilita sua remoção da lista de candidatos por serem stopwords.

(c) No corpus ECO, "Tam-be'm" foi manualmente alterada pra "Também", o que permite sua remoção uma vez que esta pode ser identificada stopword.

\subsubsection{Extração de Características}

Cada unigrama pré-processado de cada corpus é considerado um candidato a termo. Nessa segunda avaliação experimental, para cada candidato, foram consideradas as características utilizadas na primeira avaliação experimental, porém foram adicionados 1 método híbrido (glossEx) e 3 medidas híbridas (weirdness, thd e $t d s$ ). Essas medidas híbridas são mais complexas do que as utilizadas na primeira avaliação experimental da ILATE, que foram a ocorrência $(c g)$ e frequência de ocorrência do candidato no corpus de língua geral (textitfreq_cg). Nessa segunda avaliação experimental, também foram adicionadas 2 medidas estatísticas (atf e ridf). Então, um total de 25 características foram utilizadas nessa avaliação experimental, conforme mostradas na Tabela 5.5. As medidas e o método adicionados nessa segunda avaliação estão destacados em negrito nessa tabela.

Na primeira avaliação experimental da ILATE, assumiu-se que termos poderiam ser substantivos, adjetivos ou verbos. Por exemplo, no domínio de computação, o verbo "formatar" poderia ser um termo. Entretanto, na segunda avaliação experimental, além da adição das seis características citadas, outra diferença é que ela assumiu que termos são sempre substantivos. Nesse sentido, a característica sintagma abrange somente os candidatos que fazem parte de sintagmas nominais, enquanto que a primeira avaliação considerava também os que faziam parte de sintagmas adjetivais e verbais. Logo, para a característica $p m$ na segunda avaliação experimental, foram considerados somente os candidatos que são substantivos, enquanto que a primeira avaliação considerava também os adjetivos e verbos. 
Tabela 5.5: Medidas, métodos e formas de obtenção de conhecimento utilizados na segunda avaliação experimental.

\begin{tabular}{|c|c|c|}
\hline Sigla & Caracteristica & $\begin{array}{c}\text { Valor } \\
\text { resultante }\end{array}$ \\
\hline \multicolumn{3}{|c|}{ Medidas Estatísticas } \\
\hline 1. $\operatorname{comGram}^{* *}$ & comprimento do $n$-grama & numérico \\
\hline 2. $t f$ & frequência de termo & numérico \\
\hline 3. atf & frequência média de termo & numérico \\
\hline 4. ridf & frequência residual inversa de documento (Church, 1995) & numérico \\
\hline 5. $d f$ & frequência de documentos & numérico \\
\hline 6. $t f-i d f$ & frequência de termo - frequência inversa de documento (Salton e Buckley, 1987) & numérico \\
\hline 7. $t v^{*}$ & variância do termo (Liu et al., 2005) & numérico \\
\hline 8. $t v q^{*}$ & qualidade da variância do termo (Dhillon et al., 2003) & numérico \\
\hline 9. $t c^{*}$ & contribuição do termo (Liu et al., 2003) & numérico \\
\hline \multicolumn{3}{|c|}{ Medidas/Métodos Híbridos } \\
\hline 1. $c g$ & se o candidato aparece em um corpus de língua geral & binário \\
\hline 2. freq_cg & frequência do termo em um corpus de língua geral & numérico \\
\hline 3. weirdness & $\begin{array}{l}\text { distribuição do candidato no corpus de domínio e } \\
\text { em um corpus de língua geral (Ahmad et al., 1999) }\end{array}$ & numérico \\
\hline 4. thd & $\begin{array}{l}\text { índice termhood: frequência ponderada do termo no corpus de domínio e } \\
\text { em um corpus de língua geral (Kit e Liu, 2008) }\end{array}$ & numérico \\
\hline 5. tds & índice de especificidade de domínio (Park et al., 2008) & numérico \\
\hline 6. $g l o s s E x$ & $\begin{array}{l}\text { probabilidade de ocorrência do candidato no corpus de domínio } \\
\text { e em um corpus de língua geral (Kozakov et al., 2004a) }\end{array}$ & numérico \\
\hline 7. c-value & frequência e tamanho em gramas do candidato (Frantzi et al., 1998) & numérico \\
\hline 8. nc-value & contexto no qual o candidato aparece (Frantzi et al., 1998) & numérico \\
\hline \multicolumn{3}{|c|}{ Formas de Obtenção de Conhecimento Linguístico } \\
\hline 1. sintagma & sintagma nominal & binário \\
\hline 2. núcleo_sintagma & núcleo de sintagma nominal (Estopa et al., 2005) & binário \\
\hline 3. $p m$ & classe gramatical & binário \\
\hline 4. $e i$ & expressão indicativa & binário \\
\hline 5. $n_{\text {_ }}$ subst. ${ }^{\Delta}$ & número de substantivos & numérico \\
\hline 6. n_adj. ${ }^{\Delta}$ & número de adjetivos & numérico \\
\hline 7. $n \_$verbo ${ }^{\Delta}$ & número de verbos & numérico \\
\hline 8. $n_{-}$po $^{\Delta}$ & total de palavras que deram origem ao candidato radicalizado & numérico \\
\hline
\end{tabular}

\subsubsection{Aplicação de Filtros}

Na segunda avaliação experimental, a etapa de aplicação de filtros foi reproduzida da mesma maneira como foi feita para a primeira avaliação. Entretanto, como os candidatos e o conjunto de características obtidos na primeira avaliação são diferentes da segunda avaliação, consequentemente, as matrizes de candidatos também são diferentes.

A matriz de candidatos pré-processados do corpus (Todos CTs) juntamente com todas suas características extraídas (Todas Caract.) é também chamada de Todos CTs Todas Caract. Assim como para a primeira avaliação experimental, foi feita a seleção de candidatos utilizando o Filtro $D F$, que preserva apenas os candidatos que ocorrem em pelo menos dois documentos no corpus, e o Filtro $D F_{-} S N_{-} P M$, que, a partir do resultado do Filtro DF, mantém os candidatos que fazem parte de sintagmas nominais e que, ao mesmo tempo, foram anotados pelo parser como sendo substantivos. O número de (radicais de) candidatos obtidos inicialmente pela segunda avaliação experimental (em Todos CTs) foi 9.997, 16.013 e 41.335, para os corpora, respectivamente, ECO, EaD e Nano. Ao usar o Filtro DF, esse número diminuiu 54,65\%, 49,67\% e 55,00\%, e ao usar o Filtro DF_SN_PM diminuiu 66,41\%,63,80\% e 69,44\% em relação ao número de todos os candidatos inicialmente obtidos (Todos CTs).

Na Figura 5.15, são comparadas as quantidades de candidatos (Todos CTs) resultantes da primeira avaliação experimental (gráfico (a)) contra o uso da segunda avaliação (gráfico (b)). Adicionalmente, são indicados os números de candidatos de cada corpus considerando as diferentes filtragens (Filtro $D F$ e Filtro $D F_{-} S N_{-} P M$ ) realizadas nos candidatos. 
Ainda nessa figura, são mostradas as quantidades de termos pertencentes à lista de termos de referência de cada corpus que foram mantidas após os pré-processamentos.

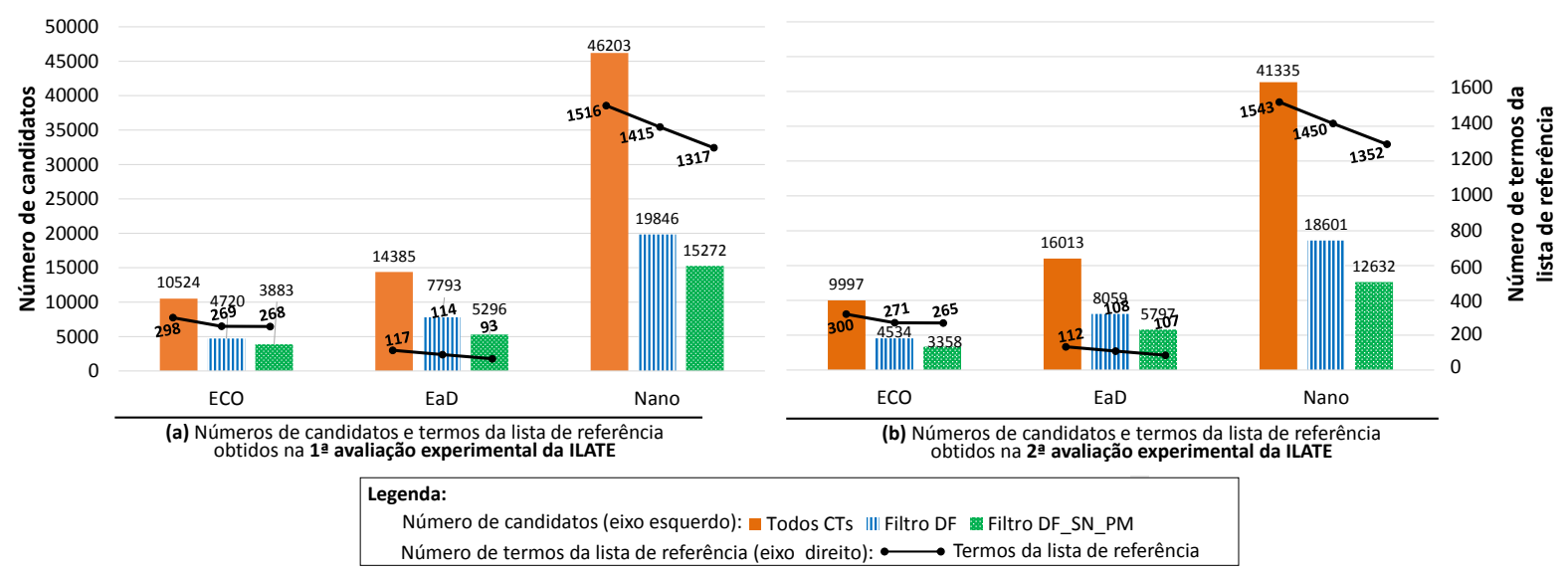

Figura 5.15: Comparação do número de candidatos considerados por cada filtro aplicado vs. número de termos da lista de referência mantidos por cada filtro.

Analisando a quantidade de candidatos obtida pelas duas avaliações experimentais, verifica-se que tanto para o corpus ECO como para Nano, o número de candidatos diminuiu independentemente de se considerar: (i) todos os candidatos pré-processados (Todos $C T s$ ), (ii) somente os candidatos que se mantiveram após a aplicação do Filtro DF ou (iii) os que se mantiveram com o uso do Filtro $D F_{-} S N_{-} P M$. É interessante ressaltar que tal diminuição pode ser vista intuitivamente como útil para a extração de termos, uma vez que um conjunto de candidatos menor levará menos tempo para ser processado pelo extrator. Por exemplo, para o corpus ECO, quando utilizados todos os candidatos préprocessados (Todos CTs) na primeira avaliação experimental, tem-se 10524 candidatos. Enquanto que ao considerar todos os candidatos pré-processados (Todos CTs) na segunda avaliação, esse número caiu para 9.997 .

Outra vantagem do uso da segunda avaliação experimental é que, em geral, esta manteve mais termos verdadeiros (termos da lista de referência do respectivo corpus) entre os candidatos do que a primeira avaliação. Por exemplo, para o corpus ECO, a diminuição de candidatos feita pela segunda avaliação manteve 300 termos verdadeiros, enquanto que a primeira avaliação manteve 298. Na primeira avaliação, foram removidos dois candidatos que são termos verdadeiros ("sedimento" e "AT") devido ao fato que seus radicais (respectivamente, "sed" e "at") correspondem aos radicais das seguintes stopwords: "sede" (conjugação do verbo ser) e "at" (preposição em inglês). O termo "AT" corresponde ao símbolo do elemento químico ástato.

Em suma, ao considerar os resultados dos experimentos realizados neste trabalho, pode-se afirmar que as decisões tomadas na segunda avaliação experimental da ILATE são favoráveis para os corpora EaD e Nano porque conseguem diminuir mais ainda o número de candidatos a termos mantendo mais os termos verdadeiros entre tais candidatos do que quando seguidas as decisões da primeira avaliação experimental. No entanto, para o corpus EaD, essa vantagem é proveniente das decisões da primeira avaliação, sendo esta mais recomendada para ser utilizada para esse corpus.

Até esse ponto dos experimentos, tem-se, para cada corpus, três matrizes de candidatos com todas as características extraídas. Assim como na primeira avaliação experimental, foi realizada uma seleção de características para cada uma dessas matrizes de candidatos com o objetivo de identificar quais características são melhores para a tarefa de extração de termos. Os mesmos métodos de seleção de características baseados em aprendizado de máquina foram utilizados na segunda avaliação experimental: CFS_SubsetEval 
com o método de busca RandomSearch (CFS_RS); CFS_SubsetEval com o BestFirst como método de busca $\left(C F S_{-} B F\right)$; $C B F_{-}$SubsetEval usando o RandomSearch como método de busca $\left(C B F_{-} R S\right)$; e $C B F_{-}$SubsetEval com o BestFirst como método de busca $\left(C B F_{-} B F\right)$.

Na Figura 5.16, são mostrados, para cada corpus (ECO, EaD e Nano), os conjuntos de características selecionados por cada um dos métodos de seleção $\left(C F S_{-} R S, C F S_{-} B F\right.$, $C B F_{-} R S$ e $\left.C B F_{-} B F\right)$ utilizando cada uma das matrizes de entrada contendo todos os candidatos pré-processados (Todos CTs). Ainda na Figura 5.16, são mostrados os conjuntos de características selecionados pelos métodos quando as matrizes continham os candidatos mantidos após a realização de diferentes filtragens (Filtro DF e Filtro $\left.D F_{-} S N_{-} P M\right)$.

\begin{tabular}{|c|c|c|c|c|}
\hline & Método/Corpus & ECO & EaD & Nano \\
\hline \multirow{4}{*}{5} & CFS_RS & $\begin{array}{l}\text { atf, tf-idf, tvq, thd, glossEx, núcleo_sintagma, pm, } \\
\text { n_subst., n_adj. }\end{array}$ & atf, tc, weirdness, thd, ei & tvq, ridf, thd, ei, núcleo_sintagma, pm, n_adj., n_po \\
\hline & CFS_BF & idem ao CFS_RS usando Todas Caract. & atf, weirdness, ridf, thd, ei & tvq, ridf, thd, ei, núcleo_sintagma, $n \_$subst., adj, n_po \\
\hline & CBF_RS & $\begin{array}{l}\text { comGram, freq, atf, df, tf-idf, } \\
\text { weirdness, ridf, thd, tds, glossEx } \\
\text { sintagma, núcleo_sintagma, } n \_s\end{array}$ & $\begin{array}{l}\text { freq, atf, df, tf-idf, tv, tvq, tc, c } \\
\text { glossEx, ei, c-value, nc-value }\end{array}$ & $\begin{array}{l}\text { comGram, freq, atf, } \\
\text { weirdness, ridf, the }\end{array}$ \\
\hline & $\mathrm{CBF}_{-} \mathrm{BF}$ & $\begin{array}{l}\text { comGram, freq, atf, df, tf-idf, tv, tvq, tc, freq_cg, } \\
\text { weirdness, ridf, thd, tds, glossEx, ei, nc-value, } \\
\text { sintagma, sintagma, } n \text { _subst., n_adj., n_verbo, n_po }\end{array}$ & $\begin{array}{l}\text { freq, atf, df, tf-idf, tv, tvq, tc, cg, weirdness, thd, tds, } \\
\text { glossEx, ei, nc-value, sintagma, pm, n_subst., n_adj., } \\
\text { n_verbo, n_po }\end{array}$ & $\begin{array}{l}\text { comGram, freq, att, df, tf-idf, tv, t } \\
\text { thd, tds, glossEx, ei, nc-value, n } \\
\text { n_subst., n_adj., n_ve }\end{array}$ \\
\hline \multirow{4}{*}{ 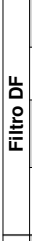 } & CFS_RS & $\begin{array}{l}\text { atf, tf-idf, tvq, tc, weirdness, thd, glossEx, } \\
\text { núcleo_sintagma, pm, n_subst. }\end{array}$ & $\begin{array}{l}\text { atf, tvq, weirdness, ridf, thd, tds, glossEx, ei, n_subst., } \\
\text { n_adj. }\end{array}$ & $\begin{array}{l}\text { atf, tffidf, tv, tv } \\
\text { núcleo_sintagn }\end{array}$ \\
\hline & CFS_BF & $\begin{array}{l}\text { atf, tf-idf, tvq, tc, weirdness } \\
\text { pm, } n \_\end{array}$ & atf, tvq, weirdness, ridf, thd, tds, glossEx, ei, n_subst. & \\
\hline & CBF_RS & $\begin{array}{l}\text { atf, df, tv, tvq, tc, cg, fr } \\
\text { glossEx, ei, c-ve } \\
\text { núcleo_sintagma, pm, }\end{array}$ & $\begin{array}{l}\text { atf, df, tf-idf, tc, cc } \\
\text { sEx, ei, nc-value, }\end{array}$ & $\begin{array}{r}\text { comG } \\
\text { weird } \\
\text { núcleo_si }\end{array}$ \\
\hline & CBF_BF & $\begin{array}{r}\text { freq, atf, df, tv, tvq, tc, cg, we } \\
\text { glossEx, ei, nc-value, sintagma } \\
\text { n_subst., n_ad }\end{array}$ & $\begin{array}{r}\text { freq, atf, df, tf-idf, tv, tvq, tc, cg, frec } \\
\text { thd, tds, ei, nc-value, núcleo_sinta } \\
\text { n_adj., n_po }\end{array}$ & $\begin{array}{r}\text { comGram, freq, atf } \\
\text { thd, tds, glossEx, } \\
\text { n_subs }\end{array}$ \\
\hline \multirow{4}{*}{ 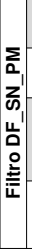 } & c & tf-idf, tvq, thd, glossEx, & DSS & \\
\hline & CFS_BF & $\mathrm{a}$ & eq, & \\
\hline & CBF_RS & $\begin{array}{r}\text { freq, atf, df, tf-idf, tv, tvq, tc, c } \\
\text { tds, glossEx, ei, nc-value, si } \\
\text { n_adj., n }\end{array}$ & $\begin{array}{l}\text { com } \\
\text { weird } \\
\text { nú }\end{array}$ & $\begin{array}{l}\text { comGram, freq, a } \\
\text { ridf, thd, tds, } \\
\text { núcleo_sintagma, }\end{array}$ \\
\hline & CBF_BF & $\begin{array}{l}\text { freq, atf, df, tf-idf, tv, tvq, tc, cg, ridf, thd, tds, glossEx, } \\
\text { ei, nc-value, núcleo_sintagma, pm, n_subst., n_adj., } \\
\text { n_po }\end{array}$ & $\begin{array}{l}\text { comGram, freq, atf, df, tv, tvq, tc, cg, freq_cg, weirdness, } \\
\text { ridf, thd, tds, glossEx, ei, nc-value, sintagma, pm, } \\
\text { n_subst., n_adj., n_po }\end{array}$ & $\begin{array}{l}\text { comGram, freq, atf, df, tf-idf, tv, tvq, tc, weirdness, ridf, } \\
\text { thd, tds, glossEx, ei, nc-value, sintagma, pm, n_subst., } \\
\text { n_adj., n_verbo, n_po }\end{array}$ \\
\hline
\end{tabular}

Figura 5.16: Seleção de características considerando diferentes filtragens de candidatos realizadas na segunda avaliação experimental da ILATE.

Ao considerar a quantidade de características selecionada por cada método para cada caso, - por exemplo, o CFS_RS escolheu 9 características considerando Todos CTs do corpus ECO - calcula-se que esses métodos de seleção de características escolheram, em média, 46 características. Especificamente para os corpora ECO e EaD, os métodos de seleção $C F S_{-} R S$ e $C F S \_B F$ escolheram o mesmo conjunto de características quando utilizaram como entrada os candidatos que se mantiveram durante o uso do Filtro DF_SN_PM. Para o corpus EaD, tais métodos $\left(C F S_{-} R S\right.$ e $\left.C F S_{-} B F\right)$ também selecionaram o mesmo conjunto de características quando utilizaram como entrada todos os candidatos.

Na Figura 5.17, é comparado quanto (em porcentagem) cada característica foi escolhida pelos métodos de seleção de características nas duas avaliações experimentais considerando os 3 corpora utilizados.

Considerando a seleção de características feita por quatro métodos diferentes a partir dos 3 corpora, a característica thd foi escolhida por $97 \%$ dos métodos de seleção, sendo, portanto, considerada a mais relevante para a classificação de termos, segundo os métodos utilizados. Em seguida, vieram $n_{-}$subst. (proposta na pesquisa apresentada nesta tese) e atf escolhidas por $92 \%$ dos métodos de seleção. Resumidamente, observa-se que algumas características híbridas (thd, glossEx e weirdness) são as mais escolhidas pelos métodos.

As características propostas nesta pesquisa, que são $n_{-} s u b s t ., n_{-} a d j ., n_{-}$po e $n_{-} v e r b o$,

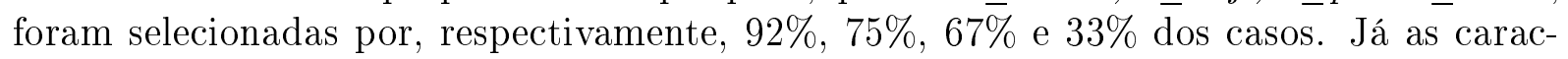
terísticas de outra área, que são tvq, tv, tc e comGram foram indicadas como relevantes 


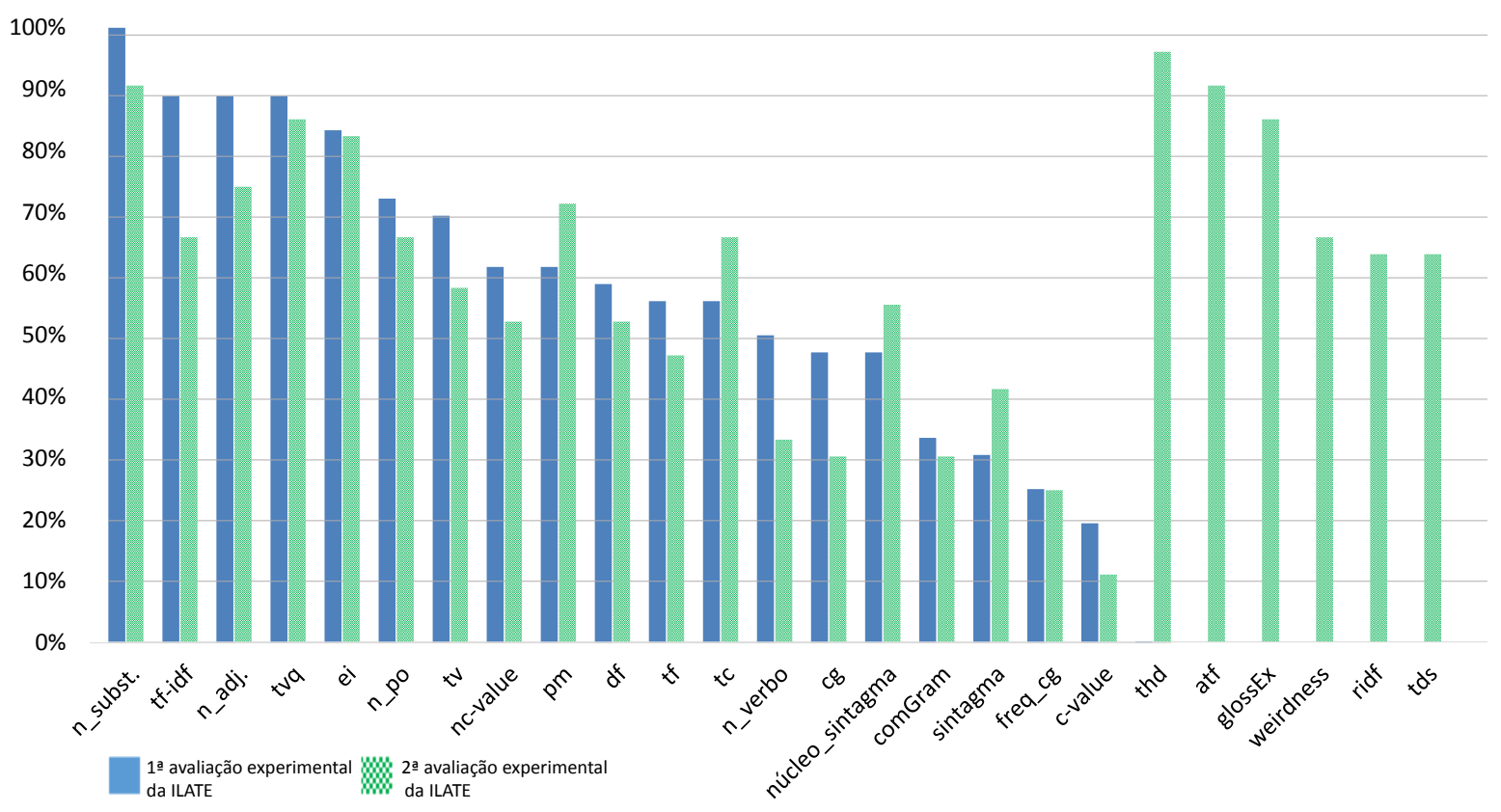

Figura 5.17: Comparação das distribuições das características selecionadas nas duas avaliações experimentais da ILATE considerando os 3 corpora utilizados.

por, respectivamente, $86 \%, 58 \%, 67 \%$ e $31 \%$ dos casos.

\subsubsection{Classificação Indutiva de Candidatos a Termos}

Os mesmos cinco algoritmos de classificação e as mesmas configurações destes que foram utilizados na primeira avaliação experimental foram considerados nesta avaliação. Os algoritmos são: Nä̈ve Bayes (NB), J48, Support Vector Machine (SVM), K-Nearest Neighbors (KNN) e JRIP.

Os cinco algoritmos foram executados para cada matriz de candidatos a termos de cada corpus visando gerar automaticamente uma lista de candidatos considerados termos do domínio em questão (termos extraídos) segundo o algoritmo de classificação utilizado.

Para cada lista de termos extraídos, foram calculadas precisão, cobertura e medida F.

\subsection{Apresentação, Análise e Discussão dos Resultados da Segunda Avaliação Experimental da ILATE}

Para comparar os termos extraídos obtidos, adotou-se o método para avaliação descrito anteriormente na Seção 4.3 do Capítulo 4, página 70. As discussões acerca dos resultados foram divididas em três partes: (i) discussão sobre os resultados das duas Avaliações Experimentais da ILATE, (ii) comparação e discussão sobre os resultados da segunda avaliação experimental com outras medidas/métodos de extração de termos e (iii) discussão acerca das características dos candidatos consideradas para a extração de termos utilizando a segunda avaliação experimental da ILATE.

\subsubsection{Discussão sobre os Resultados das duas Avaliações Experimentais da ILATE}

Para analisar o impacto do refinamento do pré-processamento dos textos e a adição de características mais complexas dos candidatos a termos na extração de termos, os 
resultados da primeira avaliação experimental da ILATE (versão 1) foram comparados aos resultados da segunda avaliação experimental (versão 2). Os resultados da primeira avaliação experimental foram apresentados anteriormente nas Figuras de 5.6 a 5.14, página 86. Os resultados da segunda avaliação experimental são apresentados nas Figuras de 5.18 a 5.26 a seguir. Finalmente, a comparação dos resultados dessas duas avaliações é apresentada nas Figuras de 5.27 a 5.35, página 103.

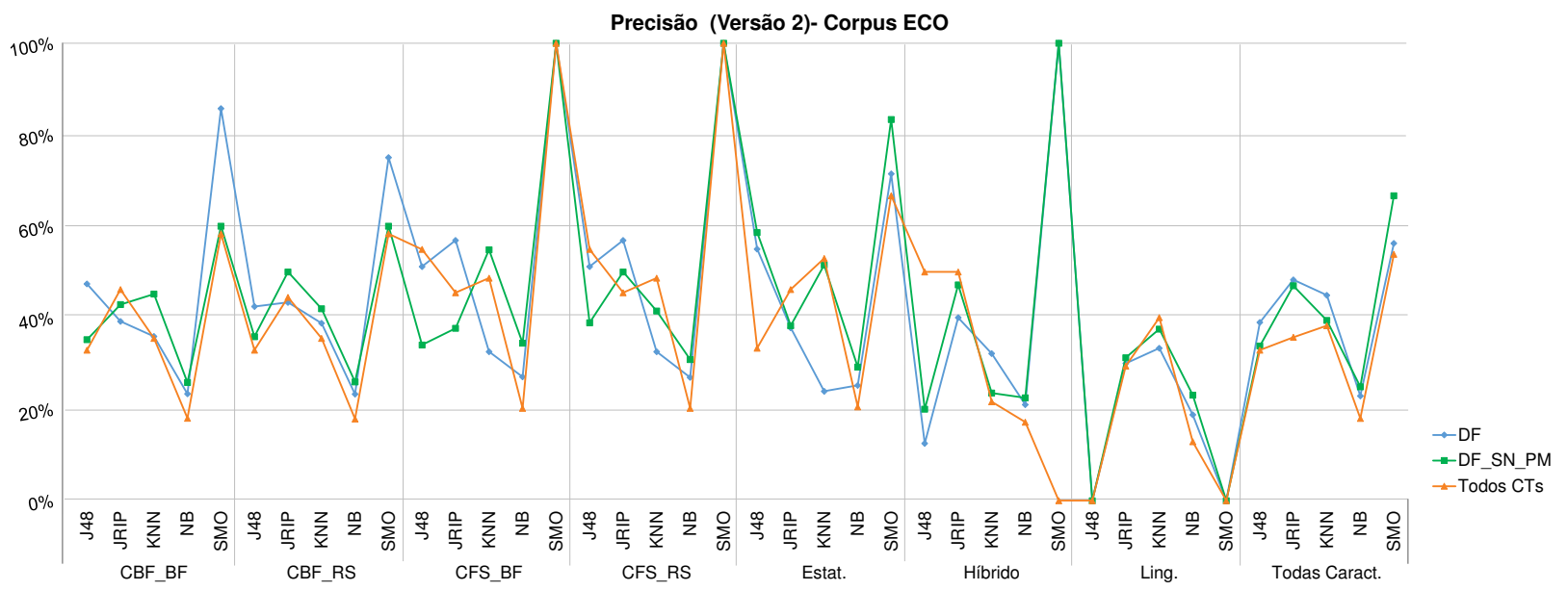

Figura 5.18: Resultados de precisão obtidos na segunda avaliação experimental - Corpus ECO.

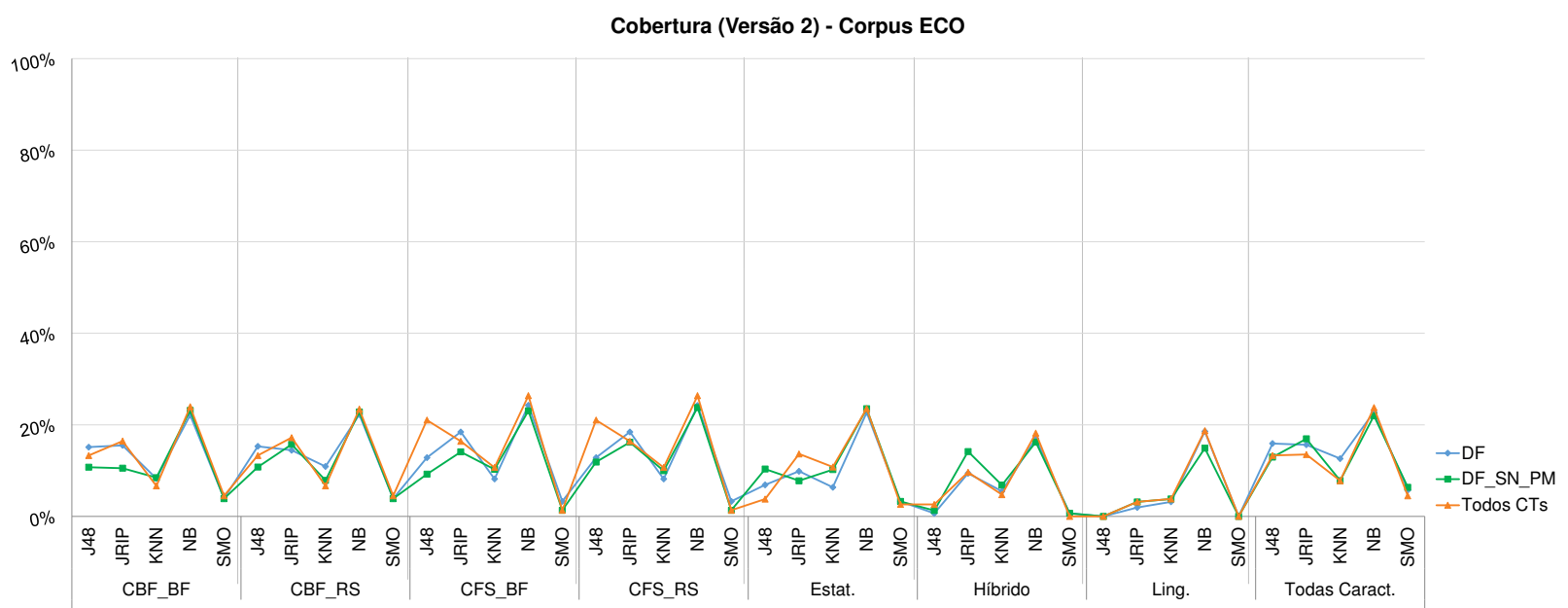

Figura 5.19: Resultados de cobertura obtidos na segunda avaliação experimental - Corpus ECO.

Para cada corpus (ECO, EaD e Nano), as medidas de avaliação (precisão, cobertura e medida $\mathrm{F}$ ) foram calculadas para cada conjunto de características indicado por cada um dos métodos de seleção de características $\left(C F S_{-} R S, C F S_{-} B F, C B F_{-} R S\right.$ e $\left.C B F_{-} B F\right)$. Esses métodos de seleção, por sua vez, utilizaram como entradas as matrizes de candidatos obtidas por diferentes filtragens (Todos CTs, Filtro DF e Filtro DF_SN_PM). Para os experimentos, também foram consideradas todas as características dos candidatos juntas (Todas Caract.), somente as características linguísticas (Ling.), somente as estatísticas (Estat.) e somente as características híbridas (Hibrido).

O cálculo das coberturas das duas avaliações experimentais foi realizado da mesma maneira, ou seja, foi descontado o número de termos verdadeiros removidos durante a seleção de candidatos.

Ao comparar os resultados das duas avaliações experimentais, observou-se que dependendo da medida de avaliação que se deseja considerar, poder-se-ia seguir as decisões 


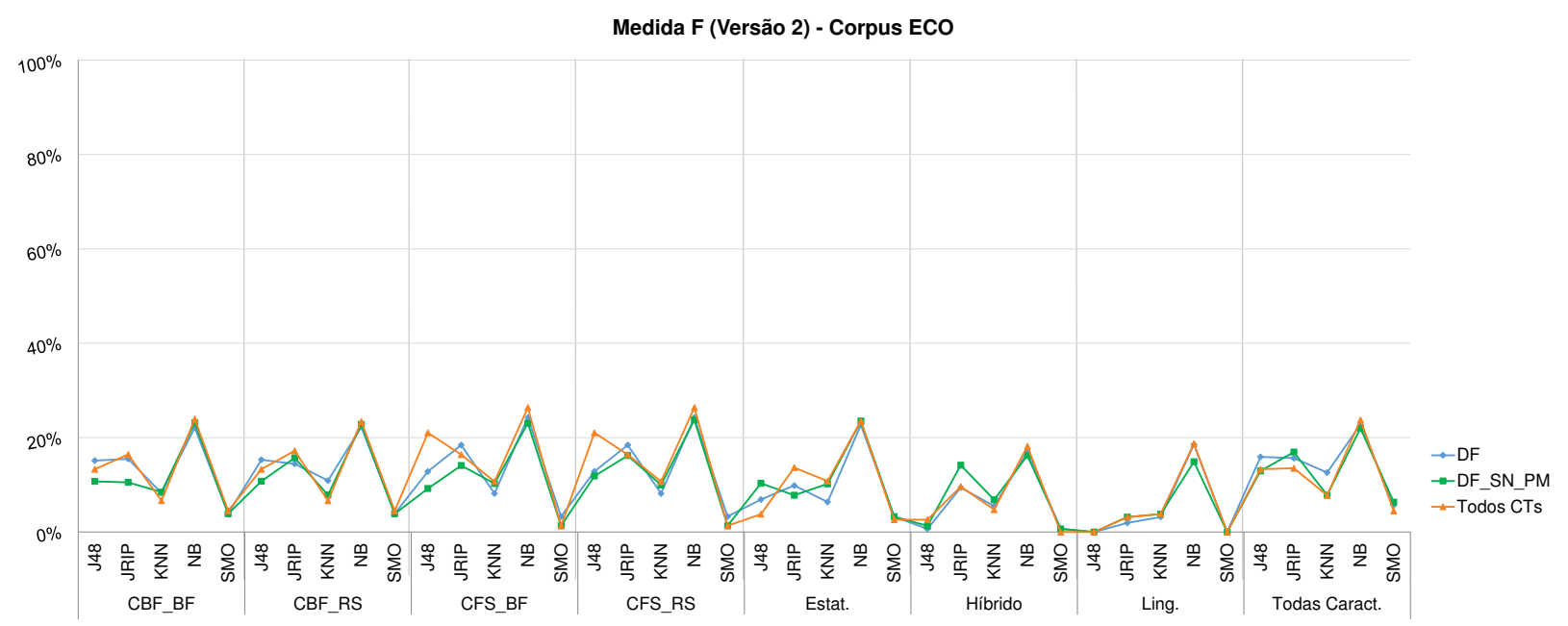

Figura 5.20: Resultados de medida F obtidos na segunda avaliação experimental - Corpus ECO.

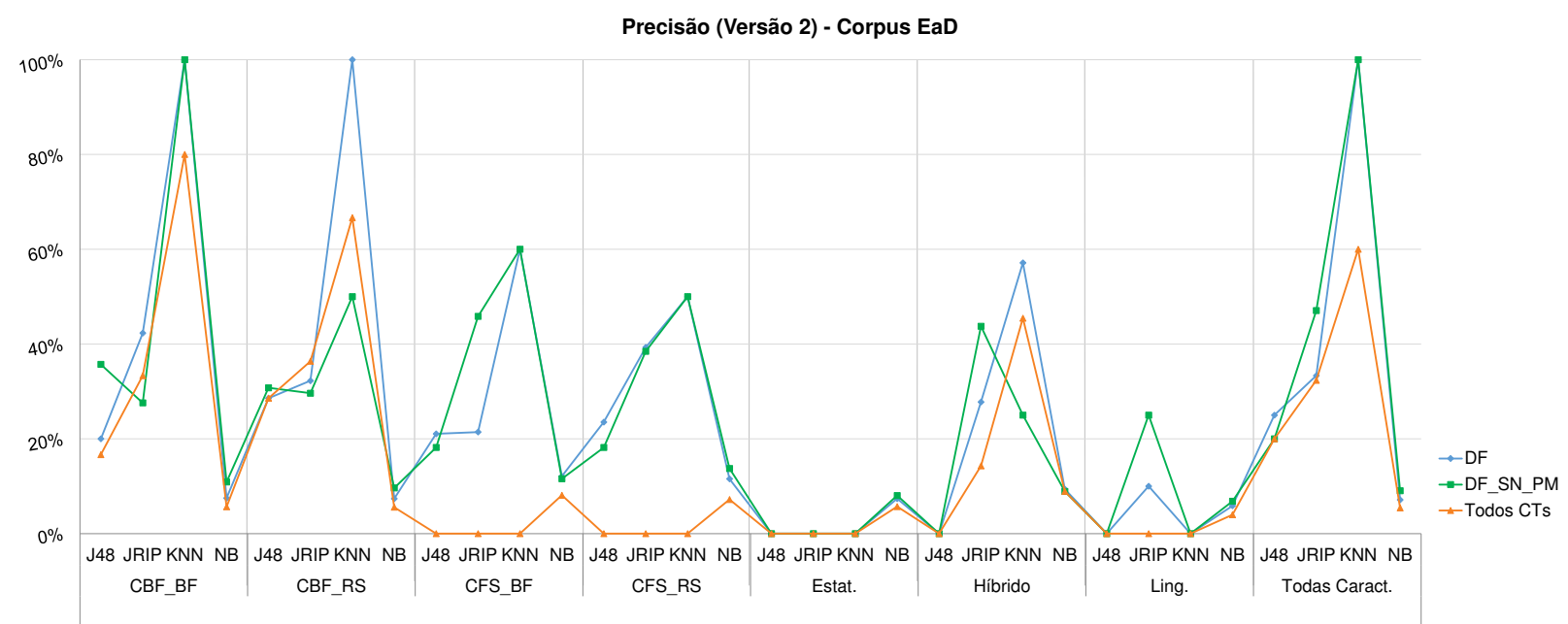

Figura 5.21: Resultados de precisão obtidos na segunda avaliação experimental - Corpus EaD.

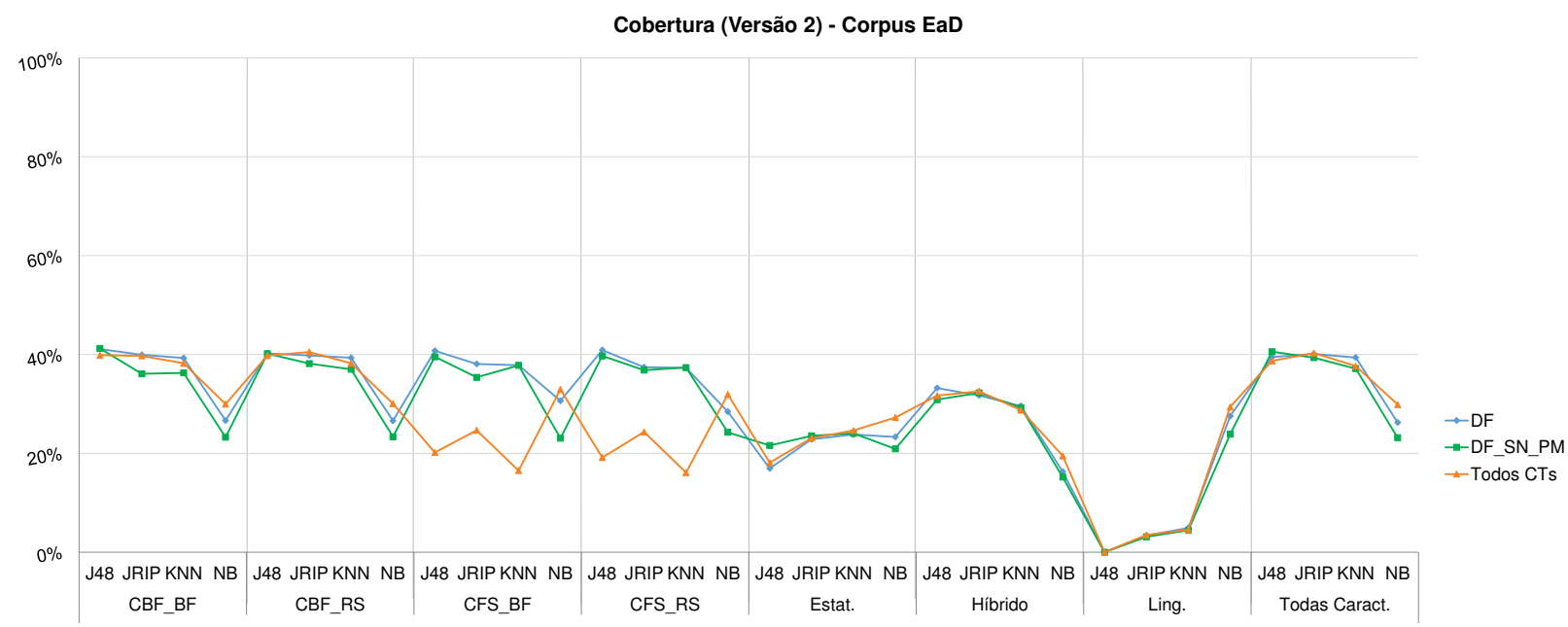

Figura 5.22: Resultados de cobertura obtidos na segunda avaliação experimental - Corpus EaD.

tomadas tanto na primeira avaliação experimental como na segunda, dependendo o que se deseja priorizar na extração dos termos, conforme discutido a seguir.

Ao analisar os valores de precisão, verifica-se que refinar o pré-processamento e adição de características híbridas mais complexas é independente para os corpora ECO e 


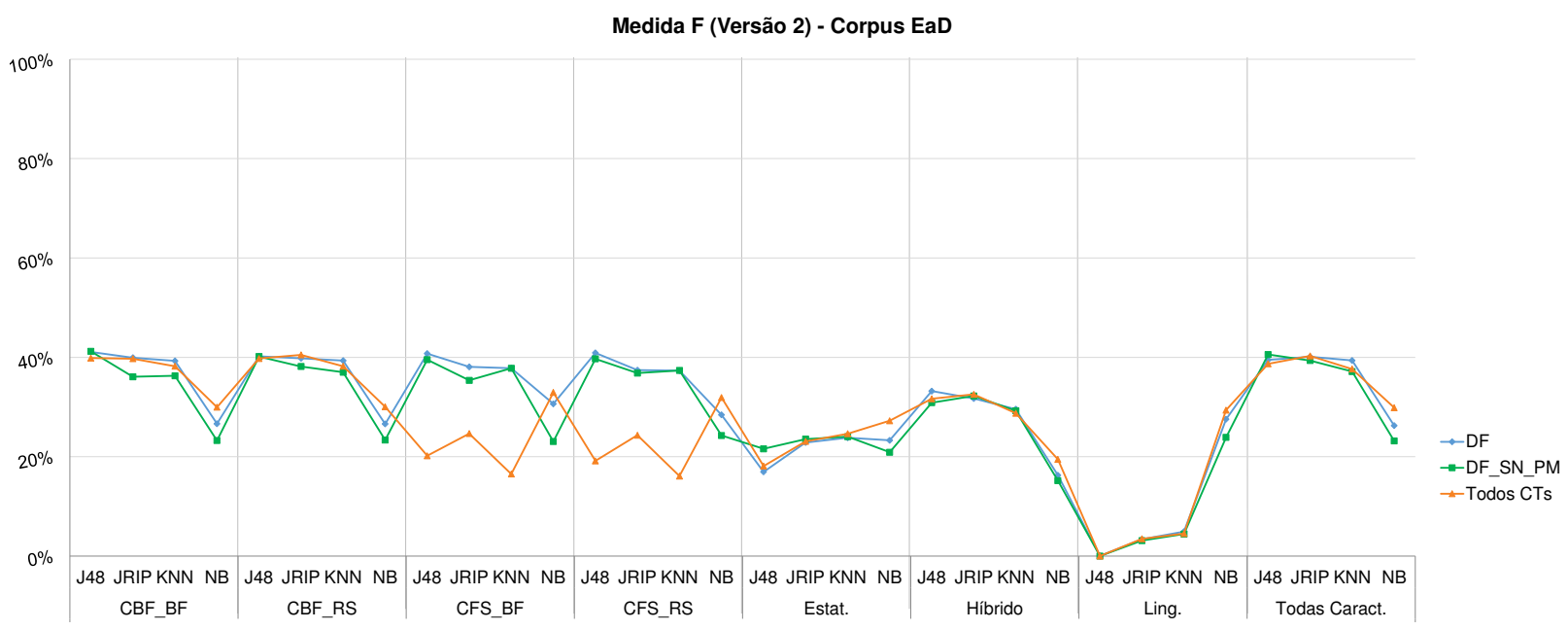

Figura 5.23: Resultados de medida F obtidos na segunda avaliação experimental - Corpus EaD.

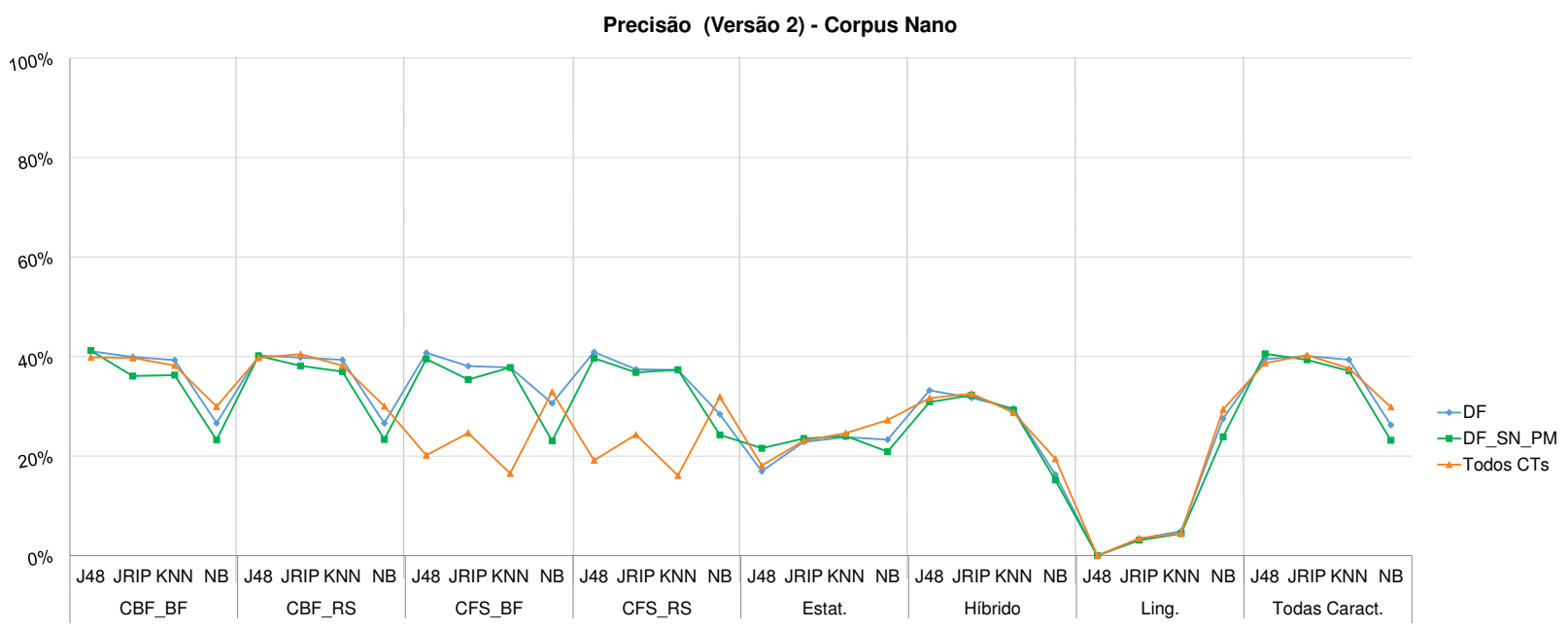

Figura 5.24: Resultados de precisão obtidos na segunda avaliação experimental - Corpus Nano.

Cobertura (Versão 2) - Corpus Nano

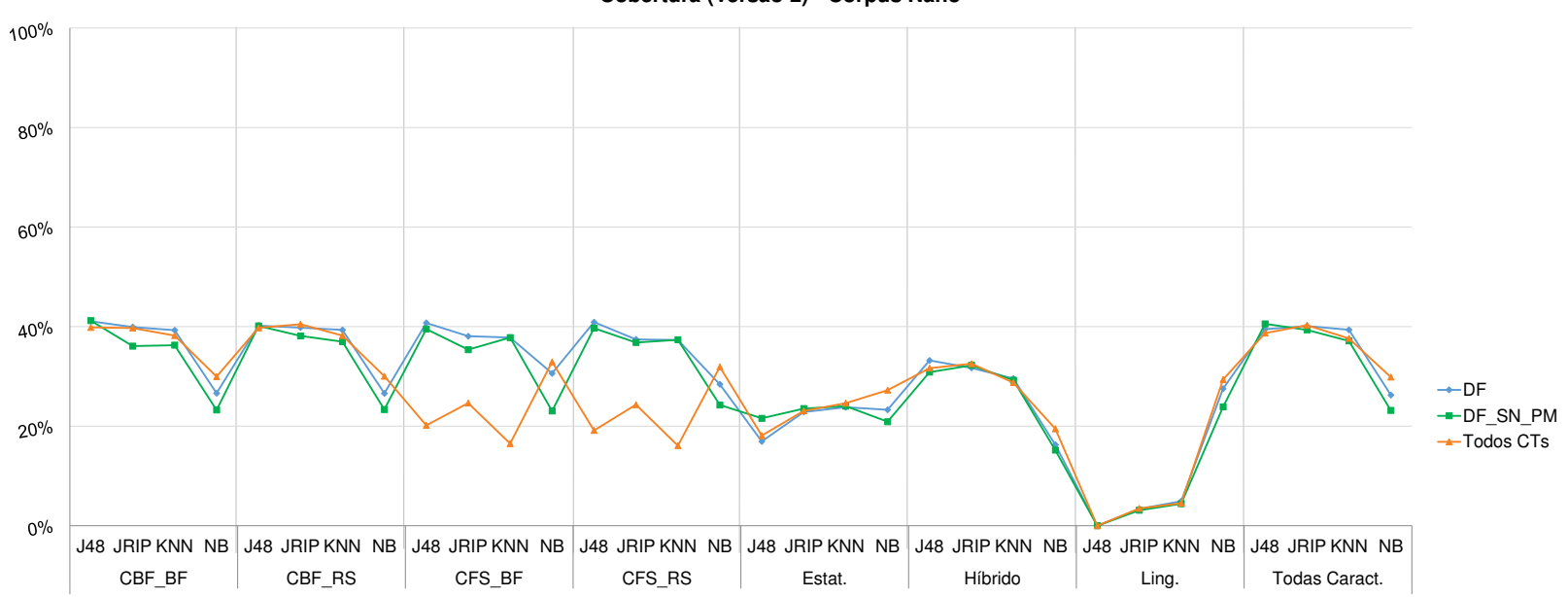

Figura 5.25: Resultados de cobertura obtidos na segunda avaliação experimental - Corpus Nano.

EaD, uma vez que para alguns conjuntos de candidatos as decisões tomadas na primeira avaliação experimental da ILATE é melhor e, para outros, as decisões da segunda avaliação é melhor. Já para o corpus Nano, obtêm-se precisões mais altas ao adotar primeira avaliação experimental, exceto quando se utiliza o indutor NB. 


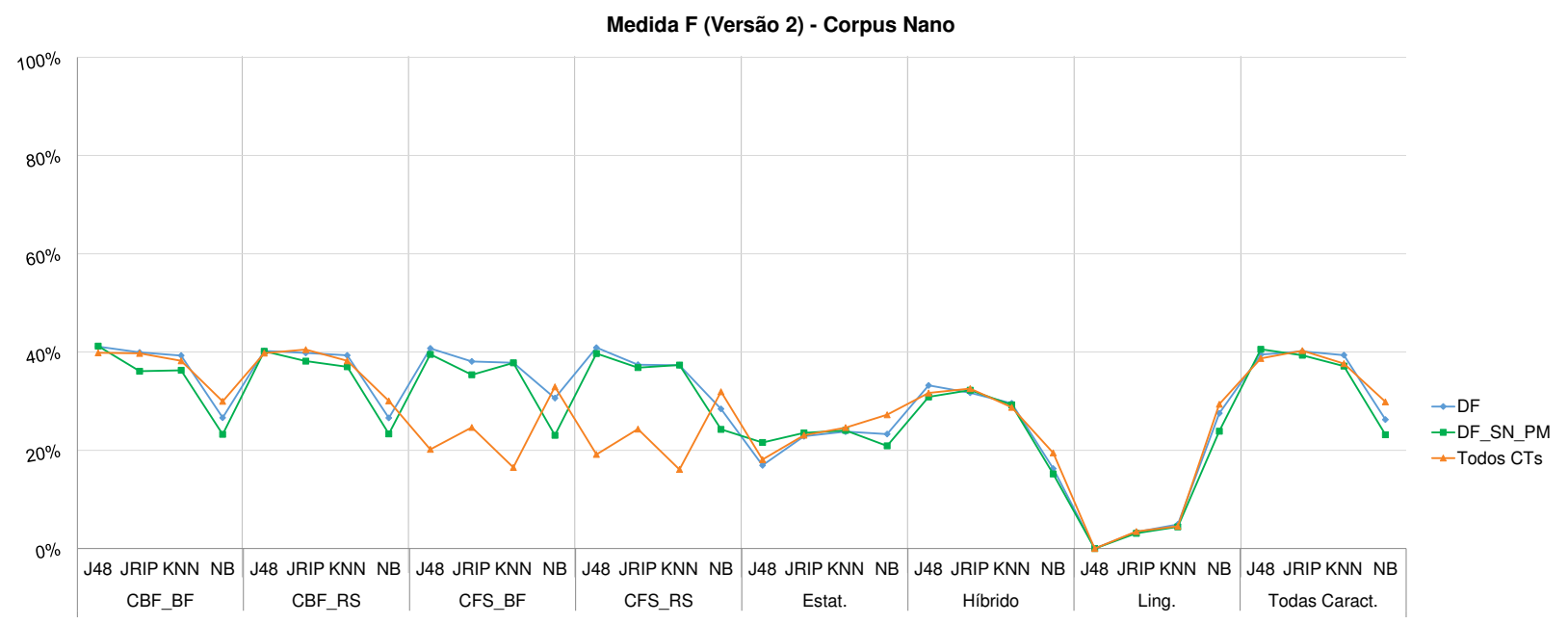

Figura 5.26: Resultados de medida F obtidos na segunda avaliação experimental - Corpus Nano.

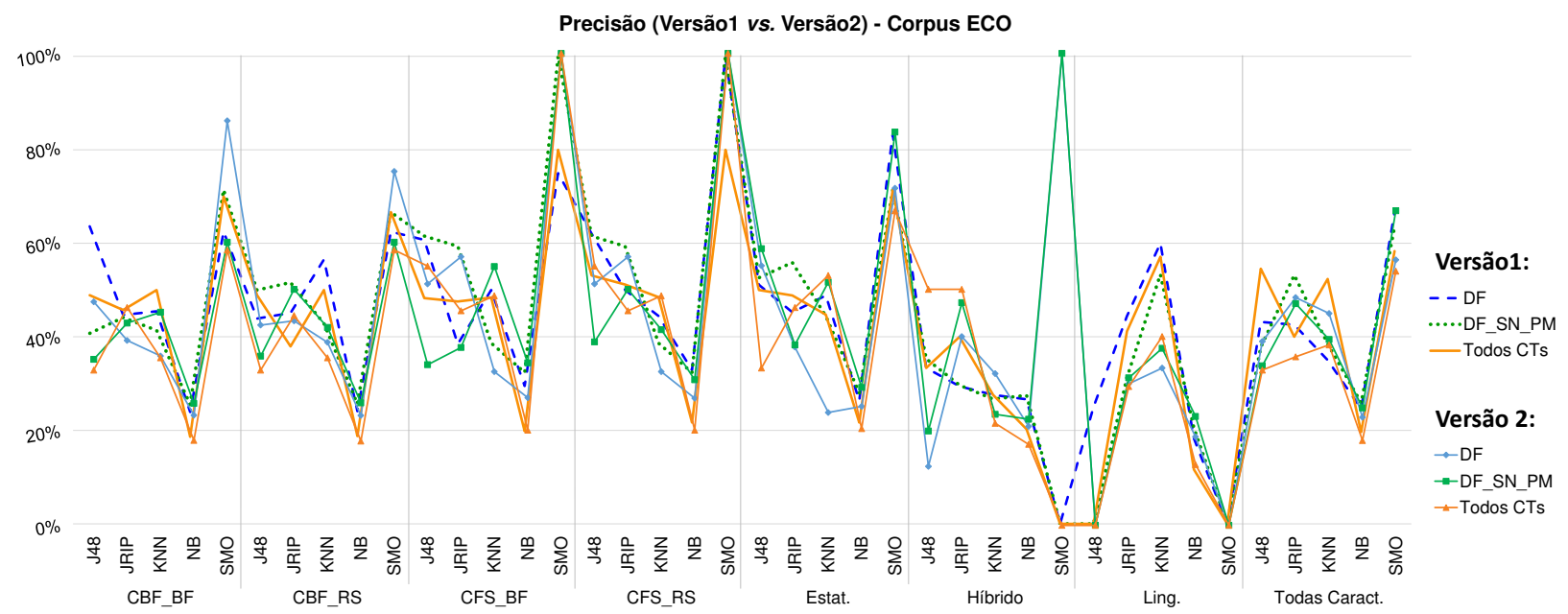

Figura 5.27: Resultados de precisão obtidos nas duas avaliações experimentais - Corpus ECO.

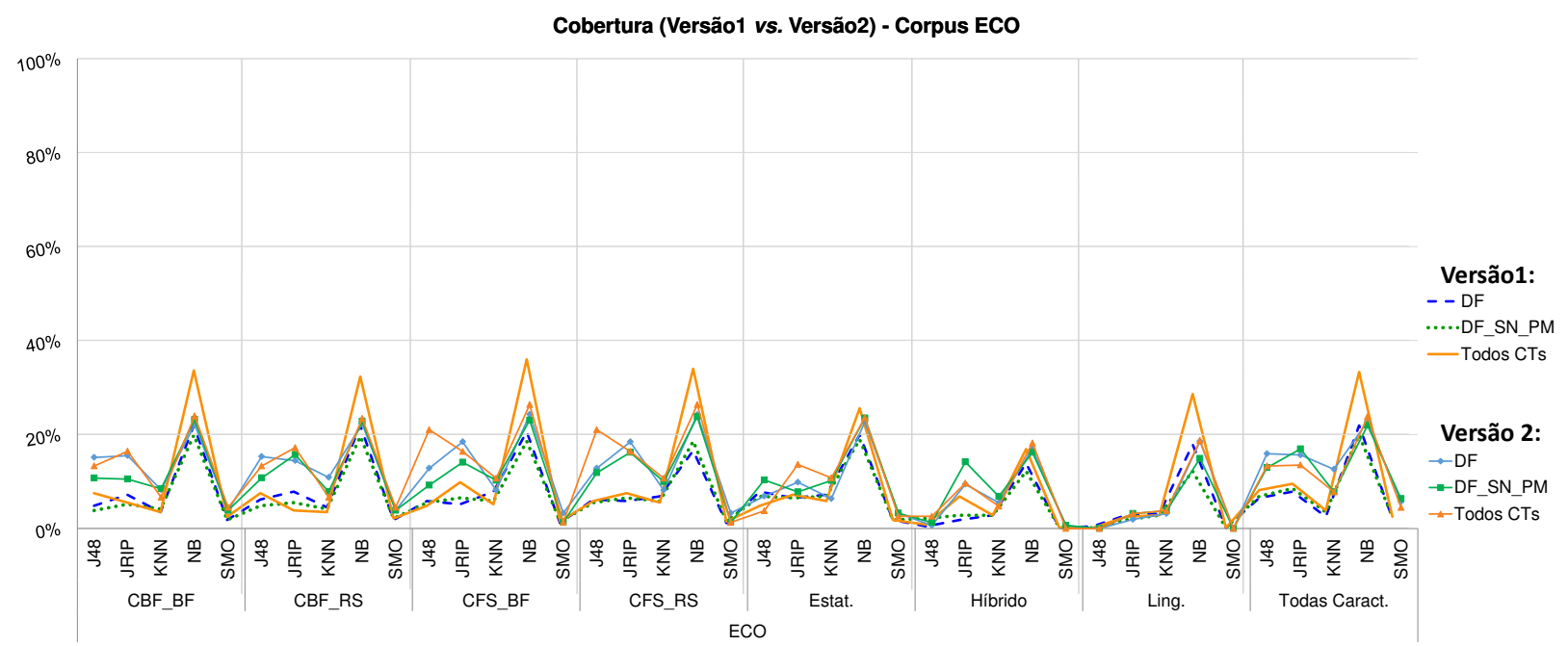

Figura 5.28: Resultados de cobertura obtidos nas duas avaliações experimentais - Corpus ECO.

Em relação a cobertura, para o corpus ECO, quando se utilizaram somente os candidatos que se mantiveram após a aplicação do Filtro $D F$ ou os que se mantiveram após o uso do Filtro $D F_{-} S N_{-} P M$, as coberturas mais altas foram obtidas na segunda avaliação experimental. Já quando se utilizaram todos os candidatos pré-processados (Todos CTs), 


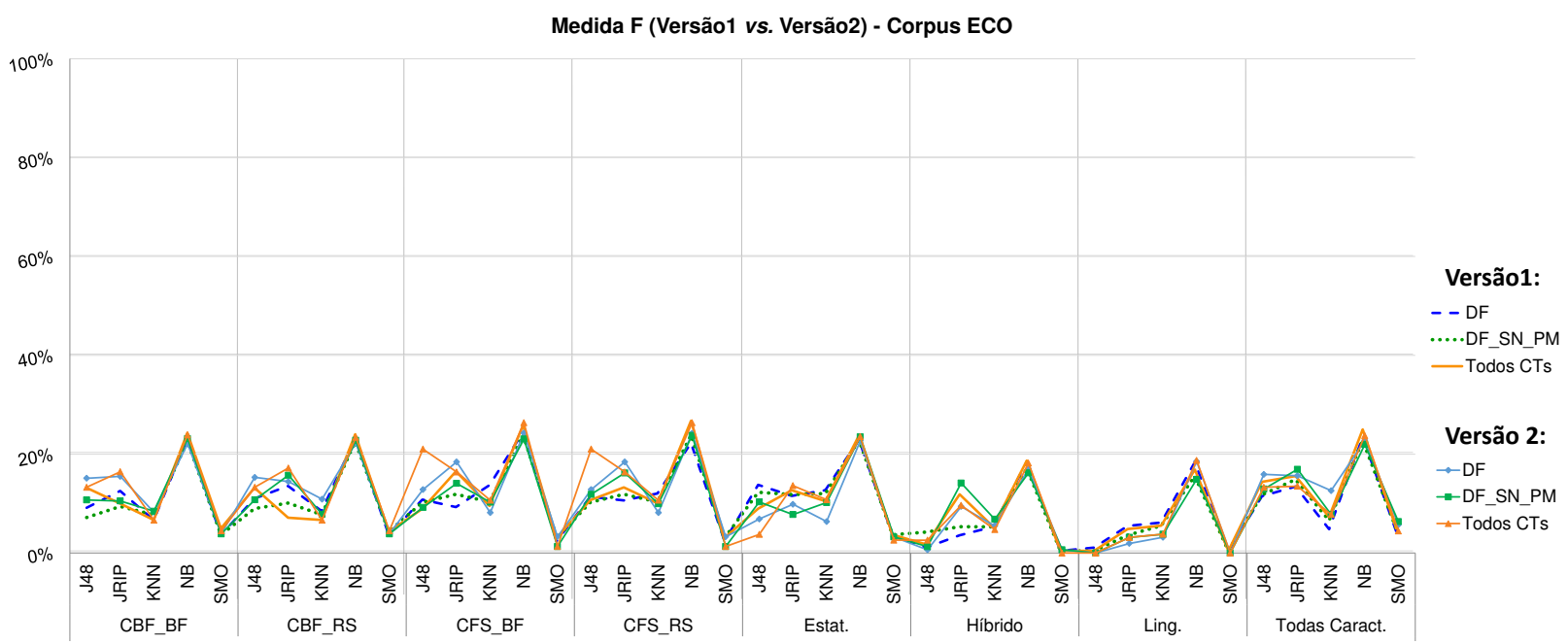

Figura 5.29: Resultados de medida F obtidos nas duas avaliações experimentais - Corpus ECO.

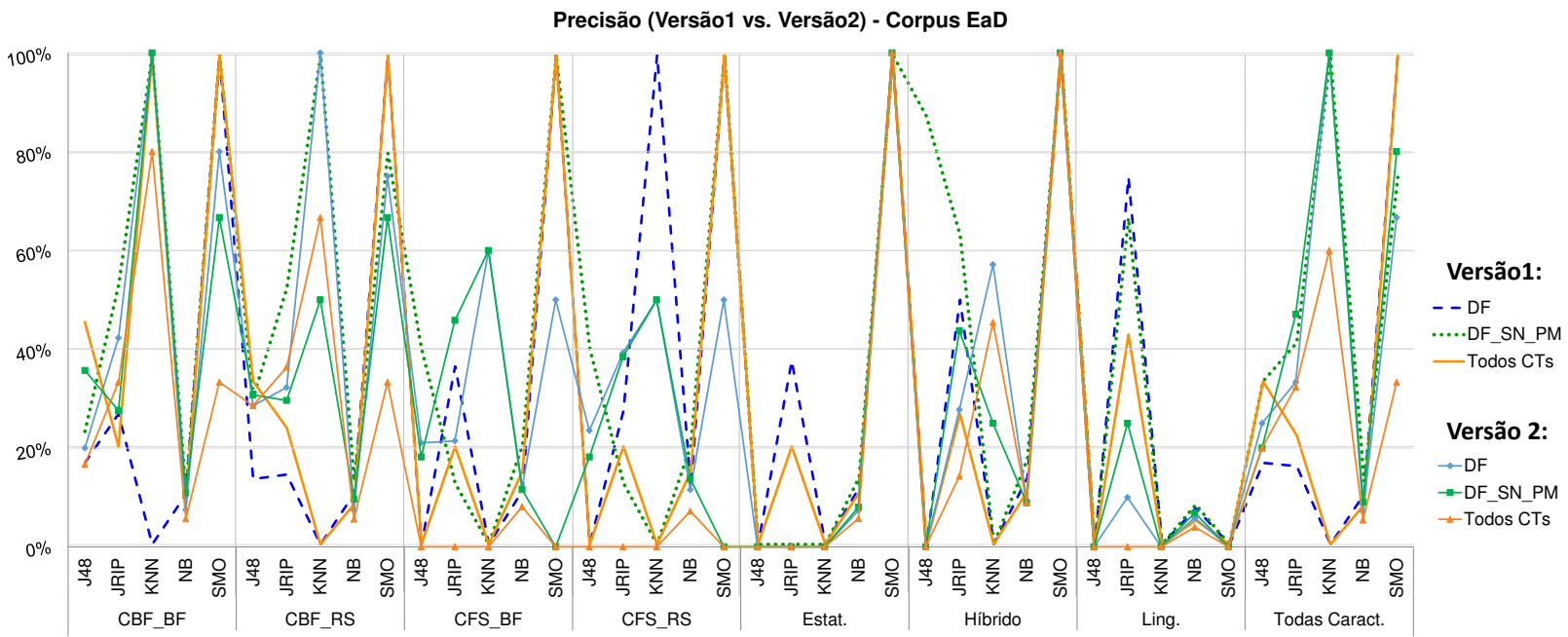

Figura 5.30: Resultados de precisão obtidos nas duas avaliações experimentais - Corpus EaD.

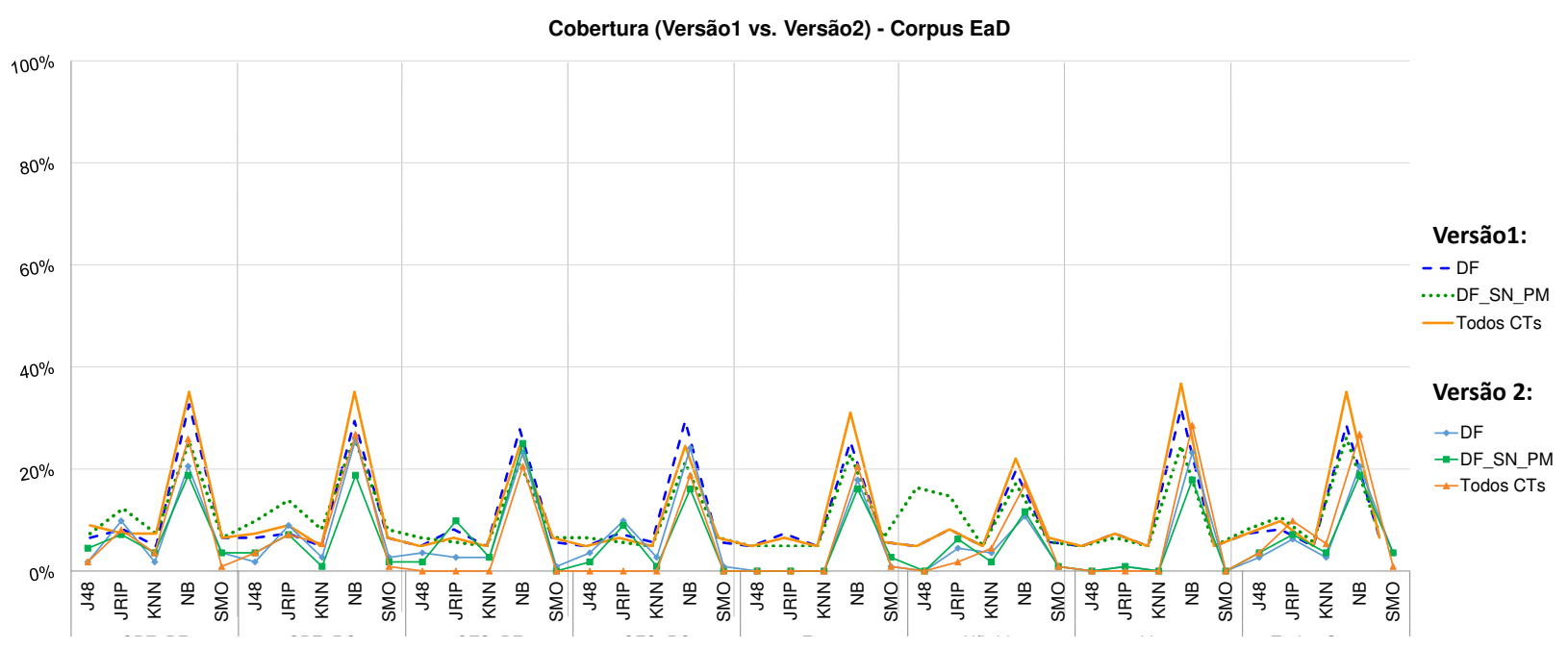

Figura 5.31: Resultados de cobertura obtidos nas duas avaliações experimentais - Corpus EaD.

recomenda-se seguir as decisões da primeira avaliação experimental. Para o corpus EaD, a maioria dos resultados foi melhor ao utilizar a primeira avaliação. Entretanto, para o corpus Nano, em geral, as coberturas mais altas foram alcançadas na segunda avaliação. 


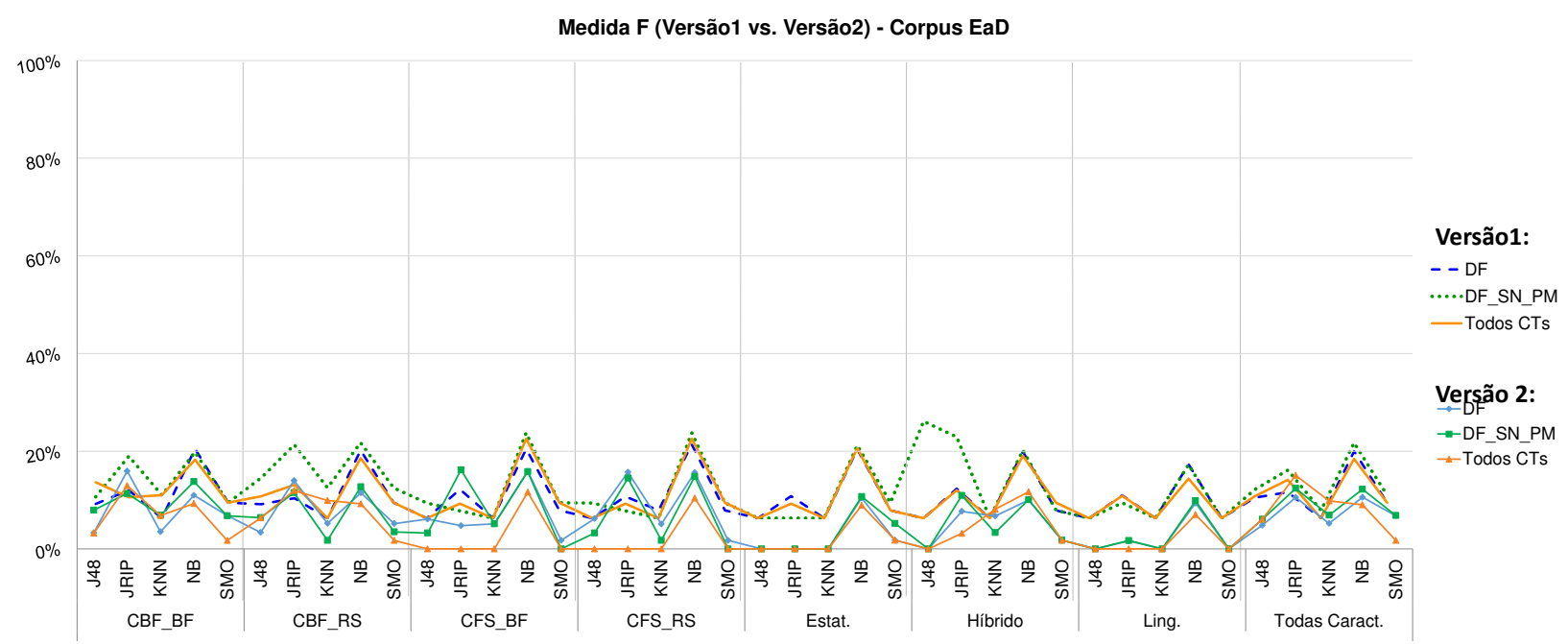

Figura 5.32: Resultados de medida F obtidos nas duas avaliações experimentais - Corpus EaD.

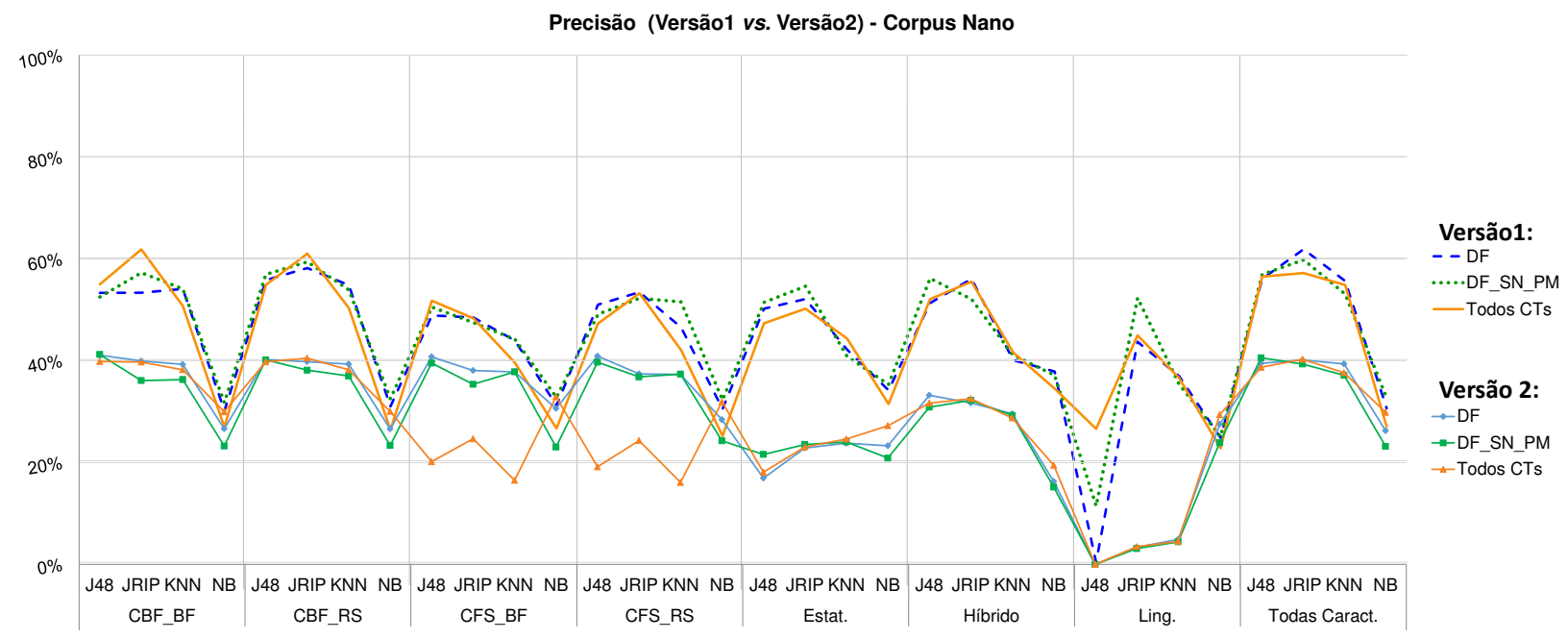

Figura 5.33: Resultados de precisão obtidos nas duas avaliações experimentais - Corpus Nano.

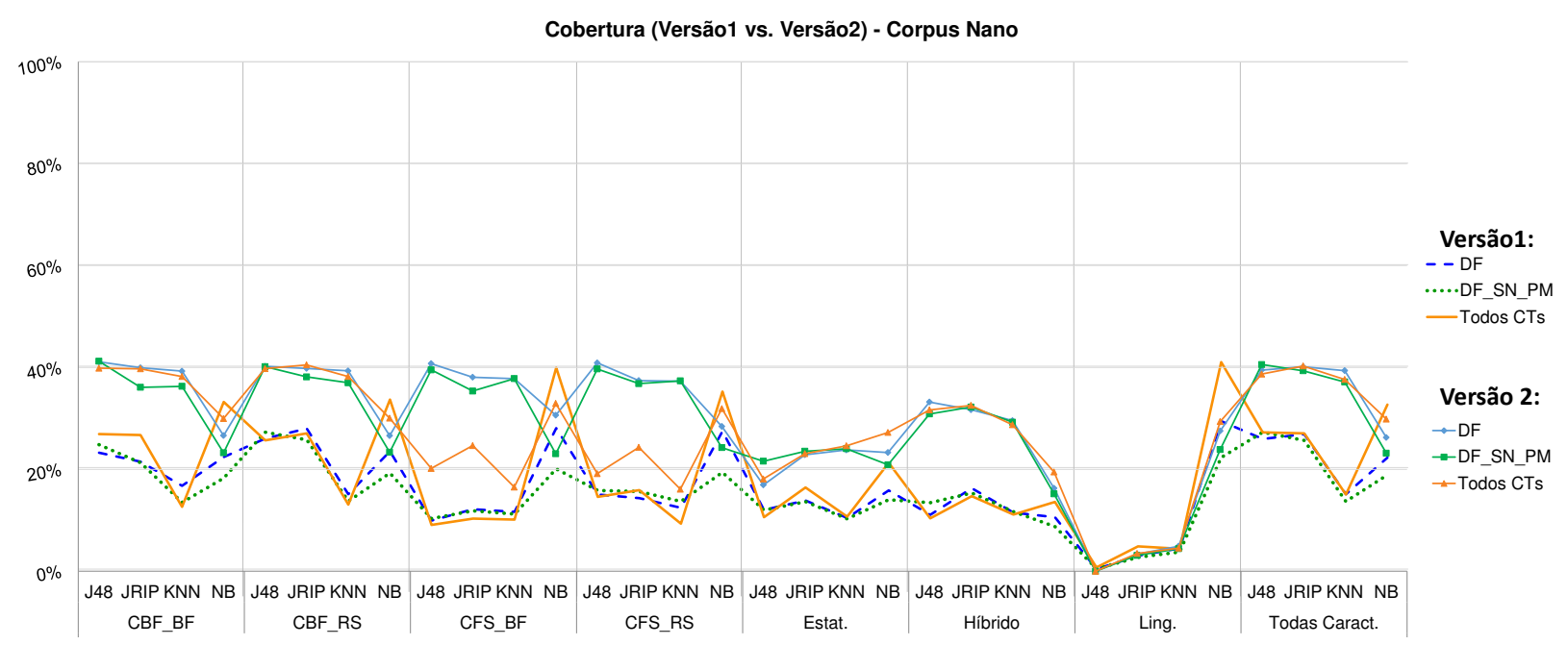

Figura 5.34: Resultados de cobertura obtidos nas duas avaliações experimentais - Corpus Nano.

Para os corpora ECO e Nano, os resultados de medida F da segunda avaliação experimental (máximo $\mathrm{MF}=41,21 \%$ ) foram mais altos ou similares aos da primeira avaliação (máximo $\mathrm{MF}=37,50 \%$ ), mas em nenhum caso mais baixos. Já para o corpus EaD, ge- 


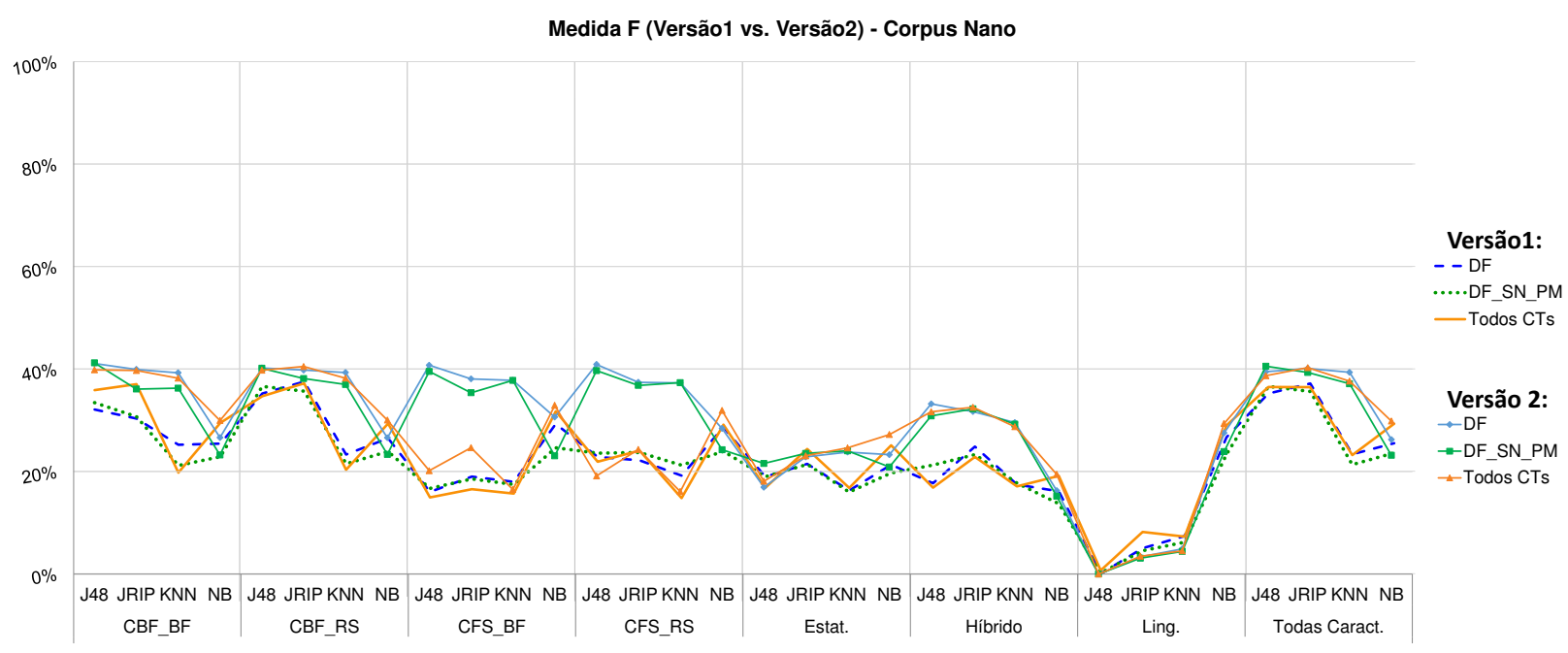

Figura 5.35: Resultados de medida F obtidos nas duas avaliações experimentais - Corpus Nano.

ralmente os resultados mais altos de medida $\mathrm{F}$ foram alcançados na primeira avaliação experimental, exceto para alguns casos do indutor JRIP.

\subsubsection{Discussões sobre os Resultados da ILATE em Relação a outros Trabalhos de Extração de Termos}

Os resultados alcançados pela abordagem ILATE na segunda avaliação experimental foram comparados com os resultados obtidos utilizando diferentes formas de extração de termos, a saber:

1. "Baselines", que são as medidas $t f$ e $t f-i d f$;

2. Extração tradicional de termos (referenciada como "Comparações extras" e detalhada na Subseção 4.1 do Capítulo 4, página 55;

3. Os métodos ExPorTer_linguístico e ExPorTer_híbrido (Zavaglia et al., 2007), que realizam extração de termos simples para o português do Brasil. Esses métodos são referenciados como "Estado da arte" e são descritos na Subseção 3.5.1 do Capítulo 3, página 38; e

4. EAT realizada na primeira avaliação experimental da ILATE e descrita na Seção 5.2.

Nas três tabelas apresentadas a seguir, é mostrada a comparação dos resultados mais altos de cada forma de extração de termos citada anteriormente. Nessas tabelas, a coluna "Descrição" corresponde à classificação de cada "Método" de extração utilizado para obtenção dos valores mais altos de precisão $(\mathrm{P}(\%))$, cobertura $(\mathrm{C}(\%))$ e medida $\mathrm{F}(\mathrm{MF}(\%))$.

Nessas tabelas, os resultados mais altos de precisão, cobertura e medida F são destacados com a cor cinza. Assim como feito na primeira avaliação experimental, quando o maior resultado é alcançado utilizando (praticamente) todo o corpus, destaca-se também o segundo resultado mais alto correspondente a mesma medida. Por exemplo, para o corpus ECO (Tabela 5.6), o valor mais alto de cobertura (100\%) foi alcançado pelas medidas freq_cg, weirdness, thd e nc-value considerando (praticamente) o corpus inteiro (8850 a 9950 candidatos). Assim como discutido anteriormente, esse resultado era esperado uma vez que os termos obrigatoriamente devem estar contidos no corpus do domínio em questão. Sendo assim, destacou-se o segundo resultado mais altos de cobertura $(99,67 \%)$ atingido pelas medidas $t f$ e $t f-i d f$ ao utilizar também todo o corpus (9950 candidatos), 
o que não é uma vantagem. Então, o terceiro valor mais alto de cobertura $(89,18 \%)$ foi destacado, sendo que este utilizou os 150 candidatos mais bem ranqueados pelo método ExPorTer_linguístico. Com base nessa análise, considera-se 89,18\% o valor mais alto de cobertura para o corpus ECO.

Tabela 5.6: Comparação dos resultados mais altos das duas avaliações experimentais da ILATE - Corpus ECO.

\begin{tabular}{|c|c|c|c|c|}
\hline Descriçãao & Método & $P(\%)$ & $C(\%)$ & $M F(\%)$ \\
\hline \multirow{3}{*}{$\begin{array}{l}1^{\mathrm{a}} \text { avaliação } \\
\text { experimental } \\
\text { da ILATE }\end{array}$} & $\begin{array}{l}\text { CFS_RS - DF - SVM ou CFS_RS/ } \\
\text { CFS-BF - DF SN PM - SVM }\end{array}$ & 100,00 & 1,01 a 1,34 & 1,99 a 2,65 \\
\hline & CFS_BF - Todos CTs - NB & 19,81 & 35,91 & 25,54 \\
\hline & CFS_RS - Todos CTs - NB & 21,67 & 33,89 & 26,44 \\
\hline \multirow{3}{*}{$\begin{array}{l}2^{\mathrm{a}} \text { avaliação } \\
\text { experimental } \\
\text { da ILATE }\end{array}$} & $\begin{array}{l}\text { CFS_BF/CFS_RS/Híbrido - } \\
\text { DF/DF_SN_PM - SVM ou }\end{array}$ & & & \\
\hline & 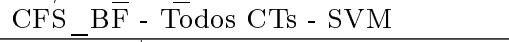 & 100,00 & 0,33 a 1,67 & 0,66 a 3,28 \\
\hline & CFS_BF/CFS_RS - Todos CTs - NB & 20,18 & 38,00 & 26,36 \\
\hline \multirow{5}{*}{ Baselines } & tf-idf $(50)$ & 50,00 & 8,33 & 14,29 \\
\hline & tf-idf $(300)$ & 26,00 & 26,00 & 26,00 \\
\hline & tf e tf-idf $(9950)$ & 3,01 & 99,67 & 5,83 \\
\hline & $\operatorname{tff}(50)$ & 42,00 & 7,00 & 12,00 \\
\hline & $\mathrm{tf}(400)$ & 21,25 & 28,33 & 24,29 \\
\hline \multirow{2}{*}{ Estado da arte } & ExPorTer_linguístico & 2,74 & 89,18 & 5,32 \\
\hline & ExPorTer_híbrido & 12,76 & 23,25 & 16,48 \\
\hline \multirow{4}{*}{$\begin{array}{l}\text { Comparações } \\
\text { extras }\end{array}$} & tc $(50)$ & 52,00 & 8,67 & 14,86 \\
\hline & $\begin{array}{l}\text { freq_cg, weirdness, } \\
\text { thd e nc-value ( } 8850 \text { a } 9950)\end{array}$ & 3,02 a 3,39 & 100,00 & 5,85 a 6,56 \\
\hline & $\operatorname{tvq}(400)$ & 25,75 & 34,33 & 29,43 \\
\hline & Corpus inteiro (9950) & 3,02 & 100,00 & 5,85 \\
\hline
\end{tabular}

Na Tabela 5.6, são apresentados os resultados para o corpus ECO. Observa-se que se atingiu $100 \%$ de precisão nas duas avaliações experimentais da ILATE. Em relação a primeira avaliação experimental, o valor máximo de cobertura foi alcançado por 3 matrizes de candidatos diferentes, a saber: (i) $C F S_{-} R S-D F-S V M$, ou seja, uma matriz contendo os candidatos que se mantiveram após o uso do Filtro DF com as características selecionadas pelo método $C F S_{-} R S$; (ii) $C F S_{-} R S-D F_{-} S N_{-} P M-S V M$, isto é, uma matriz contendo os candidatos que se mantiveram após o uso do Filtro $D F_{-} S N_{-} P M$ com as características selecionadas pelo método $C F S_{-} R S$; ou (iii) $C F S_{-} B F_{-}-D F_{-} S N_{-} P M$ - $S V M$, que utilizou também o Filtro $D F_{-} S N_{-} P M$ mas com o método de seleção de características chamado $C F S_{-} B F$. Essas três matrizes de candidatos utilizaram o indutor SVM. Já na segunda avaliação experimental, a EAT atingiu $100 \%$ de precisão com 8 diferentes matrizes de candidatos pertencentes ao corpus ECO, a saber: $C F S \_B F-D F$ $S V M, C F S_{-} B F-D F_{-} S N_{-} P M-S V M, C F S_{-} R S-D F-S V M, C F S_{-} R S-\overline{D F}{ }_{-} S N_{-} P M$ - SVM, Hiźrido - DF - SVM, Hibrido - DF_SN_PM - SVM, CFS_BF - To dos $\bar{C} T s$ $S V M$ ou $C F S_{-} B F / C F S \_R S-T o d o s C T s-N B$. Todas essas matrizes utilizaram o indutor SVM nas duas avaliações experimentais.

Mesmo que as precisões do corpus ECO sejam iguais nas duas avaliações experimentais, na segunda avaliação alcançaram-se valores de cobertura (38\%) levemente mais altos do que na primeira $(35,91 \%)$. Além disso, para os corpora ECO e Nano, foi utilizada uma menor quantidade de candidatos para extrair termos na segunda avaliação experimental. Entretanto, a cobertura mais alta alcançada para esse corpus foi de $89,18 \%$ pelo método ExPorTer_linguístico.

Ainda para o corpus ECO, o resultado mais alto de medida F foi 29,43\% utilizando os 400 primeiros candidatos a termos mais bem ranqueados pela medida tvq. Ressalta-se que os valores de medida $\mathrm{F}$ obtidos na primeira avaliação experimental (máximo 26,44\% com $C F S \_R S$ - Todos $C T s-N B$ ) foram similares aos da primeira avaliação (máximo 26,36\% com CFS_BF/CFS_RS - Todos CTs - NB). As medidas tf-idf e tf também 
atingiram valores similares de cobertura (26\% e 24,29\%) utilizando, respectivamente, os 300 e 400 candidatos mais bem ranqueados por cada uma dessas medidas. Entretanto, como discutido anteriormente, devido a dificuldade em saber quantos candidatos devem ser utilizados por essas medidas, considera-se que a ILATE, independentemente da avaliação experimental considerada, tem vantagem em relação a essas medidas, uma vez que seleciona os candidatos automaticamente. Também, como os valores da ILATE nas duas avaliações experimentais foram similares, acredita-se que é vantajoso seguir as decisões tomadas na segunda avaliação experimental, uma vez que esta trabalha com uma quantidade menor de candidatos.

Na Tabela 5.7, são apresentados os resultados para o corpus EaD. Observa-se que é mais aconselhável seguir as decisões tomadas na primeira avaliação experimental da ILATE do que na segunda devido ao fato que a primeira trabalha com números de candidatos menores e atinge resultados de cobertura e medida F superiores. Mesmo que o valor máximo de precisão para esse corpus seja igual nas duas avaliações experimentais, nos casos em que a precisão é $100 \%$, os valores de cobertura e medida F foram levemente superiores na segunda avaliação experimental. Entretanto, acredita-se que essa diferença não seja suficiente para se seguir a segunda avaliação experimental da ILATE no lugar da primeira para o corpus EaD.

Tabela 5.7: Comparação dos resultados mais altos das duas avaliações experimentais da ILATE - Corpus EaD.

\begin{tabular}{|c|c|c|c|c|}
\hline Descrição & Método & $P(\%)$ & $C(\%)$ & $M F(\%)$ \\
\hline \multirow[t]{3}{*}{$\begin{array}{l}1^{\mathrm{a}} \text { avaliação } \\
\text { experimental } \\
\text { da ILATE }\end{array}$} & $\begin{array}{l}\text { CBF_BF/CFS_BF/CFS_RS/Estat./Híbrido } \\
\text { - DF/DF_SN_PM - SVM ou CBF_BF/ } \\
\text { CBF_RS/CFS_BF/Estat./Híbrido/ } \\
\text { Todas Caract. - Todos CTs - SVM ou } \\
\text { Todas Caract./CBF_RS/CBF_BF - } \\
\text { DF_SN_PM - KNN ouCFS_RS - DF - } \\
\text { KNN ou Todas Caract./CBF_RS - DF - } \\
\text { SVM ou CBF BF - Todos CTs - KNN }\end{array}$ & 100,00 & 0,85 a 3,42 & 1,69 a 6,61 \\
\hline & Ling. - Todos $\bar{C}$ Ts - NB & 4,94 & 33,33 & 8,60 \\
\hline & Híbrido - DF SN PM - J48 & 87,50 & 11,97 & 21,05 \\
\hline \multirow[t]{4}{*}{$\begin{array}{l}2^{\text {a }} \text { avaliação } \\
\text { experimental } \\
\text { da ILATE }\end{array}$} & 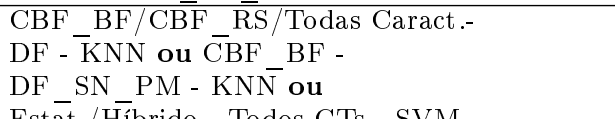 & & & \\
\hline & Estāt./Híbrido - Todos CTs - SVM & 100,00 & 0,89 a 3,57 & 1,77 a 6,90 \\
\hline & Ling. - Todos CTs - NB & 3,99 & 28,57 & 7,00 \\
\hline & CBF $\quad$ BF - DF - JRIP & 42,31 & 9,82 & 15,94 \\
\hline \multirow{5}{*}{ Baselines } & tf-idf $(50)$ & 22,00 & 9,82 & 13,58 \\
\hline & tf-idf $(100)$ & 15,00 & 13,39 & 14,15 \\
\hline & tf e tfidf (11100 a 15000) & 0,75 a 1,01 & 100,00 & 1,48 a 2,00 \\
\hline & tf $(50)$ & 18,00 & 8,04 & 11,11 \\
\hline & tf $(150)$ & 10,67 & 14,29 & 12,21 \\
\hline \multirow{2}{*}{ Estado da arte } & ExPorTer_linguístico & 0,33 & 89,70 & 0,66 \\
\hline & ExPorTer_híbrido & 0,07 & 17,64 & 0,15 \\
\hline \multirow[t]{3}{*}{$\begin{array}{l}\text { Comparações } \\
\text { extras }\end{array}$} & $\begin{array}{l}\text { rf, atf, df, tv, tvq, freq_cg, } \\
\text { tc, c-value }(11100 \text { a } 15000)\end{array}$ & 0,75 a 1,01 & 100,00 & 1,48 a 2,00 \\
\hline & tds e glossEx $(50)$ & 36,00 & 16,07 & 22,22 \\
\hline & Corpus inteiro (16000) & 0,70 & 100,00 & 1,39 \\
\hline
\end{tabular}

Na Tabela 5.8, são apresentados os resultados para o corpus Nano. A precisão mais alta $(84,51 \%)$ foi alcançada na primeira avaliação experimental, entretanto na segunda avaliação atingiu valor aproximado $(81,24 \%)$. O valor de cobertura mais alto $(94,10 \%)$ foi obtido pelas medidas tf e rf ao considerar entre 14900 e 15000 primeiros candidatos a termos mais bem ranqueados por tais medidas. Com o mesmo número de candidatos (14900 a 15000), a medida $t f-i d f$ atingiu uma cobertura bem similar (94,04\%). Em seguida, o método ExPorTer_linguístico conseguiu 89,40\% de cobertura. Ao comparar as coberturas obtidas nas duas avaliações experimentais, observou-se um aumento de $2,69 \%$ quando se segue as decisões da segunda avaliação. Esta última também melhorou o resultado de 
medida F $(41,21 \%)$, sendo este o valor máximo alcançado para esse corpus.

Tabela 5.8: Comparação dos resultados mais altos das duas avaliações experimentais da ILATE - Corpus Nano.

\begin{tabular}{|c|c|c|c|c|}
\hline Descrição & Método & $P(\%)$ & $C(\%)$ & $M F(\%)$ \\
\hline \multirow{4}{*}{$\begin{array}{l}1^{\mathrm{a}} \text { avaliação } \\
\text { experimental } \\
\text { da ILATE }\end{array}$} & Todas Caract. - & & & \\
\hline & DF_SN_PM - SVM & 84,51 & 3,81 & 7,29 \\
\hline & Ling. - Todos CTs - NB & 22,47 & 40,80 & 28,98 \\
\hline & CBF $\mathrm{RS}-\mathrm{DF}-\mathrm{JRIP}$ & 58,01 & 27,70 & 37,50 \\
\hline \multirow{3}{*}{$\begin{array}{l}2^{\mathrm{a}} \text { avaliação } \\
\text { experimental } \\
\text { da ILATE }\end{array}$} & CFS ${ }^{-}$BF /CFS RS - Todos CTs - SVM & 81,25 & 0,84 & 1,67 \\
\hline & CFS_BF - Todos CTs - NB & 26,49 & 43,49 & 32,92 \\
\hline & CBF ${ }^{-}$BF - DF $\quad$ SN $\quad$ PM - J48 & 60,50 & 31,25 & 41,21 \\
\hline \multirow{6}{*}{ Baselines } & tf-idf $(50)$ & 58,00 & 1,88 & 3,64 \\
\hline & tf-idf $(3150)$ & 26,98 & 55,09 & 36,22 \\
\hline & tf-idf (14900 a 1500$)$ & 9,67 a 9,74 & 94,04 & 17,54 a 17,65 \\
\hline & tf $(50)$ & 48,00 & 1,56 & 3,01 \\
\hline & $\mathrm{tf}(3200)$ & 26,38 & 54,70 & 35,59 \\
\hline & $\mathrm{tf}(14900$ a 15000$)$ & 9,68 a 9,74 & 94,10 & 17,55 а 17,66 \\
\hline \multirow{2}{*}{ Estado da arte } & ExPorTer_linguístico & 3,75 & 89,40 & 7,20 \\
\hline & ExPorTer híbrido & 1,68 & 35,35 & 3,22 \\
\hline \multirow{3}{*}{$\begin{array}{l}\text { Comparações } \\
\text { extras }\end{array}$} & $\operatorname{tvq}(50)$ & 66 & 2,14 & 4,14 \\
\hline & rf $(14900$ a 15000$)$ & 9,68 a 9,74 & 94,10 & 17,55 a 17,66 \\
\hline & Corpus inteiro (41335) & 0,04 & 100,00 & 0,07 \\
\hline
\end{tabular}

Para dar uma ideia geral do tempo de processamento da classificação dos termos, na Tabela 5.9, são mostrados os resultados mais altos obtidos nas duas avaliações experimentais da ILATE juntamente com o tempo (em segundos) utilizado pelo algoritmo para induzir um modelo de classificação (Tempo de Modelagem - TM) e o tempo gasto para efetivamente realizar a classificação dos candidatos em termos e não-termos (Tempo de Classificação - TC). Quando o tempo corresponder à zero $(0,00)$ na tabela significa que o algoritmo não utilizou nem um segundo completo para classificar os candidatos.

Tabela 5.9: Comparação dos tempos gastos para extrair termos utilizando as duas avaliações experimentais da ILATE.

\begin{tabular}{|c|c|c|c|c|c|c|c|}
\hline Corpus & Descrição & Método & $P(\%)$ & $C(\%)$ & $M F(\%)$ & $T M($ seg $)$ & $T C(\mathrm{seg})$ \\
\hline \multirow{6}{*}{$\mathrm{ECO}$} & \multirow{3}{*}{$\begin{array}{l}1^{\mathrm{a}} \text { avaliação } \\
\text { experimental } \\
\text { da ILATE }\end{array}$} & $\begin{array}{l}\text { CFS RS - DF - SVM ou CFS RS/ } \\
\text { CFS - BF - DF - SN PM - SVM }\end{array}$ & 100,00 & 1,01 a 1,34 & $\begin{array}{r}1,99 \mathrm{a} \\
2,65\end{array}$ & $\begin{array}{r}0,4 \mathrm{a} \\
2,63\end{array}$ & 0,01 \\
\hline & & CFS $\overline{B F}-$ Todos CTs - NB & 19,81 & 35,91 & 25,54 & 0,00 & 0,00 \\
\hline & & CFS_RS - Todos CTs - NB & 21,67 & 33,89 & 26,44 & 0,00 & 0,00 \\
\hline & \multirow{3}{*}{$\begin{array}{l}2^{\mathrm{a}} \text { avaliação } \\
\text { experimental } \\
\text { da ILATE }\end{array}$} & $\begin{array}{l}\mathrm{CFS}^{-} \mathrm{BF} / \mathrm{CFS} \mathrm{RS} / \mathrm{H} \text { brido - } \\
\mathrm{DF} / \overline{\mathrm{D}} \mathrm{F} \text {-SN_PM - SVM ou }\end{array}$ & & & $0,66 \mathrm{a}$ & $2,04 \mathrm{a}$ & \\
\hline & & CFS B B $-\overline{T o d o s}$ CTs - SVM & 100,00 & 0,33 a 1,67 & 3,28 & 8,35 & 0,01 \\
\hline & & CFS BF/CFS RS - Todos CTs - NB & 20,18 & 38,00 & 26,36 & 0,00 & 0,00 \\
\hline \multirow{6}{*}{ EaD } & \multirow[t]{3}{*}{$\begin{array}{l}1^{\mathrm{a}} \text { avaliação } \\
\text { experimental } \\
\text { da ILATE }\end{array}$} & $\begin{array}{l}\text { CBF BF/CFS BF/CFS RS/Estat./Híbrido } \\
\text { - DF/DF_SN_PM - SVM ou CBF_BF/ } \\
\text { CBF_RS/CFS_BF /Estat./Híbrido/ } \\
\text { Todas Caract. - Todos CTs - SVM ou } \\
\text { Todas Caract./CBF_RS/CBF_BF - } \\
\text { DF_SN_PM - KNN ou CFS_RS - DF - } \\
\text { KNN ou Todas Caract./CBF RS - DF - } \\
\text { SVM ou CBF_BF - Todos CTs - KNN }\end{array}$ & 100,00 & 0,85 a 3,42 & $\begin{array}{r}1,69 \mathrm{a} \\
6,61\end{array}$ & $\begin{array}{r}0,00 \mathrm{a} \\
20,00\end{array}$ & $\begin{array}{r}0,00 \mathrm{a} \\
58,12\end{array}$ \\
\hline & & Ling. - Todos CTs - NB & 4,94 & 33,33 & 8,60 & $\begin{array}{r}20,00 \\
0,57\end{array}$ & 0,04 \\
\hline & & Híbrido - DF SN PM - J48 & 87,50 & 11,97 & 21,05 & 0,00 & 0,00 \\
\hline & \multirow[t]{3}{*}{$\begin{array}{l}2^{\mathrm{a}} \text { avaliação } \\
\text { experimental } \\
\text { da ILATE }\end{array}$} & $\begin{array}{l}\text { CBF BF/CBF } \overline{R S} / \text { Todas Caract.- } \\
\text { DF - KNN ou } \overline{C B F} \text { BF - } \\
\text { DF S SN PM - KNN ou } \\
\text { Estat./Híbrido - Todos CTs - SVM }\end{array}$ & 100,00 & 0.89 а 3.57 & $\begin{array}{r}1,77 \mathrm{a} \\
6.90\end{array}$ & $\begin{array}{r}0,00 \mathrm{a} \\
8,68\end{array}$ & $\begin{array}{r}0,0052 \\
\text { a } 0.09\end{array}$ \\
\hline & & Ling. - Todos CTs - NB & 3,99 & 28,57 & 7,00 & 0,01 & 0,00 \\
\hline & & CBF_BF - DF - JRIP & 42,31 & 9,82 & 15,94 & 0,04 & 0,0 \\
\hline \multirow{6}{*}{ Nano } & \multirow{3}{*}{$\begin{array}{l}1^{\mathrm{a}} \text { avaliação } \\
\text { experimental } \\
\text { da ILATE }\end{array}$} & $\begin{array}{l}\text { Todas Caract. - } \\
\text { DF SN PM - SVM }\end{array}$ & 84,51 & 3,81 & 7,29 & 70,17 & 0,17 \\
\hline & & Ling. - Todos CTs - NB & 22,47 & 40,80 & 28,98 & 0,02 & 0,00 \\
\hline & & CBF_RS - DF - JRIP & 58,01 & 27,70 & 37,50 & 0,62 & 0,00 \\
\hline & \multirow{3}{*}{$\begin{array}{l}2^{\mathrm{a}} \text { avaliação } \\
\text { experimental } \\
\text { da ILATE }\end{array}$} & CFS BF/CFS RS - Todos CTs - SVM & 81,25 & 0,84 & 1,67 & 420,14 & 0,70 \\
\hline & & CFS BF - Todos CTs - NB & 26,49 & 43,49 & 32,92 & 0,02 & 0,00 \\
\hline & & CBF_BF-DF_SN_PM-J48 & 60,50 & 31,25 & 41,21 & 0,24 & 0,00 \\
\hline
\end{tabular}

É importante ressaltar que os experimentos desta pesquisa foram executados paralelamente em diferentes servidores com diferentes configurações de acordo com a disponibilidade dos recursos computacionais. Portanto, tais tempos servem para se ter uma ideia do quanto se gasta para classificar os termos desses domínios e não servem para comparar um algoritmo com outro. 


\subsubsection{Discussão acerca das Características dos Candidatos Consideradas para a Extração de Termos Utilizando a Segunda Avaliação Experimental da ILATE}

Na Tabela 5.10, são mostrados exemplos reais do domínio de Nanociência e Nanotecnologia. Nessa tabela, são apresentados tanto os radicais ${ }^{6}$ dos candidatos (coluna "Radicais") como as palavras que deram origem a tais radicais (coluna "Palavras originais"). Nessa tabela, destacam-se em negrito as palavras que correspondem aos termos do domínio de Nanociência e Nanotecnologia. Uma das vantagens de se trabalhar com os radicais dos candidatos, além de reduzir o número destes, é a possibilidade de abranger o termo (por exemplo, nanotecnológico) e suas variações (como nanotecnológicos, nanotecnológica e nanotecnológicas). Entretanto, abrange-se também candidatos considerados não-termos pelos especialistas do domínio em questão (p. ex., nanotecnólogos) e erros presentes no corpus (como nanotecnologi). Tais erros foram identificados nessa tabela por *, seja eles de digitação (nanotecnologi e fibr), ortográficos (como nanotecnológos) ou candidatos em uma língua estrangeira (fibre).

Ainda nessa tabela é apresentada a frequência de cada palavra no corpus Nano. Por exemplo, o candidato (radical) fibr tem frequência total igual a 874, entretanto, esta corresponde à soma das frequências das palavras que deram a tal radical: (fibres) $3+$ $($ fibrosos $) 3+($ fibra $) 488+$ (fibras) $367+($ fibr $) 1+$ (fibrosas) $2+$ (fibrosa $) 5+$ (fibre) $1+($ fibroso $) 4=874$.

Tabela 5.10: Palavras que deram origens aos radicais utilizados como exemplos do corpus Nano.

\begin{tabular}{|c|c|}
\hline Radical & Palavras originais \\
\hline nanotecnolog: 4173 & $\begin{array}{l}\text { nanotecnologi*: } 4 \text {, nanotecnológico: } 23 \text {, nanotecnológicos: } 71 \text {, } \\
\text { nanotecnologia: } 3739 \text {, nanotecnologias: } 248 \text {, nanotecnologos }{ }^{*}: 1 \text {, } \\
\text { nanotecnológica: } 49 \text {, nânotecnologia*: } 1 \text {, nanotecnólogos: } 4 \text {, } \\
\text { nanotecnologistas: } 1 \text {, nanotecnológicas: } 29 \text {, nanotecnologica*: } 3\end{array}$ \\
\hline fibr: 874 & $\begin{array}{l}\text { fibres*: } 3 \text {, fibrosos: } 3 \text {, fibra: } 488 \text {, fibras: } 367, \text { fibr*: } 1, \\
\text { fibrosas: } 2 \text {, fibrosa: } 5 \text {, fibre*: } 1 \text {, fibroso: } 4\end{array}$ \\
\hline evolu: 110 & $\begin{array}{l}\text { evolui: } 23 \text {, evoluída: } 1 \text {, evoluem: } 8 \text {, evoluir: } 16 \text {, evoluindo: } 12 \text {, } \\
\text { evoluídas: 1, evoluíram: } 7 \text {, evoluiu: } 5 \text {, evolutivo: } 8 \text {, evoluído: } 12 \text {, } \\
\text { evoluídos: } 2 \text {, evolu*: } 1 \text {, evolutiva: } 12 \text {, evoluam: } 1 \text {, evolutivas: } 1\end{array}$ \\
\hline inov: 1306 & $\begin{array}{c}\text { inovativa: } 24 \text {, inovador: } 35 \text {, inovam: } 5 \text {, inovadores: } 53 \text {, inovar: } 23 \text {, } \\
\text { inovativos: } 6 \text {, inovativas: } 13 \text {, inovadora: } 22 \text {, inovando: } 1, \\
\text { inovações: } 162 \text {, inovou: } 1 \text {, inovamos: } 2 \text {, inovaram: } 2 \text {, inova: } 33 \text {, } \\
\text { inovativo: } 19 \text {, inovadoras: } 53 \text {, inovação: } 852\end{array}$ \\
\hline
\end{tabular}

A seguir, é discutido como as características de diferentes níveis de conhecimento ajudam na classificação dos termos. Para isso, considerando os exemplos dados na Tabela 5.10, são identificados, na Tabela 5.11, candidatos extraídos corretamente, mas também ruídos, o que permite afirmar que, embora a ILATE, independente da avaliação experimental considerada, melhora consideravelmente os resultados da EAT em relação aos métodos de extração de termos simples para o português já existentes na literatura, ainda há melhorias que devem ser feitas.

Na EAT encontrada na literatura, uma das maneiras de se identificar um termo é verificar se o candidato é sintagma nominal, uma vez que os especialistas de domínio preferem termos que são substantivos. Ao se trabalhar com os radicais dos candidatos, se uma das palavras que deram origem aos radicais for sintagma nominal, o radical é dito como sintagma, o que dificulta a identificação de termos. Dentre os exemplos reais mostrados na tabela, verifica-se que todos são sintagmas nominais (características sintagma $=1$ ). Porém, observa-se que os radicais dos candidatos que são termos foram originados de uma

\footnotetext{
${ }^{6}$ Radicais obtidos pela implementação de radicalização disponível no PTStemmer ${ }^{1}$.
} 
Tabela 5.11: Exemplos de resultados da ILATE utilizando o corpus Nano.

\begin{tabular}{|c|c|c|c|c|}
\hline $\begin{array}{ll}\text { Caracteristicas } & \text { Candidatos } \\
\end{array}$ & nanotecnolog & fibr & evolu & $i n o v$ \\
\hline comGram & 12 & 4 & 5 & 4 \\
\hline$t f$ & 4173 & 874 & 110 & 1306 \\
\hline$a t f$ & 6,39 & 6,78 & 1,86 & 4,95 \\
\hline$d f$ & 653 & 129 & 59 & 264 \\
\hline$t f-i d f$ & 872,83 & 798,39 & 137,85 & 786,83 \\
\hline$t v$ & 152816,14 & 177271,32 & 466,55 & 137062,34 \\
\hline$t v q$ & 142623,42 & 172072,48 & 272,92 & 132215,26 \\
\hline$t c$ & 377214,91 & 244446,19 & 9126,57 & 284380,82 \\
\hline$c g$ & 0 & 1 & 1 & 1 \\
\hline freq_cg & 0 & 971 & 1042 & 934 \\
\hline weirdness & 1,00 & 1,00 & 809,97 & 1,00 \\
\hline ridf & 0,50 & 2,68 & 5,20 & 1,73 \\
\hline thd & 1,00 & 0,99 & 0,89 & 1,00 \\
\hline$t d s$ & 6181,02 & 9,51 & 1,12 & 14,77 \\
\hline glossEx & 8,13 & 2,32 & 0,30 & 2,74 \\
\hline$e i$ & 1 & 1 & 0 & 0 \\
\hline c-value & 4173 & 874 & 110 & 1306 \\
\hline nc-value & 8931,48 & 0,84 & 1,74 & 3,40 \\
\hline sintagma & 1 & 1 & 1 & 1 \\
\hline nucleo_sintagma & 1 & 1 & 1 & 1 \\
\hline$p m$ & 1 & 1 & 1 & 1 \\
\hline n_subst. & 4 & 4 & 1 & 3 \\
\hline$\overline{n \_a d j .}$ & 4 & 4 & 4 & 7 \\
\hline$n$ _verbo & 1 & 0 & 6 & 6 \\
\hline$n_{-} p o$ & 9 & 9 & 15 & 17 \\
\hline É termo? & Sim & Sim & Não & Não \\
\hline
\end{tabular}

quantidade maior de substantivos $\left(n_{-}\right.$subst.) do que verbos $\left(n_{-}\right.$verbo). Dessa maneira, exemplifica-se como a característica $n_{\text {_ }}$ subst., que foi proposta nesta pesquisa, ajudou na identificação dos termos do domínio em questão. Essa afirmação é respaldada pelo fato de que $92 \%$ dos métodos de seleção de características também escolheram $n_{-}$subst. como uma característica relevante para a classificação de termos.

É também interessante analisar alguns casos. Por exemplo, o candidato fibr tem frequência média tanto no corpus do domínio $(t f=874)$ como no corpus de língua geral $($ freq_cg $=971)$. Essas duas características $(t f$ e freq_cg) poderiam indicar que fibr não seria um termo. No entanto, outras características podem ajudar a concluir que esse candidato é um termo, uma vez que ocorre em 129 dos 1.057 textos $(12,20 \%$ dos documentos), é bem distribuído por todo o corpo e não tem frequências muito elevadas, se considerar que não-termos ainda podem ter frequências mais altas, como é o caso do não-termo inov $(t f=1306)$. O candidato nanotecnolog é mais frequente do que fibra e ambos mantêm uma distribuição não uniforme em todo o corpo (porque têm valor de $t v$ alto). Entretanto, nanotecnolog não ocorre no corpus de língua geral (porque tem $c g=0$ ), o que ajuda a classificá-lo como um termo.

Ao comparar fibr com evolu, este último tem valores de $t f$, $d f$ e $t f-i d f$ menores, mas ambos ocorrem no corpus de língua geral $(c g=1)$. Por outro lado, evolu tem valores de $t d s$ e glossEx menores do que os outros exemplos de candidatos apresentados aqui, sendo que essas duas características consideram corpus de língua geral. Além disso, evolu provavelmente não é definido ou descrito nos textos do corpus pois não ocorre perto de alguma expressão indicativa $(e i)$. Tais características indicam que esse candidato não é um termo desse domínio. Finalmente, inov foi corretamente classificado como não-termo já que tem maior frequência $(t f)$ do que $f i b r$ e evolu e não ocorre perto de uma expressão indicativa $(e i)$, mesmo que tenha alguns valores de características que normalmente os termos têm ( $d f$, tf-idf, nc-value, sintagma, nucleo_sintagma e pm). Contudo, embora evolu seja um núcleo de sintagma, quando se analisa a origem do seu radical, existem mais 
palavras que são adjetivos e verbos (correspondendo, respectivamente, às características $n_{-} a d j .=4$ e $n_{-}$verbo=6) do que substantivos $\left(n_{-}\right.$subst. $\left.=1\right)$. Isto pode indicar que as características que dependem da frequência do radical podem ser prejudicadas, uma vez que essa frequência também pode referir-se à adjetivos e/ou verbos.

\subsection{Considerações Finais}

Ao analisar os resultados dos 3 corpora, observou-se que a ILATE, independente da avaliação experimental realizada, atinge os resultados mais altos de precisão em relação a todos os métodos e medidas comparados. A ILATE atinge valores de medida $\mathrm{F}$ bem similares ou superiores aos resultados das medidas ( $t f, t f-i d f, t v q$, $t d s$ e $g l o s s E x)$ que necessitam utilizar um limiar para cortar o ranking de candidatos usado para a extração. Em relação as duas avaliações experimentais realizadas, dependendo do objetivo em que os termos extraídos serão utilizados (ou seja, se é necessário obter boa precisão, cobertura ou boa medida F), pode-se então escolher entre quais decisões seguir durante a aplicação da ILATE. As decisões tomadas na segunda avaliação experimental da ILATE - refinamento do pré-processamento dos textos do corpus e adição de características híbridas mais complexas - são recomendadas para se alcançar resultados mais altos de precisão e medida $\mathrm{F}$, enquanto que as decisões da primeira avaliação são recomendadas quando o foco é obtenção na cobertura mais alta. 

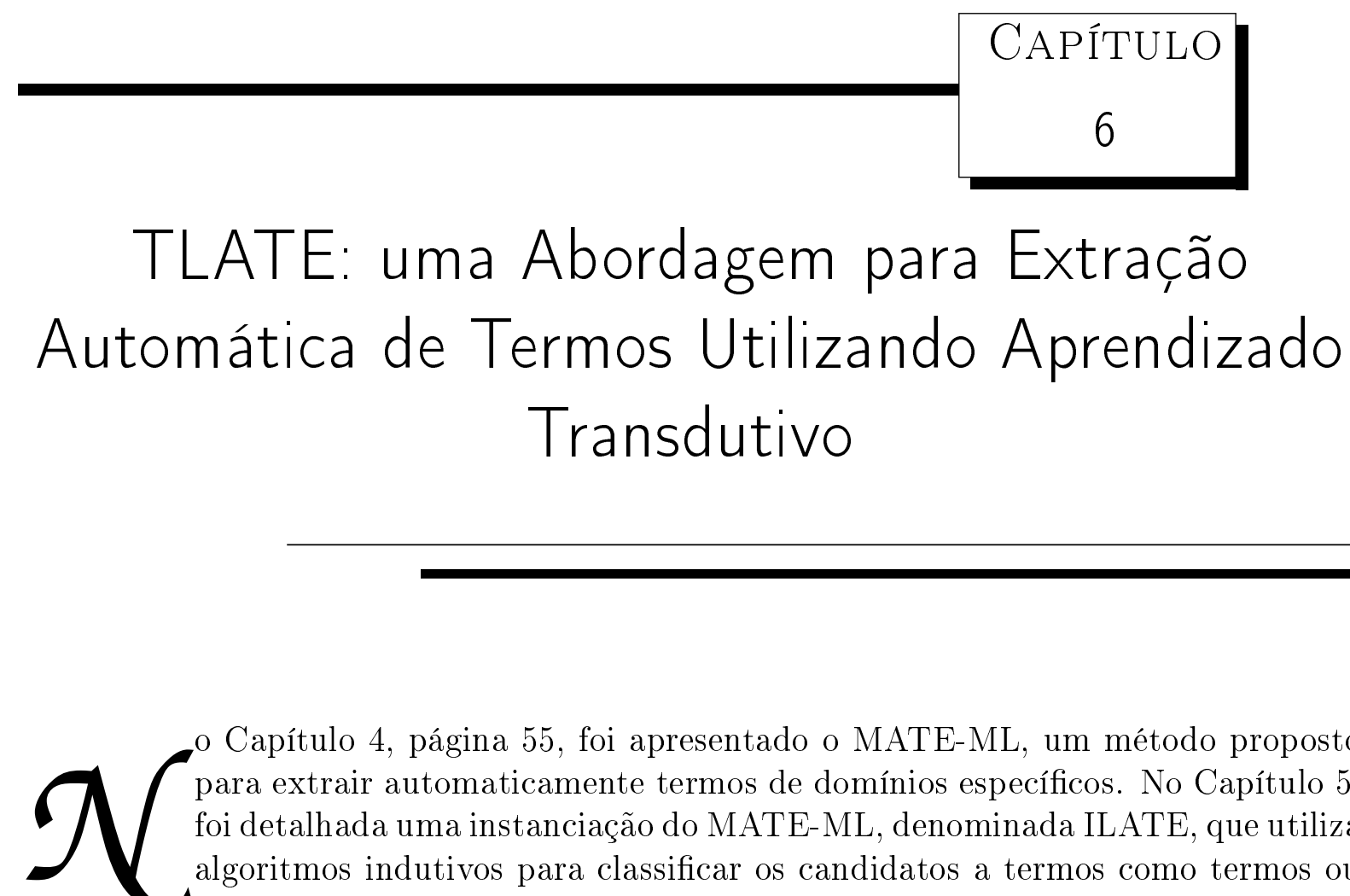
Capítulo 4, página 55, foi apresentado o MATE-ML, um método proposto para extrair automaticamente termos de domínios específicos. No Capítulo 5, foi detalhada uma instanciação do MATE-ML, denominada ILATE, que utiliza algoritmos indutivos para classificar os candidatos a termos como termos ou não-termos de domínios específicos. A abordagem ILATE conseguiu automatizar a escolha de quais candidatos deveriam ser considerados termos e melhorar os resultados de precisão e medida F da extração de termos simples para o português do Brasil em relação aos métodos de extração de termos simples encontrados na literatura. A ILATE herda uma limitação do próprio aprendizado supervisionado, que é a necessidade de se ter um grande número de candidatos rotulados como termos e não-termos para a construção de um modelo de classificação para, então, melhor classificar novos candidatos. Visando superar essa limitação, é proposta, como parte do trabalho desta tese, a abordagem TLATE que utiliza o aprendizado semissupervisionado transdutivo para extrair termos. Para alcançar resultados similares aos obtidos por classificadores indutivos, o aprendizado transdutivo requer um número inferior de candidatos rotulados para realizar a classificação. Ressaltase que, com a revisão literária realizada até o momento, não foram encontrados trabalhos nos quais o aprendizado transdutivo tenha sido aplicado à EAT. Considerando o cenário no qual se tenha um corpus de entrada e poucos candidatos rotulados como termos e não-termos do mesmo domínio, o aprendizado transdutivo pode ser considerado como uma boa alternativa, uma vez que necessita de menos candidatos rotulados do que no aprendizado indutivo por não induzir um modelo de classificação.

\subsection{Descrição da Abordagem TLATE}

A abordagem proposta utiliza classificação transdutiva e por essa razão é denominada "aprendizado transdutivo para extração automática de termos", TLATE, do inglês, $\underline{\boldsymbol{T}}$ ransductive $\underline{\boldsymbol{L}}$ earning for $\underline{\boldsymbol{A}}$ utomatic $\underline{\boldsymbol{T}}$ erm $\underline{\boldsymbol{E}} x t r a c t i o n$ (Conrado et al., 2013a). Tanto a abordagem TLATE como a ILATE (Capítulo 5) instanciam o método MATE-ML (Capítulo 4) e são divididas em quatro etapas automatizadas que permitem realizar adap- 
tações dependendo da aplicação na qual os termos extraídos serão utilizados. As etapas da TLATE, ilustradas na Figura 6.1 e destacadas em negrito a seguir, são: (1) Préprocessamento dos Textos; (2) Extração de Características; (3) Aplicação de Filtros; e (4) Classificação Transdutiva de Candidatos a Termos.

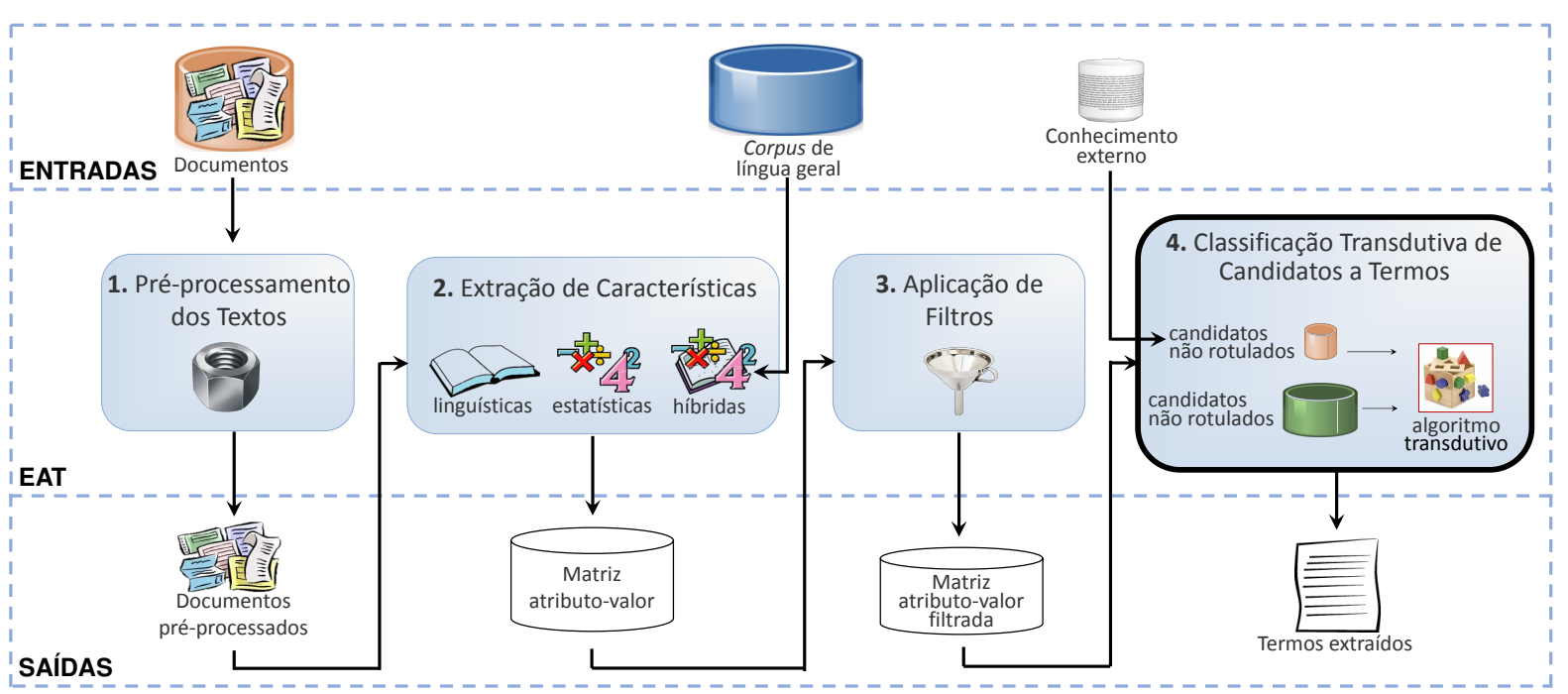

Figura 6.1: Abordagem para extração automática de termos utilizando aprendizado transdutivo (TLATE).

As etapas da TLATE de Pré-processamento dos Textos, Aplicação de Filtros e Extração de Características são iguais as etapas da abordagem ILATE. Essas etapas foram detalhadas na Seção 5.1 do Capítulo 5, página 73.

O diferencial da TLATE em relação à ILATE está na etapa de Classificação Transdutiva de Candidatos a Termos. Na abordagem TLATE, é proposta a aplicação de algoritmos transdutivos para classificar candidatos como termos ou não-termos. Esses algoritmos classificam candidatos não rotulados mas conhecidos sem criar um modelo de classificação, o que é possível porque esses algoritmos propagam a informação dos dados rotulados para os dados não rotulados. Devido a essa propagação, a TLATE requer um número inferior de candidatos rotulados para realizar a classificação se comparada com a ILATE.

A classificação dos candidatos a termos realizada na TLATE utiliza aprendizado semissupervisionado transdutivo que propaga os rótulos dos candidatos rotulados e utiliza os candidatos não rotulados para classificar os outros candidatos não rotulados. Nesse aprendizado, os candidatos e suas características são geralmente representados por uma rede que, por sua vez, representa um corpus. Uma rede pode ser caracterizada como um conjunto de objetos (candidatos) e relações entre eles que, por sua vez, é formalmente definida como $N=\langle\mathcal{O}, \mathcal{R}, \mathcal{W}\rangle$, no qual $\mathcal{O}$ representa um conjunto de objetos, $\mathcal{R}$ representa um conjunto de relações entre tais objetos e $\mathcal{W}$ representa os pesos dessas relações. $\mathcal{O}$ é composto pelos objetos rotulados $\left(\mathcal{O}^{L}\right)$ e não rotulados $\left(\mathcal{O}^{U}\right)$, ou seja, $\mathcal{O}=\mathcal{O}^{L} \cup \mathcal{O}^{U}$.

A partir de $\mathcal{O}^{L}$, os algoritmos transdutivos propagam a informação desses candidatos a termos para os candidatos não rotulados por meio das conexões da rede. Quando a informação desses candidatos é propagada para os candidatos não rotulados, a informação desses últimos também é utilizada para auxiliar na classificação dos demais candidatos. Ao término da aplicação da TLATE, tem-se como saída final uma lista de (candidatos a) termos do domínio em questão gerada pelo algoritmo transdutivo. 


\subsection{Avaliação Experimental da TLATE}

Visando identificar o impacto da extração automática de termos utilizando aprendizado transdutivo (TLATE) foi realizada uma avaliação experimental utilizando os mesmos três corpora considerados na avaliação da ILATE. Esses corpora estão na língua portuguesa do Brasil e pertencem a diferentes domínios: ECO, EaD e Nano.

O mesmo pré-processamento dos textos dos corpora de entrada realizado na segunda avaliação experimental da ILATE (detalhado na Seção 5.4 do Capítulo 5, página 93) foi feito para a TLATE, uma vez que na segunda avaliação da ILATE consideraram-se uma variedade maior de características. Cada unigrama pré-processado de cada corpus é considerado um candidato a termo. Para cada candidato, assim como na ILATE, foram extraídas 25 características dos candidatos a termos que pertencem a diferentes níveis de conhecimento (linguístico, estatístico e híbrido). Essas características foram detalhadas na Seção 5.4 do Capítulo 5.

Após o cálculo das características dos candidatos a termos, tem-se uma matriz de candidatos que contém todos os candidatos pré-processados do corpus (Todos CTs) e todas as características extraídas (Todas Caract.), chamada de Todos CTs - Todas Caract.. Assim como para a ILATE, também foi realizada a aplicação de filtros que consistiu nas seleções de características e de candidatos a partir da matriz Todos CTs - Todas Caract., nas quais geraram 23 outras matrizes. Um total de 24 matrizes de candidatos a termos para cada corpus, anteriormente mostradas na Figura 5.2, página 80, foram consideradas nessa avaliação experimental.

Visando minimizar a influência da escolha de algoritmos transdutivos e seus parâmetros na extração de termos, a extração utilizando cada uma das 24 matrizes de candidatos a termos de cada corpus foi avaliada considerando variações dos algoritmos, parâmetros e número de candidatos previamente rotulados, conforme serão detalhadas nas Subseções 6.2.1 e 6.2.2. Considerando essas variações, no total, para cada corpus, têm-se 3.456 resultados.

Devido a quantidade de variações consideradas nos experimentos, não foi possível executar os algoritmos transdutivos quando a quantidade de candidatos a termos avaliada foi superior a 16.000. Por essa razão, não foi realizada a extração de termos considerando todos os candidatos sem filtragem dos corpora EaD e Nano, porque estes são representados por uma matriz contendo 16.013 e 41.335 candidatos, respectivamente. Também não realizou-se a extração de termos a partir dos 18.601 candidatos do corpus Nano que foram mantidos após a aplicação do Filtro DF. Sendo assim, a extração de termos foi realizada a partir de todos os candidatos sem filtragem do corpus ECO (9.997), a partir dos candidatos mantidos após a aplicação do Filtro DF nos corpora ECO (4.534) e EaD (8.059) e a partir dos candidatos mantidos após o uso do Filtro $D F_{-} S N_{-} P M$ nos corpora ECO (3.358), EaD (5.797) e Nano (12.632). Essas quantidades de candidatos foram anteriormente apresentadas na Seção 5.4 do Capítulo 5, página 93.

\subsubsection{Geração de Redes Homogêneas baseadas em Similaridade}

Para classificar os candidatos a termos como termos ou não-termos considerando cada uma das matrizes de candidatos e utilizando a propagação de rótulos, cada candidato a termo corresponde a um objeto de uma rede. Uma rede construída com os candidatos a termos de um domínio é considerada uma rede homogênea baseada em similaridade. Tal rede é considerada homogênea porque é composta por objetos de um único tipo. Como não há informação sobre as relações entre os objetos (candidatos) da rede, os trabalhos da literatura sugerem que se utilizem medidas de proximidade (Zhu et al., 2005; Sousa et al., 
2013) com o objetivo de calcular a similaridade entre os objetos e conectá-los para, então, criar a rede. É por esta razão que a rede formada por candidatos a termos é baseada em similaridade. Para calcular tal similaridade, utilizou-se a distância euclidiana, como sugerido por Tan et al. (2014).

A distância euclidiana entre os objetos $o_{i}$ e $o_{j}$ corresponde ao comprimento do segmento de linha que os conecta $\left(r_{o_{i} o_{j}}\right)$. Considera-se $o_{i}=\left(o_{i 1}, o_{i 2}, \ldots, o_{i n}\right)$ e $o_{j}=\left(o_{j_{1}}, o_{j_{2}}, \ldots, o_{j_{n}}\right)$ como dois candidatos a termos em um espaço euclidiano $n$-dimensional, sendo que cada dimensão corresponde ao valor de uma característica desses candidatos. Com isso, a distância de $o_{i}$ para $o_{j}$ ou de $o_{j}$ para $o_{i}$ é formalmente descrita por:

$$
\Omega\left(o_{i}, o_{j}\right)=\Omega\left(o_{j}, o_{i}\right)=\sqrt{\left(o_{j 1}-o_{i 1}\right)^{2}+\left(o_{j_{2}}-o_{i 2}\right)^{2}+\cdots+\left(o_{j_{n}}-o_{i n}\right)^{2}}=\sqrt{\sum_{m=1}^{n}\left(o_{j_{m}}-o_{i m}\right)^{2}}
$$

Nesta tese, adotou-se a construção de redes homogêneas baseadas em similaridade mais utilizadas pela comunidade que estuda o aprendizado transdutivo (Sousa et al., 2013; Zhou et al., 2004; Zhu et al., 2003), a saber: Exp (Zhu et al., 2005) e KNN mútua (Sousa et al., 2013). Dessa maneira, foram abrangidas duas diferentes abordagens para geração das redes (Zhu et al., 2005): (i) ponderação das relações com alguma função e corte das bordas de acordo com um limiar ou (ii) conectar os objetos aos seus $k$ objetos mais similares. Como citado anteriormente, cada uma dessas redes, destacadas em negrito a seguir, utilizou como medida de proximidade a distância euclidiana.

Na rede Exp, o peso da relação entre os objetos $o_{i}$ e $o_{j}\left(w_{o_{i}, o_{j}}\right)$ é dado pela função $\operatorname{Exp} \exp \left(-\Omega\left(o_{i}, o_{j}\right)^{2} / \sigma^{2}\right)$, no qual $\Omega$ corresponde à função de distância e $\sigma$ controla a abertura da função Exp. Nesta pesquisa, foram avaliadas diferentes aberturas da função Exp, sendo elas: $\sigma=\{0,05,0,35,0,75\}$, conforme sugerido por Rossi et al. (2014).

Na rede $K \mathrm{NN}$ mútua, os objetos $o_{i}$ e $o_{j}$ são conectados se $o_{j}$ for um dos $k$ vizinhos mais próximos de $o_{i}$ e $o_{i}$ for um dos $k$ vizinhos mais próximos de $o_{j}$. Nesta pesquisa, a rede $K \mathrm{NN}$ mútua foi construída utilizando quantidades variadas de vizinhos de candidatos a termos, sendo eles: $k=\{1,17,57\}$. Essa rede foi avaliada no trabalho de Sousa et al. (2013) com $k=\{4,5,6, \ldots, 40\}$ e, nesta tese, optou-se por avaliar a menor quantidade de vizinhos possível (1), uma média (17) e uma alta (57). Ressalta-se que, para realizar a propagação de rótulos, é necessário que todos os candidatos sejam conectados ao menos com um outro candidato. Por isso, quando não há mutualidade de conexão para um candidato, este é conectado com seu vizinho mais próximo.

Uma vez que a rede é criada, algoritmos de aprendizado transdutivo podem ser aplicados para realizar a tarefa de classificação. A seguir, apresentam-se algumas definições sobre os dados de entrada que são necessárias para o entendimento dos algoritmos descritos posteriormente. Considerando que $\mathcal{C}=\left\{c_{1}, c_{2}, \ldots, c_{l}\right\}$ representa um conjunto de classes de um corpus, para classificar objetos em uma rede, cada objeto $o_{i}$ deve possuir sua "informação de classe" que é um vetor $\mathbf{f}_{o_{i}}=\left\{f_{1}, f_{2}, \ldots, f_{|\mathcal{C}|}\right\}$ contendo os pesos de um objeto para cada classe. Todas as informações de classes dos objetos em uma rede são armazenados em uma matriz $\mathbf{F}=\left\{\mathbf{f}_{o_{1}}, \mathbf{f}_{o_{2}}, \ldots, \mathbf{f}_{|\mathcal{O}|}\right\}$. A informação de classe de um objeto rotulado $o_{i}$ é armazenado em um vetor $\mathbf{y}_{o_{i}}=\left\{y_{1}, y_{2}, \ldots, y_{|C|}\right\}^{T}$ que possui o valor 1 na posição correspondente a sua classe real e 0 nas outras posições. Todas as informações de classe são representadas em uma matriz $\mathbf{Y}=\left\{\mathbf{y}_{o_{1}}, \mathbf{y}_{o_{i}}, \ldots, \mathbf{y}_{\mid \mathcal{O}^{L}}\right\}$. Os pesos das conexões entre os objetos são armazenados na matriz $\mathbf{W}$. O grau dos objetos da rede é armazenada na matriz diagonal $\mathbf{G}$, ou seja, $g_{i, i}=\sum_{o_{j} \in \mathcal{O}} w_{i, j}$.

Nesta pesquisa, a obtenção dessas informações foi instanciada para a tarefa de extração de termos. Nesse caso, o conjunto de classes rotuladas do corpus contém duas classes: 
termo e não-termo, sendo, portanto, representado formalmente por $\mathcal{C}=\{$ termo, não-termo $\}$. Logo, a informação de classe contém dados referentes às classes termo e não-termo e o objeto representa o candidato a termo. Portanto, a informação de classe de cada candidato é armazenada em um vetor como $\mathbf{f}_{o_{i}}=\left\{f_{\text {termo }}, f_{\text {não-termo }}\right\}$.

\subsubsection{Algoritmos de Aprendizado Transdutivo}

Dois algoritmos de aprendizado transdutivo tradicionais mais utilizados na comunidade foram considerados na pesquisa apresentada nesta tese, a saber: Gaussian Fields and Harmonic Functions (GFHF) (Zhu et al., 2003) e Learning with Local and Global Consistency (LLGC) (Zhou et al., 2004). Ambos algoritmos são baseados em regularização, ou seja, duas suposições devem ser satisfeitas, que são: (i) a informação de classe de um objeto (aqui, candidato a termo) deve ser similar à informação de classe de seus vizinhos e (ii) a informação de classe de um objeto obtido durante o processo de classificação deve ser igual à informação de classe real. Essas suposições podem ser representadas em um framework de regularização dado pela seguinte função de custo (Zhu et al., 2005):

$$
Q(\mathbf{F})=\frac{1}{2} \sum_{o_{i}, o_{j} \in \mathcal{O}} w_{o_{i}, o_{j}} \Omega\left(\mathbf{f}_{o_{i}}, \mathbf{f}_{o_{j}}\right)+\mu \sum_{o_{i} \in \mathcal{O}^{L}} \Omega^{\prime}\left(\mathbf{f}_{o_{i}}, \mathbf{y}_{o_{i}}\right)
$$

na qual $\mu$ corresponde ao parâmetro de regularização que dá a importância para cada suposição e $\Omega$ representa a função de distância. Os algoritmos de classificação com aprendizado transdutivo usados nesta pesquisa são:

1. O algoritmo GFHF considera a distância entre os objetos vizinhos, representada pelo quadrado da subtração dos seus vetores de informação de classe. Além disso, esse algoritmo considera que $\mu \rightarrow \infty$, ou seja, para minimizar a função de custo, $\mathbf{f}_{o_{i}}$ de cada objeto rotulado deve ser igual a $\mathbf{y}_{o_{i}}$. Então, a função para minimização de custo utilizada pelo GFHF é:

$$
Q(\mathbf{F})=\frac{1}{2} \sum_{o_{i}, o_{j} \in \mathcal{O}} w_{o_{i}, o_{j}}\left(\mathbf{f}_{o_{i}}-\mathbf{f}_{o_{j}}\right)^{2}+\lim _{\mu \rightarrow \infty} \mu \sum_{o_{i} \in \mathcal{O}^{L}}\left(\mathbf{f}_{o_{i}}-\mathbf{y}_{o_{i}}\right)^{2}
$$

A classificação final de um objeto $o_{i}\left(\lambda\left(o_{i}\right)\right)$ usando GFHF é dada pelo conceito de Class Mass Normalization:

$$
\lambda\left(o_{i}\right)=\arg \max _{1 \leq m \leq|\mathcal{C}|} \operatorname{Pr}\left[c_{m}\right] \cdot \frac{f_{o_{i}, m}\left(\mathcal{O}^{U}\right)}{\sum_{o_{j} \in \mathcal{O}} f_{o_{j}, m}(\mathcal{O})}
$$

no qual $\operatorname{Pr}\left[c_{m}\right]$ corresponde a probabilidade de ocorrer a classe $c_{m}$ nos objetos rotulados. A solução iterativa do GFHF (Zhu et al., 2003) é apresentada no Algoritmo 1.

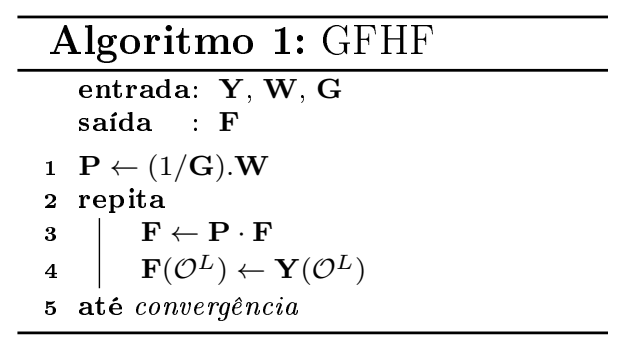


2. No algoritmo LLGC a função de distância entre objetos vizinhos é dada pela diferença quadrática dos vetores de informação de classe dos objetos ponderados pelo grau de cada objeto. Dessa maneira, se diminui a importância dos objetos que possuem muitas conexões na rede. Esse algoritmo assume $0<\mu<1$ (Zhou et al., 2004). A função a ser minimizada pelo LLGC é dada por:

$$
Q(\mathbf{F})=\frac{1}{2} \sum_{o_{i}, o_{j} \in \mathcal{O}} w_{o_{i}, o_{j}}\left(\frac{1}{\sqrt{g_{i}}} \mathbf{f}_{o_{i}}-\frac{1}{\sqrt{g_{j}}} \mathbf{f}_{o_{j}}\right)^{2}+\mu \sum_{o_{i} \in \mathcal{O}^{L}}\left\|\mathbf{f}_{o_{i}}-\mathbf{y}_{o_{i}}\right\|^{2}
$$

A classificação final de um objeto $o_{i}$ usando LLGC é dada por meio do argumento máximo do vetor de informação de classe:

$$
\lambda\left(o_{i}\right)=\arg \max _{1 \leq m \leq|\mathcal{C}|} f_{o_{i}, m}
$$

A solução iterativa do LLGC (Zhou et al., 2004) é apresentada no Algoritmo 2.

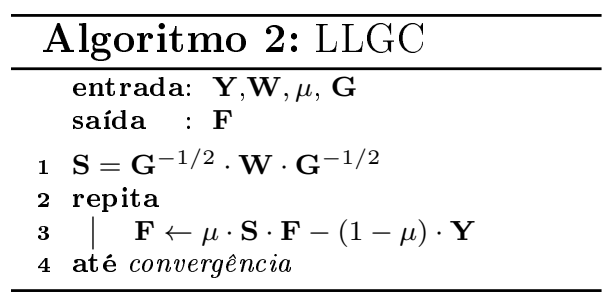

Neste trabalho, foram testados diferentes valores do parâmetro $\mu$ utilizado pelo LLGC, a saber: $\mu=\{0,1,0,5,0,9\}$.

Os algoritmos transdutivos LLGC e GFHF, especificamente suas soluções iterativas apresentadas anteriormente, classificaram separadamente os candidatos das 24 matrizes de candidatos a termos de cada corpus. O número máximo de iterações foi fixada em 1000, uma vez que ele é um limite comum para soluções iterativas (Rossi et al., 2014).

Com o objetivo de avaliar qual é a quantidade de termos do domínio $\left(\mathcal{O}^{L_{\text {termo }}}\right)$ mínima necessária para realizar a extração de termos obtendo resultados satisfatórios, a extração de termos foi realizada considerando $\left|\mathcal{O}^{L_{\text {termo }}}\right|=\{1,10,20,30,40,50\}$. Por exemplo, quando $\left|\mathcal{O}^{\text {Ltermo }}\right|=1$, o algoritmo de classificação transdutiva utilizou 1 candidato rotulado como termo e 1 candidato rotulado como não-termo; quando $\left|\mathcal{O}^{L_{\text {termo }}}\right|=10$, utilizouse 10 candidatos rotulados como termos e 10 como não-termos; e assim sucessivamente. Esses candidatos rotulados foram escolhidos de forma aleatória.

\subsection{Apresentação, Análise e Discussão dos Resultados da TLATE}

Para analisar os termos extraídos, adotou-se o método para avaliação descrito anteriormente na Seção 4.3 do Capítulo 4, página 70. Dessa maneira, os termos extraídos utilizando cada uma das matrizes de candidatos foram comparados aos termos da lista de referência do domínio em questão por meio do cálculo das seguintes medidas de avaliação objetiva: precisão, cobertura e medida F. A matriz de contingência utilizada para se calcular essas medidas foi gerada por meio da soma dos resultados obtidos pelas 10 execuções feitas para cada algoritmo. Os resultados dessas medidas de avaliação foram contrastados com os resultados de trabalhos baselines ( $t f$ e $t f-i d f$ ), de medidas e métodos de extração de termos encontrados na literatura e com os resultados obtidos na segunda 
avaliação experimental da ILATE. As discussões sobre os resultados da avaliação experimental apresentada anteriormente são divididas em duas partes: (i) discussão sobre os resultados da TLATE (Subseção6.3.2) e (ii) discussões sobre os resultados da TLATE em relação à ILATE e outros trabalhos de extração de termos (Subseção 6.3.3).

Para facilitar o entendimento da extração de termos realizada pela TLATE, a seguir, é apresentado um exemplo de propagação de rótulos para classificar os candidatos a termos em termos e não-termos.

\subsubsection{Exemplo de Propagação de Rótulos para Classificar os Candidatos a Ter- mos}

Para exemplificar a classificação de candidatos a termos em termos e não-termos utilizando TLATE, considera-se o domínio de Nanociência e Nanotecnologia. Foram escolhidos cinco termos e cinco não-termos desse domínio, conforme mostrado na Tabela 6.1.

Tabela 6.1: Termos e não-termos considerados para exemplificar a classificação.

\begin{tabular}{c|c}
\hline Termos & Não-termos \\
\hline eletrônica, fibra, função, nanotecnologia e oxicloração & discriminador, elaboração, evolução, financiamento e inovação \\
\hline
\end{tabular}

Esses candidatos a termos foram representados utilizando a rede $K \mathrm{NN}$ mútua, na qual os candidatos são conectados se ambos são um dos 7 vizinhos mais próximos deles mesmo. A proximidade dos candidatos foi calculada usando a distância euclidiana. Na Figura 6.2, é ilustrada a rede dos candidatos, na qual os termos estão em uma caixa na cor verde com borda tracejada e os não-termos na bege com borda contínua. Observase que o termo "nanotecnologia" conectou-se mutualmente somente com outros termos ("função" e "fibra"). O não-termo "evolução" conectou-se mutualmente tanto com termos ("oxicloração", "função" e "fibra") como com não-termos ("inovação", "financiamento", "elaboração" e "discriminador"). A rede criada conseguiu identificar que "evolução" está mais próximo dos não-termos, uma vez que as distâncias variam de 1,15 a 2,03 dos nãotermos e de 2,15 a 2,58 dos termos.

A propagação de rótulos foi feita utilizando o algoritmo de aprendizado transdutivo LLGC com $\mu=0,7$ e usando 2 candidatos rotulados, sendo um termo (nanotecnologia) e um não-termo (evolução). Na Tabela 6.2, é mostrado o estado inicial dos candidatos a termos, no qual somente os candidatos rotulados ("nanotecnologia" e "evolução") têm valor 1 para suas classes. Nessa tabela, são mostradas as informações de classe de todos os candidatos considerados para cada uma das 5 iterações realizadas nesse exemplo. Essa informação indica os pesos dos candidatos para cada classe segundo o algoritmo LLGC. Nessa tabela, também é mostrada a classe original de cada objeto (penúltima coluna da tabela) e a classe predita (última coluna da tabela) após a propagação de rótulos. Por exemplo, "fibra" foi classificado como termo porque na iteração 5 seu peso para cada classe termo $\left(C_{1}=0,10\right)$ é maior do que o da classe não-termo $\left(C_{0}=0,09\right)$.

Considerando essa tabela e a rede mostrada na Figura 6.2, observa-se que o termo "eletrônica" foi conectado somente com o não-termo "discriminador" e por essa razão foi classificado erroneamente como não-termo. Devido ao fato que o termo "oxicloração" conectou-se com um maior número de não-termos do que termos, o LLGC o classificou erroneamente como não-termo. Entretanto, os termos "função" e "fibra" foram corretamente classificados como termos e todos os não-termos também foram corretamente classificados como não-termos. 


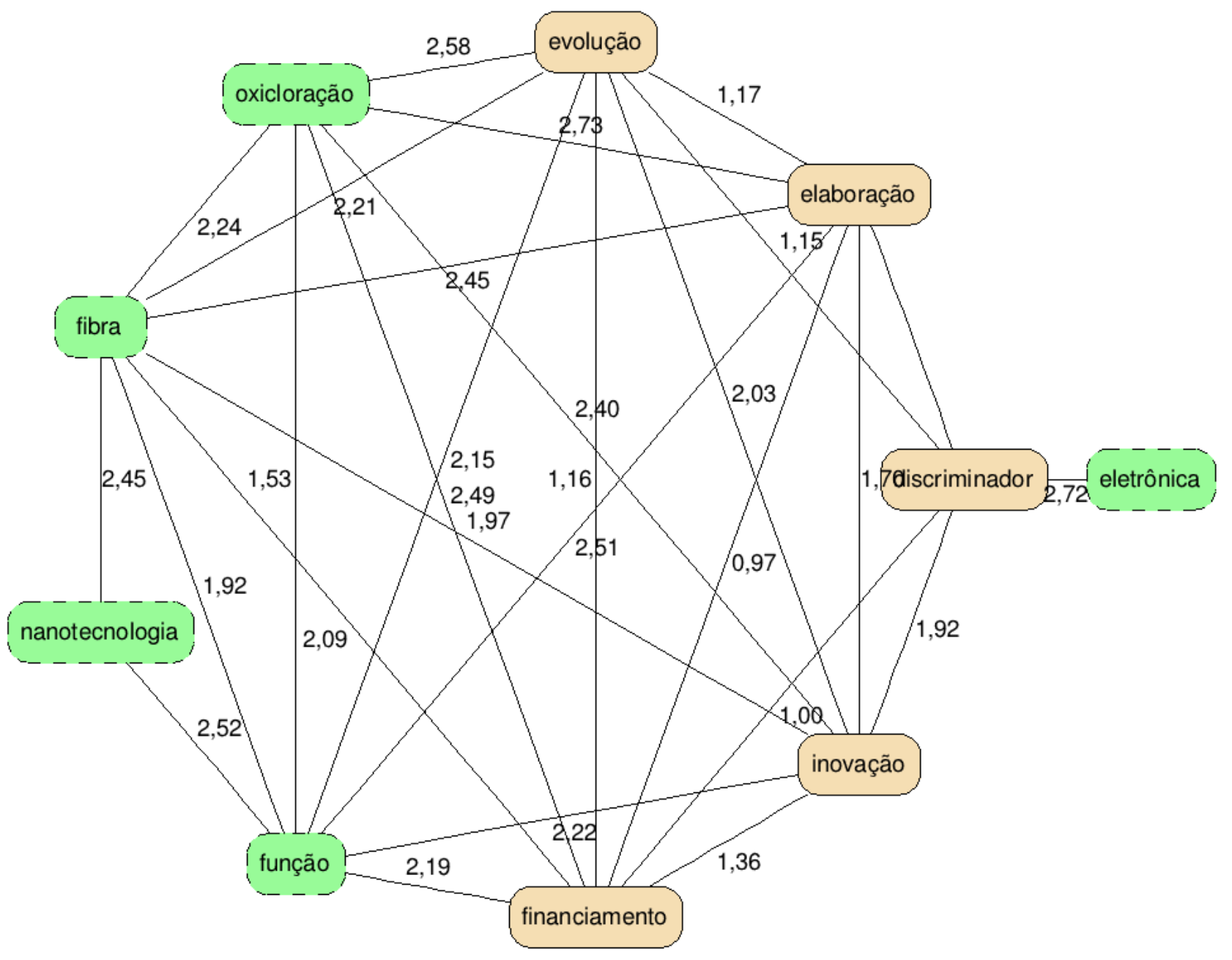

Figura 6.2: Exemplo de representação dos candidatos a termos utilizando rede.

Tabela 6.2: Exemplo de propagação de rótulos para classificar os candidatos a termos.

\begin{tabular}{|c|c|c|c|c|c|c|c|c|c|c|c|c|c|c|}
\hline \multirow[t]{2}{*}{$\begin{array}{r}\text { Candidato } \\
\text { a termo }\end{array}$} & \multicolumn{2}{|c|}{$\begin{array}{l}\text { Estado } \\
\text { inicial }\end{array}$} & \multicolumn{2}{|c|}{ Iteração 1} & \multicolumn{2}{|c|}{ Iteração 2} & \multicolumn{2}{|c|}{ Iteração 3} & \multicolumn{2}{|c|}{ Iteração 4} & \multicolumn{2}{|c|}{ Iteração 5} & \multirow[t]{2}{*}{$\begin{array}{c}\text { Classe } \\
\text { original }\end{array}$} & \multirow[t]{2}{*}{$\begin{array}{l}\text { Classe } \\
\text { predita }\end{array}$} \\
\hline & $C_{0}$ & $C_{1}$ & $C_{0}$ & $C_{1}$ & $C_{0}$ & $C_{1}$ & $C_{0}$ & $C_{1}$ & $C_{0}$ & $C_{1}$ & $C_{0}$ & $C_{1}$ & & \\
\hline nanotecnologia & 0 & 1 & 0,00 & 0,30 & 0,04 & 0,38 & 0,03 & 0,03 & 0,04 & 0,34 & 0,04 & 0,33 & 1 & 1 \\
\hline evolução & 1 & 0 & 0,30 & 0,00 & 0,37 & 0,04 & 0,35 & 0,03 & 0,36 & 0,04 & 0,35 & 0,04 & 0 & 0 \\
\hline oxicloração & 0 & 0 & 0,14 & 0,00 & 0,09 & 0,03 & 0,10 & 0,03 & 0,09 & 0,03 & 0,09 & 0,03 & 1 & 0 \\
\hline eletrônica & 0 & 0 & 0,00 & 0,00 & 0,03 & 0,00 & 0,02 & 0,00 & 0,02 & 0,01 & 0,02 & 0,00 & 1 & 0 \\
\hline função & 0 & 0 & 0,11 & 0,20 & 0,08 & 0,08 & 0,10 & 0,11 & 0,09 & 0,10 & 0,09 & 0,10 & 1 & 1 \\
\hline fibra & 0 & 0 & 0,11 & 0,20 & 0,08 & 0,08 & 0,10 & 0,11 & 0,09 & 0,09 & 0,09 & 0,10 & 1 & 1 \\
\hline inovação & 0 & 0 & 0,11 & 0,00 & 0,09 & 0,04 & 0,09 & 0,03 & 0,09 & 0,04 & 0,09 & 0,04 & 0 & 0 \\
\hline financiamento & 0 & 0 & 0,07 & 0,00 & 0,08 & 0,05 & 0,07 & 0,32 & 0,08 & 0,04 & 0,08 & 0,04 & 0 & 0 \\
\hline elaboração & 0 & 0 & 0,07 & 0,00 & 0,09 & 0,05 & 0,08 & 0,03 & 0,08 & 0,04 & 0,08 & 0,04 & 0 & 0 \\
\hline discriminador & 0 & 0 & 0,08 & 0,00 & 0,05 & 0,00 & 0,07 & 0,02 & 0,06 & 0,01 & 0,06 & 0,02 & 0 & 0 \\
\hline
\end{tabular}

\subsubsection{Discussão sobre os Resultados da TLATE}

No mundo real, o usuário final dos termos extraídos pode estar interessado em maximizar alguma medida de avaliação dependendo em qual aplicação os termos serão utilizados. Por exemplo, ele pode estar interessado em extrair todos os termos verdadeiros, mesmo que o conjunto de candidatos extraídos contenha não-termos (maximização da cobertura). Por outro lado, o usuário pode estar interessado em extrair somente os termos verdadeiros, mesmo que o conjunto de candidatos extraídos não contém todos os termos verdadeiros (maximização da precisão). O usuário também pode estar interessado na maximização do equilíbrio entre a cobertura e a precisão (maximização da medida $\mathrm{F}$ ).

Devido a quantidade de resultados (3.456 para cada corpus), nas Tabelas de 6.3 a 6.11, são apresentados os 25 primeiros resultados mais altos (top-25) de precisão $(\mathrm{P}(\%))$, 
cobertura $(\mathrm{C}(\%))$ e medida $\mathrm{F}(\mathrm{MF}(\%))$ para cada corpus. Nessas tabelas, também são indicados a seleção de características, a seleção de candidatos, o algoritmo transdutivo considerado (Alg.), a quantidade de candidatos a termos rotulados $\left(\left|\mathcal{O}^{L}\right|\right)$, o tipo da rede utilizada para representar os candidatos (Rede), o parâmetro utilizado para criar a rede ( $\sigma$ para rede Exp e $k$ para a rede $K \mathrm{NN}$ ) e o parâmetro utilizado pelo algoritmo LLGC $(\mu)$.

Tabela 6.3: Resultados top-25 de precisão da EAT utilizando aprendizado transdutivo - Corpus ECO.

\begin{tabular}{|c|c|c|c|c|c|c|c|c|c|}
\hline Seleção de Caract. & Seleção de CTs & Alg. & $\left|\mathcal{O}^{L \text { termos }}\right|$ & Rede & $\sigma / k$ & $\mu$ & $P(\%)$ & $\mathrm{C}(\%)$ & MF(\%) \\
\hline CFS_RS & DF_PM_SN & GFHF & 10 & Exp & 0,05 & - & 100,00 & 0,04 & 0,08 \\
\hline Todas Caract. & ${ }^{-} \mathrm{DF}$ & LLGC & 40 & Exp & 0,75 & 0,9 & 25,30 & 19,15 & 21,80 \\
\hline $\mathrm{CBF}$ RS & DF & LLGC & 40 & Exp & 0,75 & 0,9 & 25,28 & 18,98 & 21,68 \\
\hline Todas Caract. & DF & LLGC & 30 & Exp & 0,75 & 0,9 & 23,39 & 18,86 & 20,88 \\
\hline $\mathrm{CBF}$ RS & DF & LLGC & 30 & Exp & 0,75 & 0,9 & 23,27 & 18,61 & 20,68 \\
\hline $\mathrm{CBF}^{-} \mathrm{RS}$ & DF $\mathrm{PM} \quad \mathrm{SN}$ & LLGC & 1 & Exp & 0,05 & 0,9 & 22,64 & 0,45 & 0,89 \\
\hline $\mathrm{CBF}^{-} \mathrm{RS}$ & $-{ }_{\mathrm{DF}}$ & LLGC & 50 & Exp & 0,75 & 0,9 & 21,35 & 20,50 & 20,92 \\
\hline Todas Caract. & DF & LLGC & 50 & Exp & 0,75 & 0,9 & 21,20 & 20,59 & 20,89 \\
\hline Ling. & DF & LLGC & 30 & $K \mathrm{NN}$ & 17 & 0,9 & 19,72 & 0,57 & 1,12 \\
\hline Todas Caract. & DF & LLGC & 20 & Exp & 0,75 & 0,9 & 19,31 & 21,54 & 20,37 \\
\hline CBF_RS & DF & LLGC & 20 & Exp & 0,75 & 0,9 & 19,20 & 21,47 & 20,27 \\
\hline $\mathrm{CBF}^{-} \mathrm{RS}$ & DF_PM_SN & LLGC & 1 & Exp & 0,05 & 0,5 & 18,81 & 0,72 & 1,39 \\
\hline $\mathrm{CBF}^{-} \mathrm{RS}$ & $-{ }_{\mathrm{DF}}$ & LLGC & 40 & Exp & 0,35 & 0,9 & 17,74 & 41,17 & 24,80 \\
\hline Todas Caract. & DF & LLGC & 40 & Exp & 0,35 & 0,9 & 17,72 & 41,21 & 24,79 \\
\hline $\mathrm{CBF} \quad \mathrm{RS}$ & DF & LLGC & 30 & Exp & 0,35 & 0,9 & 16,92 & 41,74 & 24,08 \\
\hline Todas Caract. & DF & LLGC & 30 & Exp & 0,35 & 0,9 & 16,92 & 41,78 & 24,09 \\
\hline Ling. & DF & LLGC & 20 & $K \mathrm{NN}$ & 17 & 0,9 & 16,36 & 0,35 & 0,69 \\
\hline $\mathrm{CBF} \mathrm{RS}$ & DF & LLGC & 20 & Exp & 0,35 & 0,9 & 16,26 & 42,10 & 23,46 \\
\hline Todas Caract. & DF & LLGC & 20 & Exp & 0,35 & 0,9 & 16,24 & 42,14 & 23,45 \\
\hline Ling. & DF & LLGC & 40 & $K \mathrm{NN}$ & 17 & 0,9 & 16,00 & 0,34 & 0,67 \\
\hline Estat. & Todos CTs & LLGC & 10 & Exp & 0,35 & 0,9 & 15,82 & 33,10 & 21,41 \\
\hline Todas Caract. & DF & LLGC & 50 & Exp & 0,35 & 0,9 & 15,74 & 42,07 & 22,91 \\
\hline $\mathrm{CBF}$ RS & DF & LLGC & 50 & Exp & 0,35 & 0,9 & 15,70 & 41,89 & 22,84 \\
\hline $\mathrm{CBF}^{-} \mathrm{RS}$ & DF $\quad$ PM $\quad$ SN & LLGC & 1 & Exp & 0,05 & 0,1 & 14,73 & 0,72 & 1,37 \\
\hline Estat. & Todos ${ }^{C T s}$ & LLGC & 20 & Exp & 0,35 & 0,9 & 14,64 & 33,43 & 20,37 \\
\hline
\end{tabular}

Tabela 6.4: Resultados top-25 de cobertura da EAT utilizando aprendizado transdutivo - Corpus ECO.

\begin{tabular}{|c|c|c|c|c|c|c|c|c|c|}
\hline Seleção de Caract. & Seleção de CTs & Alg. & $\mid \mathcal{O}^{L}$ termos $\mid$ & Rede & $\sigma / k$ & $\mu$ & $P(\%)$ & $\mathrm{C}(\%)$ & MF(\%) \\
\hline Estat. & $\mathrm{DF} \quad \mathrm{PM} \quad \mathrm{SN}$ & GFHF & 10 & $K \mathrm{NN}$ & 17 & & 7,64 & 100,00 & 14,19 \\
\hline CBF_RS & $\mathrm{DF}_{-}^{-} \mathrm{PM}_{-}^{-} \mathrm{SN}$ & LLGC & 20 & $K \mathrm{NN}$ & 17 & 0,9 & 7,39 & 100,00 & 13,76 \\
\hline Estat. & $\mathrm{DF}_{-}^{-} \mathrm{PM}_{-}^{-} \mathrm{SN}$ & GFHF & 20 & $K \mathrm{NN}$ & 1 & - & 7,38 & 100,00 & 13,75 \\
\hline CBF_RS & $\mathrm{DF}_{-}^{-} \mathrm{PM}_{-}^{-} \mathrm{SN}$ & LLGC & 20 & $K \mathrm{NN}$ & 1 & 0,1 & 7,38 & 100,00 & 13,75 \\
\hline $\mathrm{CBF}_{-}^{-} \mathrm{RS}$ & $\mathrm{DF}_{-}^{-} \mathrm{PM}_{-}^{-} \mathrm{SN}$ & LLGC & 20 & $K \mathrm{NN}$ & 1 & 0,5 & 7,38 & 100,00 & 13,75 \\
\hline $\mathrm{CBF}_{-}^{-} \mathrm{RS}$ & $\mathrm{DF}_{-}^{-} \mathrm{PM}_{-}^{-} \mathrm{SN}$ & LLGC & 20 & $K \mathrm{NN}$ & 1 & 0,9 & 7,38 & 100,00 & 13,75 \\
\hline $\mathrm{CFS}_{-\mathrm{BF}}^{-}$ & $\mathrm{DF}_{-}^{-} \mathrm{PM}_{-}^{-} \mathrm{SN}$ & LLGC & 20 & Exp & 0,35 & 0,9 & 7,38 & 100,00 & 13,75 \\
\hline $\mathrm{CFS}^{-} \mathrm{BF}$ & $\mathrm{DF}^{-} \mathrm{PM}_{-}^{-} \mathrm{SN}$ & LLGC & 20 & $K \mathrm{NN}$ & 1 & 0,1 & 7,38 & 100,00 & 13,75 \\
\hline $\mathrm{CFS}^{-} \mathrm{BF}$ & $\mathrm{DF}^{-} \mathrm{PM}_{-}^{-} \mathrm{SN}$ & LLGC & 20 & $K \mathrm{NN}$ & 1 & 0,5 & 7,38 & 100,00 & 13,75 \\
\hline $\mathrm{CFS}^{-} \mathrm{BF}$ & $\mathrm{DF}^{-} \mathrm{PM}^{-} \mathrm{SN}$ & LLGC & 20 & $K \mathrm{NN}$ & 1 & 0,9 & 7,38 & 100,00 & 13,75 \\
\hline Estat. & $\mathrm{DF}_{-}^{-} \mathrm{PM}_{-}^{-} \mathrm{SN}$ & LLGC & 20 & $K \mathrm{NN}$ & 1 & 0,1 & 7,38 & 100,00 & 13,75 \\
\hline Estat. & $\mathrm{DF}^{-} \mathrm{PM}_{-}^{-} \mathrm{SN}$ & LLGC & 20 & $K \mathrm{NN}$ & 1 & 0,5 & 7,38 & 100,00 & 13,75 \\
\hline Estat. & $\mathrm{DF}^{-} \mathrm{PM}_{-}^{-} \mathrm{SN}$ & LLGC & 20 & $K \mathrm{NN}$ & 1 & 0,9 & 7,38 & 100,00 & 13,75 \\
\hline CBF_RS & $\mathrm{DF}_{-}^{-} \mathrm{PM}_{-}^{-} \mathrm{SN}$ & LLGC & 30 & $K \mathrm{NN}$ & 17 & 0,9 & 7,13 & 100,00 & 13,31 \\
\hline Estat. & $\mathrm{DF}_{-}^{-} \mathrm{PM}_{-}^{-} \mathrm{SN}$ & GFHF & 30 & $K \mathrm{NN}$ & 1 & - & 7,13 & 100,00 & 13,30 \\
\hline CBF_RS & $\mathrm{DF}_{-}^{-} \mathrm{PM}_{-}^{-} \mathrm{SN}$ & LLGC & 30 & $K \mathrm{NN}$ & 1 & 0,1 & 7,13 & 100,00 & 13,30 \\
\hline $\mathrm{CBF}^{-} \mathrm{RS}$ & $\mathrm{DF}_{-}^{-} \mathrm{PM}_{-}^{-} \mathrm{SN}$ & LLGC & 30 & $K \mathrm{NN}$ & 1 & 0,5 & 7,13 & 100,00 & 13,30 \\
\hline $\mathrm{CBF}^{-} \mathrm{RS}$ & $\mathrm{DF}^{-} \mathrm{PM}_{-}^{-} \mathrm{SN}$ & LLGC & 30 & $K \mathrm{NN}$ & 1 & 0,9 & 7,13 & 100,00 & 13,30 \\
\hline $\mathrm{CFS}^{-} \mathrm{BF}$ & $\mathrm{DF}^{-} \mathrm{PM}_{-}^{-} \mathrm{SN}$ & LLGC & 30 & $K \mathrm{NN}$ & 1 & 0,1 & 7,13 & 100,00 & 13,30 \\
\hline $\mathrm{CFS}_{-}^{-} \mathrm{BF}$ & $\mathrm{DF}_{-}^{-} \mathrm{PM}_{-}^{-} \mathrm{SN}$ & LLGC & 30 & $K \mathrm{NN}$ & 1 & 0,5 & 7,13 & 100,00 & 13,30 \\
\hline $\mathrm{CFS}_{-}^{-} \mathrm{BF}$ & $\mathrm{DF}_{-}^{-} \mathrm{PM}_{-}^{-} \mathrm{SN}$ & LLGC & 30 & $K \mathrm{NN}$ & 1 & 0,9 & 7,13 & 100,00 & 13,30 \\
\hline Estat. & $\mathrm{DF}_{-}^{-} \mathrm{PM}_{-}^{-} \mathrm{SN}$ & LLGC & 30 & Exp & 0,75 & 0,9 & 7,13 & 100,00 & 13,30 \\
\hline Estat. & $\mathrm{DF}_{-}^{-} \mathrm{PM}_{-}^{-} \mathrm{SN}$ & LLGC & 30 & $K \mathrm{NN}$ & 1 & 0,1 & 7,13 & 100,00 & 13,30 \\
\hline Estat. & $\mathrm{DF}_{-}^{-} \mathrm{PM}_{-}^{-} \mathrm{SN}$ & LLGC & 30 & $K \mathrm{NN}$ & 1 & 0,5 & 7,13 & 100,00 & 13,30 \\
\hline Estat. & $\mathrm{DF}_{-}^{-} \mathrm{PM}_{-}^{-} \mathrm{SN}$ & LLGC & 30 & $K \mathrm{NN}$ & 1 & 0,9 & 7,13 & 100,00 & 13,30 \\
\hline
\end{tabular}

Como exemplo de análise de resultados, na Tabela 6.3, observa-se que o valor mais alto obtido de precisão da extração de termos a partir do corpus ECO foi $100 \%$ quando considerados os candidatos a termos mantidos após a aplicação do Filtro DF_PM_SN e utilizadas as características dos candidatos selecionadas pelo método $C F S_{-} R S$. Esse valor de precisão foi alcançado quando esses candidatos foram representados pela rede Exp com abertura da função $\operatorname{Exp} \sigma=0,05$. Nesse caso, aplicou-se o algoritmo GFHF o qual utilizou 10 candidatos rotulados como termos e 10 como não-termos para classificar os demais candidatos em termos e não-termos. Essa precisão de $100 \%$ acompanha valores de cobertura $(0,04 \%)$ e medida F $(0,08 \%)$ baixos. Por essa razão, é interessante observar também os demais valores mostrados na Tabela 6.3. Por exemplo, da segunda a quarta linha dessa tabela, têm-se valores de precisão em torno de $23 \%$ que acompanham medida 
Tabela 6.5: Resultados top-25 de medida F da EAT utilizando aprendizado transdutivo - Corpus ECO.

\begin{tabular}{rrrrrrrrrr}
\hline Seleção de Caract. & Seleção de CTs & Alg. & $\mid \mathcal{O}^{L}$ termos $\mid$ & Rede & $\sigma / k$ & $\mu$ & P(\%) & C(\%) & MF(\%) \\
\hline CBF_RS & DF & LLGC & 40 & Exp & 0,35 & 0,9 & 17,74 & 41,17 & 24,80 \\
Todas Caract. & DF & LLGC & 40 & Exp & 0,35 & 0,9 & 17,72 & 41,21 & 24,79 \\
Todas Caract. & DF & LLGC & 30 & Exp & 0,35 & 0,9 & 16,92 & 41,78 & 24,09 \\
CBF_RS & DF & LLGC & 30 & Exp & 0,35 & 0,9 & 16,92 & 41,74 & 24,08 \\
CBF_RS & DF & LLGC & 20 & Exp & 0,35 & 0,9 & 16,26 & 42,10 & 23,46 \\
Todas Caract. & DF & LLGC & 20 & Exp & 0,35 & 0,9 & 16,24 & 42,14 & 23,45 \\
Todas Caract. & DF & LLGC & 50 & Exp & 0,35 & 0,9 & 15,74 & 42,07 & 22,91 \\
CBF_RS & DF & LLGC & 50 & Exp & 0,35 & 0,9 & 15,70 & 41,89 & 22,84 \\
CBF_RS & DF & LLGC & 40 & Exp & 0,35 & 0,1 & 13,64 & 54,34 & 21,80 \\
Todas Caract. & DF & LLGC & 40 & Exp & 0,75 & 0,9 & 25,30 & 19,15 & 21,80 \\
Todas Caract. & DF & LLGC & 40 & Exp & 0,35 & 0,1 & 13,58 & 54,42 & 21,73 \\
CBF_RS & DF & LLGC & 40 & Exp & 0,75 & 0,9 & 25,28 & 18,98 & 21,68 \\
CBF_RS & DF & LLGC & 30 & Exp & 0,35 & 0,5 & 13,70 & 52,03 & 21,68 \\
Todas Caract. & DF & LLGC & 30 & Exp & 0,35 & 0,5 & 13,68 & 52,15 & 21,67 \\
CBF_RS & DF & LLGC & 30 & Exp & 0,35 & 0,1 & 13,47 & 54,90 & 21,64 \\
Todas Caract. & DF & LLGC & 30 & Exp & 0,35 & 0,1 & 13,45 & 55,02 & 21,62 \\
CBF_RS & DF & GFHF & 40 & Exp & 0,75 & - & 13,70 & 51,00 & 21,60 \\
Todas Caract. & DF & GFHF & 40 & Exp & 0,75 & - & 13,65 & 51,09 & 21,55 \\
CBF_RS & DF & GFHF & 30 & Exp & 0,75 & - & 13,60 & 51,41 & 21,51 \\
Todas Caract. & DF & GFHF & 30 & Exp & 0,75 & - & 13,58 & 51,54 & 21,50 \\
CBF_RS & DF & GFHF & 20 & Exp & 0,75 & - & 13,53 & 51,44 & 21,43 \\
Estat. & Todos CTs & LLGC & 10 & Exp & 0,35 & 0,9 & 15,82 & 33,10 & 21,41 \\
Todas Caract. & DF & GFHF & 20 & Exp & 0,75 & - & 13,51 & 51,48 & 21,40 \\
Todas Caract. & DF & LLGC & 20 & Exp & 0,75 & 0,5 & 13,38 & 53,29 & 21,39 \\
CBF_RS & DF & LLGC & 20 & Exp & 0,35 & 0,5 & 13,40 & 52,66 & 21,37 \\
\hline
\end{tabular}

Tabela 6.6: Resultados top-25 de precisão da EAT utilizando aprendizado transdutivo - Corpus EaD.

\begin{tabular}{|c|c|c|c|c|c|c|c|c|c|}
\hline Seleção de Caract. & Seleção de CTs & Alg. & $\mid \mathcal{O}^{L}$ termos $\mid$ & Rede & $\sigma / k$ & $\mu$ & $\mathbf{P}(\%)$ & $\mathrm{C}(\%)$ & $\operatorname{MF}(\%)$ \\
\hline CBF $\quad \mathrm{BF}$ & $\mathrm{DF} \quad \mathrm{PM} \quad \mathrm{SN}$ & LLGC & 50 & Exp & 0,75 & 0,9 & 100,00 & 0,18 & 0,35 \\
\hline Todas Caract. & $\mathrm{DF}^{-} \mathrm{PM}^{-} \mathrm{SN}$ & LLGC & 50 & Exp & 0,75 & 0,9 & 66,67 & 0,35 & 0,69 \\
\hline Estat. & $-\quad-\mathrm{DF}$ & LLGC & 10 & Exp & 0,75 & 0,9 & 33,33 & 0,10 & 0,20 \\
\hline Estat. & DF PM SN & LLGC & 20 & Exp & 0,75 & 0,9 & 25,00 & 0,23 & 0,45 \\
\hline Híbrido & $\mathrm{DF}^{-} \mathrm{PM}^{-} \mathrm{SN}$ & LLGC & 20 & Exp & 0,75 & 0,9 & 25,00 & 0,23 & 0,45 \\
\hline $\mathrm{CBF}$ RS & $\mathrm{DF}$ & LLGC & 40 & Exp & 0,75 & 0,9 & 25,00 & 0,15 & 0,29 \\
\hline $\mathrm{CBF}^{-} \mathrm{RS}$ & DF $P M \quad S N$ & LLGC & 40 & Exp & 0,75 & 0,9 & 23,53 & 0,60 & 1,16 \\
\hline $\mathrm{CFS}^{-} \mathrm{RS}$ & $\mathrm{DF}^{-} \mathrm{PM}^{-} \mathrm{SN}$ & GFHF & 1 & $K \mathrm{NN}$ & 1 & - & 23,08 & 0,57 & 1,10 \\
\hline $\mathrm{CFS}^{-} \mathrm{RS}$ & $\mathrm{DF}^{-} \mathrm{PM}^{-} \mathrm{SN}$ & GFHF & 1 & $K \mathrm{NN}$ & 17 & - & 23,08 & 0,57 & 1,10 \\
\hline $\mathrm{CFS}^{-} \mathrm{RS}$ & $\mathrm{DF}^{-} \mathrm{PM}^{-} \mathrm{SN}$ & GFHF & 1 & $K \mathrm{NN}$ & 57 & - & 23,08 & 0,57 & 1,10 \\
\hline $\mathrm{CFS}^{-} \mathrm{RS}$ & $\mathrm{DF}^{-} \mathrm{PM}^{-} \mathrm{SN}$ & LLGC & 1 & $K \mathrm{NN}$ & 17 & 0,1 & 23,08 & 0,57 & 1,10 \\
\hline $\mathrm{CFS}^{-} \mathrm{RS}$ & $\mathrm{DF}^{-} \mathrm{PM}^{-} \mathrm{SN}$ & LLGC & 1 & $K \mathrm{NN}$ & 17 & 0,5 & 23,08 & 0,57 & 1,10 \\
\hline $\mathrm{CFS}^{-} \mathrm{RS}$ & $\mathrm{DF}^{-} \mathrm{PM}^{-} \mathrm{SN}$ & LLGC & 1 & $K \mathrm{NN}$ & 17 & 0,9 & 23,08 & 0,57 & 1,10 \\
\hline $\mathrm{CFS}^{-} \mathrm{RS}$ & $\mathrm{DF}^{-} \mathrm{PM}^{-} \mathrm{SN}$ & LLGC & 1 & $K \mathrm{NN}$ & 1 & 0,1 & 23,08 & 0,57 & 1,10 \\
\hline $\mathrm{CFS}^{-} \mathrm{RS}$ & $\mathrm{DF}^{-} \mathrm{PM}^{-} \mathrm{SN}$ & LLGC & 1 & $K \mathrm{NN}$ & 1 & 0,5 & 23,08 & 0,57 & 1,10 \\
\hline $\mathrm{CFS}^{-} \mathrm{RS}$ & $\mathrm{DF}-\mathrm{PM}^{-} \mathrm{SN}$ & LLGC & 1 & $K N N$ & 1 & $\begin{array}{l}0,0 \\
0,9\end{array}$ & $\begin{array}{l}20,00 \\
23,08\end{array}$ & 0,57 & 1,10 \\
\hline $\mathrm{CFS}^{-} \mathrm{RS}$ & $\mathrm{DF}^{-} \mathrm{PM}^{-} \mathrm{SN}$ & LLGC & 1 & $K \mathrm{NN}$ & 57 & 0,1 & 23,08 & 0,57 & 1,10 \\
\hline $\mathrm{CFS}^{-} \mathrm{RS}$ & $\mathrm{DF}^{-} \mathrm{PM}^{-} \mathrm{SN}$ & LLGC & 1 & $K \mathrm{NN}$ & 57 & 0,5 & 23,08 & 0,57 & 1,10 \\
\hline $\mathrm{CFS}^{-} \mathrm{RS}$ & $\mathrm{DF}^{-} \mathrm{PM}^{-} \mathrm{SN}$ & LLGC & 1 & $K \mathrm{NN}$ & 57 & 0,9 & 23,08 & 0,57 & 1,10 \\
\hline Estat. & $\mathrm{DF}^{-} \mathrm{PM}^{-} \mathrm{SN}$ & LLGC & 30 & Exp & 0,75 & 0,9 & 23,08 & 0,39 & 0,76 \\
\hline Híbrido & $\mathrm{DF}^{-} \mathrm{PM}^{-} \mathrm{SN}$ & LLGC & 30 & Exp & 0,75 & 0,9 & 23,08 & 0,39 & 0,76 \\
\hline Todas Caract. & $\mathrm{DF}^{-} \mathrm{PM}^{-} \mathrm{SN}$ & LLGC & 40 & Exp & 0,75 & 0,9 & 22,22 & 1,48 & 2,78 \\
\hline CFS BF & $-\mathrm{DF}$ & LLGC & 10 & Exp & 0,75 & 0,9 & 20,00 & 0,10 & 0,20 \\
\hline $\mathrm{CBF}^{-}{ }_{\mathrm{BF}}$ & DF PM SN & LLGC & 40 & Exp & 0,75 & 0,9 & 17,57 & 1,94 & 3,49 \\
\hline $\mathrm{CBF}^{-} \mathrm{BF}$ & $\mathrm{DF}^{-} \mathrm{PM}^{-} \mathrm{SN}$ & GFHF & 1 & $K \mathrm{NN}$ & 1 & - & 17,02 & 0,75 & 1,45 \\
\hline
\end{tabular}

Tabela 6.7: Resultados top-25 de cobertura da EAT utilizando aprendizado transdutivo - Corpus EaD.

\begin{tabular}{|c|c|c|c|c|c|c|c|c|c|}
\hline Seleção de Caract. & Seleção de CTs & Alg. & $\mid \mathcal{O}^{L}$ termos $\mid$ & Rede & $\sigma / k$ & $\mu$ & $\mathbf{P}(\%)$ & $\mathrm{C}(\%)$ & $\operatorname{MF}(\%)$ \\
\hline CBF_RS & DF & LLGC & 30 & $K \mathrm{NN}$ & 57 & 0,9 & 0,97 & 99,36 & 1,93 \\
\hline Estat. & DF & LLGC & 50 & $K \mathrm{NN}$ & 17 & 0,1 & 0,72 & 99,14 & 1,44 \\
\hline Estat. & DF & LLGC & 50 & $K \mathrm{NN}$ & 17 & 0,5 & 0,72 & 99,14 & 1,44 \\
\hline Estat. & DF & LLGC & 50 & $K \mathrm{NN}$ & 17 & 0,9 & 0,72 & 99,14 & 1,44 \\
\hline Estat. & DF & LLGC & 40 & $K \mathrm{NN}$ & 17 & 0,1 & 0,85 & 99,12 & 1,68 \\
\hline Estat. & DF & LLGC & 40 & $K \mathrm{NN}$ & 17 & 0,5 & 0,85 & 99,12 & 1,68 \\
\hline Estat. & DF & LLGC & 40 & $K \mathrm{NN}$ & 17 & 0,9 & 0,85 & 99,12 & 1,68 \\
\hline Ling. & DF & GFHF & 40 & Exp & 0,35 & - & 1,18 & 98,68 & 2,33 \\
\hline Ling. & DF & GFHF & 40 & Exp & 0,75 & - & 1,18 & 98,68 & 2,33 \\
\hline Ling. & DF & GFHF & 50 & Exp & 0,35 & - & 1,01 & 98,63 & 2,00 \\
\hline Ling. & DF & GFHF & 50 & Exp & 0,75 & - & 1,01 & 98,63 & 1,99 \\
\hline Ling. & DF & GFHF & 30 & Exp & 0,75 & - & 1,35 & 98,60 & 2,65 \\
\hline Ling. & DF & GFHF & 30 & Exp & 0,35 & - & 1,34 & 98,60 & 2,65 \\
\hline Ling. & DF & GFHF & 20 & Exp & 0,75 & - & 1,52 & 98,53 & 2,99 \\
\hline Ling. & DF & GFHF & 20 & Exp & 0,35 & - & 1,52 & 98,53 & 2,99 \\
\hline Estat. & DF & GFHF & 40 & $K \mathrm{NN}$ & 17 & - & 0,85 & 98,39 & 1,68 \\
\hline Estat. & DF & GFHF & 50 & $K \mathrm{NN}$ & 17 & - & 0,72 & 98,29 & 1,43 \\
\hline $\mathrm{CBF} \quad \mathrm{BF}$ & DF & LLGC & 50 & $K \mathrm{NN}$ & 57 & 0,9 & 0,73 & 97,59 & 1,44 \\
\hline Todas Caract. & DF & GFHF & 50 & Exp & 0,35 & - & 1,07 & 96,92 & 2,13 \\
\hline Todas Caract. & DF & GFHF & 30 & Exp & 0,35 & - & 1,51 & 96,81 & 2,97 \\
\hline Todas Caract. & DF & GFHF & 40 & Exp & 0,35 & - & 1,26 & 96,78 & 2,48 \\
\hline Todas Caract. & DF & GFHF & 50 & Exp & 0,75 & - & 1,12 & 96,75 & 2,22 \\
\hline Todas Caract. & DF & GFHF & 20 & Exp & 0,35 & - & 1,73 & 96,49 & 3,41 \\
\hline Todas Caract. & DF & GFHF & 40 & Exp & 0,75 & - & 1,30 & 96,49 & 2,56 \\
\hline Todas Caract. & DF & GFHF & 30 & Exp & 0,75 & - & 1,55 & 95,79 & 3,06 \\
\hline
\end{tabular}

F acima de $20 \%$ sendo esses, portanto, resultados mais interessantes do que a precisão de $100 \%$. 
Capítulo 6. TLATE: uma Abordagem para Extração Automática de Termos Utilizando Aprendizado Transdutivo

Tabela 6.8: Resultados top-25 de medida F da EAT utilizando aprendizado transdutivo - Corpus EaD.

\begin{tabular}{|c|c|c|c|c|c|c|c|c|c|}
\hline Seleção de Caract. & Seleção de CTs & Alg. & $\mid \mathcal{O}^{L}$ termos $\mid$ & Rede & $\sigma / k$ & $\mu$ & $\mathbf{P}(\%)$ & $\mathrm{C}(\%)$ & MF(\%) \\
\hline CBF_BF & DF_PM_SN & LLGC & 30 & $K \mathrm{NN}$ & 17 & 0,1 & 11,59 & 17,14 & 13,83 \\
\hline $\mathrm{CBF}^{-} \mathrm{BF}$ & $\mathrm{DF}^{-} \mathrm{PM}^{-} \mathrm{SN}$ & LLGC & 30 & $K \mathrm{NN}$ & 1 & 0,1 & 11,59 & 17,14 & 13,83 \\
\hline $\mathrm{CBF}_{-}^{-} \mathrm{BF}$ & $\mathrm{DF}_{-}^{-} \mathrm{PM}_{-}^{-} \mathrm{SN}$ & LLGC & 30 & $K \mathrm{NN}$ & 57 & 0,1 & 11,59 & 17,14 & 13,83 \\
\hline $\mathrm{CBF}_{-}^{-} \mathrm{BF}$ & $\mathrm{DF}_{-}^{-} \mathrm{PM}_{-}^{-} \mathrm{SN}$ & GFHF & 30 & $K \mathrm{NN}$ & 1 & - & 11,49 & 17,14 & 13,76 \\
\hline $\mathrm{CBF}_{-}^{-} \mathrm{BF}$ & $\mathrm{DF}_{-}^{-} \mathrm{PM}_{-}^{-} \mathrm{SN}$ & GFHF & 30 & $K \mathrm{NN}$ & 17 & - & 11,49 & 17,14 & 13,76 \\
\hline $\mathrm{CBF}_{-}^{-} \mathrm{BF}$ & $\mathrm{DF}_{-}^{-} \mathrm{PM}_{-}^{-} \mathrm{SN}$ & GFHF & 30 & $K \mathrm{NN}$ & 57 & - & 11,49 & 17,14 & 13,76 \\
\hline $\mathrm{CBF}^{-} \mathrm{BF}$ & $\mathrm{DF}^{-} \mathrm{PM}^{-} \mathrm{SN}$ & LLGC & 30 & $K \mathrm{NN}$ & 17 & 0,5 & 11,49 & 17,14 & 13,76 \\
\hline $\mathrm{CBF}_{-}^{-} \mathrm{BF}$ & $\mathrm{DF}_{-}^{-} \mathrm{PM}_{-}^{-} \mathrm{SN}$ & LLGC & 30 & $K \mathrm{NN}$ & 17 & 0,9 & 11,49 & 17,14 & 13,76 \\
\hline $\mathrm{CBF}_{-}^{-} \mathrm{BF}$ & $\mathrm{DF}_{-}^{-} \mathrm{PM}_{-}^{-} \mathrm{SN}$ & LLGC & 30 & $K \mathrm{NN}$ & 1 & 0,5 & 11,49 & 17,14 & 13,76 \\
\hline $\mathrm{CBF}_{-}^{-} \mathrm{BF}$ & $\mathrm{DF}_{-}^{-} \mathrm{PM}_{-}^{-} \mathrm{SN}$ & LLGC & 30 & $K \mathrm{NN}$ & 1 & 0,9 & 11,49 & 17,14 & 13,76 \\
\hline $\mathrm{CBF}_{-}^{-} \mathrm{BF}$ & $\mathrm{DF}_{-}^{-} \mathrm{PM}_{-}^{-} \mathrm{SN}$ & LLGC & 30 & $K \mathrm{NN}$ & 57 & 0,5 & 11,49 & 17,14 & 13,76 \\
\hline $\mathrm{CBF}^{-} \mathrm{BF}$ & $\mathrm{DF}^{-} \mathrm{PM}^{-} \mathrm{SN}$ & LLGC & 30 & $K \mathrm{NN}$ & 57 & 0,9 & 11,49 & 17,14 & 13,76 \\
\hline $\mathrm{CBF}^{-} \mathrm{BF}$ & $\mathrm{DF}^{-} \mathrm{PM}^{-} \mathrm{SN}$ & LLGC & 20 & $K \mathrm{NN}$ & 17 & 0,1 & 13,54 & 13,33 & 13,43 \\
\hline $\mathrm{CBF}^{-} \mathrm{BF}$ & $\mathrm{DF}^{-} \mathrm{PM}^{-} \mathrm{SN}$ & LLGC & 20 & $K \mathrm{NN}$ & 1 & 0,1 & 13,54 & 13,33 & 13,43 \\
\hline $\mathrm{CBF}_{-}^{-} \mathrm{BF}$ & $\mathrm{DF}_{-}^{-} \mathrm{PM}_{-}^{-} \mathrm{SN}$ & LLGC & 20 & $K \mathrm{NN}$ & 57 & 0,1 & 13,54 & 13,33 & 13,43 \\
\hline $\mathrm{CBF}^{-} \mathrm{BF}$ & $\mathrm{DF}^{-} \mathrm{PM}^{-} \mathrm{SN}$ & GFHF & 20 & $K \mathrm{NN}$ & 1 & - & 13,46 & 13,33 & 13,39 \\
\hline $\mathrm{CBF}^{-} \mathrm{BF}$ & $\mathrm{DF}^{-} \mathrm{PM}^{-} \mathrm{SN}$ & GFHF & 20 & $K \mathrm{NN}$ & 17 & - & 13,46 & 13,33 & 13,39 \\
\hline $\mathrm{CBF}^{-} \mathrm{BF}$ & $\mathrm{DF}^{-} \mathrm{PM}_{-}^{-} \mathrm{SN}$ & GFHF & 20 & $K \mathrm{NN}$ & 57 & - & 13,46 & 13,33 & 13,39 \\
\hline $\mathrm{CBF}_{-}^{-} \mathrm{BF}$ & $\mathrm{DF}_{-}^{-} \mathrm{PM}_{-}^{-} \mathrm{SN}$ & LLGC & 20 & $K \mathrm{NN}$ & 17 & 0,5 & 13,46 & 13,33 & 13,39 \\
\hline $\mathrm{CBF}_{-}^{-} \mathrm{BF}$ & $\mathrm{DF}_{-}^{-} \mathrm{PM}_{-}^{-} \mathrm{SN}$ & LLGC & 20 & $K \mathrm{NN}$ & 17 & 0,9 & 13,46 & 13,33 & 13,39 \\
\hline $\mathrm{CBF}_{-}^{-} \mathrm{BF}$ & $\mathrm{DF}_{-}^{-} \mathrm{PM}_{-}^{-} \mathrm{SN}$ & LLGC & 20 & $K \mathrm{NN}$ & 1 & 0,5 & 13,46 & 13,33 & 13,39 \\
\hline $\mathrm{CBF}^{-} \mathrm{BF}$ & $\mathrm{DF}^{-} \mathrm{PM}^{-} \mathrm{SN}$ & LLGC & 20 & $K \mathrm{NN}$ & 1 & 0,9 & 13,46 & 13,33 & 13,39 \\
\hline $\mathrm{CBF}^{-} \mathrm{BF}$ & $\mathrm{DF}^{-} \mathrm{PM}^{-} \mathrm{SN}$ & LLGC & 20 & $K \mathrm{NN}$ & 57 & 0,5 & 13,46 & 13,33 & 13,39 \\
\hline $\mathrm{CBF}^{-} \mathrm{BF}$ & $\mathrm{DF}^{-} \mathrm{PM}^{-} \mathrm{SN}$ & LLGC & 20 & $K \mathrm{NN}$ & 57 & 0,9 & 13,46 & 13,33 & 13,39 \\
\hline $\mathrm{CBF}_{-}^{-} \mathrm{BF}$ & $\mathrm{DF}_{-}^{-} \mathrm{PM}_{-}^{-} \mathrm{SN}$ & LLGC & 40 & $K \mathrm{NN}$ & 17 & 0,1 & 9,68 & 21,64 & 13,38 \\
\hline
\end{tabular}

Tabela 6.9: Resultados top-25 de precisão da EAT utilizando aprendizado transdutivo - Corpus Nano.

\begin{tabular}{|c|c|c|c|c|c|c|c|c|c|}
\hline Seleção de Caract. & Seleção de CTs & Alg. & $\mid \mathcal{O}^{L}$ termos $\mid$ & Rede & $\sigma / k$ & $\mu$ & $P(\%)$ & $\mathrm{C}(\%)$ & $\operatorname{MF}(\%)$ \\
\hline Híbrido & DF $\quad$ PM $\quad \mathrm{SN}$ & GFHF & 1 & $K \mathrm{NN}$ & 17 & - & 42,11 & 0,13 & 0,26 \\
\hline Híbrido & $\mathrm{DF}^{-} \mathrm{PM}^{-} \mathrm{SN}$ & LLGC & 1 & $K \mathrm{NN}$ & 17 & 0,1 & 42,11 & 0,13 & 0,26 \\
\hline Híbrido & $\mathrm{DF}^{-} \mathrm{PM}_{-}^{-} \mathrm{SN}$ & LLGC & 1 & $K \mathrm{NN}$ & 17 & 0,5 & 42,11 & 0,13 & 0,26 \\
\hline Híbrido & $\mathrm{DF}^{-} \mathrm{PM}^{-} \mathrm{SN}$ & LLGC & 1 & $K \mathrm{NN}$ & 17 & 0,9 & 42,11 & 0,13 & 0,26 \\
\hline CFS BF & $\mathrm{DF}^{-} \mathrm{PM}^{-} \mathrm{SN}$ & LLGC & 50 & Exp & 0,35 & 0,9 & 29,30 & 44,76 & 35,41 \\
\hline $\mathrm{CBF}^{-} \mathrm{BF}$ & $\mathrm{DF}^{-} \mathrm{PM}^{-} \mathrm{SN}$ & LLGC & 50 & Exp & 0,35 & 0,9 & 29,10 & 30,99 & 30,01 \\
\hline $\mathrm{CBF}^{-} \mathrm{RS}$ & $\mathrm{DF}^{-} \mathrm{PM}^{-} \mathrm{SN}$ & LLGC & 50 & Exp & 0,35 & 0,9 & 29,10 & 30,99 & 30,01 \\
\hline Ling. & $\mathrm{DF}_{-}^{-} \mathrm{PM}_{-}^{-} \mathrm{SN}$ & LLGC & 50 & Exp & 0,35 & 0,9 & 29,02 & 8,25 & 12,84 \\
\hline $\mathrm{CFS} \mathrm{BF}$ & $\mathrm{DF}^{-} \mathrm{PM}^{-} \mathrm{SN}$ & LLGC & 50 & Exp & 0,75 & 0,9 & 28,98 & 26,23 & 27,54 \\
\hline Ling. & $\mathrm{DF}^{-} \mathrm{PM}^{-} \mathrm{SN}$ & LLGC & 40 & Exp & 0,35 & 0,9 & 28,08 & 11,36 & 16,17 \\
\hline Estat. & $\mathrm{DF}^{-} \mathrm{PM}^{-} \mathrm{SN}$ & LLGC & 50 & Exp & 0,75 & 0,9 & 27,82 & 20,81 & 23,81 \\
\hline Estat. & $\mathrm{DF}^{-} \mathrm{PM}^{-} \mathrm{SN}$ & LLGC & 40 & Exp & 0,35 & 0,9 & 27,50 & 42,97 & 33,54 \\
\hline CFS BF & $\mathrm{DF}^{-} \mathrm{PM}^{-} \mathrm{SN}$ & LLGC & 30 & Exp & 0,35 & 0,9 & 27,49 & 47,55 & 34,84 \\
\hline $\mathrm{CBF}^{-} \mathrm{BF}$ & $\mathrm{DF}^{-} \mathrm{PM}^{-} \mathrm{SN}$ & LLGC & 50 & Exp & 0,75 & 0,5 & 27,45 & 64,73 & 38,55 \\
\hline $\mathrm{CBF}^{-} \mathrm{RS}$ & $\mathrm{DF}^{-} \mathrm{PM}^{-} \mathrm{SN}$ & LLGC & 50 & Exp & 0,75 & 0,5 & 27,45 & 64,73 & 38,55 \\
\hline Estat. & $\mathrm{DF}^{-} \mathrm{PM}^{-} \mathrm{SN}$ & LLGC & 50 & Exp & 0,35 & 0,9 & 27,44 & 41,86 & 33,15 \\
\hline CFS RS & $\mathrm{DF}^{-} \mathrm{PM}^{-} \mathrm{SN}$ & LLGC & 50 & Exp & 0,35 & 0,9 & 27,33 & 37,58 & 31,65 \\
\hline $\mathrm{CFS}^{-} \mathrm{BF}$ & $\mathrm{DF}^{-} \mathrm{PM}^{-} \mathrm{SN}$ & LLGC & 30 & Exp & 0,75 & 0,9 & 27,30 & 35,50 & 30,86 \\
\hline $\mathrm{CBF}^{-} \mathrm{BF}$ & $\mathrm{DF}^{-} \mathrm{PM}^{-} \mathrm{SN}$ & GFHF & 50 & Exp & 0,75 & - & 27,26 & 64,40 & 38,31 \\
\hline $\mathrm{CBF}^{-} \mathrm{RS}$ & $\mathrm{DF}^{-} \mathrm{PM}^{-} \mathrm{SN}$ & GFHF & 50 & Exp & 0,75 & - & 27,26 & 64,40 & 38,31 \\
\hline $\mathrm{CFS}^{-} \mathrm{BF}$ & $\mathrm{DF}^{-} \mathrm{PM}^{-} \mathrm{SN}$ & LLGC & 40 & Exp & 0,35 & 0,9 & 27,25 & 37,70 & 31,63 \\
\hline $\mathrm{CBF}^{-} \mathrm{BF}$ & $\mathrm{DF}^{-} \mathrm{PM}^{-} \mathrm{SN}$ & LLGC & 40 & Exp & 0,75 & 0,5 & 27,24 & 63,70 & 38,17 \\
\hline $\mathrm{CBF}^{-} \mathrm{RS}$ & $\mathrm{DF}^{-} \mathrm{PM}^{-} \mathrm{SN}$ & LLGC & 40 & Exp & 0,75 & 0,5 & 27,24 & 63,70 & 38,17 \\
\hline $\mathrm{CBF}^{-} \mathrm{BF}$ & $\mathrm{DF}^{-} \mathrm{PM}^{-} \mathrm{SN}$ & LLGC & 50 & Exp & 0,35 & 0,5 & 27,12 & 70,10 & 39,10 \\
\hline $\mathrm{CBF}^{-} \mathrm{RS}$ & $\mathrm{DF}^{-} \mathrm{PM}^{-} \mathrm{SN}$ & LLGC & 50 & Exp & 0,35 & 0,5 & 27,12 & 70,10 & 39,10 \\
\hline
\end{tabular}

Tabela 6.10: Resultados top-25 de cobertura da EAT utilizando aprendizado transdutivo - Corpus Nano.

\begin{tabular}{|c|c|c|c|c|c|c|c|c|c|}
\hline Seleção de Caract. & Seleção de CTs & Alg. & $\mid \mathcal{O}^{L}$ termos $\mid$ & Rede & $\sigma / k$ & $\mu$ & $\mathrm{P}(\%)$ & $\mathrm{C}(\%)$ & $\operatorname{MF}(\%)$ \\
\hline CFS_RS & DF_PM_SN & LLGC & 40 & $K \mathrm{NN}$ & 57 & 0,9 & 13,17 & 87,02 & 22,88 \\
\hline $\mathrm{CFS}_{-}^{-} \mathrm{RS}$ & $\mathrm{DF}_{-}^{-} \mathrm{PM}_{-}^{-} \mathrm{SN}$ & GFHF & 50 & $K \mathrm{NN}$ & 57 & & 13,44 & 85,17 & 23,22 \\
\hline $\mathrm{CFS}_{-}^{-} \mathrm{RS}$ & $\mathrm{DF}_{-}^{-} \mathrm{PM}_{-}^{-} \mathrm{SN}$ & LLGC & 40 & $K \mathrm{NN}$ & 57 & 0,5 & 13,35 & 79,77 & 22,87 \\
\hline $\mathrm{CFS}^{-} \mathrm{RS}$ & $\mathrm{DF}^{-} \mathrm{PM}^{-} \mathrm{SN}$ & LLGC & 50 & $K \mathrm{NN}$ & 57 & 0,9 & 13,18 & 78,36 & 22,57 \\
\hline $\mathrm{CFS}_{-}^{-} \mathrm{RS}$ & $\mathrm{DF}_{-}^{-} \mathrm{PM}_{-}^{-} \mathrm{SN}$ & GFHF & 40 & $K \mathrm{NN}$ & 57 & & 13,40 & 78,32 & 22,88 \\
\hline $\mathrm{CFS}^{-} \mathrm{RS}$ & $\mathrm{DF}_{-}^{-} \mathrm{PM}_{-}^{-} \mathrm{SN}$ & LLGC & 50 & $K \mathrm{NN}$ & 57 & 0,5 & 13,41 & 78,32 & 22,91 \\
\hline Híbrido & $\mathrm{DF}_{-}^{-} \mathrm{PM}_{-}^{-} \mathrm{SN}$ & GFHF & 50 & Exp & 0,05 & & 22,27 & 77,74 & 34,62 \\
\hline CFS_BF & $\mathrm{DF}_{-}^{-} \mathrm{PM}_{-}^{-} \mathrm{SN}$ & LLGC & 50 & Exp & 0,35 & 0,1 & 26,41 & 77,72 & 39,42 \\
\hline Híbrido & $\mathrm{DF}^{-} \mathrm{PM}_{-}^{-} \mathrm{SN}$ & GFHF & 40 & Exp & 0,05 & & 23,03 & 77,38 & 35,50 \\
\hline $\mathrm{CFS} \quad \mathrm{BF}$ & $\mathrm{DF}^{-} \mathrm{PM}^{-} \mathrm{SN}$ & LLGC & 50 & Exp & 0,75 & 0,1 & 25,42 & 77,32 & 38,26 \\
\hline $\mathrm{CFS}^{-} \mathrm{RS}$ & $\mathrm{DF}^{-} \mathrm{PM}^{-} \mathrm{SN}$ & LLGC & 30 & $K \mathrm{NN}$ & 57 & 0,9 & 13,22 & 77,31 & 22,58 \\
\hline $\mathrm{CFS}_{-}^{-} \mathrm{BF}$ & $\mathrm{DF}_{-}^{-} \mathrm{PM}_{-}^{-} \mathrm{SN}$ & LLGC & 40 & Exp & 0,35 & 0,1 & 26,76 & 77,09 & 39,73 \\
\hline $\mathrm{CFS}^{-} \mathrm{RS}$ & $\mathrm{DF}^{-} \mathrm{PM}^{-} \mathrm{SN}$ & LLGC & 20 & $K \mathrm{NN}$ & 57 & 0,9 & 13,38 & 76,75 & 22,78 \\
\hline $\mathrm{CFS}_{-}^{-} \mathrm{BF}$ & $\mathrm{DF}_{-}^{-} \mathrm{PM}_{-}^{-} \mathrm{SN}$ & LLGC & 40 & Exp & 0,75 & 0,1 & 25,60 & 76,65 & 38,38 \\
\hline $\mathrm{CFS}^{-} \mathrm{BF}$ & $\mathrm{DF}_{-}^{-} \mathrm{PM}^{-} \mathrm{SN}$ & LLGC & 30 & Exp & 0,75 & 0,1 & 24,81 & 75,98 & 37,41 \\
\hline Todas Caract. & $\mathrm{DF}_{-}^{-} \mathrm{PM}_{-}^{-} \mathrm{SN}$ & LLGC & 40 & Exp & 0,35 & 0,1 & 26,63 & 75,81 & 39,42 \\
\hline Todas Caract. & $\mathrm{DF}_{-}^{-} \mathrm{PM}_{-}^{-} \mathrm{SN}$ & LLGC & 50 & Exp & 0,35 & 0,1 & 26,33 & 75,76 & 39,08 \\
\hline CBF_BF & $\mathrm{DF}^{-} \mathrm{PM}^{-} \mathrm{SN}$ & LLGC & 50 & Exp & 0,35 & 0,1 & 26,41 & 75,49 & 39,13 \\
\hline $\mathrm{CBF}^{-} \mathrm{RS}$ & $\mathrm{DF}^{-} \mathrm{PM}^{-} \mathrm{SN}$ & LLGC & 50 & Exp & 0,35 & 0,1 & 26,41 & 75,49 & 39,13 \\
\hline CBF Best First & $\mathrm{DF}^{-} \mathrm{PM}^{-} \mathrm{SN}$ & LLGC & 40 & Exp & 0,35 & 0,1 & 26,78 & 75,47 & 39,54 \\
\hline CBF_RS & $\mathrm{DF}^{-} \mathrm{PM}_{-}^{-} \mathrm{SN}$ & LLGC & 40 & Exp & 0,35 & 0,1 & 26,78 & 75,47 & 39,54 \\
\hline $\mathrm{CFS}_{-\mathrm{BF}}^{-}$ & $\mathrm{DF}^{-} \mathrm{PM}_{-}^{-} \mathrm{SN}$ & LLGC & 20 & Exp & 0,75 & 0,1 & 23,52 & 75,43 & 35,86 \\
\hline $\mathrm{CFS}^{-} \mathrm{BF}$ & $\mathrm{DF}^{-} \mathrm{PM}^{-} \mathrm{SN}$ & LLGC & 30 & Exp & 0,35 & 0,1 & 26,05 & 75,38 & 38,72 \\
\hline Híbrido & $\mathrm{DF}_{-}^{-} \mathrm{PM}_{-}^{-} \mathrm{SN}$ & GFHF & 30 & Exp & 0,05 & & 22,30 & 75,21 & 34,40 \\
\hline Todas Caract. & $\mathrm{DF}_{-}^{-} \mathrm{PM}_{-}^{-} \mathrm{SN}$ & LLGC & 30 & Exp & 0,35 & 0,1 & 25,68 & 74,42 & 38,18 \\
\hline
\end{tabular}

A seleção de candidatos a termos avalia a extração realizada considerando todos os candidatos sem nenhuma filtragem, os candidatos mantidos após a aplicação do Filtro 
Tabela 6.11: Resultados top-25 de medida F da EAT utilizando aprendizado transdutivo - Corpus Nano.

\begin{tabular}{|c|c|c|c|c|c|c|c|c|c|}
\hline Seleção de Caract. & Seleção de CTs & Alg. & $\mid \mathcal{O}^{L}$ termos $\mid$ & Rede & $\sigma / k$ & $\mu$ & $\mathbf{P}(\%)$ & $\mathbf{C}(\%)$ & MF(\%) \\
\hline CFS_BF & DF_PM_SN & LLGC & 40 & Exp & 0,35 & 0,1 & 26,76 & 77,09 & 39,73 \\
\hline $\mathrm{CBF}^{-} \mathrm{BF}$ & $\mathrm{DF}^{-} \mathrm{PM}^{-} \mathrm{SN}$ & LLGC & 40 & Exp & 0,35 & 0,1 & 26,78 & 75,47 & 39,54 \\
\hline $\mathrm{CBF}^{-} \mathrm{RS}$ & $\mathrm{DF}^{-} \mathrm{PM}^{-} \mathrm{SN}$ & LLGC & 40 & Exp & 0,35 & 0,1 & 26,78 & 75,47 & 39,54 \\
\hline $\mathrm{CFS}^{-} \mathrm{BF}$ & $\mathrm{DF}^{-} \mathrm{PM}^{-} \mathrm{SN}$ & LLGC & 40 & Exp & 0,35 & 0,5 & 26,99 & 73,18 & 39,44 \\
\hline $\mathrm{CFS}^{-} \mathrm{BF}$ & $\mathrm{DF}^{-} \mathrm{PM}^{-} \mathrm{SN}$ & LLGC & 50 & Exp & 0,35 & 0,1 & 26,41 & 77,72 & 39,42 \\
\hline Todas Caract. & $\mathrm{DF}^{-} \mathrm{PM}^{-} \mathrm{SN}$ & LLGC & 40 & Exp & 0,35 & 0,1 & 26,63 & 75,81 & 39,42 \\
\hline CFS BF & $\mathrm{DF}^{-} \mathrm{PM}^{-} \mathrm{SN}$ & LLGC & 50 & Exp & 0,35 & 0,5 & 26,86 & 74,01 & 39,41 \\
\hline $\mathrm{CBF}^{-} \mathrm{BF}$ & $\mathrm{DF}^{-} \mathrm{PM}^{-} \mathrm{SN}$ & LLGC & 50 & Exp & 0,35 & 0,1 & 26,41 & 75,49 & 39,13 \\
\hline $\mathrm{CBF}^{-} \mathrm{RS}$ & $\mathrm{DF}^{-} \mathrm{PM}^{-} \mathrm{SN}$ & LLGC & 50 & Exp & 0,35 & 0,1 & 26,41 & 75,49 & 39,13 \\
\hline $\mathrm{CBF}^{-} \mathrm{BF}$ & $\mathrm{DF}^{-} \mathrm{PM}^{-} \mathrm{SN}$ & LLGC & 50 & Exp & 0,35 & 0,5 & 27,12 & 70,10 & 39,10 \\
\hline $\mathrm{CBF}^{-} \mathrm{RS}$ & $\mathrm{DF}^{-} \mathrm{PM}^{-} \mathrm{SN}$ & LLGC & 50 & Exp & 0,35 & 0,5 & 27,12 & 70,10 & 39,10 \\
\hline Todas Caract. & $\mathrm{DF}^{-} \mathrm{PM}^{-} \mathrm{SN}$ & LLGC & 50 & Exp & 0,35 & 0,1 & 26,33 & 75,76 & 39,08 \\
\hline CFS BF & $\mathrm{DF}^{-} \mathrm{PM}^{-} \mathrm{SN}$ & LLGC & 40 & Exp & 0,75 & 0,5 & 26,91 & 70,76 & 38,99 \\
\hline Todas Caract. & $\mathrm{DF}^{-} \mathrm{PM}^{-} \mathrm{SN}$ & LLGC & 50 & Exp & 0,35 & 0,5 & 26,96 & 70,39 & 38,98 \\
\hline $\mathrm{CBF} \quad \mathrm{BF}$ & $\mathrm{DF}^{-} \mathrm{PM}^{-} \mathrm{SN}$ & LLGC & 40 & Exp & 0,35 & 0,5 & 27,00 & 69,86 & 38,95 \\
\hline $\mathrm{CBF}^{-} \mathrm{RS}$ & $\mathrm{DF}^{-} \mathrm{PM}^{-} \mathrm{SN}$ & LLGC & 40 & Exp & 0,35 & 0,5 & 27,00 & 69,86 & 38,95 \\
\hline $\mathrm{CFS}^{-} \mathrm{BF}$ & $\mathrm{DF}^{-} \mathrm{PM}^{-} \mathrm{SN}$ & LLGC & 30 & Exp & 0,35 & 0,1 & 26,05 & 75,38 & 38,72 \\
\hline Todas Caract. & $\mathrm{DF}^{-} \mathrm{PM}^{-} \mathrm{SN}$ & LLGC & 40 & Exp & 0,35 & 0,5 & 26,71 & 70,23 & 38,71 \\
\hline CFS BF & $\mathrm{DF}^{-} \mathrm{PM}^{-} \mathrm{SN}$ & LLGC & 50 & Exp & 0,75 & 0,5 & 26,40 & 72,21 & 38,66 \\
\hline $\mathrm{CFS}^{-} \mathrm{BF}$ & $\mathrm{DF}^{-} \mathrm{PM}^{-} \mathrm{SN}$ & GFHF & 40 & Exp & 0,75 & - & 26,69 & 69,82 & 38,62 \\
\hline $\mathrm{CBF}^{-} \mathrm{BF}$ & $\mathrm{DF}^{-} \mathrm{PM}^{-} \mathrm{SN}$ & LLGC & 50 & Exp & 0,75 & 0,5 & 27,45 & 64,73 & 38,55 \\
\hline $\mathrm{CBF}^{-} \mathrm{RS}$ & $\mathrm{DF}^{-} \mathrm{PM}^{-} \mathrm{SN}$ & LLGC & 50 & Exp & 0,75 & 0,5 & 27,45 & 64,73 & 38,55 \\
\hline $\mathrm{CBF}^{-} \mathrm{BF}$ & $\mathrm{DF}^{-} \mathrm{PM}^{-} \mathrm{SN}$ & LLGC & 50 & Exp & 0,75 & 0,1 & 26,07 & 73,59 & 38,51 \\
\hline $\mathrm{CBF}^{-} \mathrm{RS}$ & $\mathrm{DF}^{-} \mathrm{PM}^{-} \mathrm{SN}$ & LLGC & 50 & Exp & 0,75 & 0,1 & 26,07 & 73,59 & 38,51 \\
\hline $\mathrm{CFS}^{-} \mathrm{BF}$ & $\mathrm{DF}^{-} \mathrm{PM}^{-} \mathrm{SN}$ & LLGC & 40 & Exp & 0,75 & 0,1 & 25,60 & 76,65 & 38,38 \\
\hline
\end{tabular}

DF e os mantidos após o uso do Filtro $D F_{-} P M_{-} S N$. Para $76 \%$ dos top-25 resultados de precisão (Tabela 6.3) e $96 \%$ dos top-25 valores de medida F (Tabela 6.5) do corpus ECO, o Filtro DF foi mais indicado para ser utilizado. O uso desse filtro também ajudou a atingir todos os top-25 resultados mais altos de cobertura para o corpus EaD. Já as coberturas mais altas do corpus ECO foram alcançadas quando utilizado o Filtro DF_PM_SN. Este último também auxiliou na obtenção dos valores mais altos de precisão (88\% dos top-25) e todos os casos do top-25 resultados de medida F, ambos para o corpus EaD.

A seleção de características possibilita a avaliação dos níveis de conhecimento dos quais pertencem as características dos candidatos utilizadas para diferenciar termos de nãotermos. Os top-25 resultados de cobertura do corpus EaD foram alcançados utilizando somente características estatísticas, somente linguísticas ou todos os níveis juntos (Tabela 6.7). Para os demais resultados desse corpus e dos corpora ECO e Nano, a maioria dos top-25 resultados faz uso de características de diferentes níveis de conhecimento ao mesmo tempo. Esse fato enfatiza a importância de se utilizar diferentes tipos de características ao mesmo tempo.

Considerando a quantidade de candidatos rotulados utilizados para a classificação de termos, a maioria dos top-25 resultados do corpus ECO é atingida utilizando 20 ou 30 candidatos rotulados e do corpus Nano, utilizando 40 ou 50 candidatos rotulados. Para o corpus EaD, não foi encontrado um padrão de quantidade de candidatos rotulados para ser utilizado visando alcançar os melhores resultados. Para esse corpus, 20 ou 30 candidatos rotulados são necessários para atingir valores mais altos de medida $\mathrm{F}, 30,40$ ou 50 candidatos rotulados são necessários para bons valores de cobertura e 50 candidatos rotulados para atingir a precisão máxima alcançada. Entretanto, no caso da precisão, é interessante notar que se utilizar somente 1 candidato rotulado como termo e 1 candidato rotulado como não-termo é possível conseguir precisão boa (23,08\%, Tabela 6.6).

É importante ressaltar que erros cometidos pelo parser utilizado interfere diretamente na EAT. Por exemplo, na TLATE, alguns nomes próprios ${ }^{1}$, como "CNPq" e "Wilson", foram erroneamente extraídos como termos porque o parser o identificou como nomes comuns, mas deveria reconhecê-los como nomes próprios. Esse fato ressalta a importância de se realizar um pré-processamento dos textos de entrada de forma cuidadosa.

\footnotetext{
${ }^{1}$ Os exemplos de nomes próprios utilizados foram erroneamente extraídos como termos ao utilizar a matriz de candidatos Todas Caract. - Filtro $D F_{-} P M_{-} S N$ do corpus Nano com o algoritmo transdutivo LLGC com $\mu=0,9$ usando 50 candidatos rotulados e- rede Exp com $\sigma=0.5$.
} 


\subsubsection{Discussões sobre os Resultados da TLATE em Relação à ILATE e outros Trabalhos de Extração de Termos}

Os resultados alcançados pela abordagem TLATE foram comparados com os resultados obtidos utilizando diferentes formas de extração de termos, a saber:

1. "Baselines", que são as medidas $t f$ e $t f$ - $i d f$;

2. Extração tradicional de termos (referenciada como "Comparações extras" e detalhada na Subseção 4.1 do Capítulo 4, página 55);

3. Os métodos ExPorTer_linguístico e ExPorTer_híbrido (Zavaglia et al., 2007), que realizam extração de termos simples para o português do Brasil. Esses métodos são referenciados como "Estado da arte" e são descritos na Subseção 3.5.1 do Capítulo 3 , página 38 ; e

4. EAT realizada nesta pesquisa utilizando aprendizado indutivo (segunda avaliação experimental da ILATE, detalhada na Seção 5.4 do Capítulo 5, página 93).

Nas Tabelas 6.12, 6.13 e 6.14, é mostrada a comparação dos resultados mais altos obtidos com cada forma de extração de termos citada anteriormente. Nessas tabelas, a coluna "Descrição" corresponde à classificação de cada "Método" de extração utilizado para obtenção dos valores mais altos de precisão $(\mathrm{P}(\%))$, cobertura $(\mathrm{C}(\%))$ e medida $\mathrm{F}$ $(\mathrm{MF}(\%))$.

Para dar uma ideia geral do tempo de processamento da classificação dos termos, nas Tabelas 6.12, 6.13 e 6.14, são mostrados tempo (em segundos) utilizado pelo algoritmo para, no caso da ILATE, induzir um modelo de classificação e, no caso da TLATE, criar a rede de candidatos e todas matrizes utilizadas (Tempo de Modelagem - TM) e o tempo gasto para efetivamente realizar a classificação dos candidatos em termos e nãotermos (Tempo de Classificação - TC). Quando o tempo corresponder à zero $(0,00)$ na tabela significa que o algoritmo não utilizou nem um segundo completo para classificar os candidatos. É importante ressaltar que os experimentos desta pesquisa foram executados paralelamente em diferentes servidores com diferentes configurações de acordo com a disponibilidade dos recursos computacionais. Portanto, tais tempos servem para se ter uma ideia do quanto se gasta para classificar os termos desses domínios e não servem para comparar um algoritmo com outro. Observa-se que, em geral, os algoritmos indutivos gastam mais tempo induzindo o modelo de classificação do que os algoritmos transdutivos gastam para criar a rede de candidatos e todas matrizes necessárias. Entretanto, os algoritmos indutivos são bem mais rápidos para classificar os candidatos.

Para o corpus ECO, atingiu-se $100 \%$ de precisão com a TLATE e com a ILATE. Nesse caso, a vantagem de se utilizar a TLATE é o fato de necessitar de somente 10 candidatos rotulados como termos e 10 como não-termos, o que economiza o tempo de especialista do domínio para sua rotulação. Ao utilizar a TLATE, é possível alcançar cobertura de 100\%, bem como ao utilizar algumas das medidas da literatura para extração de termos ( freq_cg, weirdness, thd e nc-value). As medidas da literatura $t f$ e $t f$-idf também alcançam valores de cobertura similares, 99,67\%. A vantagem da TLATE em relação a essas medidas é que a TLATE é totalmente automática e com apenas 1 candidato rotulado como termo e 1 como não-termo já é possível atingir $100 \%$ de cobertura. O resultado mais alto de medida F foi 29,43\% utilizando os 400 primeiros candidatos a termos mais bem ranqueados pela medida $t v q$. Como citado no Capítulo 5 , página 73 , é interessante que a medida $t v q$ tenha alcançado a medida $F$ mais alta uma vez que ela foi utilizada para a tarefa de extração de termos pela primeira vez, segundo a pesquisa literária realizada. Destaca-se também 
Tabela 6.12: Comparação dos resultados mais altos obtidos com a TLATE vs. diferentes formas de extração de termos - Corpus ECO.

\begin{tabular}{|c|c|c|c|c|c|c|}
\hline Descrição & Método & $P(\%)$ & $C(\%)$ & $M F(\%)$ & $T M($ seg. $)$ & $T C($ seg. $)$ \\
\hline \multirow{3}{*}{ TLATE } & $\begin{array}{l}\mathrm{CFS}=\mathrm{RS}-\mathrm{DF}=\mathrm{PM}-\mathrm{SN}-\mathrm{GFHF}- \\
O^{L}=10-\mathrm{Rede}=\operatorname{Exp}(\sigma=0,05)\end{array}$ & 100,00 & 0,04 & 0,08 & 0,00 & $30.830,00$ \\
\hline & 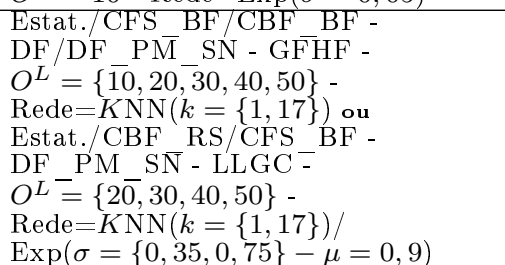 & 4,98 a 7,39 & 100,00 & 6,60 a 14,19 & 0,00 & 0,00 a 27,00 \\
\hline & $\begin{array}{l}\text { CBF RS - DF - LLGC - } O^{L}=40- \\
\text { Rede }=\operatorname{Exp}(\sigma=0,35-\mu=0,9)\end{array}$ & 17,74 & 41,17 & 24,80 & 0,00 & $37.766,00$ \\
\hline \multirow[t]{2}{*}{ ILATE } & $\begin{array}{l}\text { CFS BF /CFS RS/Híbrido - } \\
\text { DF/DF SN PM - SVM ou } \\
\text { CFS BF - Todos CTs - SVM }\end{array}$ & 100,00 & 0,33 a 1,67 & 0,66 a 3,28 & 20,24 a 8,35 & 0,01 \\
\hline & CFS BF/CFS RS - Todos CTs - NB & 20,18 & 38,00 & 26,36 & 0,00 & 0,00 \\
\hline \multirow{5}{*}{ Baselines } & tf-idf $\overline{(50)}$ & 50,00 & 8,33 & 14,29 & - & - \\
\hline & tf-idf $(300)$ & 26,00 & 26,00 & 26,00 & - & - \\
\hline & tf e tf-idf (9950) & 3,01 & 99,67 & 5,83 & - & - \\
\hline & $\mathrm{tf}(50)$ & 42,00 & 7,00 & 12,00 & - & - \\
\hline & $\operatorname{tf}(400)$ & 21,25 & 28,33 & 24,29 & - & - \\
\hline \multirow{2}{*}{ Estado da arte } & ExPorTer_linguístico & 2,74 & 89,18 & 5,32 & - & - \\
\hline & ExPorTer híbrido & 12,76 & 23,25 & 16,48 & - & - \\
\hline \multirow{4}{*}{$\begin{array}{l}\text { Comparações } \\
\text { extras }\end{array}$} & tc $(50)$ & 52,00 & 8,67 & 14,86 & - & - \\
\hline & $\begin{array}{l}\text { freq_cg, weirdness, } \\
\text { thd e nc-value ( } 8850 \text { a } 9950)\end{array}$ & 3,02 a 3,39 & 100,00 & 5,85 a 6,56 & - & $\begin{array}{l}- \\
-\end{array}$ \\
\hline & $\operatorname{tvq}(400)$ & 25,75 & 34,33 & 29,43 & - & - \\
\hline & Corpus inteiro (9950) & 3,02 & 100,00 & 5,85 & - & - \\
\hline
\end{tabular}

Tabela 6.13: Comparação dos resultados mais altos obtidos com a TLATE vs. diferentes formas de extração de termos - Corpus EaD.

\begin{tabular}{|c|c|c|c|c|c|c|}
\hline Descrição & Método & $P(\%)$ & $C(\%)$ & $M F(\%)$ & $T M($ seg. $)$ & $T C($ seg. $)$ \\
\hline \multirow{3}{*}{ TLATE } & $\begin{array}{l}\mathrm{CBF}{ }_{\mathrm{BF}}-\mathrm{DF} \mathrm{PM}_{-} \mathrm{SN}_{-} \\
\mathrm{LLG}-O^{L}=50- \\
\mathrm{Rede}=\operatorname{Exp}(\sigma=0,75-\mu=0,9)\end{array}$ & 100,00 & 0,18 & 0,35 & 0,00 & $56.400,00$ \\
\hline & $\begin{array}{l}\text { CBF_RS - DF - LLGC - } O^{L}=30- \\
\text { Rede }=K N N(k=57-\mu=0,9)\end{array}$ & 0,97 & 99,36 & 1,93 & 0,00 & 265,00 \\
\hline & $\begin{array}{l}\text { CBF BF - DF_PM_SN - LLGC - } \\
\text { LLGC }-O^{L}=30- \\
\text { Rede }=K N N(k=1 / 17 / 57-\mu=0,1)\end{array}$ & 11,59 & 17,14 & 13,83 & 0,00 & $55.593,00$ \\
\hline \multirow[t]{3}{*}{ ILATE } & $\begin{array}{l}\text { CBF BF/CBF RS/Todas Caract.- } \\
\text { DF - KNN ou CBF BF - } \\
\text { DF SN PM - KNN ou }\end{array}$ & & & & & \\
\hline & Estāt./Híbrido - Todos CTs - SVM & 100,00 & 0,89 a 3,57 & 1,77 a 6,90 & 0,00 a 8,68 & 0,0052 a 0,09 \\
\hline & Ling. - Todos CTs - NB & 3,99 & 28,57 & 7,00 & 0,01 & 0,00 \\
\hline \multirow{5}{*}{ Baselines } & $\mathrm{CBF}^{\prime}-\mathrm{BF}^{-}-\mathrm{DF}-\mathrm{JRIP}$ & 42,31 & 9,82 & 15,94 & 0,04 & 0,00 \\
\hline & $\frac{t f-i d f(50)}{t f-i d f(100)}$ & 22,00 & $\begin{array}{r}9,82 \\
13,39\end{array}$ & 13,58 & - & - \\
\hline & tf e tf-idf $(11100$ a 15000$)$ & 0,75 a 1,01 & 100,00 & $\begin{array}{r}14,15 \\
1,48 \text { a } 2,00\end{array}$ & - & $\frac{-}{-}$ \\
\hline & $\mathrm{tf}(50)$ & 18,00 & 8,04 & 11,11 & - & - \\
\hline & $\operatorname{tf}(150)$ & 10,67 & 14,29 & 12,21 & - & - \\
\hline \multirow{2}{*}{ Estado da arte } & ExPorTer_linguístico & 0,33 & 89,70 & 0,66 & - & - \\
\hline & ExPorTer & 0,07 & 17,64 & 0,15 & - & - \\
\hline \multirow[t]{3}{*}{$\begin{array}{l}\text { Comparações } \\
\text { extras }\end{array}$} & $\begin{array}{l}\text { rf, atf, df, tv, tvq, freq cg, } \\
\text { tc, c-value }(11100 \text { a } 15000)\end{array}$ & 0,75 a 1,01 & 100,00 & 1,48 a 2,00 & - & $\begin{array}{l}- \\
-\end{array}$ \\
\hline & tds e glossEx $(50)$ & 36,00 & 16,07 & 22,22 & - & - \\
\hline & Corpus inteiro (16000) & 0,70 & 100,00 & 1,39 & - & - \\
\hline
\end{tabular}

que a ILATE e a TLATE alcançaram resultados parecidos de medida F, sendo $26,36 \%$ e $24,80 \%$, respectivamente.

Para o corpus EaD, assim como para o corpus ECO, o uso da TLATE e da ILATE alcança $100 \%$ de precisão. A extração de termos realizada com TLATE atinge 99,36\% de cobertura para o corpus EaD, sendo superior ao estado da arte $(89,70 \%)$ e igual aos valores alcançados pelas medidas $t f, t f-i d f, r f$, atf, $d f, t v, t v q, f r e q \_c g, t c$ e c-value. A medida $\mathrm{F}$ mais alta $(22,22 \%)$ é atingida quando se utiliza $t d s$ ou glossEx, seguida da ILATE $(15,94 \%)$ e da TLATE $(13,83 \%)$.

Para o corpus Nano, o uso da ILATE alcança os valores mais altos de precisão $(81,25 \%)$ e de medida F $(41,21 \%)$. Ao utilizar a TLATE, pode-se atingir medida $\mathrm{F}(39,73 \%)$ parecida à da ILATE. O valor mais alto de cobertura $(94,10 \%)$ foi obtido pelas medidas 
Tabela 6.14: Comparação dos resultados mais altos obtidos com a TLATE vs. diferentes formas de extração de termos - Corpus Nano.

\begin{tabular}{|c|c|c|c|c|c|c|}
\hline Descrição & Método & $P(\%)$ & $C(\%)$ & $M F(\%)$ & $T M($ seg. $)$ & $T C($ seg. $)$ \\
\hline \multirow[t]{3}{*}{ TLATE } & $\begin{array}{l}\text { Híbrido - DF PM SN - GFHF - } O^{L}=1 \text { - } \\
\text { Rede }=K \mathrm{NN}(\bar{k}=17) \text { ou } \\
\text { Híbrido - DF PM SN - LLGC - } O^{L}=1- \\
\text { Rede }=K N N(\bar{k}=17-\mu=0,1 / 0,5 / 0,9)\end{array}$ & 42,11 & 0,13 & 0,26 & 0,00 & $77.678,00$ \\
\hline & $\begin{array}{l}\text { CFS_RS - DF_PM SN - LLGC - } \\
O^{L}=40-\text { Rede- }=K \mathrm{NN}(k=57-\mu=0,9)\end{array}$ & 13,17 & 87,02 & 22,88 & 0,00 & $7.653,00$ \\
\hline & $\begin{array}{l}\text { CFS_BF - DF_PM_SN - LLGC- } \\
O^{L}=40-\text { Rede-Exp }(\sigma=0,35-\mu=0,1)\end{array}$ & 26,76 & 77,09 & 39,73 & 0,00 & $51.694,00$ \\
\hline \multirow{3}{*}{ ILATE } & CFS BF/CFS RS - Todos CTs - SVM & 81,25 & 0,84 & 1,67 & 420,14 & 0,70 \\
\hline & CFS BF - Todos C'Ts - NB & 26,49 & 43,49 & 32,92 & 0,02 & 0,00 \\
\hline & CBF BF-DF SN PM - J48 & 60,50 & 31,25 & 41,21 & 0,24 & 0,00 \\
\hline \multirow{6}{*}{ Baselines } & tf-idf $\overline{(50)}$ & 58,00 & 1,88 & 3,64 & - & - \\
\hline & tf-idf $(3150)$ & 26,98 & 55,09 & 36,22 & - & - \\
\hline & tf-idf (14900 a 1500$)$ & 9,67 a 9,74 & 94,04 & 17,54 a 17,65 & - & - \\
\hline & $\mathrm{tf}(50)$ & 48,00 & 1,56 & 3,01 & - & - \\
\hline & $\operatorname{tf}(3200)$ & 26,38 & 54,70 & 35,59 & - & - \\
\hline & $\mathrm{tf}(14900$ a 15000$)$ & 9,68 a 9,74 & 94,10 & 17,55 a 17,66 & - & - \\
\hline \multirow{2}{*}{ Estado da arte } & ExPorTer_linguístico & 3,75 & 89,40 & 7,20 & - & - \\
\hline & ExPorTer_híbrido & 1,68 & 35,35 & 3,22 & - & - \\
\hline \multirow{3}{*}{$\begin{array}{l}\text { Comparações } \\
\text { extras }\end{array}$} & $\operatorname{tvq}(50)$ & 66,00 & 2,14 & 4,14 & - & - \\
\hline & rf $(14900$ a 15000$)$ & 9,68 a 9,74 & 94,10 & 17,55 a 17,66 & - & - \\
\hline & Corpus inteiro (41335) & 0,04 & 100,00 & 0,07 & - & - \\
\hline
\end{tabular}

$t f$ e $r f$, seguida da medida $t f$-idf (94,04\%), do método ExPorTer_linguístico (89,40\%) e da TLATE $(87,02 \%)$.

Exceto para a obtenção da cobertura a partir do corpus EaD, o uso do algoritmo LLGC geralmente obtém os resultados mais altos. Acredita-se que o LLGC é mais aconselhável para a extração de termos do que o GFHF devido a duas razões: (i) o LLGC não permite candidatos com os graus maiores dominem a propagação dos rótulos dos candidatos e (ii) o LLGC permite mudar a informação de classe dos candidatos rotulados durante o processo de classificação de termos.

\subsection{Considerações Finais}

Considerando a revisão literária realizada nesta pesquisa, tem-se como uma das contribuições desta tese a avaliação do aprendizado transdutivo para a extração automática de termos.

Ao analisar os resultados dos 3 corpora utilizados, o uso do aprendizado de máquina na EAT (ILATE ou TLATE) sempre alcança valores mais altos de precisão (os melhores resultados estão acima de $81,25 \%$ ) e alto valor de cobertura (os melhores resultados estão acima de 87,02\%) em relação a todos os métodos e medidas comparados. Exceto para o corpus EaD, o uso da TLATE e da ILATE consegue alcançar resultados de medida F superiores (ILATE para corpus Nano: 41,21\%) ou equivalentes (TLATE para o corpus ECO: 24,80\%) aos resultados mais altos obtidos. Assim, considera-se que as abordagens ILATE e TLATE são boas opções para se extrair termos uma vez que sua extração é feita de maneira totalmente automática, ao contrário da maioria das medidas encontradas na literatura.

Ao comparar os resultados da TLATE com da ILATE, deve-se ressaltar que a ILATE utilizou 10-fold cross validation, na qual $90 \%$ dos candidatos a termos do corpus foram utilizados para treinar o modelo de classificação e $10 \%$ foram usados para testar a classificação dos candidatos. Enquanto que para a TLATE foram realizadas 10 execuções do algoritmo transdutivo, nas quais utilizou, no pior caso, 50 termos e 50 não-termos $(1,49 \%$ do total de candidatos) considerando os 3358 candidatos do corpus ECO mantidos após a aplicação do Filtro $D F_{-} S N_{-} P M$. Dessa maneira, teoricamente a ILATE tende a obter resultados mais altos que a TLATE, uma vez que conhece previamente um número bem maior de candidatos. Mesmo assim, os resultados da TLATE são geralmente similares ou 
superiores aos da ILATE.

Na Tabela 6.15, são listadas as principais vantagens e desvantagens das abordagens ILATE e TLATE. Uma vantagem da ILATE é que, por adotar o aprendizado indutivo, não é necessário conhecer todos os candidatos a serem rotulados previamente, uma vez que nesse aprendizado um modelo de classificação é induzido, o que permite rotular novos candidatos não conhecidos como termos ou não-termos. Enquanto que a TLATE, por não induzir um modelo, necessita propagar os rótulos cada vez que novos candidatos são classificados. Entretanto, a desvantagem da ILATE é a necessidade de um número considerável de candidatos rotulados para que seja possível obter resultados satisfatórios, enquanto que a TLATE requer um número inferior de candidatos rotulados para realizar a classificação. A TLATE requer mais tempo computacional e memória para o seu processamento. Entretanto, quando é possível reduzir o número de candidatos a termos (p.ex., aplicando o Filtro $\left.D F_{-} S N_{-} P M\right)$, considera-se a TLATE uma abordagem mais vantajosa porque requer um pequeno número de candidatos rotulados para realizar a extração dos termos. Dessa maneira, o esforço maior realizado durante a extração de termos é no processamento computacional e não no trabalho humano para rotular grande quantidade de candidatos a termos.

Tabela 6.15: Vantagens e desvantagens das abordagens ILATE e TLATE.

\begin{tabular}{|c|c|}
\hline$I L A T E$ & $T L A T E$ \\
\hline $\begin{array}{l}\bigodot \text { Não necessita conhecer todos os candidatos a } \\
\text { serem rotulados previamente. }\end{array}$ & $\begin{array}{l}\odot \text { Necessita conhecer todos os candidatos a } \\
\text { serem rotulados previamente. }\end{array}$ \\
\hline $\begin{array}{l}\odot \text { Induz modelo de classificação, o que permite } \\
\text { rotular novos candidatos não conhecidos como termos } \\
\text { ou não-termos. }\end{array}$ & $\begin{array}{l}\odot \text { Não induz modelo de classificação, por isso } \\
\text { necessita propagar os rótulos cada vez que novos } \\
\text { candidatos são classificados. }\end{array}$ \\
\hline $\begin{array}{l}\odot \text { Requer menos tempo computacional e memória } \\
\text { para o seu processamento. }\end{array}$ & $\begin{array}{l}\bigodot \text { Requer mais tempo computacional e memória } \\
\text { para o seu processamento. }\end{array}$ \\
\hline $\begin{array}{l}\because \text { Requer um número considerável de candidatos } \\
\text { rotulados para que seja possível obter resultados } \\
\text { satisfatórios. }\end{array}$ & $\begin{array}{l}\because \text { Requer um número inferior de candidatos } \\
\text { rotulados para realizar a classificação. }\end{array}$ \\
\hline $\begin{array}{l}\Theta \text { Esforço maior realizado durante a extração } \\
\text { de termos está no trabalho humano para rotular um } \\
\text { número considerável de candidatos a termos. }\end{array}$ & $\begin{array}{l}\bigodot \text { Esforço maior realizado durante a extração de } \\
\text { termos está no processamento computacional e não } \\
\text { no trabalho humano. }\end{array}$ \\
\hline
\end{tabular}

Com as avaliações experimentais realizadas nesta tese, pode-se verificar que há configurações adotadas para a extração de termos baseada em aprendizado transdutivo (abordagem TLATE), o qual necessita de menos candidatos rotulados do que no aprendizado indutivo, com resultados satisfatórios. Há configurações da TLATE que alcançam valores (i) de cobertura superiores; outras configurações da TLATE atingem (ii) precisões geralmente superiores; e outras alcançam valores (iii) de medidas F sempre similares se comparados com os resultados da extração de termos utilizando aprendizado indutivo, o qual induz um modelo de classificação utilizando candidatos rotulados para classificar os não rotulados (ILATE).

Retoma-se a hipótese principal levantada nesta tese de que, com a junção de características pertencentes a diferentes níveis de conhecimento (linguístico, estatístico e híbrido), é possível melhorar os resultados de EAT. Essa hipótese foi validada tanto pela ILATE como pela TLATE uma vez que para a maioria dos top-25 resultados dos três corpora considerados faz-se uso de características de diferentes níveis de conhecimento ao mesmo tempo, sendo que isso enfatiza a importância de se utilizar diferentes tipos de características ao mesmo tempo. Os top-25 resultados de cobertura do corpus EaD foram alcançados utilizando somente características estatísticas, somente linguísticas ou todos os níveis juntos (Tabela 6.7), mostrando que mesmo para esse caso a junção de características atinge resultados tão bom quanto características pertencentes a um único nível de conhecimento. 
Finalmente, com as avaliações experimentais realizadas, verifica-se que a aplicação do aprendizado de máquina é vantajosa para a tarefa de extração de termos, uma vez que automatiza e possibilita o uso de diversas características dos candidatos a termos, alcançando, assim, resultados, em geral, mais altos ou similares em relação aos métodos e medidas encontrados na literatura (Tabelas 6.12, 6.13 e 6.14 do Capítulo 6, páginas 126 e 127). 



\section{Conclusões e Trabalhos Futuros}

extração dos termos é extremamente útil tanto sob a perspectiva linguística como computacional. Na perspectiva linguística, os termos são a base de aplicações como a construção de dicionários, taxonomias e ontologias de domínios específicos, e na perspectiva computacional, são a base de tarefas como recuperação e extração de informação e sumarização de domínios específicos. Os termos extraídos devem ser adequados para a tarefa na qual serão utilizados (por exemplo, classificação, agrupamento ou análise de sentimentos). O termo "Inteligência Artificial", do domínio da computação, seria um bom descritor para documentos do domínio, entretanto seria pouco relevante para classificação de subáreas desse domínio. Por essa razão, nesta tese, são apresentadas configurações de extração de termos diferentes que favorecem a maximização da medida de avaliação de precisão, cobertura ou medida F. Vale ressaltar que, quando a maximização da precisão é discutida, são também mostrados os valores de cobertura e medida F respectivos para essa precisão e assim, sucessivamente, para as outras duas medidas de avaliação. Dessa maneira, dependendo da tarefa na qual os termos serão utilizados, pode-se escolher a configuração de extração mais adequada.

No Capítulo 3, página 17, desta tese, foi apresentada uma revisão vasta da extração de termos na língua portuguesa do Brasil. Observou-se que, embora a extração de termos venha sendo bastante explorada nos últimos anos, ainda há problemas a serem investigados, como o elevado número de candidatos a termos presente na extração de termos e a escolha manual ou semiautomática dos candidatos que devem ser considerados termos durante a extração tradicional de termos.

Esses problemas serviram como principais motivações para a realização desta pesquisa, na qual foi proposto o MATE-ML, um método para extração automática de termos, descrito no Capítulo 4, página 55, que faz uso de um conjunto rico de características de candidatos a termos pertencentes a diferentes níveis de conhecimento. Esses níveis correspondem ao linguístico, estatístico e híbrido. O MATE-ML automatiza a tarefa de extração de termos por utilizar aprendizado de máquina.

Um problema específico da extração de termos simples na língua portuguesa do Brasil é que seus resultados ainda são inferiores se comparados com a extração de outras línguas como a inglesa e a espanhola. Outra motivação desta pesquisa foi avançar o estado da arte para esse tipo de extração. Para isso, o método para EAT proposto nesta tese foi aplicado a esse tipo de extração. Ressalta-se que o MATE-ML é facilmente adaptável para extrair termos simples em outras línguas ou termos complexos tanto em português com em outras línguas. Para isso, é necessário ter um parser na língua que se deseja 
extrair termos.

No Capítulo 5, é apresentada uma instanciação do método para EAT proposto nesta pesquisa, sendo que esse aplica a classificação indutiva para extrair termos de domínios específicos. No Capítulo 6, é apresentada uma outra instanciação do método para EAT proposto que utiliza a classificação transdutiva. As vantagens e desvantagens dessas duas instanciações são discutidas nessa seção.

Além disso, foram propostas estratégias de extração automática de termos que reduzem o elevado número de candidatos a termos presente na extração pela adoção de filtros. Os experimentos relacionados a essa redução de candidatos foram apresentados nos Capítulos 5 e 6.

As hipóteses que sustentam o trabalho apresentado nesta tese, os problemas da extração de termos abordados aqui e as principais contribuições obtidas são apresentados na Seção 7.1. As contribuições que já foram publicadas ou aceitas para publicação são listadas na Seção 7.2. Finalmente, as limitações e sugestões de trabalhos futuros são discutidas na Seção 7.3.

\subsection{Contribuições}

Os dois grandes problemas da extração de termos abordados nesta pesquisa foram:

1. A escolha manual ou semiautomática dos candidatos considerados termos durante a extração tradicional de termos: normalmente os extratores de termos selecionam candidatos a termos com base em algum conhecimento linguístico para então aplicar a esses candidatos medidas ou combinação de medidas (e/ou heurísticas) para criar um ranking com esses candidatos (Pazienza et al., 2005). Quanto mais ao topo desse ranking os candidatos estão, maior a chance de que eles sejam termos. A escolha manual ou semiautomática dos candidatos do ranking que devem ser considerados termos é um problema porque necessita da presença de um especialista do domínio e/ou terminólogo, demandando mais tempo para se extrair os termos.

Para demonstrar empiricamente como é difícil escolher os candidatos nesse ranking, nesta tese, foi apresentada uma comparação de medidas, métodos e formas de obtenção de conhecimento encontrados na literatura que podem ser utilizados para a extração de termos e que utilizam ranking. Diante desse problema da extração tradicional de termos, esse experimento foi motivado por duas questões:

- "Como saber quais candidatos do ranking devem ser considerados como termos?". Levando em conta os três corpora utilizados, ao analisar os resultados da extração de termos obtidos usando diferentes limiares para o ranking de candidatos a termos, conclui-se que considerando os 50 primeiros candidatos mais bem ranqueados por alguma das medidas estatísticas e híbridas utilizadas é possível atingir o máximo de $66 \%$ de precisão (sendo que nesse caso a cobertura correspondente foi de 2,14\%). Entretanto, não há um limiar exato a ser adotado para se alcançar bons valores de cobertura e medida F.

- "Qual é a melhor medida, método ou forma de obtenção de conhecimento para criar um ranking de candidatos a termos?" Considerando os três corpora utilizados, não há uma única medida que seja melhor para todos os corpora. No entanto, as medidas estatísticas e híbridas são mais aconselháveis quando o objetivo é alcançar melhores valores de precisão e medida F, 
exceto as medidas estatísticas com_gram e ridf e a medida híbrida freq_cg, que para todos os corpora atingem resultados piores que as demais medidas. Assim, baseado nos resultados dos experimentos apresentados nesta tese, sugere-se utilizar as características puramente linguísticas juntamente com características de outros níveis de conhecimento, uma vez que somente suas coberturas são boas.

Com esse experimento, foi possível ressaltar o problema da extração tradicional de termos, que é escolher manual ou semiautomaticamente quais candidatos ranking devem ser considerados como termos. Com isso, tal experimento também serviu como uma das grandes motivações para a proposta do MATE-ML, um método para extração automática de termos. Esse método aplica técnicas da área de aprendizado de máquina, o que automatiza a tarefa de extração. Ressalta-se que esse experimento foi descrito na Seção 4.1 do Capítulo 4, página 55.

2. O elevado número de candidatos a termos: gera complexidade em tempo e recursos computacionais para lidar com um número elevado de candidatos durante a realização da extração automática de termos.

MATE-ML sugeriu o uso de filtros visando reduzir o número de candidatos a termos considerados na tarefa de EAT. Um dos filtros utilizou a conhecida medida estatística $d f$ - frequência do documento (Filtro $D F$ ) e o outro utilizou a combinação da $d f$ com a identificação de sintagma e classe gramatical pré-estabelecida (Filtro $\left.D F_{-} S N_{-} P M\right)$ ao mesmo tempo. Dessa maneira, conseguiu-se reduzir o elevado número de candidatos a termos presente na extração de termos. Por exemplo, para os três corpora utilizados, o uso do Filtro $D F_{-} S N_{-} P M$ reduziu mais de $63 \%$ da quantidade de candidatos a termos em relação ao número de todos os candidatos inicialmente obtidos (Figura 5.15 do Capítulo 5, página 97). Ressalta-se que tal redução de candidatos, em geral, conseguiu manter a representatividade do corpus. Por exemplo, para o corpus Nano, o valor mais alto de medida F foi 41,1\% obtido com o uso do Filtro $D F_{-} S N_{-} P M$ (Tabela 5.8 do Capítulo 5, página 109). Entretanto, é necessário reduzir mais a quantidade de candidatos sem remover os termos do domínio em questão para, então, possivelmente conseguir resultados da EAT ainda melhores.

Ao diminuir a quantidade de candidatos a termos a ser utilizada para a EAT, possivelmente, a lista de termos extraídos pode ser menor. Em aplicações reais, nas quais não se têm listas de termos de referências para avaliar os resultados dos extratores, a diminuição da lista de (candidatos a) termos extraídos possivelmente poderia amenizar o esforço humano empregado para validar tais termos. Dessa maneira, considerando que o método proposto para EAT, o MATE-ML, extraia bons candidatos a termos, esse poderia (i) facilitar a validação dos candidatos extraídos feita por especialistas do domínio e (ii) melhorar os resultados de tarefas que utilizam os candidatos extraídos, por exemplo, organização e recuperação de informação e classificação de textos.

Baseado na motivação por solucionar ou minimizar esses problemas, as principais contribuições obtidas com o desenvolvimento da pesquisa descrita nesta tese foram:

1. Revisão literária vasta da extração de termos para o português do Brasil que inclui também uma organização e um mapeamento dos trabalhos na língua portuguesa, bem como uma síntese de todos os trabalhos encontrados. Essa revisão até então não 
existia na literatura, sendo essa apresentada no Capítulo 3 e publicada em Conrado et al. (2014).

2. Proposta de um método para extração automática e híbrida de termos, o MATE-ML, que foi descrito no Capítulo 4 e publicado em Conrado et al. (2013c). Adicionalmente, uma outra contribuição foi a instanciação do MATE-ML em duas abordagens: (i) abordagem para extração híbrida e automática de termos utilizando aprendizado indutivo - IL ATE e (ii) abordagem para extração híbrida e automática de termos utilizando aprendizado transdutivo - TLATE. As principais novidades consideradas aqui é a aplicação do aprendizado transdutivo para a EAT (utilizado na abordagem TLATE) e a aplicação ao mesmo tempo de um conjunto rico de características de candidatos pertencentes a diferentes níveis de conhecimento - linguístico, estatístico e híbrido (utilizado nas abordagens ILATE e TLATE), uma vez que essas duas aplicações não foram encontradas na literatura. A abordagem ILATE, juntamente com os experimentos que a utilizaram, foi apresentada no Capítulo 5 e publicada em Conrado et al. (2013b). Já a abordagem TLATE e seus experimentos foram descritos no Capítulo 6, página 113, sendo que os experimentos utilizando o corpus ECO foram publicados em Conrado et al. (2013a).

3. Eficácia da EAT ao utilizar as abordagens propostas (ILATE e TLATE). Os resultados obtidos por tais abordagens foram comparados (i) com 21 formas de extração tradicional de termos encontradas na literatura variando limiares de corte do ranking dos candidatos, (ii) com 2 métodos considerados como o estado da arte da extração de termos simples do português do Brasil (ExPorTer_linguístico e ExPorTer_híbrido) e (ii) comparados entre si. O uso da ILATE e TLATE alcança geralmente resultados mais altos de precisão (acima de 81,25\%) e alto resultados de cobertura (acima de 87,02\%) em relação a todos os métodos e medidas comparados. Os resultados de precisão e medida F da ILATE foram superiores ou similares aos valores atingidos pelas 21 formas de extração tradicional de termos e foram superiores aos valores dos 2 métodos estado da arte. Os resultados de cobertura obtidos a partir do uso da TLATE são sempre superiores aos da ILATE. Os resultados obtidos pelas abordagens ILATE e TLATE foram apresentados, respectivamente, nos Capítulos 5 e 6 .

4. Avaliação de quatro medidas para a EAT que foram originalmente propostas para outras tarefas. As medidas $t v q$, $t v$ e $t c$ foram originalmente propostas para a tarefa de seleção de características e a medida comGram foi originalmente utilizada para a tarefa de reconhecimento de entidades nomeadas. Nesta tese, essas quatro medidas foram avaliadas na: (i) extração tradicional de termos (detalhada na Seção 4.1 do Capítulo 4), (ii) ILATE (descrita no Capítulo 5 e publicada em Conrado et al. (2013b)) e (iii) TLATE (apresentada no Capítulo 6 e publicada em Conrado et al. (2013a)). As características $t v q$, tv, tc e comGram foram indicadas como relevantes para a classificação de candidatos em termos e não-termos por, respectivamente, $88,89 \%, 69,44 \%, 55,56 \%$ e $33,33 \%$ dos casos de seleção de características que utiliza aprendizado de máquina e que foi realizada considerando a primeira avaliação experimental da ILATE e por $86 \%, 58 \%, 67 \%$ e $31 \%$ dos casos considerando tanto a segunda avaliação experimental da ILATE como a avaliação experimental da TLATE.

5. Proposta de quatro novas medidas para a EAT, sendo elas: $n_{-} s u b s t ., n_{-} a d j$., $n \_$po e $n_{-}$verbo. Tais características foram eleitas como relevantes, respectivamente, 
por $100 \%, 88,89 \%, 77,22 \%$ e $50 \%$ dos casos de seleção de características que utiliza aprendizado de máquina e que foi realizada considerando a primeira avaliação experimental da ILATE (Seção 5.1 do Capítulo 5, página 73) e por 92\%, 75\%, 67\% e $33 \%$ dos casos considerando tanto a segunda avaliação experimental da ILATE (Seção 5.4, página 93) como a avaliação experimental da TLATE (Seção 6.1 do Capítulo 6, página 113). Parte dos experimentos que utilizam essas características foram publicados em Conrado et al. (2013a) e Conrado et al. (2013b).

6. Duas avaliações experimentais utilizando a ILATE. É recomendado seguir as decisões tomadas na segunda avaliação experimental da ILATE para se alcançar, em geral, resultados mais altos de precisão e medida F. As decisões tomadas pela primeira avaliação experimental da ILATE são recomendadas quando o foco é obter cobertura mais alta do que precisão ou medida F. Essa comparação das duas avaliações experimentais foi detalhada na Seção 5.4 do Capítulo 5, página 93.

Com essas contribuições, foi possível validar as seguintes hipóteses apresentadas nesta pesquisa:

1. Com a junção de características pertencentes a diferentes níveis de conhecimento (linguístico, estatístico e híbrido), é possível melhorar os resultados de EAT. Essa hipótese foi validada em relação à precisão e medida $\mathrm{F}$ da extração de termos simples do português do Brasil, uma vez que os valores mais altos da ILATE e TLATE foram alcançados quando se utilizaram ao mesmo tempo características linguísticas, estatísticas e híbridas. 69,44\% dos subconjuntos de características escolhidos pelos métodos de seleção de características que utilizam aprendizado de máquina elegeram características que possuem conhecimento linguístico, estatístico e híbrido ao mesmo tempo (Subseção 5.2.3 do Capítulo 5, página 79 ).

2. Reduzir o elevado número de candidatos a termos presente na extração de termos mantendo a representatividade do domínio em questão melhorará os resultados da extração. Essa hipótese foi validada porque os melhores valores de cobertura (acima de $82 \%$ ) para os três corpora de teste foram alcançados quando o número de candidatos a termos foi reduzido (ver resultados de cobertura da ILATE e da TLATE nas Tabelas 6.12, 6.13 e 6.14 do Capítulo 6, páginas 126 e 127).

3. A automatização da escolha de quais candidatos devem ser considerados como termos durante o processo de extração de termos não afetará negativamente os resultados da extração e a aplicação do aprendizado de máquina na extração automática de termos obterá resultados melhores do que a extração tradicional de termos. Essas duas hipóteses foram validadas porque, ao analisar os resultados dos 3 corpora utilizados, a automatização da forma de escolha dos candidatos (ou seja, o uso do aprendizado de máquina na EAT) alcança, em geral, resultados mais altos ou similares em relação aos métodos e medidas encontrados na literatura (Tabelas 6.12, 6.13 e 6.14 do Capítulo 6, páginas 126 e 127).

\subsection{Lista de Publicações}

A relevância de algumas das contribuições obtidas no decorrer do doutorado podem ser apreciadas em artigos publicados em revistas da área de pesquisa. Esses artigos são listados a seguir. 
1. Conrado, M. S., Di Felippo, A., Pardo, T. A. S. e Rezende, S. O. (2014). A Survey of the Automatic Term Extraction for Brazilian Portuguese. In Journal of the Brazilian Computer Society (JBCS), vol. 20, no. 1, p. 12, 2014.

2. Koza, W. A.; Solana, Z.; Conrado, M. S.; Rezende, S. O.; Pardo, T. A. S. (2011). Díaz-Labrador, J.; Abaitua, J.; Extracción terminológica en el dominio médico a partir del reconocimiento de sintagmas nominales. In Revista de Lingüística Informática, Modelización e Ingeniería Lingüística (Revista Infosur), Rosario, Argentina, p. $27-40$.

\section{Adicionalmente, foram publicados os seguintes artigos em conferências da área:}

1. Conrado, M. S., Pardo, T. A. S. e Rezende, S. O. (2013). A machine learning approach to automatic term extraction using a rich feature set. In Proceedings of the Conference of the North American Chapter of the Association for Computational Linguistics: Human Language Technologies (NAACL-HLT) - Student ResearchWorkshop (SRW), Atlanta, Georgia, p. 16-23. Association for Computational Linguistics.

2. Conrado, M. S., Pardo, T. A. S. e Rezende, S. O. (2013). Exploration of a rich feature set for automatic term extraction. In F. Castro, A. Gelbukh e M. González (Eds.), Advances in Artificial Intelligence and its Applications (MICAI), Volume 8265 of Lecture Notes in Computer Science, p. 342-354. Springer Berlin Heidelberg.

3. Conrado, M. S., Rossi, R. G., Pardo, T. A. S. e Rezende, S. O. (2013). Applying transductive learning for automatic term extraction: The case of the ecology domain. In Proceedings of the IEEE Second International Conference on Informatics and Applications (ICIA), p. 264-269.

4. Conrado, M. S., Gutiérrez, V. A. L. e Rezende, S. O. (2012). Evaluation of normalization techniques in text classification for portuguese. In B. Murgante, O. Gervasi, S. Misra, N. Nedjah, A. M. A. C. Rocha, D. Taniar, e B. O. Apduhan (Eds.), 12th International Conference on Computational Science and Applications (ICCSA), Lecture Notes in Computer Science, Salvador, BA, Brasil, p. 618-630. Springer.

5. Conrado, M. S., Koza, W. A., Díaz-Labrador, J., Abaitua, J., Rezende, S. O., Pardo, T. A. S. e Solana, Z. (2011). Extracting multiword expressions using enumerations of noun phrases in specialized domains: First experiments. In 15th Portuguese Conference on Artificial Intelligence (EPIA) - Text Mining and Applications (TeMA), Lisboa, Portugal, p. 775-789. L. Antunes, H. S. Pinto, R. Prada, P. Trigo.

6. Conrado, M. S.; Koza, W. A.; Díaz-Labrador, J.; Abaitua, J.; Rezende, S. O.; Pardo, T. A. S.; Solana, Z. (2011). Identificación de términos a partir de enumeraciones sintagmáticas nominales: Una aplicación al dominio médico. In: 40 Jornadas Argentinas de Informática (JAAIO) - Congreso Argentino de Informática y Salud (CAIS), Córdoba, Argentina: Álvaro Ruiz de Mendarozqueta, Marcelo Martín Marciszack e Mario A. Groppov, p. 57-65.

7. Conrado, M. S., Moura, M. F. e Rezende, S. O. (2009). Facilitando a avaliação de taxonomias de tópicos automaticamente geradas no domínio do agronegócio. In Universidade de Viçosa e Associação de TI de Viçosa (Ed.), $7^{\circ}$ Congresso Brasileiro de Agroinformática (SBIAgro), Viçosa-MG, Viçosa, MG, Brasil. 
8. Conrado, M. S., Marcacini, R. M., Moura, M. F. e Rezende, S. O. (2009). O efeito do uso de diferentes formas de geração de termos na compreensibilidade e representatividade dos termos em coleções textuais na Língua Portuguesa. In Proceedings of II Web and Text Intelligence (WTI) - Seventh Brazilian Symposium in Information and Human Language Technology (STIL), São Carlos, SP, p. 1-10.

\section{Outros tipos de publicações obtidas foram:}

1. Conrado, M. S.; Rezende, S. O.; Pardo, T. A. S.; Walker, M. (2012). Hybrid Term Extraction Applied to Text Mining (Pôster). Research Review Day, Santa Cruz, Califórnia, EUA.

2. Conrado, M. S.; Koza, W. A.; Díaz-Labrador, J.; Abaitua, J.; Rezende, S. O.; Pardo, T. A. S.; Solana, Z. (2011). Experiments on Term Extraction Using Noun Phrase Subclassifications (Resumo e pôster). In: Recent Advances in Natural Language Processing (RANLP), 2011, Hissar. Recent Advances in Natural Language Processing (RANLP). Shoumen: Galia Angelova, Kalina Bontcheva, Ruslan Mitkov, Nikolai Nikolov, p. 746-751.

3. Conrado, M. S., Moura, M. F. e Rezende, S. O. (2010). TaXEm: a tool for aiding the evaluation of domain topic (Resumo e demonstração de ferramenta). In 9th International Conference on Computational Processing of the Portuguese Language (PROPOR), Porto Alegre, RS. Pontifícia Universidade do Rio Grande do Sul (PUCRS), p. 1-2.

4. Moura, M. F.; Nogueira, B. M.; Conrado, M. S.; Santos, F. F.; Rezende, S. O. (2010). Um modelo para a seleção de n-gramas significativos e não redundantes em tarefas de mineração de textos. Campinas: Embrapa Informática Agropecuária (Boletim de pesquisa e desenvolvimento).

As pesquisas publicadas que foram realizadas em colaboração com outros pesquisadores são:

1. Domingues, M., Cherman, E., Nogueira, B., Conrado, S. M., Rossi, R., de Padua, R., Marcacini, R., Souza, V., Batista, G. e Rezende, S. (2013). A comparative study of algorithms for recommending given names. In Proceedings of the IEEE Second International Conference on Informatics and Applications (ICIA), p. 66-71.

2. Padua, R., Santos, F. F., Conrado, M. S., Carvalho, V. O. e Rezende, S. O. (2013). Subjective evaluation of labeling methods for association rule clustering. In F. Castro, A. Gelbukh, e M. González (Eds.), Advances in Artificial Intelligence and its Applications (MICAI), Volume 8266 of Lecture Notes in Computer Science, p. 289-300. Springer Berlin Heidelberg.

Além disso, dois trabalhos estão sendo revisados pelos autores para serem submetidos a revistas da área. O primeiro trabalho abrange as principais contribuições obtidas com a tese. O segundo trabalho, realizado com o grupo de pesquisa do qual a aluna de doutorado faz parte, contempla a extração de termos como uma das etapas para se gerar taxonomias de tópicos. Os trabalhos são:

1. Conrado, M. S.; Rossi, R. G.; Pardo, T. A. S.; Rezende, S. O. (2014). Extracting Simple Terms Using Inductive and Transductive Learning. A ser submetido ao International Journal of Information Processing $\&$ Management, p. 1-30. 
2. Rezende, S. O.; Conrado, M. S.; Nogueira, B. M.; Rossi, R. G.; Santos, F. F.; Marcacini, R. M.; Nogueira, T. M.; Albuquerque, D.; Moura, M.f. (2014). FATHER: a Framework for Automatic Generating Topic Hierarchies. A ser submetido ao Journal of ACM Transactions in Information Systems, p. 1-24.

\subsection{Limitações e Trabalhos Futuros}

A seguir, apresentam-se ideias de trabalhos futuros visando minimizar algumas limitações da pesquisa desenvolvida neste doutorado. A primeira limitação identificada é em relação à quantidade de candidatos a termos utilizada durante a extração automática de termos tanto da ILATE como da TLATE. Nesta pesquisa, durante a realização da extração automática de termos, a quantidade de candidatos foi reduzida, entretanto, seria útil diminuir ainda mais mas mantendo a representatividade do domínio em questão visando avaliar se a classificação dos candidatos melhora. Além disso, considerando que há um grande desbalanceamento na distribuição das classes, uma vez que há muito mais não-termos do que termos, como trabalho futuro, pretende-se avaliar métodos de seleção automática de exemplos (candidatos). Também se pretende aplicar algoritmos de classificação que criam os modelos de aprendizado visando induzir apenas a partir de dados textuais de uma única classe, mesmo que o objetivo final seja distinguir candidatos da classe termo daqueles que pertencem à classe não-termo (em inglês, esses algoritmos são conhecidos como One-class classification). Dessa maneira, espera-se melhorar ainda mais os resultados da tarefa de classificação dos candidatos.

A segunda limitação diz respeito à abordagem ILATE. Em realidade, tal limitação é herdada da tarefa de classificação que utiliza aprendizado indutivo, que é a necessidade de se ter um grande número de candidatos rotulados como termos e não-termos para a construção de um modelo de classificação para, então, classificar candidatos não conhecidos. Sugere-se, então, duas possíveis soluções para esse problema. A primeira solução, já avaliada nesta pesquisa, é utilizar a abordagem TLATE ao invés da ILATE, uma vez que TLATE utiliza aprendizado transdutivo, que requer um pequeno número de candidatos rotulados para classificar outros candidatos como termos e não-termos. Ainda, como trabalho futuro, pretende-se avaliar a TLATE utilizando candidatos rotulados pertencentes a outros domínios diferentes do qual se almeja extrair termos. A segunda solução, considerada também como trabalho futuro, é adaptar a ILATE para que o algoritmo de classificação seja treinado utilizando candidatos rotulados pertencentes a outros domínios para, então, utilizar o modelo de classificação gerado para predizer se os candidatos do domínio em questão são termos ou não-termos.

A abordagem TLATE classifica os candidatos que são previamente conhecidos mas não são rotulados. Dessa maneira, a terceira limitação corresponde aos casos que necessitam classificar candidatos não conhecidos, uma vez que para isso seria necessário realizar novamente todo o processo de propagação das classes, ao contrário da ILATE, que já tem um modelo de classificação que pode ser utilizado para isso. Considerando esse fato, como trabalho futuro, pretende-se testar a eficácia da abordagem para classificação de Delalleau et al. (2005) para predizer a classe de candidatos não conhecidos utilizando a TLATE.

Dentre os quatro níveis linguísticos de conhecimento - morfológico, sintático, semântico e pragmático/discursivo, descritos na Seção 3.2 do Capítulo 3, página 21 - para a extração de termos utilizando o método MATE-ML, é utilizado conhecimento linguístico do nível da sintaxe, além do estatístico e híbrido. Pode-se, então, considerar como a quarta limitação dessa pesquisa o não uso dos conhecimentos morfológico, semântico e pragmático. Assim, como trabalho futuro, pretende-se avaliar a ILATE e a TLATE agregando-lhes ca- 
racterísticas dos candidatos a termos pertencentes aos níveis morfológico e semântico. Até o momento, não está claro como obter conhecimento do nível pragmático para a extração de termos. Em relação ao nível morfológico, é possível auxiliar a extração de termos, por exemplo, com a identificação de morfemas comuns ao domínio no qual se pretende realizar a extração. Em relação ao nível semântico, pode-se auxiliar a extração de termos por desambiguar lexicalmente o sentido do candidato a termo no contexto, identificando tanto seu significado sentencial como textual.

A quinta limitação diz respeito à avaliação do método MATE-ML, uma vez que essa foi realizada para a extração de termos simples da língua portuguesa do Brasil. Assim, como trabalho futuro, pretende-se avaliar o método proposto para extração de termos simples em outras línguas e para a extração de termos complexos tanto em português como em outras línguas. É possível também expandir as características dos candidatos a termos considerando também medidas aplicáveis a termos complexos, como logaritmo da razão de máxima verossimilhança, e padrões linguísticos de termos complexos, como substantivo+adjetivo e substantivo+preposição+substantivo.

Finalmente, como trabalho futuro, pretende-se também adicionar ao método MATEML conhecimento de mundo por meio do uso da Wikipédia. Pretende-se também utilizar uma taxonomia construída a partir do corpus de entrada para realimentar as características sobre os candidatos utilizadas na extração de termos. Especificamente, pretende-se obter da taxonomia mais características dos candidatos, como em qual nível da hierarquia os candidatos se encontram, se eles pertencem a nó folha da hierarquia, quantos nós da hierarquia existem abaixo desses candidatos, etc. 



\section{Referências Bibliográficas}

ISO 1087: Terminologie - Vocabulaire. ISO, Norme Internationale ISO 1087, Geneva, Switzerland, 1990. Citado nas páginas 1, 4, 17, e 19.

AgGarwal, C.; Zhai, C. Mining text data. Springer, 2012. Citado na página 11.

Aggarwal, C. C. Mining text streams. In: Aggarwal, C.; Zhai, C., eds. Mining Text Data, 1 ed, Capítulo 9, Springer, p. 297-322, 2012a. Citado na página 15.

Aggarwal, C. C. A survey of text clustering algorithms. In: Aggarwal, C.; Zhai, C., eds. Mining Text Data, 1 ed, Capítulo 4, Springer, p. 77-128, 2012b. Citado na página 11.

Agrawal, R.; Imielinski, T.; Swami, A. N. Mining association rules between sets of items in large databases. In: Proceedings of the Association for Computing Machinery's Special Interest Group on Management of Data (SIGMOD), 1993, p. 207-216. Citado na página 11.

AhA, D. W.; KiBler, D.; AlBert, M. K. Instance-based learning algorithms. Journal of Machine Learning, v. 6, n. 1, p. 37-66, 1991. Citado na página 84.

Ahmad, K.; Gillam, L.; Tostevin, L. University of surrey participation in TREC8: Weirdness indexing for logical document extrapolation and retrieval (WILDER). In: Proceedings of the Text REtrieval Conference (TREC), 1999, p. 1-8. Citado nas páginas 32,58 , e 96 .

Almeida, G. M. B.; Aluísio, S. M.; Teline, M. F. Extração manual e automática de terminologia: comparando abordagens e critérios. Workshop em Tecnologia da Informação e da Linguagem Humana (TIL) - Sixteenth Brazilian Symposium on Computer Graphics and Image Processing (SIBGRAP), v. 1, p. 1-12, 2003. Citado nas páginas 37 e 42 .

Almeida, G. M. B.; Kamikawachi, D. S. L.; Manfrim, A. M. P.; Souza, I. P.; Izumida, F. H.; Di Felippo, A.; Zauberas, R. T.; Melchiades, F. G.; BosCHI, A. O. Glossário de revestimento cerâmico. In: Humanitas/FACUldade DE Filosofia, Letras e Ciências Humanas (FFLCH) - USP, ed. Cadernos de Terminologia, v. 4, 1 ed, São Paulo, SP: Alves, I. M. (Org.), p. 03-56, 2011. Citado nas páginas 18 e 19.

Almeida, G. M. B.; VAle, O. A. Do texto ao termo: interação entre terminologia, morfologia e linguística de corpus na extração semi-automática de termos. In: 
Isquerdo, A. N.; Finatto, M. J. B., eds. As Ciências do Léxico: Lexicologia, Lexicografia e Terminologia, v. IV, 1 ed, Campo Grande, MS: UFMS, p. 483-499, 2008. Citado nas páginas 18, 19, 27, 33, 37, 42, 43, e 78.

Aluísio, S. M. Desenvolvimento de uma estrutura conceitual (ontologia) para a área de nanociência e nanotecnologia. Relatório Técnico 276, Instituto de Ciências Matemáticas e de Computação (ICMC) - Universidade de São Paulo (USP), São Carlos, SP, 2005.

Disponível em www.icmc.usp.br/〜biblio/BIBLIOTECA/rel_tec/RT_276.pdf(21/ 03/2014) Citado nas páginas 37 e 44.

Andrews, N. O.; Fox, E. A. Recent developments in document clustering. Relatório Técnico 07-5, Department of Computer Science, Virginia Tech - Blacksburg - VA, 2007.

Disponível em http://eprints.cs.vt.edu/archive/00001000/01/docclust. $\operatorname{pdf}(21 / 03 / 2014)$ Citado na página 14.

Arampatzis, A.; Weide, T.; Bommel, P.; Koster, C. H. A. Linguistically motivated information retrieval. Relatório Técnico CSI-R9918, Faculty of Mathematics and Computing Science, University of Nijmegen, Nijmegen, The Netherlands, 2000.

Disponível em http://www.aviarampatzis.com/Avi_Arampatzis/publications/ HTMLized/encyclop/encyclop.html(08/04/2014) Citado na página 28.

Aranha, C. N. Uma abordagem de pré-processamento automático para Mineração de Textos em português: sob o enfoque da inteligência computacional. Tese de Doutorado, Departamento de Engenharia Elétrica - Pontifícia Universidade Católica do Rio de Janeiro (PUC-RJ), Rio de Janeiro, RJ, 2007. Citado na página 15.

Arauzo-Azofra, A.; Benitez, J.; Castro, J. Consistency measures for feature selection. Journal of Intelligent Information Systems, v. 30, n. 3, p. 273-292, 2008. Citado na página 79.

Arora, S.; Mayfield, E.; Penstein Rosé, C.; Nyberg, E. Sentiment classification using automatically extracted subgraph features. In: Proceedings of the 11th Conference of the North American Chapter of the Association for Computational Linguistics: Human Language Technologies (NAACL-HLT) - Workshop on Computational Approaches to Analysis and Generation of Emotion in Text (CAAGET), Los Angeles, CA: Association for Computational Linguistics, 2010, p. 131-139. Citado na página 13.

Banerjee, S.; Pedersen, T. The design, implementation, and use of the Ngram Statistic Package. In: Proceedings of the Fourth International Conference on Intelligent Text Processing and Computational Linguistics (CICLing), Mexico, 2003, p. 370-381. Citado na página 46.

Barrón-Cedeño, A.; Sierra, G.; Drouin, P.; Ananiadou, S. An improved automatic term recognition method for spanish. In: Proceedings of the 10th International Conference on Computational Linguistics and Intelligent Text Processing (CICLing), Berlin, Heidelberg: Springer-Verlag, 2009, p. 125-136. Citado nas páginas 30 e 59.

Barros, L. A. Curso básico de terminologia. Acadêmica (São Paulo, Brazil). Edusp, 2004. Citado nas páginas 18, 21, e 93. 
Batista, G. E. A.; Furtado, D. S. How k-nearest neighbor parameters affect its performance. In: Proceedings of the Argentine Symposium on Artificial Intelligence (ASAI), 2009, p. 1-12. Citado na página 85.

Batista, R. P. Características de terminologia empresarial: um estudo de caso. Dissertação de Mestrado, Programa de Pós-Graduação em Linguística Aplicada - Universidade do Vale do Rio dos Sinos (UNISINOS), RS, Brazil, 2011. Citado na página 18.

Bellot, P.; Bonnefoy, L.; Bouvier, V.; Duvert, F.; Kim, Y.-M. Large scale text mining approaches for information retrieval and extraction. In: FAUCHER, C.; JAIn, L. C., eds. Innovations in Intelligent Machines-4, v. 514 de Studies in Computational Intelligence (SCI), Springer International Publishing, p. 3-45, 2014. Citado na página 15.

Bento Carlos Dias-Da-Silva, A. D.; Nunes, M. G. V. The automatic mapping of Princeton WordNet lexical-conceptual relations onto the Brazilian Portuguese WordNet database. In: Chair), N. C. C.; Choukri, K.; MatgaArd, B.; Mariani, J.; OdiJK, J.; PIPERIDIS, S.; TAPIAS, D., eds. Proceedings of the 6th International Conference on Language Resources and Evaluation (LREC), Marrakech, Morocco: European Language Resources Association (ELRA), http://www.lrecconf.org/proceedings/lrec2008/, 2008. Citado na página 49.

Bettio, R. W. D.; Rodriguez, A. M. Técnicas aplicadas em máquinas de recuperação textual. Revista E-Tech: Tecnologias para Competitividade Industrial, v. 2, n. 1, p. 3348, 2009. Citado na página 14.

BICK, E. The Parsing System "Palavras". Automatic Grammatical Analysis of Portuguese in a Constraint Grammar Framework. Arhus: University of Arhus, 2000. Citado nas páginas $39,40,41,59$, e 89.

Bolinhas, J. A.; Neves, R. O futuro da Web semântica e sua importância nas organizações. Centro de Investigação em Inovação Empresarial e do Trabalho (IET Working Papers Series) - Número WPS03, p. 32, 2010. Citado na página 15.

BrAgA, I. A. Avaliação da influêcia da remoção de stopwords na abordagem estatística de extração automática de termos. In: Seventh Brazilian Symposium in Information and Human Language Technology (STIL), São Carlos, SP, Brazil, publicado em CDROM, 2009, p. 1-8. Citado na página 9.

Cabré, M.; SAger, J. Terminology: Theory, methods, and applications. Terminology and lexicography research and practice. J. Benjamins Publishing Company, 1999. Citado nas páginas 18 e 78.

Cabré, M. T.; Vivaldi, R. E. J. Automatic term detection: a review of current systems. In: Bourigault, D.; Jacquemin, C.; L'Homme, M.-C., eds. Recent Advances in Computational Terminology, Amsterdam/Philadelphia: John Benjamins, 2001, p. 53-88. Citado nas páginas 2, 4, 17, e 21.

Carbonell, J. G. Introduction: Paradigms for machine learning. In: Carbonell, J., ed. Machine Learning: Paradigms and Methods, London: MIT Press, p. 1-9, 1989. Citado na página 12 . 
Cardoso, P.; Maziero, E.; Jorge, M.; Seno, E.; Di Felippo, A.; Rino, L.; Nunes, M.; PARdo, T. CSTNews - a discourse-annotated corpus for single and multi-document summarization of news texts in Brazilian Portuguese. In: Proceedings of the 3rd Rhetorical Structure Theory (RST) Brazilian Meeting, Cuiabá, MT, 2011, p. 88-105. Citado na página 35.

Carletta, J. Assessing agreement on classification tasks: the kappa statistic. Computational Linguistic, v. 22, n. 2, p. 249-254, 1996. Citado na página 41.

Carroll, J. Parsing. In: Mitkov, R., ed. The Oxford Handbook of Computational Linguistics, Oxford University Press, p. 233-248, 2003. Citado na página 28.

Carvalho, D.; Marcacini, R.; Lucena, C.; Rezende, S. A process to support analysts in exploring and selecting content from online forums. Social Networking, v. 3, n. 2, p. 86-93, 2014. Citado na página 14.

Carvalho, L. S.; Oliveira lucas, E. R.; GonçAlves, L. H. Organização da informação para recuperação em redes de produção e colaboração na Web. In: Revista $A C B$, Santa Catarina, Florianópolis, 2010, p. 71-86. Citado na página 14.

Chapelle, O.; Schölkopf, B.; Zien, A. Semi-supervised learning. Cambridge, USA: MIT Press, 2006. Citado nas páginas 11 e 12.

Chiticariu, L.; Li, Y.; Raghavan, S.; Reiss, F. R. Enterprise information extraction: recent developments and open challenges. In: Proceedings of the Association for Computing Machinery's Special Interest Group on Management of Data (SIGMOD), NY, USA: ACM, 2010, p. 1257-1258. Citado na página 15.

Church, K. W. One term or two? In: Proceedings of the 18th Annual Internation ACM SIGIR Conference on Research and Development in Information Retrieval (SIGIR), New York, NY, USA: ACM, 1995, p. 310-318. Citado nas páginas 58 e 96.

Church, K. W.; HAnks, P. Word association norms, mutual information, and lexicography. In: Proceedings of the 27th Annual Meeting on Association for Computational Linguistics (ACL), Stroudsburg, PA, USA: Association for Computational Linguistics, 1989, p. 76-83. Citado na página 23.

Cintra, M. E.; Monard, M. C. A comparative study on classic machine learning and fuzzy approaches for classification problems. In: Anais do IV Congresso da Academia Trinacional de Ciências (C3N), Foz de Iguaçu, PR, Brasil, publicado em CD-ROM, 2009, p. 1-9. Citado na página 13.

Cohen, W. W. Fast effective rule induction. In: Proceedings of the International Conference on Machine Learning (ICML), 1995, p. 115-123. Citado na página 84.

Colace, F.; Santo, M. D.; Greco, L.; Napoletano, P. Text classification using a few labeled examples. Computers in Human Behavior, v. 30, n. 0, p. 689 - 697, 2014. Citado na página 13.

Coleti, J. S.; Mattos, D. F.; Barcellos Almeida, G. M. Primeiro dicionário em língua portuguesa de nanociência e nanotecnologia. In: Caderno de Resumos do II Encontro Acadêmico de Letras (EALE), São Carlos, SP, 2009, p. 1-10. Citado na página 37. 
Coleti, J. S.; Mattos, D. F.; Genoves Junior, L. C.; Candido Junior, A.; Di Felippo, A.; Almeida, G. M. B.; Aluísio, S. M.; Oliveira Junior, O. N. Compilação de corpus em Língua Portuguesa na área de nanociência/nanotecnologia: Problemas e soluções, v. 1. 192 ed. São Paulo, SP: Stella E. O.Tagnin; Oto Araújo Vale. (Org.), 167-191 p., 2008. Citado nas páginas 36, 37, e 39.

Conrado, M.; Rossi, R.; Pardo, T.; Rezende, S. Applying transductive learning for automatic term extraction: The case of the ecology domain. In: Proceedings of the IEEE Second International Conference on Informatics and Applications (ICIA), Lodz, Poland, 2013a, p. 264-269. Citado nas páginas 113, 134, e 135.

Conrado, M. S. O efeito do uso de diferentes formas de extração de termos na compreensibilidade e representatividade dos termos em coleções textuais na Lingua Portuguesa. Dissertação de Mestrado, Instituto de Ciências Matemáticas e de Computação (ICMC) - Universidade de São Paulo (USP), São Carlos, SP, 2009. Citado nas páginas 28, 34, $36,37,40,42$, e 47.

Conrado, M. S.; Di Felippo, A.; Pardo, T. A. S.; Rezende, S. O. A survey of automatic term extraction for brazilian portuguese. Journal of the Brazilian Computer Society, v. 20, n. 1, p. 12, 2014.

Disponível em http://www.journal-bcs.com/content/20/1/12 Citado nas páginas 17 e 134.

Conrado, M. S.; Gutiérrez, V. A. L.; Rezende, S. O. Evaluation of normalization techniques in text classification for Portuguese. In: Murgante, B.; Gervasi, O.; Misra, S.; Nedjah, N.; Rocha, A. M. A. C.; Taniar, D.; Apduhan, B. O., eds. 12th International Conference on Computational Science and Applications (ICCSA), Lecture Notes in Computer Science, Salvador, BA, Brasil: Springer, 2012, p. 618-630 (Lecture Notes in Computer Science, v.). Citado nas páginas 28 e 52.

Conrado, M. S.; Marcacini, R. M.; Moura, M. F.; Rezende, S. O. O efeito do uso de diferentes formas de geração de termos na compreensibilidade e representatividade dos termos em coleções textuais na Língua Portuguesa. In: Proceedings of II Web and Text Intelligence (WTI) - Seventh Brazilian Symposium in Information and Human Language Technology (STIL), São Carlos, SP, 2009a, p. 1-10. Citado na página 28.

Conrado, M. S.; Moura, M. F.; Marcacini, R. M.; Rezende, S. O. Avaliando diferentes formas de geração de termos a partir de coleções textuais. Relatório Técnico 334, Instituto de Ciências Matemáticas e de Computação (ICMC) - Universidade de São Paulo (USP), São Carlos, SP, 2009b.

Disponível em http://www.icmc.usp.br/ biblio/BIBLIOTECA/rel_tec/RT_334. $\operatorname{pdf}(21 / 03 / 2014)$ Citado nas páginas 28, 37, 40, e 42.

Conrado, M. S.; Pardo, T. A. S.; Rezende, S. O. Exploration of a rich feature set for automatic term extraction. In: CAstro, F.; Gelbukh, A.; GonzÁlez, M., eds. Advances in Artificial Intelligence and its Applications (MICAI), v. 8265 de Lecture Notes in Computer Science, Springer Berlin Heidelberg, p. 342-354, 2013b. Citado nas páginas 134 e 135.

Conrado, M. S.; Pardo, T. A. S.; Rezende, S. O. A machine learning approach to automatic term extraction using a rich feature set. In: Proceedings of the Conference of the North American Chapter of the Association for Computational Linguistics: Human 
Language Technologies (NAACL-HLT) - Student Research Workshop (SRW), Atlanta, Georgia: Association for Computational Linguistics, 2013c, p. 16-23. Citado nas páginas 74 e 134.

COUlThARD, R. J. The application of corpus methodology to translation: the JPED parallel corpus and the pediatrics comparable corpus. Dissertação de Mestrado, Programa de Pós-Graduação em Estudos da Tradução (PPGET) - Universidade Federal de Santa Catarina (UFSC), Santa Catarina, SC, 2005. Citado nas páginas 35, 36, e 45.

Cristianini, N.; ShaWe-TAYloR, J. An introduction to support vector machines and other kernel-based learning methods. Cambridge University Press, 2000. Citado na página 84.

Delalleau, O.; Bengio, Y.; Le Roux, N. Efficient non-parametric function induction in semi-supervised learning. In: Proceedings of the International Workshop on Artificial Intelligence and Statistics, 2005, p. 96-103. Citado na página 138.

Dhillon, I.; Kogan, J.; Nicholas, C. Feature selection and document clustering. In: Berry, M. W., ed. Survey of Text Mining, Springer, p. 73-100, 2003. Citado nas páginas 58,77 , e 96 .

Di Felippo, A. The TermiNet project: an overview. In: Proceedings of the 11th Conference of the North American Chapter of the Association for Computational Linguistics: Human Language Technologies (NAACL-HLT) - Young Investigators Workshop on Computational Approaches to Languages of the Americas, Los Angeles, California: Association for Computational Linguistics, 2010, p. 92-99. Citado nas páginas 5 e 46.

Dice, L. R. Measures of the Amount of Ecologic Association Between Species. Ecology, v. 26, n. 3, p. 297-302, 1945. Citado na página 23.

Ebecken, N. F. F.; Lopes, M. C. S.; Aragão, M. C. Mineração de Textos. In: ReZENDE, S. O., ed. Sistemas Inteligentes: Fundamentos e Aplicações, 1 ed, Capítulo 13, Manole, p. 337-364, 2003. Citado nas páginas 1, 7, e 47.

Estopa, R.; Martí, J.; Burgos, D.; Fernández, S.; Jara, C.; Monserrat, S.; Montané, A.; noz, P. M.; Quispe, W.; Rivadeneira, M.; Rojas, E.; Sabater, M.; Salazar, H.; Samara, A.; Santis, R.; Seghezzi, N.; Souto., M. La identificación de unidades terminológicas en contexto: de la teoría a la práctica. In: Terminología y Derecho: Complejidad de la Comunicación Multilingue, Cabré, T. and Bach, C. and Martí, J., 2005, p. 1-21. Citado nas páginas 3, 18, 58, 77, 78, e 96.

Fayyad, U.; Piatetsky-Shapiro, G.; Smyth, P.; Widener, T. The KDD process for extracting useful knowledge from volumes of data. Communications of the ACM, v. 39, n. 11, p. 27-34, 1996. Citado na página 7.

Feldman, R.; Sanger, J. The text mining handbook: Advanced approaches in analyzing unstructured data. 1st ed. Cambridge University Press, 2006. Citado nas páginas 83 e 84.

Feltrim, V. D.; GraÇas Volpe Nunes, M.; Aluísio, S. M. Um corpus de textos científicos em português para a análise da estrutura esquemática. Relatório Técnico NILC-TR-01-4, Instituto de Ciências Matemáticas e de Computação (ICMC) - Universidade de São Paulo (USP), São Carlos, SP, 2001.

Disponível em http://www.nilc.icmc.sc.usp.br/nilc/download/NILC-TR-01-4. zip(21/03/2014) Citado na página 34 . 
Ferreira, S. M. S. P.; Morais, M. H.; Mucheroni, M.; Perez, J. Estudo sobre como autores de artigos de revista de ciências da comunicação verbalizam seus objetos de estudo em termos de palavras-chave. Revista da Faculdade de Biblioteconomia e Comunicação da Universidade Federal do Rio Grande do Sul (UFRGS), v. 15, n. 2, p. 151-167, 2009. Citado na página 14.

Foong, O.-M.; Yong, S.-P.; LeE, A.-L. Text summarization in android mobile devices. In: Herawan, T.; Deris, M. M.; AbaWAJy, J., eds. Proceedings of the First International Conference on Advanced Data and Information Engineering (DaEng), v. 285 de Lecture Notes in Electrical Engineering, Springer Singapore, p. 571-578, 2014. Citado na página 14.

Frantzi, K. T.; Ananiadou, S.; TsujiI, J. I. The C-value/NC-value method of automatic recognition for multi-word terms. In: Proceedings of the Second European Conference on Research and Advanced Technology for Digital Libraries (ECDL), London, UK: Springer-Verlag, 1998, p. 585-604. Citado nas páginas 4, 18, 29, 30, 39, 41, $56,58,77,78$, e 96 .

Gama, J. Knowledge discovery from data streams. Chapman and Hall/CRC, 2010. Citado na página 15.

Gantz, J. F.; Reinsel, D. The digital universe in 2020: big data, bigger digital shadows, and biggest growth in the far east. External Publication of IDC (Analyse the Future) Information and Data, p. 1-16, 2012. Citado na página 1.

Gelbukh, A. F.; Sidorov, G.; Lavin-Villa, E.; Chanona-Hernández, L. Automatic term extraction using log-likelihood based comparison with general reference corpus. In: Proceedings of the 19th International conference on Applications of Natural Language Processing to Information Systems (NLDB), 2010, p. 248-255. Citado nas páginas 4, 49, e 50 .

Ghazi, D.; Inkpen, D.; SzPakowicz, S. Hierarchical versus flat classification of emotions in text. In: Proceedings of the 11th Conference of the North American Chapter of the Association for Computational Linguistics: Human Language Technologies (NAACL-HLT) - Workshop on Computational Approaches to Analysis and Generation of Emotion in Text (CAAGET), Los Angeles, CA: Association for Computational Linguistics, 2010, p. 140-146. Citado na página 13.

Gianoti, A. C. Descrição sintático-semântica dos termos do domínio da educação à distância em português do Brasil. Trabalho de Conclusão de Curso (Graduação em Bacharelado em Linguística) - Universidade Federal de São Carlos, 2012. Citado na página 19.

Gianoti, A. C.; Felippo, A. D. Extração de conhecimento terminológico no projeto TermiNet. Relatório Técnico NILC-TR-11-01, Instituto de Ciências Matemáticas e de Computação (ICMC) - Universidade de São Paulo (USP), São Carlos, SP, 2011. Disponível em http://www.ufscar.br/ letras/pdf/NILC-TR-11-01_ GianotiDiFelippo.pdf (21/03/2014) Citado nas páginas 35 e 60.

Gonzalez, M. A. I.; Lima, V. L. S.; Lima, J. V. Tools for nominalization: An alternative for lexical normalization. Proceedings of the VII Workshop on Computational Processing of Written and Spoken Portuguese (PROPOR), v. 3960, p. 100-109, 2006. Citado na página 28. 
Gupta, N.; Gilbert, M.; Fabbrizio, G. D. Emotion detection in email customer care. Computational Intelligence, v. 29, n. 3, p. 489-505, 2013. Citado na página 13.

Hall, M.; Frank, E.; Holmes, G.; Pfahringer, B.; Reutemann, P.; Witten, I. H. The WEKA data mining software: An update. In: Proceedings of the ACM Special Interest Group on Knowledge Discovery and Data Mining - International Conference on Knowledge Discovery and Data Mining (SIGKDD), 2009, p. 10-18. Citado na página 79 .

HaLl, M. A. Correlation-based feature subset selection for machine learning. Tese de Doutorado, University of Waikato, Hamilton, New Zealand, 1998. Citado na página 79.

Han, J.; Kamber, M. Data mining: concepts and techniques. 2nd ed. San Diego, CA: Academic, 2006. Citado na página 1.

Hearst, M. A. Untangling text data mining. In: Proceedings of the 37th Annual Meeting of the Association for Computational Linguistics on Computational Linguistics (ACL), Stroudsburg, PA, USA: Association for Computational Linguistics, 1999, p. 310. Citado nas páginas 1 e 7 .

Honorato, D. F.; Monard, M. C. Metodologia para mapeamento de informações não estruturadas descritas em laudos médicos para uma representação atributo-valor. Dissertação de Mestrado, Instituto de Ciências Matemáticas e de Computação (ICMC) - Universidade de São Paulo (USP), São Carlos, SP, 2008. Citado nas páginas 3, 37, 39 , e 42 .

Houaiss, A.; Villar, M. S. Dicionário eletrônico houaiss da língua portuguesa. Rio de Janeiro: Editora Objetiva, 2001. Citado na página 19.

JAIN, A. K. Data clustering: 50 years beyond k-means. Pattern Recognition Letters, v. 31, n. 8 , p. 651-666, 2010. Citado na página 14.

John, G. H.; LAngley, P. Estimating continuous distributions in Bayesian classifiers. In: Proceedings of the Eleventh Conference on Uncertainty in Artificial Intelligence (UAI), San Francisco, CA, USA: Morgan Kaufmann Publishers Inc., 1995, p. 338-345. Citado na página 84.

Jorge, M. L. R. C.; PArdo, T. A. S. Experiments with CST-Based multidocument summarization. In: Proceedings of TextGraphs-5: Workshop on Graph-based Methods for Natural Language Processing, Uppsala, Sweden: Association for Computational Linguistics, 2010, p. 74-82. Citado na página 14.

JuRAfsky, D.; Martin, J. H. Speech and language processing: An introduction to natural language processing, computational linguistics, and speech recognition. Prentice Hall Series in Artificial Intelligence. Prentice Hall, 2000. Citado nas páginas xvii e 27.

Kageura, K.; Umino, B. Methods of automatic term recognition - a review. Terminology, v. 3, n. 2, p. 1-23, 1996. Citado na página 22.

KaO, A.; Poteet, S. Natural language processing and text mining. Springer, 2007. Citado nas páginas 1 e 7 .

Karkali, M.; Rousseau, F.; Ntoulas, A.; Vazirgiannis, M. Efficient online novelty detection in news streams. In: Lin, X.; Manolopoulos, Y.; SRIVAstava, 
D.; HuAnG, G., eds. Web Information Systems Engineering (WISE), v. 8180 de Lecture Notes in Computer Science, Springer Berlin Heidelberg, p. 57-71, 2013. Citado na página 15.

Keerthi, S. S.; Shevade, S. K.; Bhattacharyya, C.; Murthy, K. R. K. Improvements to platt's SMO algorithm for svm classifier design. Neural Computation, v. 13, n. 3, p. 637-649, 2001. Citado na página 84.

KIM, S. N.; BALDwin, T.; KAn, M.-Y. Extracting domain-specific words - a statistical approach. In: Proceedings of the Australasian Language Technology Association Workshop (ALTA), Sydney, Australia, 2009, p. 94-98. Citado na página 31.

Kim, Y.; Street, W. N.; Menczer, F. Feature selection in unsupervised learning via evolutionary search. In: Proceedings of the 6th ACM - Special Interest Group on Knowledge Discovery and Data Mining - International Conference on Knowledge Discovery and Data Mining (SIGKDD), NY, EUA: ACM, 2000, p. 365-369. Citado na página 4.

KIT, C.; LIU, X. Measuring mono-word termhood by rank difference via corpus comparison. Terminology, v. 14, n. 2, p. 204-229, 2008. Citado nas páginas 4, 31, 56, 58, e 96.

Knoth, P.; Schmidt, M.; Smrz, P.; Zdráhal, Z. Towards a framework for comparing automatic term recognition methods. In: Conference Znalosti, 2009. Citado nas páginas 48,50 , e 56 .

Korkontzelos, I.; Klapaftis, I. P.; Manandhar, S. Reviewing and evaluating automatic term recognition techniques. In: Nordström, B.; RAnTA, A., eds. Proceedings of the 6th International Conference on Advances in Natural Language Processing, Berlin, Heidelberg: Springer-Verlag, 2008, p. 248-259 (Lecture Notes in Computer Science, v.5221). Citado na página 4.

Kozakov, L.; Park, Y.; Fin, T.; Drissi, Y.; Doganata, Y.; Cofino, T. Glossary extraction and utilization in the information search and delivery system for IBM technical support. IBM Systems Journal, v. 43, n. 3, p. 546-563, 2004a. Citado na página 96.

Kozakov, L.; Park, Y.; Fin, T.-H.; Drissi, Y.; Doganata, Y. N.; ; Confino, T. Glossary extraction and knowledge in large organisations via semantic Web technologies. In: Proceedings of the 6th International Semantic Web Conference (ISWC) and the 2nd Asian Semantic Web Conference (Se-mantic Web Challenge Track), 2004b. Citado nas páginas 4, 31, 56, e 58 .

Leskovec, J.; Backstrom, L.; Kleinberg, J. Meme-tracking and the dynamics of the news cycle. In: Proceedings of the 15th ACM - Special Interest Group on Knowledge Discovery and Data Mining - International Conference on Knowledge Discovery and Data Mining (SIGKDD), New York, NY, USA: ACM, 2009, p. 497-506. Citado na página 15.

LI, W.; XU, H. Text-based emotion classification using emotion cause extraction. An International Journal of Expert Systems with Applications (ESA), v. 41, n. 4, Part 2, p. 1742 - 1749, 2014. Citado na página 13. 
LIE, Y.; Loh, H. T.; LU, W. G. Deriving taxonomy from documents at sentence level. In: Prado, A. H.; FernedA, E., eds. Emerging Technologies of Text Mining: Techniques and Applications, 1 ed, Capítulo 5, Information Science Reference, p. 99119, 2007. Citado na página 1.

Lima, V. L.; Nunes, M.; Vieira, R. Desafios do processamento de línguas naturais. In: Anais do XXVII Congresso da Sociedade Brasileira da Computação (SBC), SBC, Rio de Janeiro, RJ: SBC, 2007, p. 2202-2216. Citado nas páginas 5 e 52.

LiU, B. Association rules and sequential patterns. In: Web Data Mining, p. 17-62, 2011. Citado na página 11.

Liu, H.; Motoda, H. Computational methods of feature selection. Chapman \& Hall/CRC Data Mining and Knowledge Discovery Series. Taylor \& Francis, 2007. Citado na página 79.

Liu, H.; Setiono, R. A probabilistic approach to feature selection - a filter solution. In: Proceedings of the 13th International Conference on Machine Learning (ICML), 1996, p. 319-327. Citado na página 79.

LiU, L.; KANG, J.; YU, J.; WANG, Z. A comparative study on unsupervised feature selection methods for text clustering. In: Proceedings of IEEE International Conference on Natural Language Processing and Knowledge Engineering (NLP-KE), 2005, p. 597-601. Citado nas páginas 26, 58, 77, e 96.

LiU, T.; LiU, S.; Chen, Z. An evaluation on feature selection for text clustering. In: Proceedings of the 10th International Conference on Machine Learning (ICML), San Francisco, CA: Morgan Kaufmann, 2003, p. 488-495. Citado nas páginas 25, 58, 77, e 96 .

Lloret, E.; Saggion, H.; Palomar, M. Experiments on summary-based opinion classification. In: Proceedings of the 11th Conference of the North American Chapter of the Association for Computational Linguistics: Human Language Technologies (NAACL-HLT) - Workshop on Computational Approaches to Analysis and Generation of Emotion in Text (CAAGET), Los Angeles, CA: Association for Computational Linguistics, 2010, p. 107-115. Citado na página 13.

LOPES, L. Extração automática de conceitos a partir de textos em língua portuguesa. Tese de Doutorado, Porto Alegre, RS. Pontifícia Universidade do Rio Grande do Sul (PUCRS), 2012. Citado nas páginas 3, 4, 32, 37, 41, 42, e 50.

Lopes, L.; Fernandes, P.; Vieira, R. Domain term relevance through $t$ - $d c f$. In: Proceedings of the 2012 International Conference on Artificial Intelligence (ICAI), Las Vegas, USA: CSREA Press, 2012, p. 1001-1007. Citado nas páginas 37, 41, e 42.

Lopes, L.; Oliveira, L. H. M.; VieirA, R. Análise comparativa de métodos de extração de termos utilizando abordagens linguistica e estatística. Relatório Técnico 053, Pontifícia Universidade Católica do Rio Grande do Sul (PUC) Porto Alegre, 2009a. Disponível em www3.pucrs.br/pucrs/files/uni/poa/facin/pos/relatoriostec/ tr053.pdf(21/03/2014) Citado nas páginas 37, 40, 42, e 46.

Lopes, L.; Oliveira, L. H. M.; VieirA, R. Portuguese term extraction methods: Comparing linguistic and statistical approaches (poster). In: Additional Proceedings of 
Ninth International Conference on Computational Processing of the Portuguese Language (PROPOR), Porto Alegre, RS. Pontifícia Universidade do Rio Grande do Sul (PUCRS): Springer, 2010a, p. 1-6. Citado nas páginas 37, 40, e 42.

Lopes, L.; VIEIRA, R. Building domain specific corpora in Portuguese language. Relatório Técnico 062, Pontifícia Universidade Católica do Rio Grande do Sul (PUC) Porto Alegre, 2010.

Disponível em http://www3.pucrs.br/pucrs/files/uni/poa/facin/pos/ relatoriostec/tr062.pdf(21/03/2014) Citado nas páginas 36 e 41.

Lopes, L.; Vieira, R. Improving Portuguese term extraction. In: CASELI, H.; Villavicencio, A.; Teixeira; AO, P., eds. Proceedings of the Workshop on Computational Processing of Written and Spoken Portuguese (PROPOR), v. 7243 de Lecture Notes in Computer Science, Springer Berlin / Heidelberg, p. 85-92, 2012. Citado nas páginas $3,37,41,42$, e 57 .

Lopes, L.; Vieira, R. Aplicando pontos de corte para listas de termos extraídos. In: Proceedings of the 9th Brazilian Symposium in Information and Human Language Technology (STIL), Fortaleza, Brasil: Sociedade Brasileira de Computaćão, 2013a, p. 79-87. Citado nas páginas 37, 42, 43, 56, e 57.

LOPEs, L.; VIEIRA, R. Building domain specific parsed corpora in portuguese language. In: Proceedings of the 10th National Meeting on Artificial and Computational Intelligence (ENIAC), Fortaleza, CE, Brazil, 2013b, p. 1-12. Citado na página 36.

Lopes, L.; Vieira, R.; Finatto, M. J.; Martins, D.; Zanette, A.; Ribeiro JuNIOR, L. C. Extração automática de termos compostos para construção de ontologias: um experimento na área da saúde. Revista Eletrônica de Comunicação, Informação E Inovação em Saúde (RECIIS), v. 3, n. 1, p. 76-88, 2009b. Citado nas páginas 37, 40, 42, e 50 .

Lopes, L.; Vieira, R.; Finatto, M. J. B.; Martins, D. Extracting compound terms from domain corpora. Journal of the Brazilian Computer Society (JBCS), p. 247-259, 2010b. Citado nas páginas 37, 40, e 42.

LORENA, A. C. Investigação de estratégias para a geração de máquinas de vetores de suporte multiclasses. Tese de Doutorado, Instituto de Ciências Matemáticas e de Computação (ICMC) - Universidade de São Paulo (USP), São Carlos, SP, 2006. Citado na página 84 .

Lovins, J. B. Development of a stemming algorithm. Mechanical Translation and Computational Linguistics, v. 11, p. 22-31, 1968. Citado na página 28.

Luhn, H. P. The automatic creation of literature abstracts. IBM Journal os Research and Development, v. 2, n. 2, p. 159-165, 1958. Citado nas páginas 9 e 56.

Mani, I.; Maybury, M. Advances in automatic text summarization. MIT Press, 2001. Citado na página 11.

Manning, C.; Schütze, H. Foundations of statistical natural language processing. MIT Press, 1999. Citado na página 25.

Manning, C. D.; Raghavan, P.; Schutze, H. Introduction to information retrieval. Cambridge University Press, 2008a. Citado nas páginas 9, 14, e 28. 
Manning, C. D.; Raghavan, P.; Schutze, H. Language models for information retrieval. In: An Introduction to Information Retrieval, Capítulo 12, Cambridge University Press, 2008b. Citado na página 11.

Manning, C. D.; Schutze, H. Foundations of statistical natural language processing. Cambridge, Massachusetts London, England: MIT Press, 2001. Citado na página 23.

Marcacini, R. M.; REzende, S. O. Incremental construction of topic hierarchies using hierarchical term clustering. In: Proceedings of the 22nd International Conference on Software Engineering and Knowledge Engineering (SEKE), Knowledge Systems Institute (KSI), 2010, p. 553-558. Citado na página 14.

Martins, C. A. Uma abordagem para pré-processamento de dados textuais em algoritmos de aprendizado. Tese de Doutorado, Instituto de Ciências Matemáticas e de Computação (ICMC) - Universidade de São Paulo (USP), São Carlos, SP, 2003. Citado nas páginas xix e 10 .

Martins, D.; Costa, K. A.; Rodegheri, G.; Lopes, L.; Vieira, R. Construção de corpora de domínio na língua portuguesa. In: Anais do X Salão de Iniciação Científica da Pontifícia Universidade do Rio Grande do Sul (PUCRS), Porto Alegre, Brasil, 2009, p. 993-995. Citado na página 36.

Maynard, D.; AnAniadou, S. Identifying contextual information for multi-word term extraction. In: Proceedings of Terminology and Knowledge Engineering Conference (TKE), Innsbruck, Austria, 1999, p. 212-221. Citado nas páginas 33 e 40.

Maynard, D.; AnAniadou, S. Identifying terms by their family and friends. In: Proceedings of Eighteenth International Conference on Computational Linguistics (CO$L I N G$ ), Saarbrucken, Germany, 2000, p. 530-536. Citado na página 56.

Megerdoomian, K.; Hadjarian, A. Mining and classification of neologisms in persian blogs. In: Proceedings of the 11th Conference of the North American Chapter of the Association for Computational Linguistics: Human Language Technologies (NAACL-HLT) - Second Workshop on Computational Approaches to Linguistic Creativity $(C A L C)$, Los Angeles, California: Association for Computational Linguistics, 2010, p. 6-13. Citado na página 13.

Mitchell, T. Machine learning. 1st ed. McGraw-Hill Education (ISE Editions), 1997. Citado nas páginas 12, 83, e 84.

Mohammed, A.; Yusof, Y.; Husni, H. Weight-based firefly algorithm for document clustering. In: Herawan, T.; Deris, M. M.; ABAWAJY, J., eds. Proceedings of the First International Conference on Advanced Data and Information Engineering (DaEng), v. 285 de Lecture Notes in Electrical Engineering, Springer Singapore, p. 259-266, 2014. Citado na página 14.

Monard, M. C.; Baranauskas, J. A. Conceitos sobre aprendizado de máquina. 1 ed. Manole, 89-114 p., 2003. Citado nas páginas xvii, 11, e 84.

Moura, M. F. Contribuições para a construção de taxonomias de tópicos em domínios restritos utilizando aprendizado estatístico. Tese de Doutorado, Instituto de Ciências Matemáticas e de Computação (ICMC) - Universidade de São Paulo (USP), São Carlos, SP, 2009. Citado nas páginas 8, 9, 14, e 69. 
Moura, M. F.; Marcacini, R. M.; Nogueira, B. M.; Conrado, M. S.; Rezende, S. O. A proposal for building domain topic taxonomies. In: WEB, P.; CARLos, S. . I., eds. I Workshop on Web and Text Intelligence (WTI) - XIX Simpósio Brasileiro de Inteligência Artificial (SBIA), Salvador, BA, 2008a, p. 83-84. Citado na página 14.

Moura, M. F.; Marcacini, R. M.; Nogueira, B. M.; Conrado, M. S.; Rezende, S. O. Uma abordagem completa para a construção de taxonomias de tópicos em um dominio. Relatório Técnico 329, Instituto de Ciências Matemáticas e de Computação (ICMC) - Universidade de São Paulo (USP), São Carlos, SP, 2008b.

Disponível em http://www.icmc.usp.br/ biblio/BIBLIOTECA/rel_tec/RT_329. pdf (21/03/2014) Citado nas páginas 14, 40, 46, e 47.

Moura, M. F.; Nogueira, B. M.; Conrado, M. S.; Santos, F. F.; Rezende, S. O. Making good choices of non-redundant n-gram words. In: DATA Mining AND Artificial Intelligence, P., ed. International Workshop on Data Mining and Artificial Intelligence (DMAI) - International Conference on Computer and Information Technology (ICCT), Khulna, Bangladesh - Khulna University of Engineering and Technology, 2008c, p. 64-71. Citado na página 8.

Moura, M. F.; Rezende, S. O. A simple method for labeling hierarchical document clusters. In: Proceedings of the Tenth International Conference on Artificial Intelligence and Applications (IASTED-AIA), Anaheim, Calgary, Zurich: Acta Press, 2010, 2010, p. 363-371. Citado na página 14.

Muniz, F.; Aluísio, S. M. NorMan extractor: automatic term extraction from technical manuals (resumo e demonstração de ferramenta). In: Ninth International Conference on Computational Processing of the Portuguese Language (PROPOR), Porto Alegre, RS. Pontifícia Universidade do Rio Grande do Sul (PUCRS), publicado em CD-ROM, 2010, p. 1-2. Citado nas páginas 3, 37, 41, e 42.

Muniz, F.; Watanabe, W. M.; Scarton, C. E.; Aluísio, S. M. Extração de termos de manuais técnicos de produtos tecnológicos: uma aplicação em sistemas de adaptação textual. In: XXXVIII Seminário Integrado de Software e Hardware (SEMISH) - Anais do XXVIII Congresso da Sociedade Brasileira de Computação (SBC), Natal, RN, 2011, p. 1293-1306. Citado nas páginas 3, 37, 41, e 42.

Muniz, F. A. M. Extração de termos de manuais técnicos de produtos tecnológicos: uma aplicação em sistemas de adaptação textual. Dissertação de Mestrado, Instituto de Ciências Matemáticas e de Computação (ICMC) - Universidade de São Paulo (USP), São Carlos, SP, 2011. Citado nas páginas 36, 37, 41, e 42.

Murthy, K.; Faruquie, T. A.; Subramaniam, L. V.; Prasad, K. H.; Mohania, M. Automatically generating term frequency induced taxonomies. In: Proceedings of the ACL - Conference Short Papers, Uppsala, Sweden: Association for Computational Linguistics, 2010, p. 126-131. Citado na página 14.

NAZAR, R. A statistical approach to term extraction. International Journal of English Studies, v. 11, n. 2, p. 159-182, 2011. Citado nas páginas 3, 4, 48, e 50.

Nenkova, A. A survey of text summarization techniques. In: AgGarwal, C.; Zhai, C., eds. Mining Text Data, 1 ed, Capítulo 3, Springer, p. 43-76, 2012. Citado na página 11. 
Nogueira, B. M. Avaliação de métodos não-supervisionados de seleção de atributos para Mineração de Textos. Dissertação de Mestrado, Instituto de Ciências Matemáticas e de Computação (ICMC) - Universidade de São Paulo (USP), São Carlos, SP, 2009. Citado nas páginas $9,10,26,47,56$, e 57 .

Nogueira, B. M.; Moura, M. F.; Conrado, M. S.; Rezende, S. O. Avaliação de métodos não-supervisionados de seleção de atributos para Mineração de Textos. In: WeB, P.; CARlos, S. I., eds. I Workshop on Web and Text Intelligence (WTI) - XIX Simpósio Brasileiro de Inteligência Artificial (SBIA), Salvador, BA, 2008, p. 59-66. Citado na página 4.

Nogueira, B. M. A.; Rezende, S. O. Análise comparativa de duas abordagens para o agrupamento semissupervisionado particional de documentos: Sementes iniciais e restrições pareadas. In: Anais do IV Congresso da Academia Trinacional de Ciências (C3N), Foz de Iguaçu, PR, Brasil, publicado em CD-ROM, 2009, p. 1-10. Citado na página 14.

Oliveira, J. F. G.; Rozenfeld, H.; Amaral, D. C. II Assembléia Geral do Instituto Fábrica do Milênio (IFM). Book \& CD, 2008. Citado na página 36.

Oliveira, L. H. M. E-Termos: Um ambiente colaborativo Web de gestão terminológica. Tese de Doutorado, Instituto de Ciências Matemáticas e de Computação (ICMC) - Universidade de São Paulo (USP), São Carlos, SP, 2009. Citado na página 45.

Pantel, P.; Lin, D. A statistical corpus-based term extractor. In: Proceedings of the Fourteenth Biennial Conference of the Canadian Society on Computational Studies of Intelligence (AI), London, UK: Springer-Verlag, 2001, p. 36-46. Citado na página 56.

Pardo, T. A. S.; Gasperin, C. V.; Caseli, H. M.; Graças Volpe Nunes, M. Computational linguistics in brazil: An overview. In: Proceedings of the 11th Conference of the North American Chapter of the Association for Computational Linguistics: Human Language Technologies (NAACL-HLT) - Young Investigators Workshop on Computational Approaches to Languages of the Americas, Los Angeles, California: Association for Computational Linguistics, 2010, p. 13-19. Citado na página 5.

Park, Y.; Patwardhan, S.; Visweswariah, K.; Gates, S. C. An empirical analysis of word error rate and keyword error rate. In: 9th Annual Conference of the International Speech Communication Association (INTERSPEECH), International Speech Communication Association (ISCA), 2008, p. 2070-2073. Citado nas páginas 31, 58, e 96 .

Pathak, J.; Cocos, C.; McCormick, J. B.; Nelsen, L. A.; Chute, C. G.; PeTERson, K. J.; SEEDORFF, M. Incorporating expert terminology and disease risk factors into consumer health vocabularies. In: Biocomputing, Capítulo 41, p. 421-432, 2013. Citado na página 1.

Pazienza, M. T.; Pennacchiotti, M.; Zanzotto, F. M. Terminology extraction: An analysis of linguistic and statistical approaches. In: SiRMAKESSIS, S., ed. Knowledge Mining Series: Studies in Fuzziness and Soft Computing, Springer Verlag, p. 255-279, 2005. Citado nas páginas 2, 4, 21, 22, 23, 27, 29, 55, 67, e 132.

Quinlan, J. R. C4.5: programs for machine learning. San Francisco, CA, USA: Morgan Kaufmann Publishers Inc., 1993. Citado na página 84. 
Ratnaparkin, A. A maximum entropy model for part-of-speech tagging. Proceedings of the Empirical Methods in Natural Language Processing Conference (EMNLP), University of Pennsylvania, p. 491-497, 1996. Citado na página 89.

Rezende, S. O.; Pugliesi, J. B.; Melanda, E. A.; Paula, M. F. Mineração de dados. In: Rezende, S. O., ed. Sistemas Inteligentes: Fundamentos e Aplicações, 1 ed, Capítulo 12, Manole, p. 307-335, 2003. Citado nas páginas xvii, 7, 8, 11, e 12.

Ribeiro, M.; Neto, M. R.; Prudêncio, R. B. C. Local feature selection in text clustering. In: International Conference on Neural Information Processing (ICONIP), Auckland, New Zealand: Lecture Notes in Computer Science (LNCS), 2008, p. 171-174. Citado nas páginas 14 e 52.

RIBEIRO JUNIOR, L. C. OntoLP: construção semi-automática de ontologias a partir de textos da Língua Portuguesa. Dissertação de Mestrado, Universidade do Vale do Rio dos Sinos (Unisinos), São Leopoldo, RS, 2008. Citado nas páginas 34, 37, 39, 40, 41, $42,45,47,50,58$, e 78 .

Ribeiro Junior, L. C.; Vieira, R. OntoLP: engenharia de ontologias em Língua Portuguesa. In: Seminário Integrado de Software e Hardware (SEMISH) - Anais do XXVIII Congresso da Sociedade Brasileira de Computação (SBC), Belém, PA: SBC, 2008, p. 1-15. Citado nas páginas 3, 37, 39, 42, 46, 50, 58, e 78.

Rino, L. H. M.; PARdo, T. A. S. A sumarização automatica de textos: Principais caracteristicas e metodologias. Anais do XXIII Congresso da Sociedade Brasileira de Computação (SBC) - III Jornada de Minicursos de Inteligência Artificial (MCIA), Campinas - SP, p. 203-245, 2003. Citado na página 14.

Rossi, R. G.; Lopes, A. A.; Rezende, S. O. A parameter-free label propagation algorithm using bipartite heterogeneous networks for text classification. In: Proceedings of ACM - Symposium on Applied Computing (SAC), ACM, 2014. Citado nas páginas 8,116 , e 118 .

Rossi, R. G.; Rezende, S. O. Building a topic hierarchy using the bag-of-relatedwords representation. In: Proceedings of ACM - Symposium on Document Engineering (DocEng), 2011, p. 195-204. Citado na página 8.

Russell, S. J.; Norvig, P. Artificial intelligence: A modern approach. 2 ed. Prentice Hall, 2003. Citado na página 79.

SAGER, J. C. A practical course in terminology processing. J. Benjamins Publishing Company, 264 p., 1990. Citado na página 18.

SAleh, I.; DARWISh, K.; FAHMY, A. Classifying wikipedia articles into NE's using SVM's with threshold adjustment. In: Proceedings of the Named Entities Workshop (NEWS), Uppsala, Sweden: Association for Computational Linguistics, 2010, p. 85-92. Citado na página 13.

Salton, G.; Buckley, C. Term weighting approaches in automatic text retrieval. Relatório Técnico, Ithaca, NY, USA, 1987.

Disponível em http://ecommons.library.cornell.edu/bitstream/1813/6721/1/ 87-881.pdf (21/03/2014) Citado nas páginas 8, 9, 10, 25, 39, 58, 77, e 96. 
Salton, G.; Yang, C. S.; Yu, C. T. A theory of term importance in automatic text analysis. Journal of the American Association Science, v. 1, n. 26, p. 33-44, 1975. Citado nas páginas 10 e 56.

SAnchez, A. E. Cumbre: Corpus linguístico del español contemporáneo: Fundamentos, metodologia, y aplicaciones. Madrid: SGEL, 1995. Citado na página 2.

Santos, C. N. Aprendizado de máquina na identificação de sintagmas nominais: o caso do português Brasileiro. Dissertação de Mestrado, Departamento de Ciência e Tecnologia (DCT) - Instituto Militar de Engenharia (IME), Rio de Janeiro, RJ, 2005. Citado na página 52.

ScHmid, H. Probabilistic part-of-speech tagging using decision trees. Proceedings of International Conference on New Methods in Language Processing (NEMLAP), p. 4449, 1994. Citado na página 39.

Sebastiani, F. Machine learning in automated text categorization. ACM Computing Surveys, v. 34, n. 1, p. 1-47, 2002. Citado nas páginas 12 e 83.

Sebastiani, F. Classification of text, automatic. In: Brown, K., ed. The Encyclopedia of Language and Linguistics, v. 2, second ed, Amsterdam, NL: Elsevier Science Publishers, p. 457-463, 2006. Citado nas páginas 12 e 13.

Shaw, M. J.; Subramaniam, C.; Tan, G. W.; Welge, M. E. Knowledge management and data mining for marketing. Decision Support Systems, v. 31, n. 1, p. 127 137, 2001. Citado na página 1.

ShEARER, C. The crisp-dm model: The new blueprint for data mining. Journal of Data Warehousing, v. 5, n. 4, 2000. Citado na página 7.

Soares, M. V.; Prati, R. C.; Monard, M. C. PreText II: Descrição da reestruturação da ferramenta de pré-processamento de textos. Relatório Técnico 333, Instituto de Ciências Matemáticas e de Computação (ICMC) - Universidade de São Paulo (USP), São Carlos, SP, 2008. Citado na página 40.

Sousa, C. A. R.; Rezende, S. O.; Batista, G. E. A. P. A. Influence of graph construction on semi-supervised learning. In: Proceeding of the European Conference on Machine Learning (ECML) and Principles and Practice of Knowledge Discovery in Databases (PKDD), 2013, p. 160-175. Citado nas páginas 115 e 116.

SouzA, J. W. C.; Felippo, A. D. Um exercício em linguística de corpus no âmbito do projeto TermiNet. Relatório Técnico NILC-TR-10-08, Instituto de Ciências Matemáticas e de Computação (ICMC) - USP, São Carlos, SP, 2010.

Disponível em www.letras.ufscar.br/pdf/NILC-TR-10-08-SouzaDiFelippo. pdf (21/03/2014) Citado nas páginas 2, 18, e 35.

SpARCK-Jones, K.; Willett, P., eds. Readings in information retrieval. San Francisco, CA, USA: Morgan Kaufmann Publishers Inc., 1997. Citado na página 28.

Steinbach, M.; Karypis, G.; Kumar, V. A comparison of document clustering techniques. In: Grobelnik, M.; Mladenic, D.; Milic-Frayling, N., eds. Proceeding of the Knowledge Discovery in Databases Conference (KDD) - Workshop on Text Mining, Boston, MA, 2000, p. 109-111. Citado na página 14. 
Sun, A.; NAIng, M.-M.; Lim, E.-P.; LAM, W. Using support vector machines for terrorism information extraction. In: Proceedings of the First NSF/NIJ Conference on Intelligence and Security Informatics (ISI), Berlin, Heidelberg: Springer-Verlag, 2003, p. 1-12. Citado na página 15.

TAGnin, S. A identificação de equivalentes tradutórios em corpora comparáveis. In: Anais do I Congresso Internacional da Associação Brasileira de Professores Universitários de Inglês (ABRAPUI), Belo Horizonte, MG: ABRAPUI, 2007, p. 1-13. Citado na página 52.

TAN, P.-N. Introduction to data mining. Pearson Education, Limited, 2013. Citado na página 12.

Tan, P.-N.; Steinbach, M.; Kumar, V. Introduction to data mining. 2 ed. Pearson Education, 792 p., 2014. Citado na página 116.

Teline, M. F. Avaliação de métodos para a extração automática de terminologia de textos em português. Dissertação de Mestrado, Instituto de Ciências Matemáticas e de Computação (ICMC) - USP, São Carlos, SP, 2004. Citado nas páginas 23, 29, 37, $42,43,46$, e 67 .

Teline, M. F.; Manfrin, A. M. P.; Aluísio, S. M. Extração automática de termos de textos em português: Aplicação e avaliação de medidas estatísticas de associação de palavras. Relatório Técnico 216, Instituto de Ciências Matemáticas e de Computação (ICMC) - USP, São Carlos, SP, 2003. Citado nas páginas 37, 38, 42, e 50.

Thomas, S.; Chatelain, C.; Heutte, L.; Paquet, T. An information extraction model for unconstrained handwritten documents. In: Twenty International Conference on Pattern Recognition (ICPR), Istanbul, Turkey, France, 2010, p. 1-4. Citado na página 15.

Turmo, J.; Ageno, A.; CatalÀ, N. Adaptive information extraction. Journal of ACM - Computing Surveys (CSUR), v. 38, n. 2, p. 4, 2006. Citado na página 15.

VApnik, V. N.; Sterin, A. On Structural Risk Minimization or Overall Risk in a Problem of Pattern Recognition. Automation and Remote Control, v. 10, n. 3, p. 1495-1503, 1977. Citado na página 12.

VIVALDI, J. Extracción de candidatos a término mediante la combinación de estrategias heterogéneas. Tese de Doutorado, Universidad Politécnica de Catalunya, Departament de Llenguatges i Sistemes Informàtics, Spain, 2001. Citado nas páginas 18 e 27.

Vivaldi, J.; Cabrera-Diego, L. A.; Sierra, G.; Pozzi, M. Using wikipedia to validate the terminology found in a corpus of basic textbooks. In: CALzOLARI, N.; Choukri, K.; MaegaArd, B.; Mariani, J.; OdJIK, J.; Piperidis, S.; Tapias, D., eds. Proceedings of the 8th International Conference on Language Resources and Evaluation (LREC), Istanbul, Turkey: ELRA, 2012, p. 3820-3827. Citado nas páginas 4 e 56.

Vivaldi, J.; MÁrquez, L.; Rodríguez, H. Improving term extraction by system combination using boosting. In: Proceedings of the 12th European Conference on Machine Learning (ECML), London, UK: Springer-Verlag, 2001, p. 515-526. Citado nas páginas 49, 70, e 73 . 
Vivaldi, J.; RodRíguez, H. Evaluation of terms and term extraction systems: A practical approach. Terminology: International Journal of Theoretical and Applied Issues in Specialized Communication, v. 13, n. 2, p. 225-248, 2007. Citado nas páginas xvii, $3,4,5,27,32,33,49$, e 56 .

Voutilainen, A. Part-of-speech tagging. In: MITKOV, R., ed. The Oxford Handbook of Computational Linguistics, Oxford University Express, p. 219-232, 2004. Citado na página 28.

WAN, X.; LI, H.; XIAO, J. Cross-language document summarization based on machine translation quality prediction. In: Proceedings of the 48th Annual Meeting of the Association for Computational Linguistics (ACL), Uppsala, Sweden: Association for Computational Linguistics, 2010, p. 917-926. Citado na página 14.

Weiss, S.; Indurkhya, N. Predictive data mining: A practical guide. The Morgan Kaufmann Series in Data Management Systems Series. Morgan Kaufmann Publishers, 1998. Citado na página 7.

Weiss, S. M.; Indurkhya, N.; Zhang, T.; Damerau, F. J. Text mining - predictive methods for analyzing unstructured information. Springer Science+Business Media, Inc., ISBN 0-387-95433-3, 2005. Citado na página 10.

Witten, I.; Frank, E.; Hall, M. Data mining: Practical machine learning tools and techniques: Practical machine learning tools and techniques. The Morgan Kaufmann Series in Data Management Systems. Elsevier Science, 2011. Citado na página 84.

Witten, I.; Moffat, A.; Bell, T. Managing gigabytes: Compressing and indexing documents and images. Morgan Kaufmann. Morgan Kaufmann Publishers, 1999. Citado na página 25.

Yavuz, T.; Guvenir, H. A. Application of k-nearest neighbor on feature projections classifier to text categorization. In: Proceedings of the 13th International Symposium on Computer and Information Sciences (ISCIS), Amsterdam, The Netherlands: IOS Press, 1998, p. 135-142. Citado na página 84.

YU, L.; LIU, H. Efficient feature selection via analysis of relevance and redundancy. Journal of Machine Learning Research (JMLR), v. 5, p. 1205 - 1224, 2004. Citado nas páginas 4 e 11.

Zavaglia, C.; Aluísio, S. M.; Nunes, M. G. V.; Oliveira, L. H. M. Estrutura ontológica e unidades lexicais: uma aplicação computacional no domínio da ecologia. Proceedings of the Fifth Workshop em Tecnologia da Informação e da Linguagem Humana (TIL) - Anais do XXVII Congresso da Sociedade Brasileira da Computação (SBC), Rio de Janeiro, p. 1575-1584, 2007. Citado nas páginas 3, 4, 18, 36, 37, 39, $42,56,78,89,106$, e 125 .

Zavaglia, C.; Oliveira, L.; Nunes, M.; Teline, M.; Aluísio, S. Avaliação de métodos de extração automática de termos para a construção de ontologias. Relatório Técnico 248, Instituto de Ciências Matemáticas e de Computação (ICMC) - USP, São Carlos, SP, 2005.

Disponível em http://www.nilc.icmc.usp.br/nilc/download/NILC-TR-05-01. pdf (21/03/2014) Citado nas páginas 3, 37, 39, e 42. 
Zhang, X.; Song, Y.; FAng, A. Term recognition using conditional random fields. In: Proceedings of the IEEE International Conference on Natural Language Processing and Knowledge Engineering (NLP-KE), 2010, p. 333-336. Citado nas páginas 48, 50, 70 , e 73 .

Zhang, Z.; Iria, J.; Brewster, C.; Ciravegna, F. A comparative evaluation of term recognition algorithms. In: Calzolari, N.; Choukri, K.; MaegaArd, B.; Mariani, J.; OdJIK, J.; Piperidis, S.; TAPiAs, D., eds. Proceedings of the 6th International Conference on Language Resources and Evaluation (LREC), Marrakech, Morocco: ELRA, 2008, p. 2108-2113. Citado nas páginas 48, 50, e 57.

Zhou, D.; Bousquet, O.; Lal, T. N.; Weston, J.; Schölkopf, B. Learning with local and global consistency. In: Advances in Neural Information Processing Systems (NIPS), 2004. Citado nas páginas 116, 117, e 118.

Zhu, X. Semi-supervised learning literature survey. Relatório Técnico 1530, Computer Sciences, University of Wisconsin-Madison, 2008.

Disponível em http://pages.cs.wisc.edu/ jerryzhu/pub/ssl_survey.pdf(21/ 03/2014) Citado nas páginas 11 e 12.

Zhu, X.; Ghahramani, Z.; Lafferty, J. Semi-supervised learning using gaussian fields and harmonic functions. In: Proceedings of the International Conference on Machine Learning (ICML), AAAI Press, 2003, p. 912-919. Citado nas páginas 116 e 117.

Zhu, X.; Lafferty, J.; Rosenfeld, R. Semi-supervised learning with graphs. Tese de Doutorado, Carnegie Mellon University, Language Technologies Institute, School of Computer Science, 2005. Citado nas páginas 115, 116, e 117.

ZIPF, G. K. Human behavior and the principle of least effort. Addison-Wesley, 1949. Citado na página 9. 